

$$
\text { , }
$$




\section{Digitized by the Internet Archive in 2011 with funding from University of Toronto}





\section{DIE JAPANISCHE AUSWANDERUNG}

VON

Dr. Ernst Grünfeld.

Supplement

zu den Mitteilungen der Deutsehen Gesellschaft

für Natur- und Völkerkunde Ostasiens,

Bd. XIV.

Alle Rechte vorbehalten.

itson

T $\tilde{\mathbf{O}} \mathbf{~} \mathbf{Y} \overline{\mathbf{O}}$

DRUCK DER HUBUNSHA.

1913 


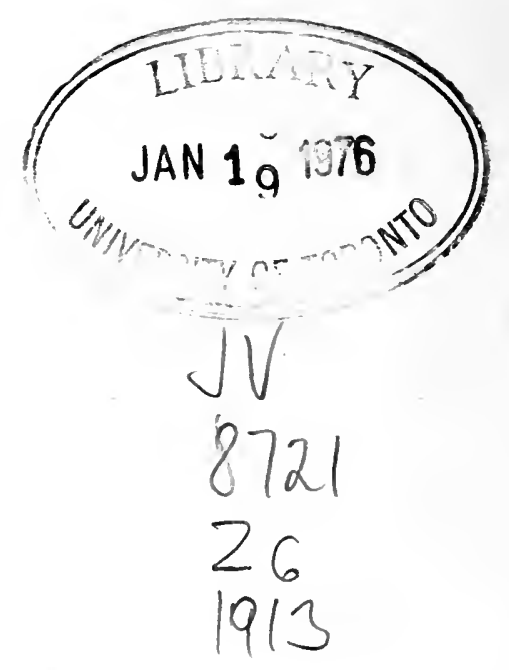




\section{DIE JAPANISCHE AUSWANDERUNG}

$\operatorname{ION}$

Dr. Ernst Grünfeld.

(Alle Rechte vorbehalten. 


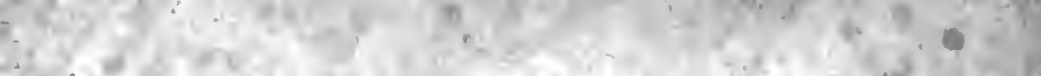

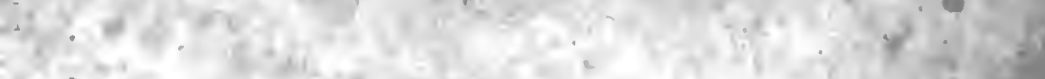

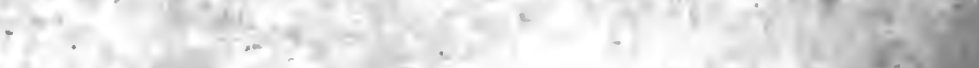

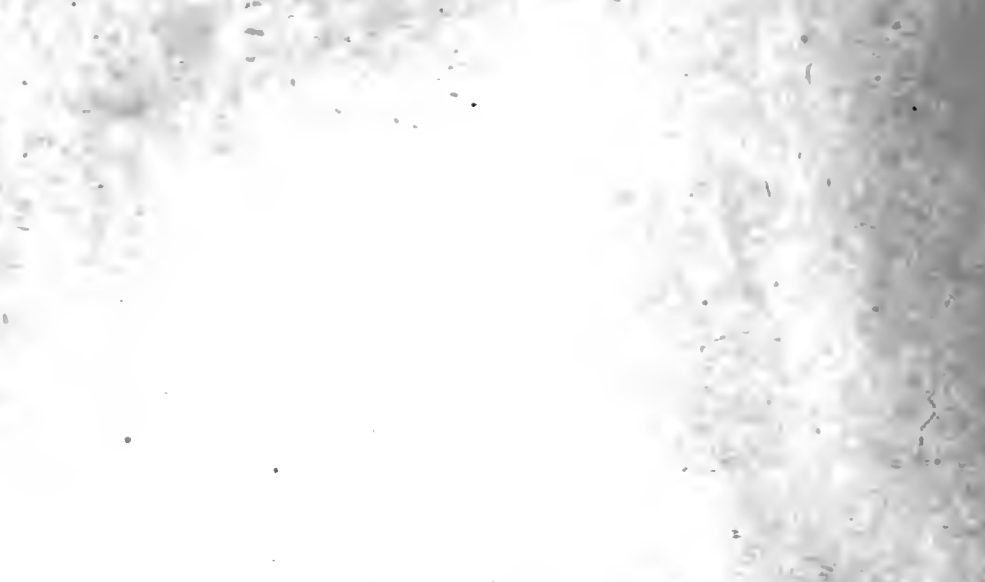

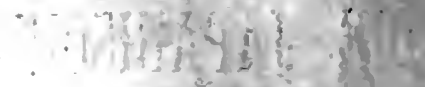
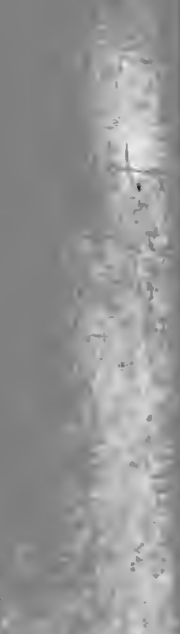

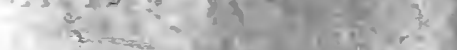
1 1 ,

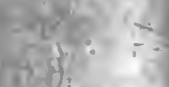

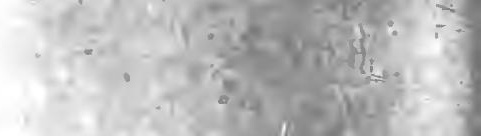

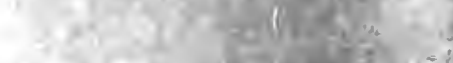

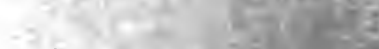
$=\frac{i d}{3}$

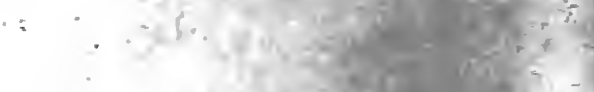
. . . .
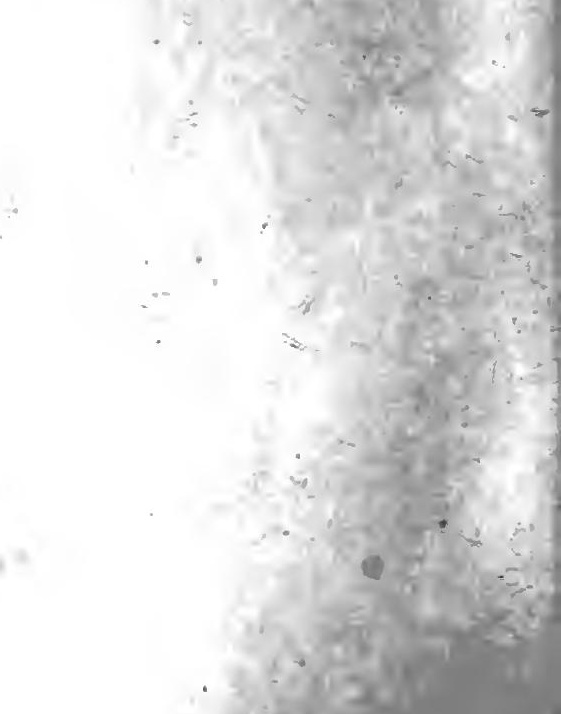


\section{I}

\section{INHALTSVERZEICHNIS.}

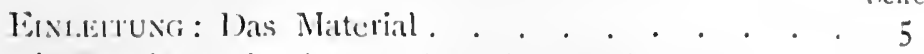

1. Die P'robleme der jatpanischen Auswanderung . • . 7

2. Statistik . . . . . . . . . . . . . . . I I

3. Grïnde der japanisclien Auswanderung, insbesondere lie Frage der Uebervöllerung . . . . . . . Is

+. Die Anfinge des japanischen Auswanderung und ein Ueberblick über ihre Entwicklung . . . . . . 30 (1)ic Anfänge S. 30 - Entwiclilung S. $32-$ Jic Auswanderer und ihre Eignung für fremele Länder. S. 35 - Dic IVege der Auswandermug S. 42 ; - Dic Agenturen S. 43 ; - Dic Auswanderungspolitile der japan. Regierung. S. 50)

5. Die Auswanderung nacl dem Osten . . . . . . 6r (Itawaii S. 6I ; - V. St. A. S. SS;-Kanada, S. I I I)

6. Dic Auswanderung nach dem übrigen Auslande . I I 4 (Iatcinisch Amerika S. I I 4 ; - Australien und dic Südsec S. I I9 - Der asiatische Kontinent S. I 2 I)

7. Dic Auswanderung nach den japanischen Kolonien. . I25 (Hokkaidō S. I25; - Sachalin S. I2S; - Formosa S. I3I; - Korea S. I34;-Die Mandschurei S. I 40 ; - Die Aufnahmefähigkeit der japan. Kolonien. S. 146$)$

8. Die Rüclivirkung der Auswanderung auf Japan und ihr Beurteilung mit lbezug auf das Auswanderungsund Bevölkerungsproblem im allgemeincn • • 147 


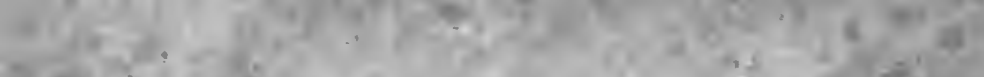

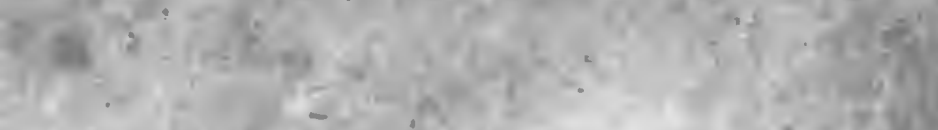

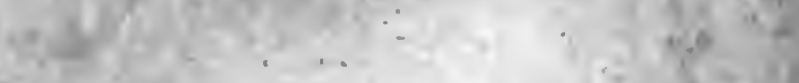

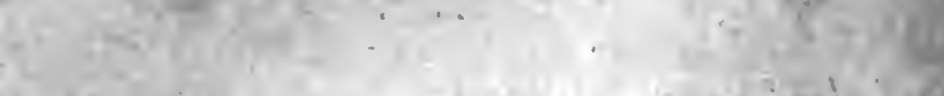

$3 \ldots, \ldots$

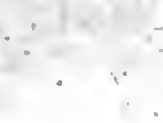

$\therefore$
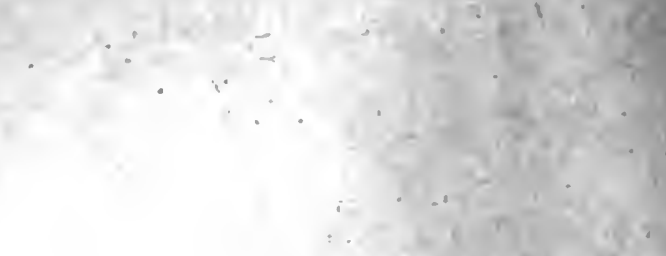

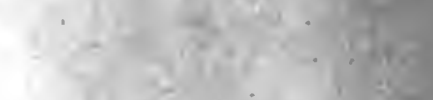

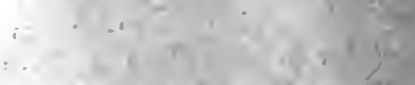

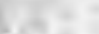

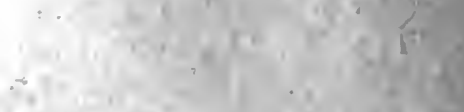

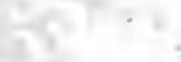

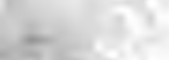

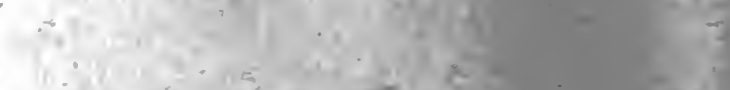

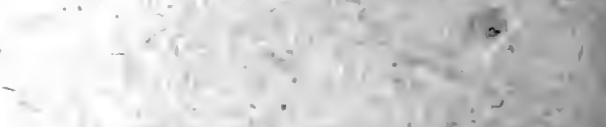

$\left(\frac{1}{4}=\right.$

$\int^{2}$

$(3)$

$x^{2}+8$

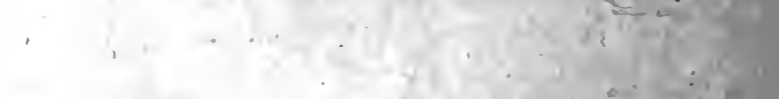

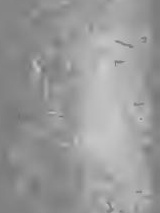

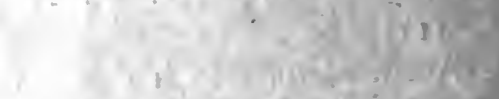

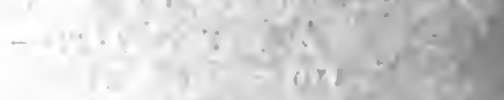

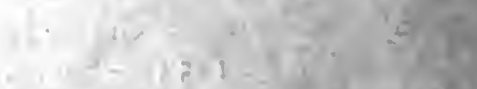

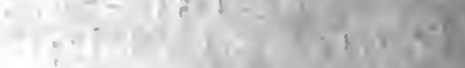

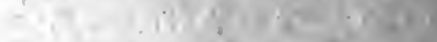

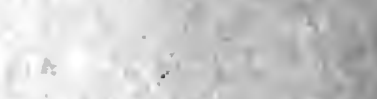

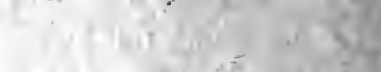

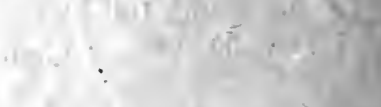
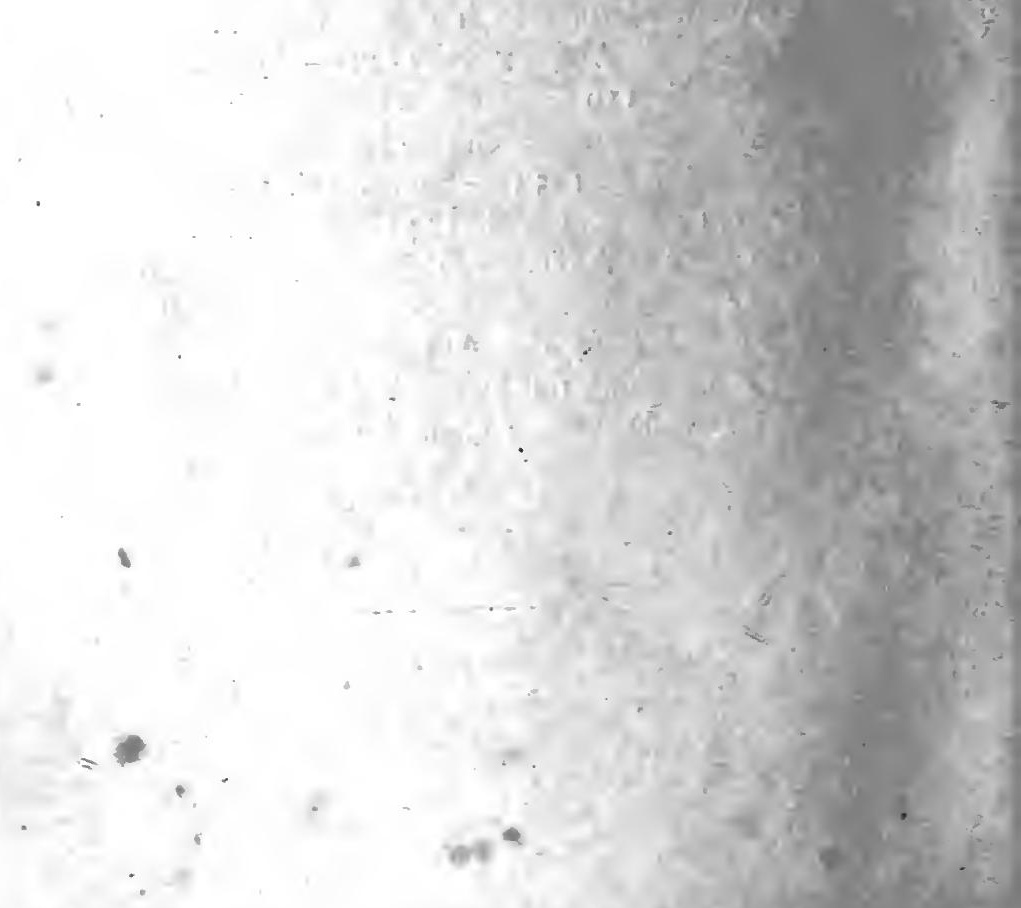


\title{
DIE JAPANISCHE AUSWANDERUNG
}

\author{
ION \\ Dr. Ernst Grünfeld.
}

\section{EINLEITUNG.}

Die japanische Auswanderung war eine zcitlang Gegenstand grossen politischen Interesses, ja 1907 schien es sogar manchem Beobachter, als ob der Schulkonflikt von San Francisco die nach dem Frieden von Portsmouth olnehin ctwas unruhig gewordene offentliche Meinung Japans so sehr erregrt hätte, dass die bereits prophezeite kriegerische Abrechnung Japans mit den Vereinigten Staaten unvermeidlich würde. Diese Ansicht unterscluätzte die staatsmännische Fähigkeit der führenden Männer sowohl in Japan als auch auf der andern Sxite des stillen Ozeans, aber sie ist doch dic Ursache, dass die japanische Auswanderung unausgesetzt zum Gegenstand politischer Betrachtungen gemacht wurde, und dass so häufig bei der Diskussion dieser Frage das Sensationelle und die Hypothese über die nüchterne, sachliche Betrachtung überwog.

Im Folgenden versuche ich die Frage vom sozialwissenschaftlichen Gesichtspunkte aus zu untersuchen und die politische Seite des Probleins beiseite zu lassen, soweit sich bei einem so komplizierten Problem, wie es das vorliegende ist, eine Isolierung überhaupt durchführen lässt.

Das Material zur Frage der japanischen Auswanderung war schwer zugänglich. Das einzige Buch in einer europäischen Sprache, das als Vorarbeit gelten kann, ${ }^{1}$ steht ganz unter dem Zeichen der politischen Plauderei und Sensation; und wenn auch Aubcrt, wie die meisten seiner schreibenden Landsleute, ausgezeichnet zu erzählen und anzuregen weiss, so ist doch sein Buch, bei dem übrigens die wirtschaftlichen Gesichtspunkte zurücktreten und nur der Gegensatz zwischen Japan und Amerika zur Geltung kommt, durch die Ereignisse überholt. Das ist un so bedauerlicher, als Aubert viel Material gesammelt hat und Japaner und

1) Louis Aubert, Américains et Japonais. Paris (Co!in) $190 S$. 
Amerikaner gut kennt und schildert. Sonst standen mir noch die amerikanischen und kanadischen Berichte zur Verfügung, von denen mir allerdings zwei hier in Tökyō nicht zugänglich waren, sowie eine Reihe von Veröffentlichungen, die meist amırikanischen Ursprungs sind. Sie sind wie alle übrigen Quellen am Orte ihrer Verwendung sorgfältig verzeichnet. Auf japanischer Seite ist mir nur das Buch von Ogawahira' ${ }^{1)}$ bekannt, das versucht eine allgemeine Darstellung des Problems zu geben, aber trotz der zwei ihm vorangestellten, anspruchsvollen Vorworte japanischer Gelehrter nur wenig bietet. Ihm und einigen noch weniger wertvollen Büchern konnte ich einiges Material entnehmen. Am meisten fand sich in den 9 Bänden von Berichten über Auswanderung, die das Gaimushō (Ministerium des Aeusseren) in Tōkyō herausgegeben hat, sowie einigen amtlichen Drucksachen, die ich der Freundlichkeit der in Betracht kommenden Stellen verdanke. Dass in Japan, wo die Frage der Auswanderung in der Oeffentlichkeit soviel erörtert wird, auch nicht cin gutes Buch darüber vorhanden ist, ist kein gutes Zeichen für seinen wissenschaftlichen Geist. Ich hatte überhaupt den Eindruck, dass es nicht vicle Japaner gibt, die über die Auswanderung gut orientiert sind. Wie manche Unterredung mit verneinten Faclımännern blieb für mich ergebnislos! Umso dankbarer bin ich den Herren, denen ich meine mündlichen Informationen verdanke, für das Entgegenkommen, mit dem sie mich bei meinen Nachforschungen unterstützt haben. Das gilt insbesondere von den Herren Reg. Rat Tauaka im Ministerium des Aeusseren, Direktor im Kolonialamt Dr. Egi, Direktor Slıir zishi von der Töyō Kisen Kaishı, K. Nakamura von der Nihon Shokumin Gōshi Kaisha, Prof. B. Hoshino, meinem Uebersetzer H. Maeda, sowie den Herren des Oitasiatischen Wirtschaftsarchivs der Südmandschurischen Bahn. Im übrigen musste ich mir mein Material in Spänen zusammentragen, da natürlich nur in Amerika und Hawaii, wo die japanische Einwanderung ziffernmässig ins Gewiclst fiel, eine Veranlassung zun Entstehen einer besonderen Literatur geboten bezw. überhaupt Literatur über Einwanderung vorhanden war. Naturgemäss musste ich mich oft der Zeitungen als Quellen bedienen, was bei der allgemeinen Unzuver-.

1) R. Ogawahira Nihon imin ron (D.s japanische Auswanderungsproblem) mit Vorworten von den Prof. Nitobe u. Tajima. Tokyo 1905. Nach Drucklerrung dieser Zeilen fiel wir das Buch „American Japanese Relations" von Kyoshi K. Kazvakami (New York etc. I912) in die Ilände, das jadoch keins nesen Gesichtspunkte bietet. 
lissigkeit solcher Nachrichten nicht unbedenklich war. Im vorliegenden Falle aber ist diese Un\%uverlässiglecit noch daclurch gesteigert, dass dic Oefentlichlieit Japans über dic Auswanderung fast arm\% ununterrichtet ist, und dass die Zeitungsmeldun'sen vielfach japanischen \%eitungen entstammen die, an Sensationsmacherei und Leichtfertigkeit selbst ihre Lehmeisterin, die amerikanische Presse übertreffen. Die grösste Schwicrigkeit aber, die mir, wie jeder Arbeit über Japan begegnete, ist die Undurchdringlichkeit der japanischen Literatur für jeden Europäer infolge der Unmöglichkeit die Schriftsprache und Schrift anders als nach mehreren arbeitsreichen Jahren zu erlernen. Soweit das Studium des Landes und der Ungangssprache und Gewissenhaftigkeit dieser Schwierigkeit zu begregnen vermögen, habe ich mzine Pflicht getan. Dennoch bitte ich für ein unvorhergesehenes Versehen, etwa die Ausserachtlassung einer japanischen Veröffentlichung oder einen Uebersetzungsfehler im voraus um Entschuldigung. Ich glaube, dass es mir trotz allem geglücht ist, eine Uebersicht über die bearbeitete Frage gewo:nnen zu haben, die uns bisher die Japaner sclbst schuldig geblieben sind, und die sie bei ihrem gegenwärtigen Mangel an wissenschaftlicher Literatur vielleicht auch noch länger schuldig bleiben werden,wenigstens in einer europāischen Sprache.

\section{DIE PROBLEME JAPANISCHEN AUSIVANDERUNG.}

Auf Seite 2 des geistreichen Buches von Aubert findet sich folgende hübsche Antithese: "Le temps n'est plus ou l'Européen se plaignait de l'isolement des Chinois, des Japonais et des Coréens, de leur entêtement à fermer les frontières...... Les rôles sont reversés: c'est le monde jaune qui cherche à empiéter sur les terres d'autrui et c'est le tour des Ozcidentaux de dééndre leurs territoires." Und Aubert bemerkt weiter, dass es nicht genüge, sein Land durch Einwanderungsverbote abzuschliessen, um es zu behaupten, sondern, dass man auch tatsächlich instande sein müsse, seinen Vorsatz durchzuführen, weun z. B. ein dünı besiedelter Kontinent, wie der australische, sich jeder andern Besiedlung als der durch Briten zu verschliessen wünsche, während in sıiner Nähe sehr vo!kreiche, mächtige Staaten nach Spielraum für ihren grossen Bevölkerungszuwachs suchen. In den europäischen Hauptstädten und auf de:n Papier liesse sich das ja alles sshön erörtern, auch 
die Frage, wie sehr die Welt gewinnen könnte, wenn östliche und westliche Kultur sich vereinigten oder gar verschmölzen; in der Praxis aber gebe es die grössten Schwierigkeiten, wenn die "humanité du pain" und die "humanité du riz" einander berührten.

Aber auch, wenn man von diesen Seiten der Frage absieht, bleibt für den Nationalökonomen genug des Interessanten übrig : Die Auswanderung aus Japan stellt eine ganz andere Entwickelung dar als die aus den wichtigen Auswandererstaaten Europas. Die japanische fällt ganz in die letzten Dezennien, während bis dahin das Inselreich 250 Jahre vollständig von der Aussenwelt abgeschlossen war. Als die Auswanderung nun einsetzte, u. zw. durchaus infolge der Initiative und des Eingreifens der Regierung, da standen Japan alle die Erfahrungen zur Verfügung, die die europäischen Auswanderungsländer sich in jahrhundertelanger Erfahrung mit vielen Opfern erworben hatten.

Man wusste bereits, dass nicht jeder, der sein Vaterland verlässt, um auf unbestimmte Zeit, ja auf immer in die Ferne zu ziehen, ein bemitleidenswerter Flüchtling, ein verächtlicher Abenteurer oder ein bedauernswertes Opfer von Agenten und Rhedern ist, dass Auswanderung nicht nur einen Verlust an Soldaten, Arbeitern und Kapital bedeutet, sondern der Ausbreitung des eigenen Volkstums, des Handels und der Schiffahrt Aussichten eröffnet, ja in letzter Zeit sogar zu einer Quelie reichlicher Geldsendungen aus dem Ausland geworden ist, die für kapitalarme Länder eine grosse Rolle spielen. Auch hat die Auswanderung in jüngerer Zeit ein anderes Gesicht angenommen. Die Zunahme, Verbilligung und Erleichterung des Verkehrs hat es mit sich gebracht, dass das Verlassen des Vaterlandes keine dauernde Trennung $z u$ bedeuten braucht. Der Nachrichten-Verkehr, einschliesslich der Zeitungen, hält die Verbindung aufrecht, Besuche in der alten Heimat, oder solche der Angehörigen im neuen Wohnsitz sind in den Bereich der Möglichkeit gerückt, eine Rückkehr bietet fast nur finanzielle Schwierigkeiten, und die Gesetzgebung und Polizei aller beteiligten Staaten, die Einrichtungen grosser Transportgesellschaften, wie z. B. der deutschen Rhedereien haben die ärgsten Missstānde aus dem Weg geräumt. Da der Auswanderer seinem Heimatlande nicht mehr entfremdet zu werden braucht, hat die Auswanderung ihre Schrecken verloren und ist sogar teilweise zu einer Arbeiterwanderung geworden, die den. früher in 
Europa bereits ïblichen Binnenwanderungen der Saisonabeiter ïhnelt. Kein IVunder, dass man heute dic Nuswanderung mit freundlicheren Augen betrachtet, ja sorar in volkreichen Ländern

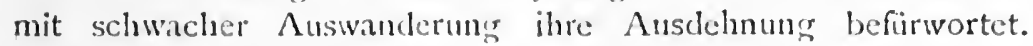
Andrerseits ist auch die Stellungnahme der Einwanderungslancker cine andere geworden. Noch heste ist Raum für grosse Volksmengen in ihnen vorhanden, aber eine Not an Mann besteht meist nicht melre, und wemn die Einwanderung beförlert wird, so sind es meist nicht mehr wirtschaftliche Gründe allein, die dazu anspornen. Andrerseits hat man erkannt, welche Bedeutung einer richtigen Auslese der Einwandernden innewohnt. Länder, wie die Vereinigten Stiaten Nordamerikas z. 13., die in den letzten Jahren über eine Million Einwanderer zugelassen luaben, wünschen sich alle körperlich, geistig, sittlich oder wirtschaftlich minder tauglichen Elemente fernzuhalten, ja, sie müssen in der Zulassung newer Bürger vorsichtig sein, wollen sic nicht die hohe Lebenshaltung ihres Volkes durch Scharen armer und allzu anspruchsloser Neuankömmlinge, ihre Sprache, Charaktereigenschaften, Sitten, kurz ihr ganzes Volkstum durch den Zuwachs an Menschen gefährden, die andern Ländern und Rassen entstammen, als die englischen, deutschen, skandinavischen und französischen Kolonisten, die dem Lande seine gegenwärtige Bevölkerung gegeben haben. Am allerwenigsten aber wünscht man die Zuwanderung von Leuten, die nicht die Absicht haben, sich dauernd sesshaft zu machen, sondern die nur ein paar Jahre die Differenz zwischen den niedrigen Löhnen ihres Landes und den oft um ein Vielfaches höheren des Einwanderungslandes geniessen wollen. Denn diese Zuwanderer stellen nicht nur keinen eigentlichen Bevölkerungszuwachs dar, sie verursachen auch noch einen grossen Kapitalexport, dem ein Einfluss fremder Waren entspricht, und vor allem, sie geben sich keine Mühe, sich dem Lande ihrer Wahl anzupassen, mit der ansässigen Bevölkerung eins zu werden und verursachen durch ihre Unkenntnis der Landessprache und Sitten, durch ihre, dem Einheimischen fremde Lebensweise, manchmal auch durch ihre niedrige Lebenshaltung und was damit zusammenhängt, erhöhte Verwaltungskosten, Missstände, sowie eine Erschwerung der Assimilation für alle übrigen Einwanderer.

Es ist begreiflich, dass es dem japanischen Auswanderer, der keine Erfahrung im Verkehr init dem Auslande hatte, der auch keine Führer in fremden Lande besass, zunächst schwer 
wurde, sich zurechtzufinden, insbesondere in Ländern, deren Sprache und Kultur so grundverschieden von der seinen waren, wie etwa die Vereinigten Staaten von Nordamerika, in die nur die wenigsten Japaner kamen, um sich dauernd anzusiedeln, während die überwiegende Mehrzahl das Land nach wenigen Jahren wieder verliess, um in der geliebten Heimat die Ersparnisse zu verzehren. Andrerseits macht das Gesagte auch begreiflich, dass die öffentliche Meinung Japans der Auswanderung meist sympathisch gegenübersteht, ja dass sogar eine sehr starke Strömung die weitere Ausgestaltung der Auswanderung verlangt. Da fast alle Auswanderer zurückkehren, hat Japan keine Verluste an Volkstum zu beklagen, wohl aber sind die kolonisatorischen Erfolge der britischen Auswanderung, die deutschen Ansiedlungen in Südamerika und die Ausbreitung der deutschen Schiffahrt und des deutschen Handels, die Geldsendungen der Italiener im Auslande oft besprochene Erscheinungen, die jedem japanischen Patrioten die Auswanderung als etwas Wünschenswertes erscheinen lassen. Dazu kommt der Glaube an den nicht zu erschöpfenden Volksreichtum Japans, über den wenig Zuverlässiges bekannt ist, das Verlangen nach Ausdehnung von Schiffahrt und Aussenhandel, nach Guthaben in Auslande, der Wunsch eines lerneifrigen Volkes, von den Zuständen im Auslande zu lernen, es den grossen Staaten Europas gleichzutun, die Bodenknappheit in dem gebirgigen Vaterlande, die geringe Kapitalkraft des Landes, wohl auch ein wenig politische Schwärmerei und Opposition gegen die Verschliessung der angelsächsischen Länder an der Küste des stillen Ozeans gegen asiatische Einwanderung, kurz, man ist der Auswancierung im allgemeinen sehr günstig gesinnt. In der Literatur und Presse kommt das beständig zum Ausdruck und selbst die Mehrzahl der japanischen Gelehrten deren Aeusserungen zu meiner Kenntnis gelangt sind, empfehlen die Auswanderung, ja, machen sogar Propaganda für sie."

1) Auf dem dritten Kongress des japanischen Vereins für Sozialpolitil in Tōkyō, auf dessen Tagesordnung die Auswanderungsfrage stand, äusserten sich hiezu neun Redner, von denen fünf gegen, vier für die Auswanderung sprachen, (siehe "Imin mondai ", Tōkyō 1909, das alle Reden enthält). Das Buch von R. Ogawahira, "Nihon imin ron " (Die japanische Auswanderungsírage), Tökyō 1905, will fiir die japanische Auswanderung Propaganda machen, und dasselbe tun die Professoren $I$. Nitobe und Tajima, die za dem Buch $\mathrm{j}$ : ein Vorwort geschrieben haben. Die übereinstimmende Haltung der Presse kann ich hier aus Mangel an Raum nicht belegen, doch ist eine grosse Anzahl von Zeitungsstimmen in Aubert's Buch zu finden. 
Auch leute, wo bereits die Liskenntuis von der geringen Bedeutung und der lintbehrlichkeit der japanischen Auswanderung fiir jeden, der sich mit der Frage ernstlich beschäftigen will, klar zu Tage liegt, hören die Anl:lagen gegenen dic , ziellose Auswanderungspolitik" "und die ., mangelnde Initiative der Regirung " in der japanischen Presse nicht auf. Männer wie der ehenalige Minister des Acusseren und Botschafter in Washington, Vicomte Aoki, und der rgI I zurückgetretenc Handelsminister Baron Oara haben bereits öffentlich die Notwendigkeit der Ausiwanderung und dic Aneiferung zur Auswanderung nach Amerika zurückgewiesen, aber nach wie vor stellen selbst die wenigen ernst $7 u$ nehmenden Zeitschriften ihre Spalten der unbedingten Verteidigung und Lobpreisung der Auswanderung zur Verfügung." Das beweist nur, dass der Grund der allgemeinen Sympathic für diesc und der wichtigste Antricb zu ihrer Fortsetzung nicht wirtschaftlicher Natur sind, sondern, wie dic beständigen Hinweise auf die grossen europäischen Kolonialreiche zeigen, auf imperialistische Expansionstendenzen zurückgeführt werden müssen.

\section{STATISTIK DER JAPANISCHEN AUSWANDERUNG.}

Bevor ich daran gehe, die Geschichte der japanischen Auswanderung zu skizzieren, will ich noch versuchen, ihren tatsächlichen Unfang durch einige statistische Angaben zu kennzeichnen und ihre Beweggründe, insbesondere die Frage der Uebervölkerung Japans $\mathrm{zu}$ untersuchen.

Freilich ist es nicht leicht, sichere Zahlen zu finden: Eine eigentliche Auswanderungsstatistik besteht nicht: es werden nur die ausgegebenen und zurückgestellten Pässe gezählt. Da seit Erlass des Auswanderungsgesetzes, insbesondere aber seit dessen strengerer Handhabıng jeder Auswanderer zum Verlassen des Landes eines Passes bedarf, so dürfte in den letzten Jahren die angegebene Zahl der Auswanderer tatsächlich richtig sein. Es ist aber zu bedenken, dass im Sinne des japanischen Gesetzes die Reisenden nach China und Korea (das inzwischen Kolonie wurde) und den Kolonien nicht als Auswanderer angesehen werden, und wenn auch für die Reise nach China Pässe ausgegeben werden, so sind es sicher nicht alle

1) Z. I3. Shin Niho: und Jitsugyō-no-Nihon, in denen die Herausgeber Graf Okama und Mastudiz selbst der Auswanderung das Wort sprechen. 
Auswanderer, die damit versehen sind. Ferner sind natürlich alle, die sich einer Kontrolle entziehen, nicht mitgezählt, und ihre Zahl dürfte nicht unbedeutend sein, insbesondere da noch immer ein starker Mädchenhandel stattfindet, der sich einer Ueberwachung $\mathrm{zu}$ entziehen weiss. Ausserdem zählt die japanische Statistik auswandernde Kinder anscheinend nicht als voll, die ganz kleinen überhaupt nicht. Die Zahl der Auswandernden nach den Kolonien ist angesichts deren Nähe und des starken Verkehrs mit dem Mutterlande schwer festzustellen, so dass die von den Kolonialregierungen ausgewiesenen Zahlen der Ein- und Rückwanderung nicht zuverlässig sein dürften. Was die Zahl der zurückgegebenen Pässe anbelangt, so ist sie wahrscheinlich zu niedrig, da das Abliefern der Pässe erfahrungsgemäss überall leicht unterbleibt, da in Japan kein Passzwang besteht und natürlich auch viele aus der Fremde zurückkehren, die ohne Pass fortgefahren sind, oder im Auslande geboren wurden. Es wurden Passe ${ }^{1)}$

\section{TABELle $\quad$ I.}

\begin{tabular}{|c|c|c|}
\hline im Jahr & ausgegeben & zuruickgestellt \\
\hline I9ว3 & 35663 & - \\
\hline 1904 & 27377 & 8525 \\
\hline 1905 & I9466 & I O I I I \\
\hline I905 & $5885 \mathrm{I}$ & 22722 \\
\hline 1907 & 43627 & I 2497 \\
\hline 1908 & 21344 & I 1654 \\
\hline I 909 & 15740 & I I 844 \\
\hline
\end{tabular}

Von den im Jahr I9Io Auswandernden waren I 280 I Männer und 2939 Frauen.2) Der Anteil der Frauen hat in den letzten Jahren zugenommen, da mehr und mehr Familien fortziehen, oder Japaner im Auslande ihre Familien nachkommen lassen oder Frauen herausrufen, um Familiell zu begründen, ein Beweis, dass die Qualität der Auswanderer zunimmt.

Die Einteilung der Auswanderer nach Berufen ist wenig

1) Japan. Statist. Jahrbuch, I9 IO.

2) Résuné Statistique, I9I I. 
durchsichtig. Auffallend ist die in den letaten Jahren merkbare Einschränkung in der Aussendung von Studenten und Arbeitern. Die Zahlen für diese Berufseruppen lauten:

TABel.e: II.

\begin{tabular}{l|r|r|r|r|r|r}
\hline & 1901 & 1905 & 1906 & 1907 & 1908 & 1909 \\
\hline Studenten & 1597 & 1127 & 3340 & 3415 & 680 & 359 \\
Arbeiter & 855 & 329 & 315 & 97 & 189 & 117 \\
\hline
\end{tabular}

Sicherlich verbergen sich viele Arbeiter unter andern Rubriken, aber in der Hauptsache dürfte es stimmen, dass ihre Auswanderung seit wenigen Jahren so gut wie abgeschnitten ist. Von den im Jahre 1909 ausgestellten Pässen waren 6503 für Russland, (einschliesslich Russisch Asien) ausgestellt, 2623 für China'), 2002 für die Vereinigten Staaten, 1276 für Peru, 1273 für Hawaii, 344 für Kanada, und 227 für die Philippinen. Der Rest vertcilt sich auf dic ganze Welt.

Eigentlich wären nun den Zahlen der Auswanderer nach den Auslande noch die der in die Kolonien Wandernden zuzuzählen, obwohl die wichtigstc Kolonie, der Hokkaidō, rechtlich gar keine Kolonie mehr ist, sondern eine Provinz, und die andern Kolonien, Formosa, Südsachalin und Korea dem Mutterlande so nahe liegen, dass man fast von Binnenwanderungen sprechen könnte. Da der Hokkaidō für die obenstehende Berechnung der Auswanderer als Mutter- also Auswanderungsland gezählt wurde, muss seine Einwanderung auch tatsächlich ausser Betracht gelassen werden. Im übrigen wanderten aus :

\section{TABELLE III.}

$\begin{array}{cccc}\text { in Jahre } & \text { Nach Formosa. } & \text { Sachalin. } & \begin{array}{c}\text { Südmandschurei } \\ \text { (Pachtgebiet) }\end{array} \\ 1908 & 20360 & 3) & -1 \\ 1909 & - & \text { 17187 } & 20641\end{array}$

1) Für Hongkong ausserdem 121 .

2) Japan. Statist. Jahrbuch 1910.

3) ebenda S. roto.

4) "Lage der Ansiedler in den Folonien," herausgegeben vom Kolonialamt, Tōkyō, 19ro/rr, ohne Datumsangabe. 
Von dort kehrten im selben Jahre zurück:

$$
\text { I } 4393 \text { I } 37 \text { I } 5
$$

Es war also der Menschenzuwachs dieser Länder durch Einwanderung :

$$
5967 \quad 3472 \quad 5294
$$

Die Zahlen für Korea sind mir nicht bekannt geworden, da keine amtlichen statistischen Mitteilungen hierüber veröfentlicht werden. Immerhin dürften mehrere Tausende von Japanern im Jahr mehr nach Korea ab-, als von dorther zuwandern. Bedenkt man nun, dass auch noch die Bahnzone in der Südmandschurei Japaner an sich zieht, so kann man leicht feststellen, dass die Auswanderung nach den Kolonien ein mehrfaches derjenigen nach dem Auslande beträgt.

Zum Vergleich mit den Auswanderungsziffern Japans seien hier die für die überseeische Auswanderung einiger europäischer Länder angeführt. Es verliessen :1)

\begin{tabular}{|c|c|c|c|c|}
\hline & $\underset{\text { Jahre }}{\operatorname{Im}}$ & Köpre & $\begin{array}{l}\text { Aus einer Ein- } \\
\text { wohnerzahl von }\end{array}$ & $\mid \begin{array}{c}\text { u. einer Be- } \\
\text { völkerungs- } \\
\text { dichte per } \mathrm{Km}^{\mathrm{g}}\end{array}$ \\
\hline $\begin{array}{c}\text { Das Deutsche } \\
\text { Reich }\end{array}$ & 1910 & 25531 & 64903423 & 120.22 \\
\hline Oesterreich & I 909 & I 29656 & 28567898 & 95.17 \\
\hline Ungarn & 1909 & 129337 & 20840578 & 64.15 \\
\hline Italien & 1909 & 625637 & 32475253 & I 13.28 \\
\hline Spanien & 1909 & 142717 & 19503068 & 38.66 \\
\hline Belgien & 1908 & 17280 & 6693548 & 227.25 \\
\hline Norwegen & 1909 & 16152 & 2392699 & $7 \cdot 44$ \\
\hline $\begin{array}{l}\text { Grossbrit. \& } \\
\text { Irland }\end{array}$ & I909 & $28876 \mathrm{I}$ & $4 \mathrm{I} 45872 \mathrm{I}$ & I 32.66 \\
\hline
\end{tabular}

TABeLLE IV.

Japan, das im Jahre Igo8 wahrscheinlich eine Wohnbevölkerung von etwa 5 I Millionen hatte, also fast soviel wie Ungarn und Italien zusammen, bei einer Bevölkerungsdichte, die etwa

1) Statist. Jahrbuch für das Deutsche Reich I9II. 
der des Vereinisten Königreichs gleichliommt, hatte cine Auswanderung, die sich mit der des Dentschen Reiches vergleichen lïsst, (wenn man die Unvollkommenheit der japanischen Daten berïcksichtigt), ja 1909 ziffermü̈ssig nicht cinmal die Norwegens erreicht, dessen ganze Bevölkerung weniger Köpfe z:̈hlt als Japans Hauptstadt mit iluren Vororten. Man kamn also die japanische Auswanderung nur als cine kleine bezeichnen, und wenn sie auch frülser etwas grösser war, so ist das doch angesichts der alltäglichen Massenwanderungen unserer Zeit keine auffallende Erscheinung, besonders, da dic Zahl der Rückwanderer cine so grosse ist. Nach diesen Angaben lässt sich das Aufselien, das die japanische Auswanderung dennoch hervoregerufen hat, nur aus ihrer Konzentration auf einige kleine Gebiete erklären. (Die Kolonien Japans sind bei dem Vergleich mit dem Auslande nicht berüclssichtigt.)

Ueber die Zahl der im Auslande lebenden Japaner gibt es gleichfalls keine zuverlässige Statistik. Das Ministerium des Aeussern sammelt dic Angaben, die ihm von den Konsulaten gemacht werden und stellt danach eine grosie statistische Tafel zusammen, die natürlich nicht genau sein kann. Immerhin mag sie einen gewissen Anhalt bieten, besonders da sie jährlich erneuert wird und so wenigstens die Veränderungen zum Ausdruck kommen. Auffallenderweise hört und liest man immer wieder andere Ziffern, alle angeblich aus antlichen Quellen, die die Zahl der Japaner im Auslande ganz verschieden darstellen. Für das Jahr I909 sind mir allein vier Angaben bekannt, davon zwei amtliche und zwei angeblich antliche (im "Japanese Yearbook," und "The Japan Financial and Fconomic Monthly") die von 42065 I bis 256434 auseinandergehen. Die letztere Zahl ist der grossen Tabelle entnommen, die das japanische Ministerium des Aeussern herausgibt, wälnrend das japanische statistische Jahrbuch für I9IO von 302616 ausgewanderten Japanern berichtet. Da das Auswanderungsivesen dem genannten Ministerium untersteht, so folge ich hier seinen Angaben und nehme an, dass Ende 1909 tatsächlich die Zahl der Japaner im Auslande 256434 war. In den japanischen Kolonien waren etwa zur selben Zeit 307279. ${ }^{1}$ Es waren also zusammen 5637I3

1) Und zwar in Korea 146147 (nach dem 3 ten Annual report on reforms and progress in Korea, compiled by the Government General of Chosen, Seoul 1910); in Sachalin 23897, in Formosa 83329 (Resumé statistique I9II S. 34/3.5); in der Mandschurei (Kwantung-Pachtgebiet und: Bahnzone) 53906 (I.age der Ansiedler 
Japaner ausserhalb des Hauptlandes. Sicherlich ist dic Zahl der Japaner in fremden Ländern nicht voll erfasst, da ja die Konsuln nicht die Möglichkeit haben Zählungen vorzunehmen. Warscheinlich halten sich die Japaner in den Kolonien und in der Fremde das Gleichgewicht, so dass Japan nicht viel Verluste an Bürgern zu beklagen liaben dürfte. Von den Japanern im Auslande waren :

\section{TABELle $\mathrm{V}$.}

\begin{tabular}{|c|c|c|c|}
\hline & 1000 & & \\
\hline & igug. & Männer. & Frauen. \\
\hline in den Vereinigten Staaten & 142469 & I 14382 & 28087 \\
\hline davon in Hawai & 65760 & 446 I 7 & 21143 \\
\hline $\begin{array}{c}\text { im Konsulatsbezirk } \\
\text { San Francisco }\end{array}$ & $5336 \mathrm{r}$ & 48590 & 4771 \\
\hline in China & 81279 & 46260 & 35019 \\
\hline „Canada & 8854 & 7717 & I I 37 \\
\hline , Peru & 4560 & 4337 & 223 \\
\hline "Australien & 3960 & $379 \mathrm{I}$ & 169 \\
\hline $\begin{array}{l}\text { " Colombo, Hongkong, } \\
\text { Singapore }\end{array}$ & 3464 & I I73 & $2291 \times$ \\
\hline ", Russisch Asien & 3600 & I 808 & I $792 x$ \\
\hline " Mexiko & 2465 & 2327 & I 38 \\
\hline , den Philippinen & 2156 & г686 & 470 \\
\hline , Niederl. Indien & $78 \mathbf{I}$ & 344 & $436 \times$ \\
\hline , Ostindien & 780 & 242 & $539 \times$ \\
\hline „Brasilien & 605 & 474 & $13 \mathbf{I}$ \\
\hline , Siam & I 84 & 123 & $6 \mathrm{r} \times$ \\
\hline " Chile & 145 & I 42 & 3 \\
\hline "Argentinien & 27 & 27 & 一 \\
\hline
\end{tabular}

Der Rest verteilt sich auf alle übrigen Länder. Zusammen \begin{tabular}{l|l|l|l|l}
256434 & $185788 \mid 70646$
\end{tabular}

in den Kolonien, herausgegeben vom Kolonialamt, Tōkyō, I9ro/11.) In der Zahı $25643+$ sind allerdings die Japaner in der Mandschurei mitgerechnet, da sie eigentlich China gehört. Bei der Summierung wären also die 53905 a'szuziehen. 
Die Ucbersicht über die geographische Verteilung, zeigt zunächst, dass mehr als dic Hälfte sich in den Vereinigten Staten Amerikas, cin Drittel in China anfhält (vergleiche das oben von der Mandschurei Gesagte). Sonst gibt es nur wenige Lïnder mit nennenswerter japanischer lëinwohnerschaft, wiederum ein Beweis für die starke Konzentration der Auswanderung auf einzelne Gebietc.

Dic Verteilung der Geschlechter weist einen durchschnittlichen Satz von nur $27.55 \%$ Iraucn auf, was darauf hindeutet, dass dic Auswanderer meist nicht dauernd sesshaft sind. Eine Ausnahme bilden Hawaii und China, wo die Japaner festen Fuss gefasst haben. Uebrigens ist auch in China die Vertcilung der Japancrinnen nicht gleichmässig. Während in den ganz chinesischen Gebieten die Männer stark überwiegen, ist in der Mandschurei (einschliesslich der Nordmandschurci) und in Shanghai das Gegenteil der Fall. Dic übrigen Gebiete, in denen das weibliche Geschlecht fast oder ganz überwiegt, sind durch ein $\mathbf{x}$ kenntlich gemacht : es sind die englischen Kolonien in Ostasien, Russisch Asien, Niederländisch Indien, und auch in Siam erreichten die Frauen 50\% der japanischen Bevölkerung. Die Erklärung für diesc Tatsache liefert teils die Berufsstatistik, teils kann ich sic aus dem Folgenden vorwegnehmen. Hauptsächlich sind es die Rubriken ,, Geishas, Prostituierte und dergleichen " und "Sonstige Berufe", die den Ueberfluss an Frauen aufnehmen, ferner in geringerem Umfange die Rubriken , Restaurants " und „Häusliche Dienstboten." Es ist eine in Ostasien bekannte Tatsache, dass Japanerinnen an der ganzen Westküste des stillen Ozeans und bis nach Aden zu finden sind, und das hat seine Gründe nicht nur in einem seit alters blühenden Mädchenhandel, der in einigen westlichen Provinzen Japans seine nicht immer unfreiwilligen Opfer fordert und gegenwärtig seine Hauptsitze in Hongkong und Dalny zu haben scheint, sondern auch in der grossen Anziehungskraft, die die Japanerinnen auch auf Europäer ausüben. Uebrigens sollen viele von den Mädchen in die Heirnat zurückkehren und den Weg zum bürgerlichen Leben wiederfinden. Interessant ist, wie tief, bis nach Sibirien hine in, der japanische Menschenstron in Russisch Asien vorgedrungen ist. Sicherlich ist die Ursache hierfür zum Teil in dem letzten Kriege zu suchen, nach dessen Beendigung viele Japaner, die den Truppen gefolgt waren, im Lande blieben.

Dem Reruf nach sind 70100 Landwirte ausgewiesen, von denen 68462 in den Vereinigten Staaten wohnen, I 7265 häusliche 
Dienstboten, (hiervon I440I in den Vereinigten Staaten), I 4445 Privatbeamte, (die meisten hiervon in Hawaii), 16622 Eisenbahnangestellte und Arbeiter, (meist in den Vereinigten Staaten), ı080o Gastwirte, Köche und dergleichen, (hiervon etwa die Hälfte in den Vereinigten Staaten), I 4708 Kaufleute, (hiervon über Soso in China), 7705 Industrielle (?) (meist in China), 7008 Regierungs- und Kommunalbeamte, (hiervon 6656 in China), 4467 Fischer, (meist in Kanada und den Vereinigten Staaten), 2558 Studenten, (hiervon 2039 in den Vereinigten Staaten), und eine grosse Reihe von andern Berufskategorieen, die sich auf die ganze Welt verteilen. Leider ist die Einteilung der Barufe wenig durchsichtig, so dass ich wiederholt einzelne der I I 2 Rubriken zu kombinieren hatte. In Südamerika sind die Japaner fast ausschliesslich ungelernte Arbeiter. Interessant ist, dass sich manche Berufe auf einzelne Gebiete konzentrieren: so sind z.B. von den 8854 Japanern in Kanada 2686 Fischer, 3158 Sägemühlenarbeiter. Der grösste Teil der Japaner in Auslande dürften Landwirte, ungelernte Arbeiter und Verkäufer persönlicher Dienstleistungen, (Köche, Gastwirte, Kellner, Raseure, Dienstboten etc.) sein. Unter den qualifizierten Arbeitern spielen die Zimmerleute eine grosse Rolle, was für jeden, der die Japaner als Meister in der Holzbehandlung kennen gelernt hat, leicht verständlich ist. Im übrigen wird ja noch bəi der Besprechung der einzelnen Auswanderungsziele von der Berufsgliederung der Auswanderer zu sprechen sein.

\section{GRUENDE DER AUSWANDERUNG, BESONDERS DIE}

\section{FRAGE DER UEBERVOELKERUNG.}

Welches sind nun die Gründe der japanischen Auswanderung? Bekanntlich gibt es für jede Auswanderung zwei Arten von Antrieben: Druck und Abstossung in der Heimat, und Anziehung von Seiten der Einwanderungsländer; oft sind beide Momente gleichzeitig wirksam. Im einzelnen gibt es, wie es scheint, kaum eine Tatsache, die nicht auch den unmittelbaren Anlass zur Auswanderung zu bieten vermöchte. Verfolgungen politischer oder religiöser Art liaben zum Entstehen der japanischen Auswanderung nicht beigetragen. Grosse wirtschaftliche Umwälzungen haben zwar in Japan stattgefunden, aber abgesehen von der grossen Steuerlast, die übrigens erst seit dem letzten Krieg besonders schwer fühlbar 
geworden ist, dürfen grerade die bïnerlichen Bevöllecrungsschichten, die diss Hauptkontingent der Auswanderer stellen, nicht allyusehr grelitten haben, ja die Zunahme der Verkehrsmittel, dic Ordnuner der Willrungsverhältnisse, dic Ordumug der Grundsteucr u. a. hat ilmen sogar munchen Vortcil \%um Ausgleich beschert. Sicherlich ist dic Lare des kleinen Mannes in Japan, mit deutschen oder amerikanischen Massstiben gemessen, nicht rosig: aber das war sic nic, und das japanische Volk ist scnügsam. Fehlt es ilso auch nicht an Leuten, dic ihre Lage in Ausland erheblich verbessern könnten, so fehlt doch meist das Bewusstsein dafür, und es mussten erst Lockungen von bereits Ausgewanderten oder Agenten hinzukommen, um die japanischen, lionservativen Landwirte aus ihrem Lande fortzuzichen, in dem sie jahrhundertelang abgeschlossen gelebt hatter. Auch darüber ist im Folgenden noch ciniges \%u sagen. Gewöhnlich hört man aber nur cine Ursache für die japanische Auswanderung anfülren: Die Uebervölicrung. Um diese Behauptung näher nachzuprüfen, was gerade im vorliegenden Fall auf allerhand Schwicrigkeiten stösst, grehe ich darauf etwas ausfïhrlicher cin.

Dic Frage ob in einem Lande Uebervöllerung herrscht oder nicht, lässt sich bekanntlich nich exalit lösen, da man dazu die Bevölkerung in Verhältnis zu den wirtschaftlichen Möglichkeiten des Landes setzen müsste, über die es genaue Daten nie geben kann. Man muss sich a!so auf die Zahlen beschränken, die die Bevölkerungsstatistik zur Verfügung stellt.

Für Japan muss man sich auch dabei ein wenig bescheiden, weil es hier noch an einer allgemeinen Volliszählung, der einzigen zuverlässigen Unterlage für eine Bevöikerungsstatistik fehlt.") Doch wird durch eine möglichst sorgfältige Registrierung der Bevölkerungsbewegung, verbunden mit einer periodischen Aufnahme der Registerbevölkerung nach Verwaltungsbezirken auf Grund der amtlichen Register einigermassen Ersatz geboten. Infolge der eigentümlichen Familienverhältnisse Japans ist es wahrscheinlich, dass die Eintragung in die Register in den Heimatsbezirken recht sorgfältig bewirkt wird, während die Registrierung der Wohnbevölkerung weniger zuverlässig sein dürfte. Die gesetzliche Registerbevölkerung Japans betrug am $3 \mathbf{I}$. XII. $1908^{2)}$

1) Die 1872 vorgenommene Aufnahme der Bevölkerung, die als Grundlage für die spätere Fortschreibung dient, konnte noch kein einwandfreies Ergebnis liefern. 2) Résumé statistique de l'empire du Japon. $25 \mathrm{e}$ année, 'Tōkyō, rgır. Seite $\mathbf{r}_{3}$. 
TABElle VI.

\begin{tabular}{|c|c|c|c|}
\hline & Einwohner & $\left|\begin{array}{c}\text { Auf einer Fläche } \\
\text { von } \mathrm{Km}^{2}\end{array}\right|$ & \begin{tabular}{|c} 
Dichte auf \\
$\mathrm{I} \mathrm{Km}^{2}$
\end{tabular} \\
\hline Mittel ) & I9co 4475 & 94792.48 & 200 \\
\hline Nördl. Honshū & 7480432 & 78225.08 & $90^{\circ}$ \\
\hline IVestl. ) & 10929374 & $5356 \mathrm{r} .4 \mathrm{I}$ & 204 \\
\hline Zus. Honshū & $374 \mathrm{I} 428 \mathrm{I}$ & 226578.97 & 165 \\
\hline Shikoku & $3288_{310}$ & 18210.03 & I $8 \mathrm{I}$ \\
\hline Kyūshū & 7748752 & 43614.48 & 178 \\
\hline Hokkaidō & I I 37455 & $940 \mathrm{I}$ I.6I & 12 \\
\hline Zus. Japan & 49588798 & 3824 I 5.09 & I 30 \\
\hline \multicolumn{4}{|l|}{ dazu } \\
\hline Formosa und Pescadores & $324043^{1)}$ & $35967.98^{4}$ & .90 \\
\hline Sachalin & $26\left(59^{2)}\right.$ & $3406 \mathrm{r} .55^{4)}$ & 0.8 \\
\hline Korea & I 307 I $177^{3)}$ & $217819.03^{4)}$ & 62 \\
\hline Zus. Kolonien & I6337774 & 287848.56 & 56.6 \\
\hline Japan mit Kolonien & 65926572 & 670263.63 & 98.4 \\
\hline
\end{tabular}

(Kwantung und die Bahnzone sind hier nicht in Rechnung gezogen.)

Das japanische Reich mit seinen Kolonien beherbergt also beiläufig ebensoviel Menschen, wie das Deutsche Reich, ist aber um ein Gebiet, das etwa Bayern + Ost- und West-Preussen entspricht, grösser. Die Besiedelung des Landes ist eine sehr dichte: besonders wenn man sich vor Augen hält, dass die Hauptinsel (Honshū) I $\sigma_{5}$ Einwohner auf I $\mathrm{Km}^{2}$ aufiveist, Kyūshū sogar i78. Euroja kennt allerdings eine noch dichtere

1) Rés. stat. I9I I. Seite 34 .

2) ebenda. Seite 35 .

3) The 3 rd annual report on reforms and progress in Korea. 1910. Seite 15/16. Korean. Bevölkerung von I910 + Nichtkoreaner nach dem Stand von 19oS.

4) Rés. stat. Seite I. (Die Zahlen für Sachalin und Korea sind nicht genau.) 
Besiedelung: Holland hat 178 , Belgien $25 \mathrm{I}$, das Rhein'and 238 , das Königreicl Saclisen 301, Südholland 454 Einwohner pro $\mathrm{Kn}^{2}$ und Grossbritanien ist mit $132 \mathrm{Seclen}$ pro $\mathrm{Km}^{2} \mathrm{immer}$ noch stärker besiedelt, als das japanische Hauptland mit seinen I30." Aber die zum Vergleiche herbeigezogenen Länder sind reicher, haben ein regeres Wirtschaftsleben und sind nicht so stark auf den Ertrag der Landwirtschaft angrewiesen wie Japan. Dafür sind wiederum die Japaner viel bedürfnisloser, brauchen auch für ihre Unterkünfte vicl weniger Raum, so dass dadurch die Verschiedenheit des Verlualtnisses zwischen Volkswohlstand und Bevölkerungszahl halbwegs ausgeglichen sein dürfte. $Z u$ bemerken ist, dass die wirtschaftliche Leistungsfähigkeit in Japan früher anfängt, dafür aber viel früher aufhört als etwa in deutschen Ländern, denn man wird bei der Neigung der Japaner, sich auf ihr Altenteil zurückzuziehen, dic obere Grenzen der produktiven Jahre bei 55 anzusetzen haben. Dies ist um so wichtiger, als die Statistik fur Japan im Jahre Igog nur Io Grossstädte mit über I0000ว Einwohnern, davon nur zwei mit mehr als josoos aufweist. Immerhin ist es aber doch die Verteilung der Städte, die die Dichte der Besiedlung der einzelnen Regicrungsbezirkz erkiärt. So hat z.B. das mittlere Honshū eine Dichte von 200 Einwohnern auf I $\mathrm{Km}^{2}$, aber hier ist zu berücksichtigen, dass der Regierungsbezirk Tōkyō eine Dichte von 1567 , Kanagawa-Ken² (mit Yoliohama) 49r, die benachbarten zwei Bezirke, Saitana und Chiba, 314 und 270 aufweisen. Ebenso wird der Durchschnitt für das westliche Honshū (204) durch die kleinen, aber stark bevölkerten Bezirke, Osaka nit I 201 und Kyōto mit 253 Einwohnern auf I $\mathrm{Km},{ }^{2}$ stark gehoben, sowie durch das Vorhandensein grö̈sserer Städte wie Kōbe und Nara. ${ }^{3)}$ Wo nicht Häfen, Verwaltungszentren oder Hancel und Industrie städtische Siedelungen hervorgerufen haben, ist in der Hauptsache die Bevölkerung in kleinen Gruppen über das tiefer gelegene Ackerland zerstreut und lebt vom Ertrage ihrer kleinen Bauernwirtschaften, die bisher fast nur mit Menschenkraft bestellt wurden. Trotz der starken Besiedlung des Landes, insbesondere im Süden

1) Die europäischen 7ahien nach Perthes, Taschen-.Atlas, Gotina, 19 Io.

2) $K$ en $=$ Regierungsbezirk.

3) Diese Zahlen nach de:n ,Etat de la population de leenpire du Japon au 31. XII. I9o8. Tōkyō I9II. Cabinet Impérial de la statisti pue génerale." Seite 2/3. Diese Zahten beziehen sich auf clie Wohnberölkerang und sind etwas höher als die auf Seite 2 mitgeteilten. 
und Westen, ist also das wirtschaftliche Leben noch durchaus nicht an der Grenze seiner Intensifizierung angelangt.

Charakteristisch dafür ist die Tatsache, dass von der gesamten Bodenfläche Japans, 36 Millionen chō, ${ }^{1)}$ nur 13.55\% landwirtschaftlich nutzbar gemacht sind. Nun ist allerdings Japan überaus gebirgig und zum Teil einer Bebauung nicht fähig, aber wenn man, wie Fachleute dies tun, ${ }^{2)}$ annimmt, dass die weniger als $15^{\circ}$ geneigten Flächen einer Bebauung fähig sind, so ständen 26.5\% der Gesamtfläche zur Verfügung. Hiervon sind erst $52 \%$ tatsächlich der Landwirtschaft nutzbar gemacht, so dass noch 4.55 Millionen chō, (4.523 Millionen ha) erschlossen werden können, von denen etwa die Hälfte im Hokkaidō liegen. Das wäre eine Fläche, die beträchtlich grösser ist als die der Schweiz oder Dänemark und mehr als zweimal so gross als die der Markgrafschaft Mähren. Natürlich ist noch die Rentabilität dieser Bebauung zu erwägen, jedenfalls aber scheint auch für Fachleute die Urproduktion Japans noch nicht an der Grenze ihrer Leistungsfähigkeit $z u$ sein. . $^{\text {) }}$

Was die Versorgung der Bevölkerung mit Nahrungsmitteln anbelangt, so hängt sie heute ganz von der Ergiebigkeit des Reisbaues ab. Eine neue amtliche Veröfentlichung ${ }^{4)}$ hat nun festgestellt, dass der Ertrag des Reisbaues von der Flächeneinheit sich ständig gehoben hat, sodass jetzt für I tan Reisland ein Ertrag von I koku 60 shō angesetzt werden kann.") Da die Denkschrift einen Jahresbedarf von I koku Reis auf den Kopf der Bevölkerung ermittelt, so kommt sie zu dem Ergebnis, dass bei Berücksichtigung der Bevölkerungsvermehrung und der zu erwartenden weiteren Vermehrung der Reisbau-Erträge, das

1) I chō $=99 \cdot 1735537$ ar.

2) Zeitschrift der Bodenre gulierungsgesellschaft in 'Tōkyō No. 4; Juli rgro.

3) In diesem Sinne äusserte sich auch der FIandelsminister Baron Oura in seinen bekannten Reden über die Ergebnisse seiner Studienreise im Auslande, in denen er versicherte, man könnte durch bessere Lanleskultur, besonders der gelsirgigen Gegenden Japans dort noch Raum für 28 Millionen und der gebirgigen Gegenden Koreas dort noch Raum für etwa halbsoviel Menschen schaffen, so dass von Uebervölkerung für die nächste Zukunft keine Rele sei. (Vergl. Hamburger Nachrichten v. I6. XI. I910). Und der Direktor der Landwirtschaftlichen Abteilung im Ministerium für Lan.lw. und Handel, Sako, äusserte sogar in einem Artikel über Auswanderung, dass Japan in den Stand gesetzt werden könne durch IHebung der Landeskultur zweimal soviel Menschen zu ernäbren als gełenwärtig. (vergl. Köln. Ztg v. IS. XI. I903).

4) „Reis“. IJer.usgegeben vom Kolonialant. Tō'kyō. April +4. (1911.)

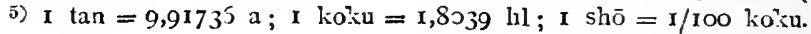


Hauptland noch im Jahr $194 \mathbf{1}$ instande scin wird, scinen B-wohnem die erforderliche Reismenere bis auf cin Defizit von ca. 5 Millionen koku zu liefern, wofur dic Kolonien leicht Ersat» bicten können. So diurfte Japan für abschbare \%eit in der bencidenswerten Lagre scin, seine Angehörigen nicht nur im eigenen Lande, sondern auch mit dessen eigenen Erzeugnissen 7.1 crnähren.

Welchen Verïnderungen unterliegen nun diese Verhältnisse, dh. in welchem Massstabe wächst die Bevölkerung Japans? Soweit das unzureichende statistische Material Japans eine Beantwortung dieser Frage zulïsst, folgt sic aus den nachstehenden Angaben, die ich der weitverbreiteten Unklarheit wegen, dic über diese Tatsachen herrscht, etwas ausführlicher als unbedingt nötig wärc, gemacht habe.

Die Zahl der Eheschliessungen in Japan betrug:

\section{Taiselle ViI.}

\begin{tabular}{|c|c|c|c|}
\hline In Jalure & $\frac{\operatorname{Im}}{\text { Jahresdurchschnitt : }}$ & $\begin{array}{l}\text { Es kamen } \\
\text { nuf } 1003\end{array}$ & $\begin{array}{l}\text { Eheschliessungen } \\
\text { Ein:v. im Jahr }\end{array}$ \\
\hline $1886-90$ & $32 \mathrm{SS}_{5} \mathrm{~S}$ & & 8.32 \\
\hline $\int 189 I-95$ & 352096 & - & $8.5 \mathrm{I}$ \\
\hline 1 Sg6-I900 & 396460 & & 9.10 \\
\hline $1901-1905$ & 378936 & & 8.19 \\
\hline 1906 & 253274 & & $7 \cdot 34$ \\
\hline Isgo7 & 433527 & & 8.88 \\
\hline I9०8 & 461940 & & $9 \cdot 32$ \\
\hline I $899-1908$ & $37^{S} 744$ & & 9.84 \\
\hline
\end{tabular}

Die Zahl der Ehescheidungen betrug :

1) I. Takano. The recent movement of population in Japan. Journal of the Royal Statistical Society. Vol. LXXIII, Part VII. July, I9ro. S. 7.\%.

2) Rẻsumẻ statistique etc. 19r1. S. IS/19. 
TABELLE VIII.

\begin{tabular}{|c|c|c|c|}
\hline Im Jahre & $\begin{array}{l}\text { Im } \\
\text { Jahresdurchschnitt : }\end{array}$ & $\begin{array}{l}\text { auf } 100 \\
\text { Einw. }\end{array}$ & $\begin{array}{c}\text { auf rooo Eheschliessungen } \\
\text { des Jahres. }\end{array}$ \\
\hline $\int 1886-98$ & I 12440 & 2.73 & 308,2 \\
\hline I S99-I905 & 64032 & 1.39 & 76,6 \\
\hline iI906 & 65510 & 1.36 & 258,5 \\
\hline 1007 & 61193 & 1.25 & 136,5 \\
\hline 1908 & 60,76 & 1.22 & I $30, \mathrm{I}$ \\
\hline I $899-\mathrm{rgos}$ & 63530 & 1.28 & I 68,0 \\
\hline
\end{tabular}

Mit den Zahlen des Auslandes verglichen, erweisen sich sowohl die Eheschliessungen als auch die Ehescheidungen in Japan als sehr zahlreich.

Nach Webb, (The New Dictionary of Statistics, London I9I I. S. 283) entfielen auf Icoo Einwohner in den Jahren I89I1900 durchschnittlich Eheschliessungen in:

\section{TABELLE IX.}

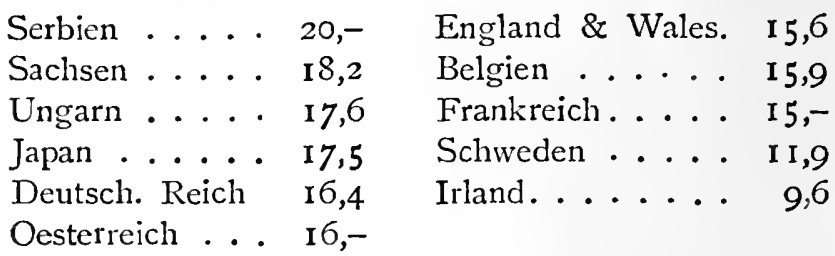

Bei dieser etwas abweichenden Berechnung, (anscheinend ist hier jede Eheschliessung als 2 angesetzt) ist die Ziffer für Japan ein wenig zu niedrig. Da mir neuere Vergleichszahlen fehlen, kann ich die jüngeren, oben mitgeteilten Ziffern für Japan nicht mehr mit denen des Auslandes vergleichen. Jedenfalls ist die Ehefrequenz des Inselreiches eine sehr starke. Noch stärker aber ist die Frequenz der Ehescheidungen. Auch nach I898, (der Aenderung der Ehegesetzgebung) wird jährlich etwa $1 / 7$ der geschlossenen Ehen wieder gelöst, während selbst in den V.St.A.

1) Takasso w.o. S. $75 x$.

2) Rés. stat. 1911 S. 1S/19. 
1906 jährlich nur 82, in der Schweiz 42, in Irankreich 3I, in Deutschland zo Ehescheidungen auf 1000 Eheschliessungen entficlen." Doch scheint auch in Japan dic Zahl der Scheidungen abzunchmen.

Die Zahl der Geburten in Japan betrug:

TABislete X.

\begin{tabular}{|c|c|c|c|c|c|}
\hline & $\begin{array}{l}\text { im Jahres- } \\
\text { durchschnitt }\end{array}$ & $\begin{array}{c}\text { auf roo } \\
\text { Einwolner }\end{array}$ & $\begin{array}{l}\text { Totgeburten } \\
\text { auf roxo } \\
\text { Einwohner }\end{array}$ & $\begin{array}{l}\text { Lebendlye- } \\
\text { burten auf } \\
\text { roo } \\
\text { Geburten }\end{array}$ & $\begin{array}{l}\text { Lebend- } \\
\text { Geburten } \\
\text { auf rooo } \\
\text { Einwohner }\end{array}$ \\
\hline I SS6-90 & I 202096 & 30,4 & I.S & 93,8 & 28.5 \\
\hline Ir $S_{91-95}$ & 1292768 & $3 I, 4$ & 2.6 & $9^{1,7}$ & 28.8 \\
\hline I S96-I900 & $14905 S 8$ & 34,2 & $3 \cdot 0$ & $9 \mathrm{I}, 2$ & 31.2 \\
\hline 1900-05 & 1633522 & 35,3 & $3 \cdot 3$ & 90,7 & 32.1 \\
\hline igo5 & I 548934 & - & - & 一 & 29.1 \\
\hline 1907 & ${ }_{17} \mathrm{SO}_{7} \mathrm{~S}_{7}$ & - & - & - & 33.2 \\
\hline 1908 & $\mathrm{IS}_{35303}$ & 一 & - & - & 33.7 \\
\hline I $899-1908$ & II) $416_{34}$ & - & - & - & - $^{3)}$ \\
\hline
\end{tabular}

I 895-1905 entfielen Lebsndgeburten auf 1000 Einwohner im Jahresdurchschnitt in : :) $^{\text {tim }}$

\section{TABELle XI.}

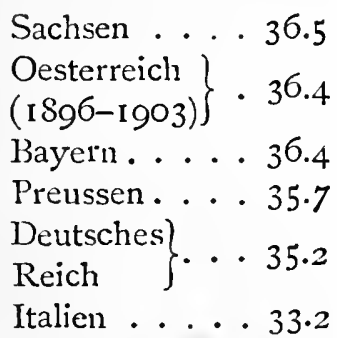

Holland ... 32.5

Japan. . . . 3 31.7

Schottland. . 29.6

$\left.\begin{array}{l}\text { England \& } \\ \text { Wales. }\end{array}\right\}$. 28.6

Frankreich. . 21.8

1) Takano, a. a. O.

2) Rés. stat. w. o. S. $18 / 19$.

3) Die Ziffer an dieser Stelle der Statistik weist augenscheinlich einen Fehler auf und ist deshalb nicht wiedergegeben.

4) Mit Ausnahme der Ziffern f. Japan nach $W$ Vebb a.a.O. 
Hieraus geht hervor, dass in Japan die Zahl der Geburten im Verhältnis zur Kopfzahl der Bevölkerung eine mittlere ist: sie hat allerdings die Tendenz, absolut und relativ zu steigen, doch ist mangels einer zuverlässigen statistischen Unterlage für eine solche Berechnung hier verschärftes Misstrauen gegenüber den Ergebnissen der Statistik geboten. Es ist sehr wahrscheinlich, dass die Verbesserung des statistischen Dienstes die Zunahme grösser erscheinen lässt, als sie tatsächlich ist. Auffallend ist die grosse Zahl der Totgeburten, die hauptsächlich auf uneheliche Geburten entfallt. (Das Verhältnis der ehelichen zu den unehelichen Totgeburten ist fast wie $\mathbf{1}: 3 .{ }^{1 \text { ) }}$

Kombiniert man die Zahl der Todesfälle und Geburten, so ergibt sich die folgende Zuwachsquote:

\section{TABELle XII.}

\begin{tabular}{|c|c|c|c|}
\hline & $\begin{array}{c}\text { Todesfälle } \\
\text { (ohne } \\
\text { Totgeburten) }\end{array}$ & $\begin{array}{c}\text { In Jahr absolut } \\
\text { auf rooo Ein-. } \\
\text { wohner }\end{array}$ & $\begin{array}{c}\text { Zuwachs auf } 1000 \text { Einw. } \\
\text { (Lebendgeburten weniger } \\
\text { Todesfälle) }\end{array}$ \\
\hline ( I 886-9o & SI 5406 & 20,6 & 7,9 \\
\hline $1891-5$ & 874192 & $2 \mathrm{I}, \mathrm{I}$ & 7,7 \\
\hline I 896-I 900 & 90666 I & 20,8 & 10,4 \\
\hline IIgoI-I905 & 973797 & $2 \mathrm{I}, \mathrm{I}$ & I I,- \\
\hline 1906 & 961550 & I 9,8 & 9,3 \\
\hline 1907 & 1024286 & $2 I, O$ & 12,2 \\
\hline I9o8 & 1038110 & 20,9 & 12,8 \\
\hline I 899-I gos & 974205 & 20,8 & - \\
\hline
\end{tabular}

Den Vergleich mit dem Auslande bietet folgende Tabelle. ${ }^{4)}$

1) Takano a.a.O. S. 764 .

2) ebenda. S. 766 .

3) Rés. stat. 1911. S. 18/19.

4) Webb w.o.S. 66. Die Zahlen für Japan sind gegen dic aus der Tabslle XI ausirestauscht. 
Tamelia XIII.

In Jahresclurchschnitt r $901-1905$.

\begin{tabular}{|c|c|c|}
\hline & $\begin{array}{l}\text { Zuwachisrate, } \\
\text { (in "/100) }\end{array}$ & $\begin{array}{c}\text { Sterberate } \\
(\text { in } 1 /(m))\end{array}$ \\
\hline Neu Seeland & 16.7 & 9.9 \\
\hline Holland & 15.5 & I $6 . \mathrm{I}$ \\
\hline Deutsches Reich & 14.9 & 19.9 \\
\hline Australischer I3und & 14.5 & 11.6 \\
\hline Dänemark & 142 & 14.8 \\
\hline England \& Wales & I2. I & $16 .-$ \\
\hline Oesterreich & II. 4 & $24 \cdot 2$ \\
\hline Grossbritannien & II. 4 & 16.3 \\
\hline Japan & 11.- & 21,1 \\
\hline Ungarn & II.- & 26,2 \\
\hline Belgien & 10.7 & I $7,-$ \\
\hline Spanien & 9.2 & $26, \mathrm{I}$ \\
\hline Brit. Indien & 5.6 & $33,-$ \\
\hline Chile & $5 \cdot 3$ & 299 \\
\hline Frankreich & г. 8 & 19,5 \\
\hline
\end{tabular}

Da der Durchschnitt 1901-05 des Krieges wegen für Japan wenig günstig ist, so schneidet es bei eirem internationalen Vergleich sehr gut $a b$, insbesondere mit seiner verhältnismässig günstigen Todesrate, die es neben das Deutsche Reich und Frankreich stellt. Da die geringe Kindersterblichkeit in Japan ein wichtiger Faktor ist, und sanitäre Verbesserungen sicherlich noch stark nachhelfen können, so darf man erwarten, dass die Sterberate auch in Zukunft eine günstige sein wird. Es ist dabei allerdings nicht $\mathrm{zu}$ vergessen, dass Japans Industrialisierung seiner Bevölkerung neue gesundheitliche Gefahren bringen muss, die heute noch kaum ins Gewicht fallen. Die Zuwachsrate der Bevölkerung ist, wie die Geburtsrate, eine mittlere und steigt, soweit sich dies beurteilen lässt, nur langsam. Auch hier gilt, was bereits bei der Geburtenstatistik gesagt werden musste. Da die Heiratsfrequenz ziemlich empfindlich bei wirtschaftlichen 
Störungen reagiert, so ist anzunehmen, dass mit der zunehmenden Konzentrierung der Bevölkerung in geschlossenen Ortschaften und der zunehmenden Schwierigkeit, sich einen Unterhalt zu verschaffen, während die Lebensansprüche immer steigen, die Zunahme nicht in allzuraschem Zeitmass fortschreiten wird, insbesondere in einem Lande, wo selbst die religiösen Anschauungen, die eine Fortpflanzung der Familie verlangen, es nicht vermocht haben, die Zuwachsrate über ein mittleres Mass zu steigern.

Geographisch verteilt sich der Zuwachs der (Register-) Bevölkerung in Japan wie folgt :1)

Mittlerer Zuwachs im Jahresdurchschnitt auf Iooo Einwohner :

TABelle XIV.

\begin{tabular}{|c|c|c|c|}
\hline & I $893-9 S$ & I 899-1903 & I) \\
\hline (Mittel & $10,1.2$ & I 3,04 & I I ,O5 \\
\hline Honshū $\{$ Nördl. & 10,12 & 12,70 & I I ,20 \\
\hline Westl. & 9,45 & I I. 35 & 10,48 \\
\hline Zusammen & 9,92 & 12,47 & 10,79 \\
\hline Shikoku & 7,22 & IO,O I & 7,50 \\
\hline Kyüshū & 13,19 & I 2,87 & I 3,09 \\
\hline Hokkaidō & 99,86 & 65,94 & $6 \mathrm{r}, 57$ \\
\hline Zusammen & I I ,22 & $\mathrm{I} 3,2 \mathrm{I}$ & I I ,93 \\
\hline
\end{tabular}

Fine weitere Aufklärung über die geographische Verteilung des Zuwachses der Wohnbevölkerung') im Jahresdurchschnitt von 1903-1908 bringt die Feststellung, dass der Zusvachs, der 12.85 auf rooo Einwohner betrug, sich hauptsächlich in den grossen Städten: Tōkyō (38.10), Osaka (32.92), Kanagawa (Yokohama) (23.OI) und ihren Bezirken fühlbar macht. Im Hokkaidō beträgt er sogar 60.21, doch erklärt sich das sowohl aus der dünnen Besiedlung als aus der planmässigen Kolonisation dieser Insel. Während nun Industric- und Handelszentren mit ihrer starken Zuwanderung weit über dem Durchsclinitt stehen,

1) Rés. stat. 19I I.

2) Kartenbeilage zu État de popalation u.s.w. rgrr. 
ist die grösste \%, lhl der Recricrungsberirke mit iher Zuwacharate gregen den Durchschnitt zurück, ja vier davon weisen sogar cine erhebliche Abnahme ihrer Bevölkeruner, (Shiga-Ken 6.37\%o ) auf. Es hat also den Anschein, als o's die Vertcilung der Bevölkerung von selbst durch die Anzichungskraft der Erwerbsgelegenheiten ins Gleichgewicht gebracht würde. Wenn die Entwickelung des Städtewesens weiter so fortschreitet wie bisher, so ist auch hier dem Menschenzuwachs in nächster Zeit ein Abfluss gesichert.

Aus all dem geht hervor, dass Japan zwar ein sehr stark besicdeltes Land ist, dass man aber nicht sagen kann, dass für lieinerlei Zuwachs mehr Raum vorhanden sei. Einige Landesteile verlieren sogar Bevölkerung, und auch die Abwanderung nach den Kolonien, die zum Teil aus den dünner besiedelten Provinzen des Nordens von statten geht, gibt Nachrückenden wieder einige Aussiclit. Schliesslich ist zu hoffen, dass die Intensifizierung des wirtschaftlichen I.ebens nach dem Vorbilde der wenigen grossen Städte, eine grössere Dichte der Besiedlung crmöglicht, so dass der jülurliche, übrigens garnicht ausserordentliche Zuwachs an Menschen vorderhand niemand zu beängstigen braucht. $\mathrm{Ob}$ der Zuwachs selbst zunimmt, lässt sich nicht genau sasen: sicher ist dagegen, dass das Heiratsalter ste:gt.

Jedenfalls ist die Auswanderung nach der Fremde für Japan nicht das einzige Rettungsmittel, womit natürlich nicht gesagt sein soll, dass nicht auch heute schon die Auswanderung mancherlei Vorteil böte, insbesondere, solange Japan ein kapitalarmes Land ist. Das führt dazu, zu untersuchen, ob die Ursachen der Auswanderung nicht ausserhalb des Landes liegen. Tatsächlich kam die erste Anregung zur Auswanderung, wie weitcr unten ausgeführt wird, vom Auslande: Der Arbeitermangel in Hawaii, WestAmerika und Canada, der Bedarf der landivirtschaftlichen und gewerblichen Grossbetriebe war nicht nur Anreiz, sondern wirkte auch darauf hin, dass der Japaner zunächst willkommen geheissen und Einrichtungen für Herbeischaffung von weiteren billigeren Arbeitskräften aus seiner Heimat getroffen wurden. Die Arbeitslöhne in Japan waren stets niedrig, und selbst heute, wo der Lohn seit Jahren schon in fortwährendem Steigen begriffen ist, ist menschliche Arbeitskraft in Japan so billig, dass nach europäischer Auffassung die Verwendung, die sie findet, oft einer Verschwendung gleichkommt. Auch heute noch beträgt der Tagelohn eines männlichen, landwirtschaftlichen Arbeiters 39 Sen, der eines weiblichen 23, und ein weiblicher Dienstbote ist 
für einen Monatslohn von 2.83 Yen zu haben. ${ }^{1)}$ Da diese Sätze viel höher als die vor zehn oder zwanzig Jahren üblichen sind, so ist leicht einzusehen, wie gross die Verlockung war, die der Unterschied zwischen den japanischen und den selbst für Ostamerikaner hohen westamerikanischen Löhnen auf die Japaner in der Heimat ausüben musste, wenn ihre Dorfgenossen, die zuerst mit staatlicher oder irgend einer andern Hilfe als Kontraktarbeiter ausgezogen waren, darüber nach Hause berichteten. Man hat sich also über die eine zeitlang stark anwachsende Auswanderungsbewegung nicht zu wundern, eher darüber, dass sie nicht ein noch grösseres Ausmass erreichte und dass die ausgewanderten Japaner, nach wenigen Jahren des Gelderwerbs in der Fremde wieder ruhig heimkehrten, nachdem sie so unvergleichlich bessere wirtschaftliche Verhältnisse und eine höhere Lebenshaltung kennen gelernt hatten. Da bekanntlich eine ständige Auswanderung selbsttätig Einrichtungen schafft, die selbst wieder für Stabilisierung der Bewegung beitragen, wie Agenturen, Schiffahrtsgesellschaften, Verkehrseinrichtungen aller Art, so ist es erklärlich, dass es des energischen Eingreifens der Regierung bedurfte, um der Bewegung Einhalt zu gebieten. Da dies aber schliesslich doch gelang, so ist darin eine Bestätigung der obigen Ausführungen zu sehen, welche für den Hauptgrund der Auswanderung den grossen wirtschaftlichen Unterschied zwischen Japan und seinen nächsten östlichen Nachbarländern halten, ohne auf den Bevölkerungsdruck und den Menschenüberfluss im Mutterland allzuviel Gewicht zu legen.

\section{DIE ANFAENGE DER AUSWANDERUNG UND EIN} UEBERBLICK UEBER IHRE ENTWICKLUNG.

Eine eigentliche Auswandererbewegung setzte erst in den So er Jahren des vorigen Jahrhunderts ein. Es hatte zwar schon lange eine Reihe mehr oder minder umfangreicher Handelskolonien in Korea und China gegeben, zu welch letzterem ja vor dem chinesisch-japanischen Kriege auch Formosa gehörte, aber auch diese kleine Auswanderung war eigentlich nur ein geduldeter Missbrauch, ja eine Gesetzesverletzung, denn seit den Tagen des Shōguns Iyemitsu galt ein von ihn i. J. I636 er-

1) Durchschnittslöhne für 1908 nach dem Résumé Statistique f. I9II. S. 57 ;

- I Yen $=100$ Sen $=$ ca. 2.10 Mark. 
lassenes Verbot, dass den Auswandernden Todesstrafe androhte. Mit der Wiederherstelluner der Kaisergewalt i. J. I 868, die die neue Zeit einleitete, entfiel das Interesse für den Abschluss Japans von der Aussenwelt, mit der in\%wischen Vertrïge abgeschlossen worden waren. Aber die romantische IFlucht einiger junger Japaner, dic das Ausland und seine Machtmittel kennen lernen wollten, - unter ihnen befand sich auch der nachmalige Fürst Ito, - beweist, dass es bis zur Aufhebung des Verbotes keinem leicht wurde, dic Grenzen zu überschreiten.

Die Auswanderung nach dem Westen folgte dem durch die greographische Lage Japans und seinen Verkehr vorgezcichneten Wes. Sie wurde mit der Zcit für den japanischen Handel von Bedeutung, füllt aber numerisch wenig ins Gewicht, hat auch nic die Aufmerksamkeit auf sich gelenkt, bis die Kriege in der Mandschurei und die Schaffung ciner Interessensphäre auf dem asiatischen Kontinent dem Handel einen politischen Rückhalt boten. Viel wichtiger war der Zug nach dem Osten. Er folgte nicht dem Handel, sondern wurde künstlich hervorgerufen. In Hawaii fehlte es an Arbeitskräften, und der damals regierende König gab sich viele Mühe, welche heranzuziehen. I 886 gelang ihm der Abschluss eines Vertrages mit der japanischen Regierung, die sich zur Lieferung von Kontraktarbeitern verpflichtete. Nach einigen Jahren war eine starke Auswanderung im Gange, an die Stelle der japanischen Regierung traten Auswandereragenturen, und bald gingen jäbrlich Tausende nach Hawaii, das nach und nach japanischen Charakter annahm. Von Hawaii setzte sich die Wanderung nach dem amerikanischen Festlande fort, und Agenten, sowie die hohen Löhne im Westen taten das übrige, um auch an der andern Seite des Stillen Ozeans japanische Ansiedlungen zu schaffen, bis der Einspruch der Vereinigten Staaten eine stetc Abnahme der japanischen Einwanderung zur Folge hatte. Auch die Auswanderung nach Hawaii, Canada und Mexiko, die eng mit der nach den Vereinigten Staaten zusammenhängt, musste aus politischen Gründen, von der japanischen Regierung eingedämmt werden, so dass die schon recht ansehnlich gewordene Auswanderung bald wieder auf wenige Tausend im Jahr zurückging. Nicht nur clie Auswanderung nach Hawaii und Nordamerika, den wichtigsten Zielen, die sich dem japanischen Auswanderer boten, wurde eingestellt, sondern auch die nach Südamerika, die erst seit kurzem aufgenommen worden war und auf die man in Japan grosse Hcffnungen gesetzt latte. Dasselbe gilt auch von Australien und den Südseeinseln, die allerdings nur eine kleine 
Zahl von Japancrn aufgenommen hatten. Eine ständig fortschreitende Entwicklung zeigt nur die Wanderungsbewegung nach den japanischen Kolonien, in denen eine jährlich wachsende Zahl von Kindern des Mutterlandes ansässig wird.

Nähere Angaben über die Auswanderung nach den einzelnen Gebieten folgen weiter unten. Hier nur noch einige Erläuterungen zur beigegebenen Uebersicht der Auswandererzahlen von I880-1909. Natürlich ist auch hier wieder daran zu erinnern, dass es sich nur um eine Registrierung der Passerteilungen handelt, dass also die Zahl der Auswanderer nicht unbeträchtlich grösser sein dürfte, insbesondere in den früheren Jahren, wo die Kontrolle kaum so genau gewesen sein dürfte wie heutzutage: aus demselben Gruncle sind auch einige auffallende Schwankungen in einzehnen Rubriken verständlich. Man sieht leicht, wie langsam die Auswanderung selbst nach dem Jahre r885 zunimmt. Die prozentuelle Zunahme war allerdings in einzelnen Jahren stark, doch waren es verhältnismässig unbedeutende Transporte, die das Land verliessen. Erst I $894 / 5$, mit dem chinesisch-japanischen Krieg, wird das anders : man merkt den Ansporn, den der siegreiche Feldzug im Auslande allen Berufen gibt. 1899 wird der Höhepunkt der Auswanderung erreicht. Dann kommen die Beschränkungen der Regierung in den Zahlen zum Ausdruck, vielleicht auch andere Momente, jedenfalls geht die Zahl der Ausivanderer stark zurück, obwohl gerade in jenen Jahren mehrere japanische Schiffahrtslinien durch den Stillen Ozean ihren Anfang nahmen. Vielleicht war auch die Besitzergreifung Hawaiis durch die Vereinigten Staaten von verzögerndem Einfluss. I902 und I903 zeigen ein plötzliches Anschwellen der Auswanderung, das man auch auf Hawaii beobachtete, dann gehen die Zahlen wieder herunter, um nach dem Kriege mit Russland eine noch nie erreichte Höhe von fast $59000 \mathrm{zu}$ erklimmen. Dann folgt ein rasches Fallen, denn die Regierung Japans muss energisch eingreifen, und 1909 weist die Statistik nicht mehr Passerteilungen aus als 1894 , wobei jedoch $\mathrm{zu}$ bemerken ist, dass jetzt niemand mehr ohne Pass ein Auswanderschiff besteigen kann, und dass auch das Ausland nur für Besitzer eines Passes offen steht. Seit 1909 ist die Auswanderung noch weiter zurückgegangen, hat also jetzt einen Tiefstand erreicht, wie vor dem chinesischjapanischen Krieg.

Die Einteilung nach Berufen lässt leider keine Schlüsse zu, da die Abgrenzung der einzelnen Gruppen wenig glücklich ist und anscheinend häufig, wenigstens in früheren Jahren, die 


\begin{tabular}{|c|c|c|c|c|c|c|c|c|c|c|}
\hline IS $(9)$ & 1930 & [1) & I9O2 & 1903 & 1001 & 1905 & $190 ;$ & 1907 & 1903 & I $(y)$ \\
\hline 1277 & $=105$ & 971 & +50 & $5(60)$ & 551 & 757 & 515 & $1+1$ & $3+3$ & 368 \\
\hline 99 & $s_{f}$ & 116 & 101 & Sy) & +5 & SS & 57 & 77 & 68 & 66 \\
\hline So? & 780 & $9^{61}$ & 1798 & 1799 & 1565 & 1095 & .3269 & $33 i 6$ & $6+5$ & 335 \\
\hline 10 & I 1 & 17 & 60 & 45 & 31 & $3:$ & 71 & 79 & 35 & 24 \\
\hline 6211 & $7.30 \mathrm{~S}$ & $+\mathrm{SSS}_{3}$ & $523 \mathrm{~s}$ & $6 \geq 4.3$ & 5505 & $2 H_{7}$ & 5271 & 3726 & 2151 & $16 \div 1$ \\
\hline 676 & $37 \mathrm{~S}$ & 2.36 & 264 & 200 & 229 & 120 & $3^{S 5}$ & $3 S_{3}$ & 210 & 242 \\
\hline 1021 & $2 \mathrm{O}_{3} \mathrm{~S}$ & $3^{55}$ & $125 t$ & $9+i$ & to & +502 & 30055 & 1350 ; & 7733 & $6+453$ \\
\hline ISS & $3 S$ & 12 & 20 & 2 & - & 561 & $19+5$ & $2 S S_{i}$ & 1217 & $35 s$ \\
\hline .419 & 1910 & 612 & I0.S & I $12 S$ & $S_{i} S$ & 313 & 263 & 9.3 & $16 \mathrm{~S}$ & 101 \\
\hline 23 & +1 & 10 & 6 & 7 & 7 & 16 & +9 & 4 & $2 I$ & 16 \\
\hline 30126 & 19372 & 6257 & 12053 & 13255 & 12107 & $3=35$ & $73 \mathrm{IS}$ & 9157 & 3109 & 976 \\
\hline 5622 & $12 S_{2}$ & 510 & 757 & 903 & 715 & $50+$ & $7 \geq S$ & $1+25$ & 1.351 & $123 \mathrm{t}$ \\
\hline+5 & SS & 76 & I IS & 71 & 35 & 10 & $2\}$ & 15 & 112 & $2 \mathrm{~S}$ \\
\hline I & 2 & 4 & 2 & - & - & 2 & - & 3 & II & 3 \\
\hline 2564 & 3924 & 6626 & 7001 & 7951 & 4328 & 4131 & $67+3$ & 6350 & $2 \mathrm{~S}_{92}$ & 2907 \\
\hline $16+6$ & $197 \mathrm{~S}$ & 2370 & 2700 & $237 \mathrm{I}$ & 1330 & 1.337 & $2 \mathrm{I}+5$ & $21+3$ & 1215 & $9^{55}$ \\
\hline $42 \mathrm{SO}_{2}$ & 37525 & 20759 & בS999 & $3^{1195^{6}}$ & $249 S_{1}$ & 16533 & $5317 \mathrm{I}$ & 36627 & $I_{7} \mathrm{IS}_{3}$ & I 2 SoI \\
\hline$S_{255}$ & ${ }_{3} \mathrm{~S}_{\mathbf{I}}$ & 3275 & 3910 & 3707 & 2393 & $26_{33}$ & $53 \mathrm{So}$ & 7000 & 4161 & 2939 \\
\hline 51057 & +1339 & $2+0.3 t$ & 32900 & 35653 & 27377 & 19166 & $5 S 351$ & $+3^{627}$ & $213+t$ & 157.0 \\
\hline
\end{tabular}




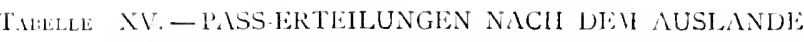

(Natch den stalistischen Jahröichern.)

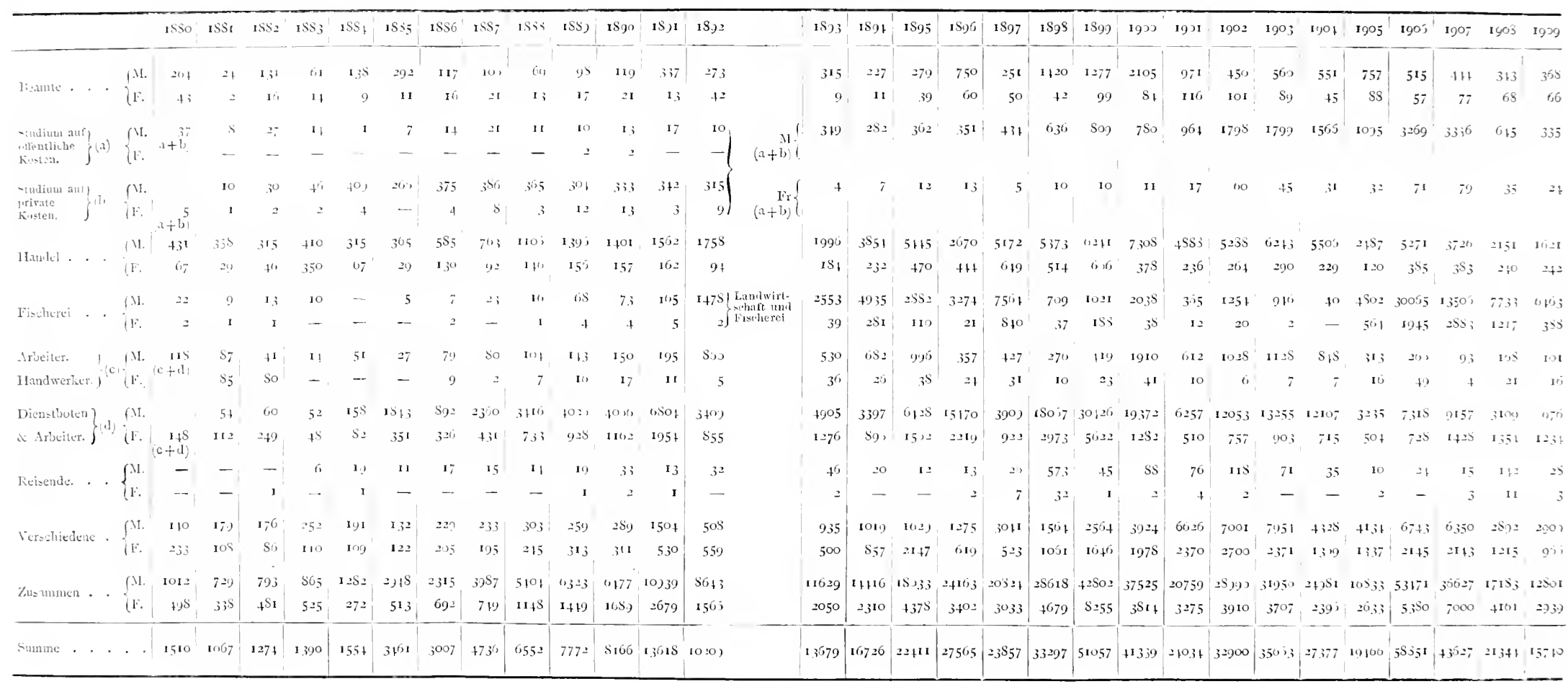


Zuteilung der Gezhhlten \%u den einzelnen Gunpen zicmlich unzuverlïssig ist. Auch ist dic Abteilung, , Verschiedenc" \%.u stark beset\%t, und die Schwanliung in den Zahlen für diese und andere Abteilungen 7.11 gross, als dass ich es unternchuren möchte aus der Berufsstatistik lolgerungen zu zichen.

Die Ziele der Auswanderurig haben in der Iauptsache wenig gewechselt, so dass das oben für dic letzten Jahre Gesagte keiner Ergänzung bedarf.

Leider versagt dic Statistik auch, wenn es sich darum handelt, die Herkunft und die übrigen Personaldaten der Auswanderer festzustellen. Die Verteilung der Auswandernden über das Land ist aber so ungleich, dass sie sofort auffält. Zumeist stammen sie nämlich aus dem Süden und Südwesten des Rciches, also der westlichen Spitze von Honshū und Kyūshū. Eine weniger starke Abwanderung weisen die übrigen Küsten der Inlandsee und cinige Regierungsbezirke in Nordhonshu auf. 1905 sollen von 74c00 Japanern, die es damals auf Hawaii gab, zwei Drittel aus dem Regierungs Bezirk Hiroshima gewesen sein $^{1)}$, und in den Jahren $1895-1903$ wurden Pässe ausgeteilt ${ }^{12}$ im Regierungs lBezirk:

\section{TABELle XVI.}

\begin{tabular}{|c|c|c|c|c|c|c|c|}
\hline & & & & & & & \\
\hline Kumamoto & & & & & & & I 2 I 4 \\
\hline Tamaguchi & & & & 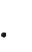 & & & 21 \\
\hline oka & . & & & & & & \\
\hline & . & & & & & & \\
\hline rama & & & & & & & 37 \\
\hline $\mathrm{ki}$ & . & . & & . & & & \\
\hline Tyc & & & & . & & & \\
\hline $\mathrm{ma}$ & & & & . & & & $2 \mathrm{I}$ \\
\hline & & & & - & & & \\
\hline & & & & . & & & \\
\hline
\end{tabular}

Es entficlen also auf Hiroshima allein ein Viertel, auf die 3 zuerst angeführten Bezirke mchr als die Hälfte aller Auswanderer. Persönliche Nachfragen bestätigten mir, dass auch

1) Y.Yoshida, Sources and causes of Japanese emigration; in ,Annals of the American Acadeiny of pol. \& sos. science. Vol. XXXIV/2 Scpt. I9c9. Philadelphia S. $377 / 87$. 
heute noch der Südwesten des Landes die m:isten Auswanderer stcllt. Eine der grössten von den 4 gegenwärtig noch tätigen Auswanderungsgesellschaften unterhält nur 4 Agenturen u. zw. in Hiroshima, Kumamoto, Wakayama und Okinawa (Lyū-Kyū Inseln). Der Bezirk, aus denı die meisten Mädchen auswa:ıdern, ist der von Nagasaki (besonders Shimabara.)

Die Gründe für diese Konzentrierung der Auswanderung sind nicht leicht nachzuweisen. Einige der wichtigsten Auswanderungszentren haben nach $F e s c a^{1)}$ arme Bōden, auch scheinen die Besitzverhältnisse der Bauern ungünstig zu sein.") Dagegen dürfte die Bevölkerungsdichte oder die starke Bevölkerungszunahme allein kaum eine triftige Erklärung abgeben, wie aus den mitgeteilten Ziffern dar Bevölkerungsstatistik harvorgeht. Auch die japanischen Autoren Yoshiza und Ogawaliira ${ }^{3)}$ glauben nicht an einen Zusammenhang zwisch en Bevölkerungsdichte und Auswanderung. Man darf all srdings nicht vergesse:a,und ich glaube, dass insbesondere Ogavoahira dics tut, - dass die Bevölkerungsdichte eines Regierungs-Bezirkes durch eine Ziffer a:sggedrückt wird, die keineswegs darüjer aufklärt, ob der Bezirk übervölkert ist oder nicht: denn die stärkste Besiedlung und geringste Abwanderung habən natürlich die Städte; man müsste also die Daten über die ländlichən Kreise habən, um sicher zu gehen. Zweifellos ist es eine Kombination von Gründen wirtschaftlicher Art, die den Boden für die Auswanderung bereitet. Es dürften aber andere Momente sein, die den Ausschlag geben, und Yosliddx hebt sie m. E. richtig hervor. Zunächst handelt es sich durchaus um Küstenbezirke, deren Bevölkerung mit dem Gedanken an Seefahrt und Handel am längsten vertraut ist, die auch $m$ sist über bessere Verkehrswege zur Küste verfügt, als dies im Innern von Honshü der Fall ist. Dann aber ist die Bevölkerung des japanischən Südens anscheinend lebhafter, unternehmungslustiger und energischer als die der übrigen Landesteile, und es ist kein Zufall, dass dieselben Landstriche die Männer gestellt haben, walche die ganze neue Geschichte Japans seit der Restauration gemacht haben und auch heute no:h machen. Schliesslich dürfte auch der Zufall eine Rolle gespielt haben, indem er die Errichtung einer Agentur oder die Förderungr der Auswanderung durch

1) M. Fesca. Beiträge zur Kenninis der juınischen Lanlwirtschaft. 2 B I:. Tōkyō I $\$$ วo.

2) I: Yosinida.

3) R. Osawahira. Niho: imin ron; Tōkyō 1935; 4. Kà. 
einen cifrieren Regieruners-13 santen verursachte. Es ist ja bekamnt, dass cine erfolereiche Auswanderung bezirksweise ansteckend wirkt, so dass dic l'ionice einer solchen Bewerrung von Jahr z.u Jahr mehr Nachahmer funden, ja dass es sogar muncherorts Sitte wirl, eine zeitlangr im Auslande $\%$ arbeiten; das ist hicr namentlich (leshalb leicht mörlich, weil fast alle japanischen Auswanderer nach einigen Jahren in dic lleimat zarücklichren und durch ihre Erfolse cinen daueruden Ansporn für ihre Mitbürger abgeben.

Am allerschwersten ist es, sich über die Beschaffenheit des Menschenmaterials Klarheit zu verschaffen, das Japan auf Auswandererschiffen verlässt. Man ist hier zu einem grossen Teil auf eine der unzuverlässigsten Quellen, die Aeusserungen der Presse angewiesen, aus der ein Chor einander widersprechender Urteile ertönt. Auf japanischer, wie auf nicht japanischer Seite gibt es sowohl überschwengliches Lob als auch die heftigsten Verurteilungen über die Leistungsfihigkeit und die sozialen und moralischen Eigenschaften der japanischen Auswanderer. Un hier klarer zu sehen, muss man unterscheiden zwischen der Beurteilung der Japaner in allgemeinen, ihrer Eignung zur Kolonisation und zur Finwanderung in andere Gebiete und zwischen der Beurteilung des tatsächlich ausgewanderten Menschenmaterials. Auch diese Finzelfragen sind nicht leicht zu beantworten. Den Charakter des japanischen Volkes zu beurteilen, ist eine Aufgabe für sich, der ich mich hier nicht unterziehen möchte: die Literatur über Japan ist umfangreich genug, um darüber Auskunft zu geben. ${ }^{1)}$ Den Befähigungsnachweis für ihre Eignung als Kolonisatoren, soweit es sich um Leistungen der Regierung handelt, haben die Japaner in Formosa und Korea erbracht. Die Geschlossenheit ihrer durchaus nationalen Kultur, das Ergebnis einer langen geographischen und geschichtlichen Abschliessung, befähigt sie in hervorragendem Masse, ihre Nationalität und Lebensweise unter andern als den heimischen Verhältnissen festzuhalten. Eine andere Frage ist es, ob sie sich zur Assimilation an fremde Kulturen eignen. Darum handelt es sich für sie bei der Einwanderung nach Nordamerika, dem einzigen Kulturgebiet, in dem sie in nennenswerter Anzahl sich anzusiedeln versucht haben. In China

1) Leser, die sich zu unterrichten wïnschen, verweise ich auf clas bekannte Buch von $B$. H. Chamberlain, Things Japanese. 5. Auf. Loadon 1905, un:1 auch die Schriften Rathgens und Munzzingers üb:x Japan. 
bestehen meist nur Handelsniederlassungen, und in der Mandschurei herrscht japanische Verwaltung, so dass den Japanern schon durch äussere Machtnittel ein Vorsprung gegeben ist. Ueberdies kommt bei den bestehenden politischen Verhältnissen eine Anpassung der Japaner an die Chinesen gar nicht in Frage. Neben der Assimilierbarkeit ist natürlich die wirtschaftliche Leistungsfähigkeit von Wichtigkeit. Obwohl die Einwanderung nach dem amerikanischen Kontinent weiter unten eingehender besprochen werden soll, muss ich doch hier vorwegnehmen, was über die Japaner als Auswanderer im allgemeinen Aufschluss geben kann.

Der grösste Teil der Japaner, die in Hawaii oder auf dem amerikanischen Festlande Beschäftigung finden, besteht aus landwirtschaftlichen Hilfskräften, aus Handwerkern und ungelernten Arbeitern. Ueber ihre wirtschaftlichen Leistungen habe ich keine Klage vernommen. Wenn es irgendwo zu Unfrieden zwischen den japanischen Arbeitern und den Arbeitgebern oder deren Beamten kam, so waren dic Ursachen fast nie in der Arbeit selbst gelegen. In Bezug auf Behandlung sind die Japaner allerdings anspruclisvoll : aber ihre Arbeit besorgen sie fleissig, haben viel Liebe und Verständnis für landwirtschaftliche Tätigkeit und für die Gewerbe, die sie bereits in der Heimat kennen gelernt haben, z.B. Tischlerei, Schneiderei, Schusterei, sie sind gute und geschickte Dienstboten und Friseure. Thre Art zu arbeiten ist allerdings oft von der der Europäer und Amerikaner verschieden. Sie nehmen die Arbeit nicht so ernst, arbeiten weniger hastig und gründlich und sind nicht so darauf bedacht, an einer bestimmten Stundenzahl festzuhalten. Sie sind eher geneigt, länger zu arbeiten, dafür aber Pausen einzulegen, während der Arbeit zu essen, zu rauchen und zu schwatzen, und das soll manche Unruhe auf den Arbcitsstellen verursacht haben. Aber schliesslich ist man mit den Leistungen fast überall $z u-$ frieden gewesen, und nach einiger Zeit gewöhnen sich auch die. Neuankömnlinge an die herschenden Sitten, besonders, da sie ausserordentlich ehrgeizig und lerneifrig sind. Wenn also die Japaner auch nicht die Chinesen als Arbeiter erreichen, so halten sie doch den Vergleich mit allen übrigen Arbeitern in den aufgezählten Beschäftigungen aus, ja sie haben sich sogar in manchen, wie z.B. den landwirtschaftlichen Arbeiten grosse Beliebtheit bei ihren Arbeitgebern verdient. Diese wird nun einigermassen dadurch getrübt, dass die japanischen Arbeiter, schwer zu belandeln sind. Sie sind, wie die im Abschnitt, über 
Amerika anzufiuluenden Quellen bezengen, selur empfindlich geeren schlechte Behindlunn, insbesondere gegen jede Verletzung der Gleichsteltung mit den weissen Arbeitern. Da die Japaner in den Ländern westlicher Kultur fast durchwegs an die Stelle der chinesischen traten, und die Nord- und Südamerikaner nicht immer imstande sind, den Unterschied festzuhalten, so hat dieser Umstand oft Grund z: Misshyclligkeiten gegeben, namentlich, da die Japaner, bei ihrer Abneigung gegen dis: Chinesen, mit diesen nicht verglichen werden wollen. Natürlich werden auch Klagren über dic Japaner laut, von denen übrigens ein Teil wieder darauf zurückzuführen ist, dass man sie in den Vereinigten Stiaten und den britischen Kolonien mit den Chinesen verglcicht. Man beklagt, dass sic im kaufmännischen Verkehr und beim Abschluss von IVerkverträgen unzuverlässig, dass sie zu sehr auf ihren Vorteil bedacht und daher als Dienstboten, Arbeiter u.s.w. wenig anhänglich sind, schliesslich auch, dass sie zu sehr zusammenkleben, jeden erreichbaren Vorteil ihren Landsleuten zuwenden, diese überall nachziehen und dadureh bei ihrem wirtschaftlichen Vordringen zugleich auch geschlossene Gruppen bilden und andere Nationen systematisch verdrängen. Alles in allem sind das keine allzuschweren Vorwürfe, verglichen mit denen, die z.B. gegenüber Arbeitern anderer Nationalität in den Vereinigten Staaten erhoben werden. Dagegen ist es sehr hoch zu veranschlagen, wenn selbst prinzipielle Gegner der Einwanderung, insbesondere der asiatischen, gegen die der Japaner wenig ernste Einwendungen z.u machen haben.

Was dic endgültige Assimilierbarkeit anbelangt, so ist ein abschliessendes Urteil hierüber, wie es scheint, noch nicht möglich. Die wenigen Erfahrungen, die seit 20 Jahren etwa auf dem amerikanischen Festland gesammelt werden könnten, reichen zu einer Beantwortung der Frage nieht aus. Nur scheint es, als ob bis in die letzte Zeit bei den Japanern im Auslande selrr wenig Neigung geherrscht hätte, sich einer fremden Umgebung rückhaltlos anzupassen. $\mathrm{Zu}$ stark hält noch die Geschichte des japanischen Inselreiches seine Kinder zusammen, zu gross sind die Unterschiede, die sich einem solchen Vorgang entgegenstellen.

Teilweise wird der geringe Einfluss der fremden Umgebung auf die Japaner in Auslande aus der Geschichte der Auswanderung erklärt. Die Auswanderer, die als Kontraktarbeiter ins Ausland gingen, blisben nur di: wenigen Jahre, die 
ihnen durch den Kontrakt vorgeschrieben waren und kehrten dann mit ihren Ersparnissen in die Heimat zurück. Sie dachten gar nicht daran, sich dem Auslande mehr anzupassen, als ihres Aufenthalts in der Fremde wegen unbedingt nötig war: im Gegenteil, das Aufgeben ihrer billigeren heimischen Lebensweise hätte sie um einen grossen Teil ihrer Ersparnisse gebracht, und wie hätten sie sich innerlich einer Ungebung anpassen sollen, an deren geistigem und Gefühlsleben sie aus Mangel an Sprachkenntnissen und Vorbildung nicht teilnehmen konnten? Immerhin scheint sich auch hier ein Wandel anzubahnen. Die Aufenthaltsdauer der Auswanderer im Auslande nimmt zu, ihre Anhänglichkeit an die heimischen Lebensgewohnheiten, ja sogar an das Vaterland nimmt ab. Die neue. Zeit, die mit ihr in Japan eingedrungene westliche Kultur und der Kapitalismus zersetzen das feste Gefüge des japanischen Lebens und der japanischen Weltanschauung wenigstens soweit, dass es manchem heimgekehrten Auswanderer, namentlich solchen, die inzwischen mit den Auslande innigere Fühlung gewonnen haben, in der Heimat zu enge wird, ganz so, wie das auch in andern Ländern der Fall ist. Ein japanischer Gewährsmann, der das Ausland und die Auswanderungsfrage sehr gut kennt, sagte mir, die Auswanderer blieben jetzt länger als früher in der Fremde und assimilierten sich auch mehr, da sie heutzutage "freier dächten." In Zahlen lässt sich diese Veränderung kaum feststellen, besonders, da die Angaben hierüber spärlich sind. Ogazvaliira berichtet im Jahre $1905^{1)}$, dass die abgeschlossenen Verträge der Kontraktarbeiter einen Aufenthalt von 2-5 Jahren im Auslande vorsehen: 2 Jahre auf den Philippinen, 3 Jahre in Hawaii, Queensland, Mexiko u.s.w., 4 in Peru, 5 in Neukaledonien. Eine von ihm im Jahre I902 im Reg. Bez. Wakayama vorgenommene Feststellung habe eine Durchschnittsdauer der Abwesenheit von 4 Jahren 4 Monaten ergeben. Inzwischen dürfte, nach Angaben, die mir im Bureau einer Auswanderungsgesellschaft gemacht wurden, die Fristen etwas länger geworden sein. Zwar werden die Kontrakte noch immer für 2-4 Jahre gemacht, aber die meisten der Auswanderer verlängern ihre Kontrakte, etwa um 3 Jahre, und von den Zurückkommenden wandern viele noch einmal aus, so dass es begreiflich ist, wenn für Hawaii neuerdings ein Durschnittsaufenthalt von Io Jahren angegeben wird. Zum Teil wird dieser Wandel schon durch die sorgfältigere Auswahl der

1) a.a.O. 6. Kap. 
Auswandernden durch die Gesellschaften und die P'olizei erklïrt, \%um 'leil anch durch die bessere Anpassung an die fremden Linder, in denen der Aufenthalt inzwischen für Japaner angenehmer geworden ist, da in ihnen, z.13. Hawaii, Cillifornien u.a. japanische Kolonicn mit allerhand Annehmlichliciten und besonderen Einrichtungen für Japancr entstanden sind. Andrerseits erklïrt auch wieder die lïngere Dauer des Aufenthalts der Japaner in der fremde ihre bessere Anpassung an diese, dic rrössere Auswanderung von lirauen, die grössere Zahl der japanischen Geburten in Auslancle und die grössere Sesshaftigkeit der Japaner in ihrer neuen lleimat. Die Lebensverhältnisse der japanischen Kaufleute im Auslande wurden natürlich clurch den Entwicklungsgang der Auswanderung weniger berülırt, da sie ja besser vorgebildet, und in engerer frühlung mit cler Bevölkerung der Einwanderungsländer, weniger Zeit brauchen, um sich zu assimilieren, besonders da ihr Beruf sic ja ohnehiu $\mathrm{zu}$ ciner Anpassung zwingt.

Auch die Qualität der Auswanderer verändert sich. Als dic Auswanderung mit den von der Regierung vermittelten Kontraktarbeitern nach Hawaii anfing, waren die cinzelnen Arbeiter ziemlich sorgfältig ausgewählt. Erst die Auswanderungsagenturen hatten ein Interesse daran, die Zalıl der Auswanderer zu vermehren, ja sogar an Stelle der bäuerlichen Arbeiter ohne Kapital, solche mit kleinen Ersparnissen zu befödern, mochten sie auch zur Feldarbeit weniger gencigt und geeignet und moralisch nicht immer einwandfrei sein. So kam viel städtisches Proletariat ins Ausland. Zum Teil Leute, die sich auch daheim wenig nützlich gemacht hatten; nicht für jeden ist aber das Ausland eine Besserungsanstalt. Der Hauptteil der Auswanderer waren durchwegs einfache Leute, aus ländlichen Verhältnissen, meist ehemalige Bauern, (nach europäischen Vorstellungen Kleinbauern und Landarbeiter) zum Teil Handwerker und Dicnstboten. Dem entspricht auch ihre Verwendung im Auslande: von den Japanern, die sich in Jahre 1902 im Auslande befanden, war die erdrückende Mehrheit landwirtschaftlich beschäftigt ${ }^{1)}$ und wir haben oben (S. I7) gesehen, dass auch heute noch Landwirte und ungelernte Arbeiter neben Handwerkern und den Verkäufern persönlicher Dienstleistungen überwiegen. Die Auswanderer sind meist erwachsen und weniger als 50 Jahre alt. Obwohl heute mehr

1) Osacuahira a.2.ก. 7. Kap. 
Frauen auswandern als früher, ist die Zahl der Familien die Japan verlassen, verhältnissmässig gering. Meist gehen die Männer allein fort und lassen ihre Familie zurück. Geht es ihnen dann in Auslande so gut, dass sie iluren Aufenthalt zu verlängern gedenken, so rufen sie manchmal, in neverer Zeit ofter, ihre Frau und ihre Kinder nach, und oft lassen sich auch ledige Japaner, vielleicht solche, die erst im Auslande herangewachsen sind, durch in Japan stets in Anspruch genommene Heiratsvermittler Bräute besorgen, die dann allein die Reise antreten.

Ueber die moralische Beschaffenheit der Auswanderer hört man die verschiedensten Urteile. Die vom Lande kommenden bieten meist keinen Anlass zur Klage. Dagegen scheinen das städtische Proletariat und die Bergbaudistrikte nicht die besten Elemente abzugeben. Man hat natürlich in Rechnung zu zichen, dass die Auswanderer durchwegs einfache Leute aus den unteren Schichten sind, dass sie daher Versuchungen leichter anheimfallen, und dass sich unter den Auswanderem aller Staaten stets eine Reihe abenteuerlustiger Gesellen befindet. Ueber das Material an Menschen, das Japan abgibt, ist wiederholt Klage geführt worden, besonders in den japanischen Kolonien, in denen man sich schliesslich, un taugliche Ansiedler zu gewinnen, genötigt gesehen hat, das Einwanderungswesen in die Regie der Folonialregierungen zu übernehmen. Namentlich brachte der russische-japanische Krieg eine Reihe unerwünschter Existenzen auf das asiatische Festland, und die Koreanische Generalresidentur (das spätere Generalgouvernement) hatte alle Mühe wieder reinen Tisch zu machen. Auch aus den Vereinigten Staaten kamen Klagen aller Art, selbst aus japanischem Munde, und die Berichterstatter, die das Auswärtige Amt in Tōkyō aussandte, brachten aus Südamerika und andern Orten gleichfalls manche ungünstige Nachricht mit. Im allgeneinen aber scheint auch lier das Schlimmste überwunden $\mathrm{zu}$ sein und clie sorgfaltige Auswahl, der heute die Auswanderer unterzogen werden, bürgt dafür, dass die Klagen nach und nach verstummen werden; trotzdem bleibt noch der Umstand übrig, dass die Japaner daheim und im Auslande nicht immer gleich zu bewerten sind. Die strenge Kontrolle, der in der Regel jeder Japaner durch seine Familie und vielerlei andere Verpflichtungen ausgesetzt ist, und die Lafcadio Hcarn als einen starken , Druck von allen Seiten “ bezeichnet, der ihm so charakteristisch scheint, dass er durch ilun das ganze Gesellschaftsleben Japans zu erklären sucht, fällt 
in Auslande fort, und der japanische Sittenkodex, der so sorgfätig jecke Einzclheit regelt, hat den liall der Auswanderung nicht vorgesehen. So kommen immer wieder Klagen darüber, dass sich Japance in Aushande $\%$ sehr gehen lassen und nach dem Grundsatz leben: Im Auslande brauche man sich nicht zu genieren. Er ist selbstrerstindlich, dass diese Grundsät\%e ausgetilgt werden müssen, um allen Anstïnden vorzubeugen.

Auch das japanisclse Urteil über lie Eignung der Japaner als Kolonisten ist nicht selır günstig. Dic japanische Zeitschrift "Taiyo" (die Sonne) hat in einer Sondernummer i.J. I9lo eine Reihe fülsrender Männer hierüber \%u Worte kommen lassen." Männer wie Savoryanagri, Ebina, Prof. Kawai und Major Neab (ein Kenner Chinas) fillen ein hartes Urteil über dic kolonisatorischen Fähigkeiten der Japaner: Sic hätten keine Ausdauer heisst es da, keinen moralischen Mut, verglichen mit dem der Westländer, keine wahre Freude am Unternehmen und an Abenteuern und keinen genossenschaftlichen Geist. Ausserdem wären sie noch zu fremdenfeindlich und nicht imstande, sich dem Auslande wirklich anzufreunden, ihr japanisches IVesen auch nur für kurze $Z$ it zu vergessen oder ihre heimischen Sitten und Anschauungen abzulegen; dabei verliessen sie sich zu sehr auf die Initiative der Regierung und seien viel zu genusssüchtig, als dass sie in der Arbeit aufgingen. Den chinesischen Kuli sei der japanische an Genügsamkeit, Arbeitsamkeit, Sparsamkeit, Ausdauer, Kraft und Gesundheit unterlegen, und das höchste Streben des Japaners der besseren Schichten im Auslande sei, ein extravagantes Leben zu führen, was natürlich dem Fortkommen abträglich sci. Während ich dieses Urteil auf Grund meiner Erfahrungen und Beobachtungen und der Ergebnisse der vorliegenden Untersuchung in der Hauptsache für richtig halte, sind die den kolonisatorischen Eigenschaften der Japaner günstigen Urteile weniger gewichtig, z.T. geradezu durch Tatsachen wiederlest, z.B. die Behauptung von der physischen Anpassungsfähigkeit an alle Klimate. Das Beste, was zugunsten der Japaner als Kolonisatoren angeführt wird, ist charakteristischerweise ihr Vergleich mit den Philippinern, unter denen sie

1) Vorgl. Bericht des Dolmetscher-Sekrelärs $K$. /to im Band V der gesammelten Berichte des Min. des Ausw. (iiber Perı) lōkyō, Dez. Igı́o. - Ebenso Aubert a.a.O.S. 322. u.a.

2) Auszugsweise wiedergegeben in einem Artikel von Historicus (Dening) im Jafan Chronicle, Weekly eả. 2j. V. 1912. 
sich nach Aussage des Konsuls Fokichi in Manila als Einwanderer hervorgetan haben.

Der Weg, den die Auswanderung nimmt, führt meist über die grossen Häfen, besonders Yokohama, Kōbe, Nagasaki und Shimonoscki (Möji), denn selbstverständlich ist die Auswanderung ausschliesslich auf den Wasserweg angewiesen. Die Ueberfahrt nach dem asiatischen Festlande wird wohl gelegcntlich durch Tramp-Schiffe besorgt, sonst aber sind es die regelmässigen Linien der grossen Gesellschaften, die den Verkehr vermitteln. Gegenwärtị̣ unterhalten 3 japanische Schiffahrtsgesellschaften regelmässige Linien, die für die Auswanderung von Wichtigkeit sind: Die Nippon-Yūsen-Kwaisha, die Dampfer nach Seattle laufen lässt, die Töyō-Kisen-Kwaisha, die eine Linie nach San Francisco und eine nach Südamerika (Manzanilla - Santa Cruz Callao - Iquique - Valparaiso) unterhält, (die letztere seit I9:6) und die Osaka-Shōsen-Kwaisha, die seit zwei Jahren den Verkehr mit Tacoma aufgenommen hat. Ausserdem kommen eine Reihe englischer und amerikanischer Linien in Betracht, die von der Royal Mail S.S. Co., der China Mutual Navigation S.S. Co., der Great Northern S.S. Co., der Boston S.S. Co., der Portland Asiatic S.S. Co., der Pacific Mail S.S. Co., der Oriental S.S. Co., der Oceanic S.S. Co., beigestellt werden. Fast alle Schiffe legen in Hawaii an.

Die Auswanderer zerfallen nach der Art ihrer Beförderung in 3 Gruppen: I) selbständige Auswanderer, die ohne die Hilfe von Agenturen auswandern: das sind insbesondere diejenigen, die ihren Bekannten und Verwandten ins Ausland folgen; 2) von Agenturen beförderte "freie" Auswanderer, die ohne Kontrakte auswandern und 3) von Agenturen beförderte Arbeiter, die unter Kontrakt, meist in grösseren Transporten an ihr Reiseziel geschafft werden. Diese Klasse von Auswanderern kommt hauptsächlich für Hawaii, Südamerika und die Inseln Australiens in Betracht. Die Gruppen 2 und 3 überwiegen weitaus, wenn auch heute nicht mehr so wie früher. Er ist daher notwendig, die japanischen Auswanderungsgesellschaften etwas eingehender zu besprechen.

Die japanische Auswanderung nahm ihren Anfang bekanntlich mit der Aussendung von Kontraktarbeitern, die von der Regierung für die Pflanzungen auf Hawaii besorgt wurden. Um: 1896 , also etwa Io Jahre später, nach dem chinesisch-japanischen Kriege, gab die Regierung die Vermittlerrolle auf. Es hatte Schwie- 
rigkeiten mit Hawaii gregreben, wïhrend de's Kricuges hatte natürlich die Auswanderung eingeschränkt werden müssen, und aus demselben Grunde hatten wohl auch schon die Pfanzer von Iawaii begonnen, in Japan Agenten $7 u$ unterhalten. Der Aufschwung nach dem siegreichen Kriege und dic grosse \%ahl der zurückgekehrten Soldaten gab der Auswanderung einen starken Antrieb, und zugleich war dies dic Zeit, in cler rasch eine ganze Reihe von Auswanderungs-Agenturen (bezw. Gesellschaften) aufkamen. Es ist klar, dass die Vermittlung und Beförderung von Kontraktarbeitern den natürlichen Boden für das Bestehen solcher Ascenturen bot. Es kam aber noch manches hinzu, was ihr Geschäft forderte und ihnen geradezu cin Monopol verleihen musste. Dic Regierung hatte seinerzeit das Vermittlungsgeschäft mit Gewissenhaftigkeit besorgt, den Pflanzungen genügsame und fleissige Feldarbeiter geliefert, die bei der Billigkeit und Anspruchslesigkeit jener Tage leicht zu haben waren, da der verhältnismässig hohe Lohn in Hawaii eine grosse Anlockung, die harte Arbeit aber nichts Ungewohntes war. Das von den Pflanzern für die Vermittlung bezahlte Geld verwendete die Regierung sorgfältig für den Transport und als Rückhalt für die krank oder notleidend gewordenen Auswanderer, sowie für ihre Zurückschaffung. Die Auswanderergesellschaften, die das Geschäft von der Regierung übernahmen, waren natürlich nicht mehr so uninteressiert wie die Regierung, obwohl es scheint, dass diese beim Entstehen der Agenturen Pate gestanden habe. Bald versuchten die Gesellschaften, nicht bloss mittellose Lcute anzuwerben, sondern solche mit etwas Vermögen. Von diesen wurde unter allerhand Vorwänden Geld genommen, obwohl die Pflanzer ja für jeden gelieferten Arbeiter zahlten, ja man ging sogar dazu über, den Auswanderern Geld zu leihen und sie dadurch in eine Schuldknechtschaft zu zwingen, die von Seiten der Geselischaften ebenso wohldurchdacht als unlöslich gemacht worden war. Dies alles wurde durch Massregeln der japanischen Regierung erleichtert, die eigentlich zum Schutze der Auswandernden getroffen worden waren. Gleichzeitig mit der Abgabe des Vermittlungsgeschäfts an die Agenturen hatte die Regierung nämlich ein Gesetz zum Schutze der Auswanderer erlassen (I 894, dann 1895), dessen Inhalt unten wiedergegeben ist. Dieses Gesetz machte die Auswanderung jedes einzelnen von der Bewilligung der Behörden abhängig, bestimmte, dass für den Fall der Not und der Rüclibeförderung Bürgschaft gestellt werden müsse und 
gab durch diese Vielregiererei die armen und unwissenden Auswanderer ganz in die Hände der Gesellschaften, vor denen sie eigentlich geschützt werden sollten. Denn diese, die anscheinend zunächst enge Fühlung mit der Regierung hatten, verschafften sich bald das Monopol, Auslandspässe zu erlangen, da diese ja nur ausgefolgt wurden, wenn die Erfordernisse für die Ueberfahrt, Bürgschaft u. dergl. erfüllt waren. Die Regelung der Bürgschaftverhältnisse aber führte bald dazu, dass die Auswanderer den Gesellschaften gegenüber dafür bürgten, dass sie ihre Verpflichtungen, besonders die Rückzahlung der Vorschüsse getreulich erfüllen würden. Die Gesellschaften waren gut organisiert und hatten eine gemeinsame Bank, die Kei-hin-Bank, die die Vorschüsse zu I $2 \frac{1}{2} \%$ hergab und das hinterlegte Bürgschafisgeld mit $4 \%$ verzinste. Da sich nun Agenten und Bank, daneben auch Unterkunftshäuser und Schiffahrtsgesellschaften in die Hände arbeiteten, war der Auswanderer, für dessen Ueberfahrt noch dazu die Pflanzer ausreichend gezahlt hatten; (den Auswanderungsbureaus natürlich) in ein Netz verstrickt, aus dessen Maschen er olne grosse Opfer nicht loskommen konnte." Die Tätigkeit der Auswanderungsgesellschaften hatte also zur Folge, dass die Ausivanderung wuchs, dass die Qualität der Arbeiter abnahm, die einzelnen Auswanderer bereits stark verschuldet ankamen und unzufrieden wurden, wenn sie sahen, dass die Schulden sich nicht so leicht abzahlen liessen, als sie auf Grund der ihnen gemuchten Versprechungen geglaubt hatten, und dass sich von der schweren Arbeit der arm:n Ausgewanderten eine Schar von nicht selten gewissenlosen Zivischenmännern ernährte. Diese Zustände, die aus den freien Auswanderern für mehrere Jahre L,ohnsklaven machten, führten unter den Japanern Hawaiis zur 13egründung einer "Japanese Reform Association," die von ihrer Regierung die Befreiung der Auswanderung von allen Beschränkungen verlangte.

Das Auswanderungsgeschäft hingegen scheint ein sehr blühendes gewesen $\mathrm{zu}$ sein. Im Jahre I 899 bestanden I 2

1) Vergl. Third Report of the Commissioner of Labor on Hawaii. 1905. Washington. 1905. S. 149 ff. wo auch einige Hinterlegungsurkunden der Kei-hinBank wörtlich wiedergegreben sind. Aus ihnen geht durchwegs hervor, dass die Auswanderer ihre Einlage, die doch eigentlich zu ihrer Sicherstellung bestimmt war, selbst in Falle von Kranklyeit u.s.w. erst nach Abtragung ihrer Schulden an die Bank wiedersehen konnten. 
Gesellschaften mit 558999 Yen Kapital," und das rasche Ansteigen der Auswanderungstiffern seit 1896 (siche Tabelle XV) beweist, dass sie ihren Geschiffskreis erfolgreich \%u erweitern wussten. Ja, es scheint sogar, dass sich dic Auswanderungsgesellschaften mit Hilfe ibres Monopols und ihrer Oreanisation auch die Pflanzer Hawaiis tributpflichtigr gemacht haben, die genötigt wurden, den Gesellschaften Beihilfen \%u zihlen. Selbst als 1900 Hawaii als amerikanisches Gebiet erliärt, und clamit die Einführung von Kontraktarbeitern entsprechend clen amerikanischen finwanderungsgesetzen straffillig wurde, ist es den Gesellschaften noch gelungen, die Pflanzer durch eine Abschuürung der Einwanderung bis zum Jahre 1905 gefügig zu erhalten."?

Den Pflanzern konnte natürlich die Verschlechtzrung des cinwandernden Arbeitermaterials und die Verteuerung der Beschaffungskosten nicht gleichgültig sein, aber sie waren zunächst wehrlos. Es kam für sie sogar noch schlinmer. Igor wurde von der japanischen Regierung die Erteilung von Pässen nach dem amerikanischen Festlande, u.z. sowohl den Vereinigten Staaten als auch nach Kanada auf Grund von Vereinbarungen eingeschränkt. Der Erfolg war, dass nun Hawaii Durchgangsstation für das Fostland wurde.

Es wanderten aus :

\section{Tabelle IVII.}

\begin{tabular}{cl|r|r|r|r}
\hline & 1900 & 1901 & 1902 & 1903 \\
\hline Nach Hawaii & 1529 & 3136 & 14490 & $909 \mathrm{I}$ \\
" V. St. A. & $75 S_{5}$ & 32 & 70 & 223 \\
" Canada & 2710 & 0 & 35 & 16 \\
\hline
\end{tabular}

Eine ganze Organisation von Agenten betrieb die Weiterbeförderung der Japaner von Hawaii nach dem Festlande, wo höhere Löhne winkten, wo es keine Kontraktarbeit mehr gab und wo man nach dem Aufenthalt in Hawaii, dem Kindergarten

1) House of Representatives, 56. Congress, I. session, document 686. Immigration of Japanese; Washington.

2) S. Report w.o.S. 152 .

3) Osacuahira a.s.O. 6. Kap. auf Grund der amtlichen Angaben. 
für japanische Auswanderer, ein besseres Fortkommen erwarten durfte. Vom I. Januar I902 bis zum 30. September 1906 wanderten 29417 Menschen von Hawaii nach dem Hauptland aus, von denen die überwiegende Mehrzahl Japaner waren.") Die Pflanzer gaben sich verzweifelte Mühe, die Abwanderung von den Inseln, die 1902 eingesetzt hatte, einzuschränken, aber trotz der Unterstützung durch den japanischen Generalkonsul in Hawaii, der seine Landsleute aufforderte, die Abmachungen der japanischen Regierung $z u$ achten, und der Central Japanese League, ohne nennenswerten Erfolg, bis die Pflanzer im Mai I905 die Löhne erhöhten. Inzwischen war auch die Regierung des Territoriums dazu übergegangen, die dort ansässigen Auswanderungsagenten zu konzessionieren, aber die Einverleibung Hawaiis in die Vereinigten Staaten Amerikas und die Lockungen seitens der Pflanzer des Festlandes machten zunächst alle Abwehrmassnalimen zu Schanden. Ausserdem kamen viele Japaner nach Hawaii, die gleich weiterbefördert werden sollten, obwohl das eine klare Umgehung des Verbotes der japanischen Regierung war. ${ }^{2}$ Dabei schwoll der Auswandererstrom nach Hawaii, dem Hauptarbeitsfeld der japanischen Agenturen weiter an, und damit auch ihr Profit und ihre Zahl. I905 gab es ihrer 30, davon 7 Einzelfirmen, das übrige Gesellschaften, meist Aktiengesellschaften und Kommanditgesellschaften. Dem Sitz der Firma nach waren Io in Tōkyō, 2 in Kumamoto, I in Kōchi, 9 in Hiroshima, 2 in Köbe, je eine in Okayama, Chiba, Sendai, Yokohama und 2 in Yamaguchi. Das grösste Kapital hatte die Tairiku Shokumin Göshi Kwaisha, (I Million Y.), dann folgte die Firma Morioka Makoto (mit 250000 Y.), dann die Kōkoku Imin Kabushiki Kwaisha (mit 200000 Y.) und die Sendai Imin Gōshi Kwaisha mit ebensoviel : sonst gab es 6 Gesellschaften mit I00000 Y, I mit 80000 , I mit 73000,7 mit 60000 , je eine mit 52000 und 51000, 9 mit 50000, 2 mit 30000 und 1 mit 2000o. Zusammen also waren in diesem Geschäfte $3276000 \mathrm{Y}$. angelegt, d.i. etwa das Sechsfache des Kapitals vom Jahre 1899 (s. o.). Von allen Firmen beförderte am meisten Auswanderer, nämlich 31000, die Tairiku Shokumin Gōshi Kwaisha, ihr folgte die Chūwō Imin Kiwaisha mit 9000, dann die Tōkyō Imin Gōshi Kwaisha mit 7400. Die kleinste Tätigkeit entfaltete die

1) Aubert a.a.O. S. 98 ft. Eт gibt auch Beispiele für die Werbeplakate der Agenten, die nach dem Festland ,, arbeiteten “.

2) Third Report w.o. S.42 ff. und Folirth Report etc. 1gro. Washinglon 19rI. 
Kyushū Imin Kabushiki Kwaisha, die nur 1500 Icutc beförderte." Die Grösse des investierten Kapitals entspricht also durchaus nicht der Tätiglecit der Agrentur. Leider konnte ich keine Nachrichten über die Geschifftsergebnisse dieser Gesellschaften erhalten. Jedenfalls scheint das Geschäft \%unächst sehr gut gregangen zu sein, sonst hätten nicht so viele firmen dabei bestehen liönnen. Aber dic Uebertreibung des Geschäftes brachte auch hicr einen Umstur\%. Dic immer zahlreicher auf dem amerikanischen Festlande ankommenden japanischen Auswanderer, die Verschlechterung ihrer Qualität als Arbeiter riefen bald einen starken Einspruch gegen alle Praktiken hervor, durch dic das Versprechen der japanischen Regierung, dic Einwanderung nach dem Festlande zu unterbinden, umgangen wurde, besonders die Einschmuggelung über die festländischen Grenzen, die schwer zu überwachen waren. Schliesslich fand dic Erregung über die Einwanderungsfrage ihren Hölepunkt in dem Schulstreit von San Francisco (1907) und den darauf folgenden Unruhen in Vancouver, und einen kurzen Zeitraum hindurch sah sogar die politische Lage sehr ernst aus. Jetzt musste die japanische Regierung eingreifen, und sie war sich anscheinend sofort darüber klar, wo des Ucbels Wurzel war. Ihren Verordnungen brauchte sie nur noch eine hinzuzufügen, die die crstmalige Auswanderung von Arbeitern ausser nach denı amerikanischen Festlande (das war eigentlich schon 1900 verboten worden) auch nach Hawaii verbot. Vor allem aber benutzte sic die Handhaben, die ihr das Auswandererschutzgesetz bot und ging energisch gegen die Agenturen vor. Es wurden Missbräuche aufgedeckt, einige Gesellschaften suspendiert und mit Geldbussen belegt: das Geschäft war ohnehin stark eingeschränlt worden, obwohl man inzwischen versucht hatte, in Südamerika und in Australien Ersatz zu finden. So kam denn, was kommen musste: Es schlossen sich mehrere Gesellschaften zusammen, andere lösten sich auf, manche mögen wohl auch in Schwierigkeiten geraten sein, obgleich es bei diesem Vermittlungsgeschäft ja kaum grosse Verbindlichkeiten geben kann, und schliesslich war der Bestand an Agenturen, und damit der Hauptanreiz zur Auswanderung gründlich zusammengeschmolzen.

1) Ogawalira a.a.O. 5. Kap. Der Third Report etc. (1906) wcist für einen etwas späteren Zeitpunkt schon 3 t Gesellschaften aus (S. 149). 
In Juli I9 I bastanden nur mehr 6 Gasellschafen, von denen jedoch eine das Geschäft ruhen liess, und eine von der Regierung suspendiert war. Die noch tätigen Gesellschaften sind Takemura Shōkıan (50000ว Y. Kapital), die Nippon Shokımin Gōshi Kwaisha und Morioka Shin \& Co. (nit je 200000 Y.), sowie die Tōyō Imin Gōshi Kwaisha (mit Io0วoว Y.). Die 2 nicht mehr tätigen Gesellschaften sind die Meiji Imin Gōshi Kwaisha (mit Soooวo Y.) und die suspendierte Meiji Shokumin Gōshi Kwaisha (mit 500000 Y.). ${ }^{1)}$ Mit Ausnahme der Takemura Shōkwan, die ihren Sitz in Kōchi hat, und der Meiji Imin Gōshi Kivaisha, die in Kumamoto eingetragen ist, sind alle in Tōkyō sesshaft. Ausserdem ist noch eine Gesellschaft, die Tairiku Imin Kwaisha in Liquidation. Takemura Shōkwan ist die Nachfolgerin der Kōkoku Shokumin Kwaisha. Die grösste und die drittgrösste der Gesellschaften nach dem Stande von 1905 (s.o.) sind also bereits von der Bildfläche verschwunden, während das Kapital der tätigen Gesellschaften auf I Million (also ein Drittel des oben festgestellten) zusammengeschrumpft ist.

Die Tätigkeit dieser 4 Gesellschaften veranschaulicht folgende :

Tabelle XVIII.

\begin{tabular}{l|r|c}
\hline Es wurden befördert von & I9ro & I. Halbj. I9I I \\
\hline Töyō Imin G.K. & I7I I & 465 \\
Morioka \& Co. & 3 I & - \\
Takiemura Shōkivan & 909 & - \\
Nippon Shokumin G.K. & $8_{3}$ & 349 \\
\hline & 3020 & 8 I 4 Aus- \\
\hline
\end{tabular}

Da mir von cinem Leiter einer dieser Firmen angegeben wurde, eine Agentur brauche mindestens 500 Auswanderer im Jahre, um bistehen zu können, so sehe ich das Ende der rückläufigen Bewegung in Auswanderergeschäft nicht ab. Die beförderten Auswanderer wurden nach Südamerika und einigen

1) I9rz hat auch diese Gasellschaft (auscheinend aus Mangel an Mitteln) zu bestchen aufgrehört. 
Inseln des australisclien Archipels geschaffe und wurden \%um Teil auf Wunsch und auf Kosten von Unternehmungen besorgt und befördert. Auch der Staat Sao Paolo zahlte für jeden Ansiedler eines ihm geworbenen Transportes. Sonst zahlte ein Teil der Auswanderer die Kosten der Ueberfahrt selbst oder nahn Vorschüsse von der $\Lambda$ gentur, die sclbst wieder Bankkredit in Anspruch nahm. Allgemein hört man die Klagen der Auswanderungsgesellschaften und der Freunde der japanischen Auswanderung, dass die Regicrung licine Auslandpässe erteilen wolle. Es sieht so aus, als ob in nächster Zeit eine Aenderung nicht \%u erwarten und die Aussicht für die Agenturen keinc allzugünstige wäre.")

Fasst man die bisherigen Ergebnisse der geschilderten Entwicklung zusammen, so fält zunächst ins Auge, einen wie grossen Einfluss die Agenturen auf die ganze Geschichte der japanischen Auswanderung ausgeübt haben : das wird verständlich, wenn man berüclisichtigt, dass diese eine willkürlich hervorgerufene Bewegung darstellt, und dass dic japanischen Auswanderer ohne führende Hand kaum in nennenswerter Anzahl den Wegr an die Arbeitsplätze übers Meer gefunden hätten. Die stramme Organisation der ganzen Bewegung, zunächst durch die Regierung, dann durch die Auswanderungsgesellschaften, deren Entstehen anscheinend von der Regierung gewünscht worden war, hat der gesamten Auswanderung ihren einheitlichen Charaliter gegeben und, wie sich aus dem Zusammenhange meiner Darstellung ergeben dürfte, auch manchen Vorteil gebracht. Die Auswanderungsgesellschaften, die in ihrer Gesantheit dem japanischen Gemeinwesen gewiss von Nutzen waren, haben allerdings den einzelnen Auswanderer zu oft ausgebeutet und seinen wirtschaftlichen und moralischen Erfolg dadurch beeinträchtigt, dass sie den Versuchungen, ihren Profit auf Kosten anderer zu stcigern, niclit zu widerstehen vermochten. Die Ergebnisse der japanischen offiziellen Auswanderungspolitik mit der Regelung des Agentenwesens sind überaus lehrreich und

1) Im Mai 1912 erfulur ich nachträglich, dass Takımura Sh. und Tōyö Imin K. inzwischen noch je 1,300 Auswanderer nach brasiliun entsentlet haben, Morioka 200 nach Peru und dic Shokumin Gōshi K. einige Hundert nach der Südsee, hxuplsächlich nach Neukaledonien. Die 5. Gesellschaft hat auch weiterhin nichts unternommen. Die Geschäftsergebnisse waren durchwegs unbefrieligend, und man erhofft atich für die nächste Zuliunft nur bescheidene Erfolge, vorausgesetzt, dass dic Regierung weiterhin elwas frigeliger mit ihrer Zustimmung zu Auswanderungsplänen ist. 
charakteristisch. Ich will versuchen, sie im Anschluss an die übrigen Massnahmen der Regierung darzustellen.

Das Eigentümlichste an der japanischen Auswanderung ist, dass sie völlig ,, von oben her " gemacht wurde. Die Regierung besorgte die ersten Auswanderer in Gestalt von Kontraktarbeitern für Hawaii, und damit war zum erstenmale eine richtige Auswanderungsbewegung. in Gang gebracht. Als die Regierung dann die Rolle eines Agenten niederlegen wollte, war natürlich die Auswanderung noch so unselbständig, zum Teil infolge ihrer Jugend, dass sie ohne Führung kaum weiterbestanden hätte. Die Regierung tat also, was sic in der merkantilistischen Meiji-Aera wiederholt getan hat, um neue Unternehmungen ins Leben zu rufen: Sie führte sie zuerst in eigener Regie durch und regte hierauf die Bildung von Privatgesellschaften an, die ihre Nachfolge übernahmen. Oft geschah es dann, dass die Männer, die als Regierungsbeante den Staatsbetrieb geleitet hatten und meist die einzigen Japaner waren, die mit solchen Angelegenheiten Bescheid wussten, in die Dienste der neuen Privat-Unternehmungen übertraten oder gar deren Gründer wurden, dies gewöhnlich mit offener oder versteckter Kapitalbeihilfe durch den Fiscus. Im vorliegenden Falle scheint sich ein ganz analoger Vorgang abgespielt zu haben. Leider sind mir genaue Mitteilungen über die Gründungen der ersten Auswanderungsgesellschaften nicht bekannt geworden, doch deutet eine Reihe von Nachrichten über die engen Bexiehungen zwischen Regierung und Gesellschaften in jener Zeit, die Schaffung des sogenannten Auswandererschutzgesetzes, das die Gesellschaften noch vor ihrem Erscheinen reglementiert, und einiges andere mit voller Bestimmtheit darauf hin. Im Auslande hat das nahe Verhältnis, in dem die Regierung zu den Agenturen stand, wiederholt den Verdacht aufkommen lassen, dass das offizielle Japan künstlich eine Auswanderung $\mathrm{zu}$ schaffen suche, um damit politische Ziele zu verfolgen, doch dürfte das kaum zutreffen. Uebrigens gab es auch Einzelfirmen als Agenturen, deren Leiter sich aus zurückgekehrten Auswanderern und dergleichen rekrutierten.

Das Auswandererschutzgesetz, Gesetz No. 70 vom 7 . April 1896, lautet mit seinen Abänderungen aus dem Jahre 1901, 1902 und 1907 wie folgt: ${ }^{1)}$

1) Da mine; Wissens eine nicitjapanisc oq Veröffutlicioung des Gəsatzes 


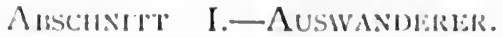

\$. Auswanderer im Sinne dieses Cesetzes sind Perionen, dic znn Zwecle der Arbeit in fremele Länder, atuserenommen China und Korea, reisen, sowie ihre Fandienangehörigen, dic mit ihnen reisen ofler sich nach ilurem Aufenthaltsort beschen.

Dic Arten der im vorigen Alsatz crwillunten Arbeit werden im Verordnungswege bestimmt.

$\$ 2$. Auswanderer kinnen nut mit Erlatubnis der Verwaltungsbelö̈rden in ci.ss Ausland reisen.

Dic Reiscerlatubnis erlischt, "emn die Reise nicht innerhalb von 6 Monaten vom Tage der biteilung der Erlaubnis angetreten wird.

§ 3. Die Verwaltungrsbehörden können bei Auswanderern, die sich nicht der Vermittelung eines Auswanderungsagenten bedienen, je nuch den Verhältnissen des Reiseziels, die Stellung von 2 oder mehr gecignet erscheinenden Bürgen verlangen.

Verfillt der betreffende Auswanderer in Kranklieit oder gerät er sonst in Not, so haben die Bürgen ihn zu unterstützen oder heimzuschaffen. Hat die Verwaltungsbehörde den Auswanderer unterstützt oder heimgeschaff, so haben die liürgen die Kosten zu ersetzen.

$\$$ 4. Wenn die Verwaltungsbehörde es zum Zwecke des Schutzes des Auswanderers, der Aufrechterhaltung der öfentlichen Ruhe oder aus diplomatischen Gründen für erforderlich hält, so kann sie die Abreise der Auswanderer sistieren oder die Erlaubnis dazu widerrufen. Der Zeitraum, während dessen die Abreise sistiert worden ist, wird in die Frist des Absatzes 2 des $\S 2$ nicht eingerechnet.

\section{Abschnitt II.-Auswandercingangenten.}

$\S 5$. Auswanderungsagenten im Sinne dieses Gesetzes sind Personen die, gleichviel unter welcher Bezeichnung, die Anwerbung von Auswanderern od:r die Vermittelung ihrer Ueberfahrt gewerbsmässig betreiben.

Auswanderungsagenten können mit Genehmigung der Verwaltungsbehörde solche Geschäfte betreiben, die in direktem Zusammenhang mit den Auswanderern stehen.

nicht erfolgt ist, gebe ich hier seinen Wortlaut wieler. Herr Dr. Nechlen'urs hatte die Giit:-, die Ve'Jersetzung auf ihre Richtigkeit hin zu prifen. 
$\S 6$. Personen, die Auswanderungsagenten zu werden wünschen, müssen die Erlaubnis der Verwaltungsbehörde einholen.

Die Erlaubnis für Auswanderungsagenten verliert ihre Gültigkeit, wenn nicht innerhalb von 6 Monaten, vom Tage der Erteilung an gerechnet, das Gewerbe eröfnet worden ist.

$\S 7$ a. Auswanderungsagenten können nur japanische Staatsangehörige oder Handelsgesellschaften werden, deren Mitglieder bezw. Aktionäre ausschliesslich aus japanischen Staatsangehörigen bestehen und die ihren Hauptgeschäftssitz in Japan haben.

Die übrigen Erfordernisse, die Auswanderungsagenten zu erfüllen haben, werden im Verordnungswege bestimnt.

$\$ 7$ b. Die Auswanderungsagenten übernehmen mit Bezug auf Auswanderer, deren Ueberfahrt sie vermittelt haben, vom Tage der Abreise an für Io volle Jahre die im $\S 3$ Abs. 2 bestimmten Pflichten der Bürgen.

$\S 8$. Wenn ein Auswanderungsagent gegen Gesetze oder Verordnungen verstösst oder anzunehmen ist, dass er die öffentliche Ruhe gefährdet, oder wenn er mit der Zahlung der von Auswanderungsagenten zu leistenden Sicherheit in Verzug gerät, so kann die Verwaltungsbehörde das Gewerbe einstellen oder die Gewerbeerlaubnis widerrufen.

$\S 9$. Durch Sistierung des Gewerbe; seitens der Behörde oder Aufgabe desselben seitens des Auswanderungsagenten wird dieser nicht von der Erfüllung von Verträgen mit bereits abgereisten Auswanderern befreit.

$\S$ Io. Ein Auswanderungsagent, der seine Geschäfte durch einen Stellvertreter betreiben lassen will, hat hierzu nach Massgabe der zu erlassenden Verordnung die Erlaubnis der Verwaltungsbehörde einzuholen.

$\S$ I I. Auswanderungsagenten dürfen Auswanderer nur nach solchen Plätzen versenden, an denen sie ein geschäftsführendes Gesellschaftsmitglied, ein Vorstandsmitglied oder einen Vertreter unterhalten.

$\S$ I2. Auswanderungsagenten dürfen nur Personen, die als Auswanderer übersiedeln, vermitteln oder anwerben.

$\S$ 13. Bei der Vermittelung oder Anwerbung von Auswanderern, die als Kontraktarbeiter übersiedeln, hat cler Auswanderungsagent mit den Auswanderern einen schriftlichen Vertrag zu schliessen, der der Genehmigung der Vcrwaltungsbchörde unterliegt.

Die Erfordernisse für einen Vertrag gemäss dem vorigen Absatz werden in Verordnungswege festgesetzt. 
\$ 14. Auswanderungsagenten dürfen von den Answanderem ausser ihrer Geboilu weder Gr:ld noch sonstige Gegrenstände atnnehmen. Dic Gebälır unterliegrt der vorlerigen Zustimmung der Verwaltungsbehörde.

$\$$ I 5 a. Auswanderungrsagenten luben bei der Anwerbungr von Auswanderen die Frist der Abreise $\%$ bestimmen und bekanntzugeben. Auswinderungsingenten, dic dic Auswanderer ohne triftigen Grund nicht innerhalh der vorherbestimmten Frist abreisen lassen, haben die durch den Aufsclubb der Abreise den Auswanderern entstehenclen Kosten zu tragen.

\$ I5 b. Die Verwaltungsbehörden können, wenn sic es für nötig erachten, dic Errichtung von Auswanderungsagenten-Gilden anordnen.

Dic Gilden haben die Figenschaft von juristischen Personen.

Die auf die Gilden bezüglichen Bestimmungen werden in Verordnungswege festgesetzt.

\section{Abscinitt III.-Sicherleitsleistung.}

$\S$ I6. Der Auswanderungsagent kann sein Gewerbe erst eröffnen, nachdem er eine Sicherheit bei der Verwaltungsbehörde hinterlegt hat.

Die Höhe der Sicherheit, die mindestens 10,000 Yen betragen muss, wird von der Verwaltungsbehörde fustgesetzt.

$\S$ I7. Die Verwaltungsbehörde kann, wenn sie es für erforderlich hält, die Höhe der Sicherheit heraufsetzen oder vermindern, jedoch darf dabei nicht unter den im vorigen Paragraphen bestimmten Betrag gegangen werden.

$\S$ is. Wenn nach Erachten der Verwaltungsbehörde ein Auswanderungsagent den Vertrag gegenüber einem Auswanderer nicht erfüllt oder den ihm nach $\S 7 \mathrm{~b}$ obliegenden Pflichten eines Bürgen nicht nachkommt, so kann die Verwaltungsbehörde aus der hinterlegten Sicherheit Ausgaben machen, um den Auswanderer zu unterstützen oder heimzuschaffen.

$\S$ 19. Bei Aufhebung des Gewerbes durch den Tod des Auswanderungsagenten, Auflösung der Gesellschaft, Widerruf der Lizenz oder aus sonstigen Gründen kann die Verwaltungsbehörde, solange sie es für nötig erachtet, die Sicherheit ganz oder zum Teil einbehalten.

$\S 20$ a. Während der Dauer des Guwerbebetriebes eines Auswanderungsagenten und der Frist, während der die Verwal- 
tungsbehörde gemäss dem vorigen Paragraphen die Einbehaltung der Sicherheit für nötig erachtet, können gegen diese ausser von den Auswanderern oder deren Erben zur Erlangung ihrer auf Grund eines gemāss diesem Gesetze geschlossenen Vertrages erworbenen Rechte von dritten keinerlei Forderungen erhoben werden.

\section{Abschnitt IV.-Ausivandererschiffe.}

$\S 20$ b. Auswandererschiffe im Sinne dieses Gesetzes sind Schiffe, die mit wenigstens 50 Auswanderern an Bord nach einem der in Verordnungswege zu bestimmenden Länder fahren.

$\S 20$ c. Die Beförderung von Auswanderern auf Auswandererschiffen kann nur mit Erlaubnis der Verwaltungsbehörden geschehen.

Personen, die die Erlaubnis gemäss dem vorstehenden Absatz erhalten haben, haben eine von der Verwaltungsbehörde zu bestimmende Sicherheit zu hinterlegen.

$\S 20 \mathrm{~d}$. Die Verwaltungsbehörde kann, wenn die Handlungsweise dessen, dem die Erlaubnis gemäss dem vorigen Absatz erteilt worden ist, gegen die gesetzlichen Bestimmungen verstösst oder die Bedingungen der Erlaubnis verietzt, oder, wenn angenommen wird, dass sie die Interessen der Auswanderer schädigt, die Erlaubnis widerrufen.

$\S 20$ e. Wer die Beförderung von Auswanderern mit Auswandererschiffen betreiben will, hat vorher die Zustimmung der Verwaltungsbehörde bezüglich der Transportsätze einzuholen.

$\S 20 \mathrm{f}$. Die Verwaltungsbehörde kann die Abfahrts- und Bestimmungshäfen der Auswandererschiffe bezeichnen.

$\S 20 \mathrm{~g}$. Die Verwaltungsbehörde kann von dem Kapitän cines Auswandererschiffs über alles, was die transportierten Auswanderer betrifft, Bericht verlangen.

\section{Abschnitt V.-Verschiedenes.}

$\S 20 \mathrm{~h}$. Ein gewerosmässiger Geldleiher, der das zur Bestreitung der Kosten der Reise oder der Vorbereitungen dazu nötige Geld an Auswanderer ausleihe:n will, hat zu den Darlehnsbedingungen vorerst die Erlaubnis der Verwaltungsbehörde einzuholen.

$\S 20 \mathrm{i}$. Wer in einem Auswanderer-Abfahrtshafen ein Gasthausgewerbe für Auswanderer betreiben will, bedarf hierzu der Erlaubnis der Verwaltungsbehörde. 
Wer die Genelamiguner des vorigen Absatzes eingeholt hat, hat bezüglich der Logiercinrichtungen, der Verpflegungs- und Unterkunftskosten sowie der sonstigen den Auswanderern zur Last fallenden Angrelegenheiten vorerst dic Zustimmung der Verwaltungsbehörde cinzuholen.

$\$ 20 \mathrm{k}$. Wer ohne Auswanderungsagent zu sein, die Verschiffung von Auswanderern vermitteln will, bedarf hicrzu der Erlaubuis der Verwaltunersbehörde.

Wer im Besitz der Erlaubnis des vorigen Absatzes ist, hat vorerst dic Zustimmung ler Verwaltungrsbehörde zu der Art der Vermittlung der Verschiffung, sowic zu den den Auswanderern zur Last fallenden Angrelegenheiten cinzuholen.

$\$ 201$. Die Verwaltungsbehörde kann, wenn die Handlungsweise dessen, dem eine Erlaubnis gemäss den beiden vorstehenden Paragraphen erteilt worclen ist, gegen die gesetzlichen Bestimmungen verstösst oder angenommen wird, dass sie die Interessen der Auswanderer schädigt, das Gewerbe sistieren oder die Gewerbeerlaubnis widerrufen.

\section{Abschnitt Vi.-Strafbestmincigex.}

$\$ 2$. Auswanderer, die ohne Reiseerlaubnis oJer unter falscher Angabe des Reiseziels oder entgegen einem Reiseverbot ausgewvandert sind, werden mit Geldstrafe von 5-50 Yen bestraft.

$\S 22$. Auswanderungsagenten und deren Vertreter, die eine gegen die Gisetze und Verordnungen verstossende Ueberfahrt von Ausivanderern vermitteln oder während des Bestehens eines Uebersiedelungsverbots die Uebersiedelung von Auswanderern veranlassen, werden mit Galdstrafe von 50-500 Yen bestraft.

$\$$ 23, Wer, ohne eine Erlaubnis der Verwaltungsbehörde zu bəsitzen, als Auswanderungsagent auftritt, sowie Auswanderungsagenten und deren Vertreter, die während einer Einstellung des Gewerbebetriebes Auswanderer anwerben oder deren Ueberfahrt vermitteln, werden mit Gildstrafe von 200-10so Yen bestraft.

Der vorstehende Absatz findet auch auf Auswanderungsagenten Anwendung, die olne Genehmigung der Verwaltungsbehörden ein Gewerbe nach $\$ 5$ Abs. 2 betreiben.

$\S$ 24. Auswanderungsagenten die sich durch einen nicht von der Behörde genehmigten Stellvertreter vertreten lassen, werden mit Geldstrafe von 20-200 Yen bestra't. Das Gl:iche 
gilt für denjenigen, der die Vertretungshandlung vorgenommen hat.

$\S 25$. Auswanderungsagenten und deren Stellvertreter, die den Vorschriften der $\S \S$ I I, I 2, I 3, I4 und I 5 Abs. I zuwiderhandeln, werden mit Geldstrafe von 50-100 Yen bestraft.

$\S 26$ a. Auswanderungsagenten und deren Stellvertreter, die unter Anwendung betrügerischer Mittel Auswanderer anwerben oder deren Ueberfahrt vermitteln, werden mit schwerer Gefängnisstrafe von I Monat bis zu I Jahr bestraft.

$\S 26 \mathrm{~b}$. Personen, die gegen die Vorschriften des $\S 20 \mathrm{c}$ verstossen, werden mit Galdstrafe von 500 bis 10000 Yen bestraft.

$\S 26$ c. Personen, die gegen die Vorschriften des $\S 20 \mathrm{e}$ verstossen, werden mit Geldstrafe von 200-3000 Yen bestraft. Das gleiche gilt von Personen, die gegen die von der Verwaltungsbehörde getroffene Bestimmung bezüglich des Abfahrtsund Ankunftshafens eines Auswandererschiffs verstossen.

$\S 26 \mathrm{~d}$. Wer es unterlässt, einen von der Verwaltungsbehörde gemäss $\S 20 \mathrm{~g}$ eingeforderten Bericht zu erstatten, wird mit Geldstrafe von 50-300 Yen bestraft.

$\S 26$ e. Wer gegen die Vorschriften der $\$ \S 20 \mathrm{i}, 20 \mathrm{k}$ und 201 verstösst, wird mit Geldstrafe von IO0-rooo Yen bestraft.

$\S 27$. Die Strafbestimmungen dieses Gesetzes finden bei Handelsçesellschaften auf die geschäftsführenden Gesellschafter oder Vorstandsmitglieder, die die von den verschiedenen Paragraphen betroffenen Handlungen vornehmen, Anwendung.

\section{Abschnitt. Vil.-Zusatzenstimmungen.}

$\S 28$. Auswanderungsagenten, die vor Inkrafttreten dieses Gesetzes mit Erlaubnis der zuständigen Behörde ihr Gewerbe betrieben haben, bedürfen beim Inkrafttreten dieses Gesetzes keiner besonderen Erlaubnis und können das Gewerbe gemäss den Bestimmungen dieses Gesetzes fortführen. Wird indes das Gewerbe nicht fortgeführt, so kommen doch bezüglich der bereits geleisteten Sicherheiten die Vorschriften dieses Gesetzes zur Anwendung.

$\S$ 29. Dieses Gesetz findet keine Anwendung auf Auswanderer, die auf Grund eines besonderen Vertrages mit Japan auswandern, noch auf deren Agenten.

$\S$ 30. Die zur Ausführung dieses Gesetzes erforderlichen Bestimmungen werden im. Verordnungswege erlassen. 
$\$ 31$. Dieses Giset\% tritt am 1. Juni 1896 in Kraft.

Dic Katiserliche Verordnunes Nr. 42 vom Jahre 1894 betreffend Auswandererschutzbestimmungen wirel vom Tare des Inkraftretens dieses Geset\%s aufigcholsen.

Als ergänzend treten neben dieses Geset\% eine Reihe von Verordnungen, von denen insbesondere die des Gaimusho (Ministerium des Aeussern) No. 3, von S. Juni 1907 wichtig ist, dis sie dic Ausfiilırungsverordnuner vorsteilt, auf die im Gesetze wiederholt verwiesen ist. Sie ist anstelle der Ausführungsverordnung getreten, dic gleichzeitig mit dem Geset\% im Jahıe I 896 erlassen wurde. Die übrigen Verordnungen und ein Koreanisches Gesetz reģeln das Auswanderungswesen in den einzelnen Kolonien.

Das Gesetz von $189^{5}$ stimmt in der Hauptsache mit der Kaiserlichen Verordnung aus dem Jalıre I 894 überein, nur waren die Strafen früher viel niedriger. Auch die Veränderungen, dic in den Jahren 1901 und 1902 mit dem Gescize vorgenommen wurden, sind nicht erleblich: nur datiert aus den Jahre 1902 die Befreiung der Auswanderer nach China und Korea von den Bestimmungen des Gesetzes. Im Jahre 1907 dagegen wurden zahlreiche und wichtige Einschübe gemacht, nämlich $\$ 5$, Abs. $z$ $\S$ I 5 b, dic ganzen Kapitel IV und V. $\$ 23$ Abs. 2 und $\$ 26$. b-2. I $\$ 95$ war also das Auswandererschutzgesetz ausserordentlich dürftig und enthielt kein Wort über Auswandererschiffe und über alle die Geschäfte, zu denen die Auswanderung Anlass gibt (Beherbergung, Geldvorschüsse etc.) Dadurch war natürlich den Agenten die Möglichiceit geboten, den Auswanderern bei jeder Gelegenheit Geld abzunehmen. Nach der letzten Redalition des Gesetzes im Jahre 1907 wurde es allerdings viel vollständiger, aber auch jetzt noch sind so grundlegende Bestimmungen wie die Bedingungen, unter denen Agenturen bewilligt und Auswanderungserlaubnisse erteilt werden, der gesetzlichen Regelung entzogen und der Entscheidung der Belhörden vorbehalten. Auffallend ist es, dass das Gesetz, das sich den Anschein gibt, als habe es nur den Schutz der Auswanderer zu besorgen, in erster Linie darauf abzielt, die Auswanderung ganz in die Hände der Regierung zu geben. Die Schutzbestimmungen sind zunäclıst mangelhaft, werden später ergänzt, bleiben aber unvollständig: dagegen ist von Anfang an die Freiheit der Auswanderung in das Ausland aufgehoben. Das Recht der Auswanderung - abgesehen von der nach China und 
Korea - haben nur diejenigen, die fest bestimmter Erwerbszweige wegen auswandern ${ }^{\text {s }}$ und eine Erlaubnis der Behörde nachweisen können. Die Erlaubnis ist aber an sachliche Erforderungen geknüpft, über deren Umgrenzung und Erfüllung die Regierung sich die alleinige Entscheidung vorbehält. Ein Recht auf Auswanderung ist niemandem gesichert, denn die Regierung ist nicht gehalten, die Reisebewilligung zu erteilen. Infolge dieser Vollmacht der Behörde ist auch nirgends festgesetzt, wer nicht auswandern dürfe, etwa Wehrpflichtige, flüchtige Verbrecher u. dergl., im Gegenteil die Behörde hat im $\S 4$ ausdrücklich das Recht zugesprochen erhalten, jedermann bedingungslos die Auswanderung zu verbieten, wenn sie dies aus besonderen Gründen für angebracht hält.

Auch sonst enthält das Gesetz nicht viel mehr als den allerdings sehr weiten Rahmen für die Verordnungsgewalt der Behörden, deren Zuständigkeit aber ebenfalls nicht zum Ausdruck grebracht ist. Die Definierung eines Auswandererschiffes und $\S$ 20. c. machen es fraglich, ob nicht auf kleineren Schiffen die Kontrolle unterbleibt: auch sind in der Verordnung des Gaimusho No. I5 vom II. Juni 1907 nicht alle Reiseziele aufgefübrt, nach denen eine Auswanderung in Betracht kommt, so dass durch Schiffwechsel in einem der nichtgenannten Reiseziele wiederum eine Möglichkeit zur Umgehung der Kontrolle gefunden werden könnte. Eine Strafbestimmung gegen cen Mädchenhandel, (analog dem $\S 48$ des deutschen Auswanderungsgesetzes vom 9. VI. I 897 ,) fehlt. ${ }^{2}$ Infolge der fast unbeschränkten Machtvollkommenheit, die das Gesetz der Behörde verleiht, fallen allerdings Lücken des Gesetzes weniger ins Gewicht, da jederzeit eine neue Verordnung erlassen, oder durch einen Verwaltungsakt eingegriffen werden kann.

Gewiss ist ein reichliches Mass von Fürsorge für die Auswanderer in Gesetz und Verordnungen enthalten. Wenn man aber die Hauptziele der ganzen Gesetzgebung zusammenfasst, so stehen neben der Humanität mindestens gleichberechtigt:

1) Nach Verordnung No. 3 des Grimusho vom 8. VI. 1907 fallen folgende Arbeiten unter $\S$ I des Gesetzes: Landwirtschaft, Fischerei (ausgen. russische Gewässer und Sachalin), Minenarbeit, Industrie, Hoch- und Tiefbau, Transportwesen, Baugewerbe, Speisenbereitung (Köche), Wäscherei, Näherei, Haarpflege, häusliche Dienste, Krankenpflege.

2) $\mathrm{Ob}$ das allgemeine Strafgesetzbuch in $\$ 8 \mathrm{I} 82 \mathrm{u}$. $224 \mathrm{ff}$. ausreichende Handhaben gegen den Mädchenlıanłlel gibt, vermag ich nicht zu beurteilen. 
Wahrung des nationalen Ansehens in Auslande und Schut\% vor Entfremdung der eigenen Untertanen. Der Bericht des Commissioner of Labor on Hawaii," gribt diesen Eindruck wie folgt wieder: „, Dic Politik cler Recricrung mit Bezug auf ihre Untertanen, dic im Auslande Aufentluatt nelumen, ist empfehlenswert. Japan unternimmt es, seine unerwünscliten und bedürftigen Untertanen unter eigene Kontrolle \%u nelimen, und übernimmt die Verantwortung für alle seine Leute, ganz gleich, wo sic sich aufhalten, wenn sie nicht selbst für ihren Unterhalt aufkommen können. Soweit es möglich ist, sich auf den nationalen, japanischen Standpunlit zu stellen, ist er mach Aeusserungen von Japanern der, tass ihr Vaterland, wic sie slauben, durch die Entehrung oder Erniedrigung seiner Angehörigen im Auslande selbst entehrt oder erniedigt werde, und dic wichtigste Aufgabe der Auswanderungsgesetzgebung schcint ihnen zu scin, dic Rückkehr derjenigen sicher zu stellen, die durch ihre Handlungsweise oder durch Unglück unwillkommene Güste fremder Länder werden liönnten........ Die Fürsorge für das Wohl des Auswanderers erfolgt teilweise unter der Voraussetzung, dass der Japaner, der sein Vaterland verlässt, dem Mikado die Treue bewahrt und nicht auswandert, um scine Staatsangehörigkeit aufzugeben oder sich dauernd in der Fremde anzusiedeln." Darin sind sich Regierung und offentliche Meinung einig, dass der Japaner im Auslande ebensogut Japaner zu sein und für sein Vaterland zu arbeiten habe, wie jeder Japaner im Inselreiche selbst. Es ist gewiss beneidenswert, dass es den Bemühungen der Regierung sowie dem Patriotismus der Bewohner Dai Nippons gelungen ist, bisher jeden Volksverlust durch Auswanderung zu verhindern. Dass dieser Vorteil auch Nachteile in Gefolge hat, dass er z. B. die wirtschaftlichen und kolonisatorischen Erfolge gefährdet, die Deutschland mit dem Verlust von Millionen deutscher Bürger bezahlt hat, gehört auf ein anderes Blatt.

So einig Regierung und offentliche Meinung aber auch grundsätzlich sind, wenn es den Vorteil Japans gilt, so war die Regierung doch in der Auswanderungspolitik stets selbständig genug, um ihre Entscheidungen auch unbekümmert um populäre Strönungen zu treffen. Das war insbesondere der Fall, als sich eine Beschränkung der Auswanderung als nötig erwies. Zuerst geschah dies I90I. Damals verbot die Regierung durch Einführung einiger neuer Bedingungen für die Erlangung von

1) Report 1905. S. I +8 . 
Auslandspässen den Unbemitteiten praktisch, wenn auch nicht der Form nach, die Auswanderung nach dem Festland der Vereinigten Staaten, um zu verhindern, dass die Amerikaner ihre Untertanen ähnlichen Ausschliessungsmassregeln unterwerfen wie die Chinesen. Mit Rücksicht auf die gleichgerichteten Vorkehrungen Japans sahen auch tatsächlich die Vereinigten Staaten von einer Ausschliessung ab, mussten aber bald benerken, dass die japanische Einwanderung nicht nur nicht aufhörte, sondern sogar zunahm. Die Auswanderungsgesellschaften beförderten ihre Kunden jetzt auf dem Umwege über Hawaii, Kanada und Mexiko, zum Teil, wie es scheint, heimlich, so dass den Amerikanern, die nicht mehr imstande waren, die Einwanderung $z u$ kontrollieren die ganze Sache höchst verdächtig wurde. Es fehlte nicht an Beschuldigungen der japanischen Regierung, der man absichtliche Umgehung des Abkommens vorwarf. Indessen scheint sich diese ganz neutral verhalten zu haben, ja sie gab, wenn es darauf ankam (z.B.in Hawaii durch ihren Generalkonsul), deutlich bekannt, dass sie auch von ihren Untertanen eine Einhaltung des von ihr gegebenen Versprechens erwarte. Mehr geschah allerdings nicht, wohl weil man der Auswanderung damals noch sehr freundlich gegenüberstand, allerhand wirtschaftliche Vorteile von ihr erwartete und vor allem, weil man wahrscheinlich den Ernst des Widerstandes in Amerika gegen die japanische Einwanderung unterschätzte.

Obwohl die Auswanderung sich nach dem ersten Eingreifen der Regierung bald erholte, besonders, nachdem man den Umweg nach den Vereinigten Staaten nutzbar gemacht hatte, scheint doch genug Widerstand gegen die Regierungspolitik aufgetaucht zu sein, wahrscheinlich, weil an der Auswanderung zu viele einflussreiche Kreise interessiert waren. Vielleicht wollte man nicht nur der Auswanderung, sondern auch der öffentlichen Meinung eine Ablenkung bieten und befreite darum im folgenden Jahre (1902) die Reisenden nach China und Korea von dem Auswandererschutzgesetz, indem man sie als Nicht-Auswanderer erklärte. Man hätte ja bloss die Behörden anzuweisen brauchen, bei Erteilung von Pässen nach China und Korea etwas freigebiger vorzugehen, um denselben tatsächlichen Erfolg zu erzielen. Dass die Regierung aber lieber das Gesetz. änderte und dadurch die Auswanderer um dessen Sclutz brachte, legt die Vermutung nahe, dass das Gesetz, wie oben ausgeführt, nicht in erster Linie den Schutz der Auswanderer bezweckt, oder aber, dass man durch die Aenderung des Gesetzes auf die Oeffentlichkeit wirken wollte. 
Die weitgehende Aufsicht, dic dic japanische Regicrung in Bezugr auf das Auswanderungrswesen ausübt und die Unselbstindigkeit der Auswanderung selbst, die sich gan\% und gall von 'Tökyö bevormumelen lïsst, haben wiederholt \%u1 Vermutung Anlass gegeben, chass die Regierung dic Auswandermng hoimlich betreibe, IIIn durch sie japanische Interessensphären in Aushande und wirtschaftliche Vorteile aller Art zu erlangen. Ein Nachweis für diese Behauptung ist meines Wissens nicht erbracht worden, auch Aubret irrt, wenn er slaubt, die Führungr dieses 13:weises sei ihm geglïclit." Es sicht allerdings so aus, als ob man sich von der Auswanderung ausschliesslich Vorteile versprochen und ihre Entwicklung sehr wohiwollenden Auges verfolgt hätte. Das ist begreiflich und kann Japan nicht zun Vorwurf gemacht werden. Mit demselben Rechte, mit dem man es beschuldigt, seine Angehörigen und deren Arbeit im Auslande zu schr dem Interesse des Vaterlandes dienstbar gemacht zu haben, kinn man die Frage aufwerfen, wie denn die Vereinigyten Staaten, Kanada etc. fordern können, dass die ganze IVelt durch Aussendung einer zahlreichen Schar tüchtimer Auswanderer in ihre Gebiete zum Aufbau cines kräftigen und reichen amerikanischen, kanadischen u.s.w. Staatswesens beitrage? Die egoistische Auswanderungspolitik Japans mag in der Durchführung etwas kleinlich sein, berechtigt ist sie rom nationalwirtschaftlichen Standpunkte aus unbedingt. Auf die Dauer konnten allerdings dic Ënwanderun`sländer dem Zuströmen nicht $7, x$ assimilierender Volksbestandteile nicht gleichgültig gegenüberstehen. I905 führte der Widerstand gegen die japanische Einwanderung in Californien zu dem Schulkonflikt in San Francisco, und ein Jahr später brachen in Vancouver aus demselben Grunde Unruhen aus, die als ernste Mahnung nicht übersehen werden komnten. Die japanische Regierung zigte sich dieser heikligen Lage gewachsen. Obwohl es in den Zeitungen bereits deutliche Zeichen des Unwillens gab und vielen japanischen Patrioten die Zeit zu einer Abrechnung mit den Vereinigten Staaten gekommen schien, dcren man wegen der ungünstigen Friedensbedingungen von Portsmouth grollte, obwohl das japanische Nationalbewusstsein sich schwer gekränkt fühlte, behielt man an der entscheidenden Stelle in Tōkyō den Kopf kühl. Welche die Erwägungen waren, die damals die Haltung der Regierung bestimmten, und wie der Verlauf der Verhandlungen im Einzelnen war, kann 
man natürlich nicht wissen. Das Ergebnis beweist jedenfalls, dass man sich in Japan klar darüber war, dass es kein Recht auf eine Einwanderung in einen fremden Staat gibt, und dass eine Auflehnung gegen die Einwanderungspolitik eines souveränen Staates unbedingt zu kriegerischen Verwickelungen führen muss. Die aufgeregte offentliche Meinung wurde also nachdrücklichst beschwichtigt, und es kam zu einer Verständigung zwischen Japan und den Vereinigten Staaten, derzufolge diese davon absahen, irgend welche Einwanderungsbeschränkungen für Japaner einzuführen, durch die deren Nationalgefühl geliränkt werden könnte. Dafür versprach die japanische Regierung, dass keiner ihrer Untertanen aus der Arbeiterklasse die erstmalige Erlaubnis zur Auswanderung nach den Vereinigten Staaten erhalten sollte, während alle übrigen, sowie die von einer Unterbrechung ihres Aufenthalts in Amerika zurückkehrenden Japaner, Reisepässe mit Angabe des Reiseziels mitbekommen sollten. Die Vereinigten Staaten wiederum verpflichteten sich' durch Zusatzabkommen zu Sektion I des Gesetzes vom 20. II. 1907 und eine Erklärung des Präsidenten Roosevelt von 14. III. I907 betreffend "Japanese and Korean Laborers skilled and unskilled," der Einwanderung von solchen Leuten, die mit Pässen für das erreichte Reiseziel versehen sein würden, keine Hindernisse in den Weg zu legen, verboten aber gleichzeitig die Einwanderung aller andern. Die japanische Regierung sah ein, dass sie auch die-selbst durch längeren $Z_{\text {wischenauf- }}$ enthalt unterbrochene-Auswanderung auf Umwegen unterbinden müsse, um ihr Versprechen einhalten zu können, und sie übernahm es daher, auch die Auswanderung nach Hawaii, Kanada und Mexiko auf gleiche $:$ eise einzuschränken. Mit Kanada wurde übrigens gleichfalls verhandelt, noch bevor eine ähnliche Missstimmung wie gegenüber den Vereinigten Staaten ausgebrochen war, was u.a. dem Uinstande zuzuschreiben ist, dass Kanada einen Teil des Japan damals engverbündeten Englands bildet, und man in Japan sehr bemüht war, die politische Freundschaft mit diesem nicht $z u$ trüben. Die Verhandlungen mit Kanada, die in Tökyō geführt wurden, kamen viel rascher zum Abschluss als die mit den Vereinigten Staaten, denn auch von seiten Kanadas musste man entgegenkommend sein,. da es als Teilnehmer am englisch-japanischen Handelsvertrag den Japanern unbeschränkte Freiheit der Einwanderung zugesichert hatte. Man kam ziemlich bald zu einem formlosen Uebsrein- 
kommen, in cem Japan sich \%u cincm Verzicht auf das Recht der freien Ginwanderung bercit erklïrte.

Dic Durchfiulurung der versprochenen Abstellung der Auswanderung aus Japan geschah schr energisch. Dic Gesetzgeblung wurde in der schon erwïhnten IVeise geindert und ereränet, den Auswanderungsagenturen wurde die sofortige Erlegung. einer erhöhten Kaution von 50000 Yen vorgeschrieben, was einer Sisticrung cines Teiles der Agenturen gleichliam, die Ueberwachung des Auswanderungswesens wurde verschärft, einige Gesellschaften wurden unterdrückt, und die Ausgab= von Pässen wurde aufs schärfste eingeschränkt. Dic Zahl der Auswanderer fiel dementsprechend von 1905 auf $1907 \mathrm{um}$ mehr als die Hälfte und ging auch in den folgenden Jahren immer mchr zurück. IViederum hiess es in der Presse, das Abkommen wäre auf Seiten Japans nicht eingehalten, aber heute ist diese 13chauptung vollkommen widerlegt und der Beweis dafür geliefert, class die japanische Regierung nicht nur willens, sondern auch imstande war, die Auswanderung ganz in der Kontrolle zu behalten. Natürlich konnte die Auswanderung nicht plötzlich abgeschnitten werden. Es wurden olnehin vicle Interessen durch ihre gewaltsame Einschnürung verletzt, und die Regierung, der ja an der Ausbreitung von Handel und Schiffahrt, an der Verbesserung der Handelsbilanz durch die Geldsendungen aus dem Auslande und an manchem andern liegen musste, bemühte sich, für - das verlorene Auswanderungsziel Ersatz zu finden. Sie veranlasste durch ihre Vertreter im Auslande und besonders hiczu entsandte Beamte die Anstellung von Untersuchungen über die Lage der Ansiedler im Auslande und über Länder, die sich zur Auswanderung eignen könnten. Diese Berichte liegen gedruckt in einer Reihe dicker Bände vor, die das Ministerium des Aeussern in Tōkyō veröffentlicht hat und deren erster in Dezember Igos ersclien. Der Inhlt dieser Bcrichte gab keine grossen Hoffnungen auf künftige Erfolge einer neuen Auswanderungsbewegung nach andern als den bisher aufgesuchten Reisezielen.

Vielleicht war das der Anlass, dass man sich in japanischen leitenden Kreisen auf die Kolonisierungsmöglichkeiten im eigenen Machtbereich besann. Zugleich war es die Zeit, wo man sich bereits mit den Vorbereitungen für die Annexion Koreas beschäftigte, jedenfalls gab am 2. Februar 1909 Graf Komura als Minister des Aeussern anlässlich einer Parlamentsdebatte über die Auswanderung eine Erklärung $a b$, die in der Presse des In- 
und Auslandes als eine programmatische Aeusserung der Regierung verstanden wurde. Sie wünscht, dass die japanische Auswanderung sich auf den fernen Osten konzentriere, nämlich auf Korea und die Mandschurei, damit sich die Japaner nicht 7.4 sehr zerstreuten und dem Vaterlande verloren gingen, auch damit nicht auf diese Weise die politischen Beziehungen zum Auslande leiden. Ein Jahr später äusserte sich Graf Komura in ähnlicher Weise, wiederum im Parlament. Diese , Konzentrationspolitik les Grafen Komura," wie man die offizielle Auswanderungspolitik von jetzt an häufig in der Presse nannte, hat grosse Debatten in der Oeffentlichkeit hervorgerufen, und allgemein hiess es, keines der beiden genannten Länder sei geeignet, einen Ersatz für Hawaii, die Vereinigten Staaten oder Kanada zu bieten. Merkwürdigerweise sieht es so aus, als ob die Regierung nichts gुetan hätte, un diese Konzentrationspolitik auch wirklich zu betätigen, ja im Frühjahr I9I I sagte man mir an zuständiger Stelle im auswärtigen Ministerium zu Tokyo, dass eine solche Politik gar nicht betrieben werde. Wenn also die Worte des Ministers nicht ein „ballon d'essai “ waren, so kann das doch nur heissen, dass sie bloss bestimmt waren, gehört zu werden, namentlich auf dem amerikanischen Festlande, auf dem man damals noch immer nicht aufgehört hatte, die japanische Einwanderung misstrauisch zu beobachten. Es wäre allerdings auch möglich, dass der von einem Teil des zweiten Ministeriums Kutsura (auch Baron Oura war dafür) gehegte Plan am IViderspruch anderer Faktoren scheiterte.

Inzwischen hat sich auch das geändert, und die kanadische und amerikanische Oeffentlichkeit ist durch die Berichte ihrer Einwanderungskommissäre darüber beruhigt, dass Japan sein Versprechen, die Einwanderung zu unterbinden, tatsächlich ausgeführt hat. Die IJaltung der Regierung unter dem 2. Ministerilim Katsura, dem Graf Komura als auswärtiger Minister angehörte (I90S-II), dürfte in der Auswanderungsfrage eine lediglich passive gewesen sein, wenigstens deutet nichts darauf hin, dass irgend eine Initiative zur Förderung der Auswanderung ergriffen wurde. Dagregen waren die Klagen der Auswanderungsagenturen ein Beweis dafür, dass tats̈̈chlich keine Auswanderungserlaubnisse erteilt wurden. Die Schiffahrtsgesellschaften, die gleichfalls zur Klage Ursache hatten, sind durch reichliche Schiffahrtssubventionen schadlos gehalten. Vielleicht gibt die Schaffung einer neuen japa!nischen Schiffahrtsverbindung nach dem Süden, von der 
viel gesprochen wird, der Auswanderung einen neuen Impuls, doch ist auf eine Massenauswanderung auch hier vorderland nicht zu rechnen. Die Auswanderungsagenturen und die übrigen Freunde der Auswanderung hatten von einem erwarteten Regierungswechsel eine weniger straffe Durchführung der Auswanderungsbeschränkung erwartet, und der Regierungrswechsel, der den Botschafter in Washington, Baron Uchida anstelle des Grafen Komura in das Ministerium des Acussern brachte, ist im Herbst I9 I auch wirklich eingetreten. lis scheint mir aber ganz unwahrscheinlich, dass dic Auswanderungspolitik der Regierung sich in den nächsten Jahren deswegen ändern sollte, da dazu kein sichtbarer Anlass vorliegt, während dic Regierung sich durch nene Verträge nit den Vereinigien Staaten NordAmerikas und Kanada gebunden hat. Fast nur versuchsweise hat das ausw. Ministerium unter Uchida die Erlaubnis zu kleinen Transporten von insgresamt etwa 2000 Leuten jährlich nach Südamerika freigegeben. Im übrigen sucht man weiter nach neuen Auswanderungszielen, doch nur solchen, wo kein zu niedriger Lohn bezahlt wird. Man will anscheinend das Entstehen eines japanischen Kuliarbeiterstandes in Auslande verhüten, treibt also eine energische Prestigepolitik, die zugleich beweist, dass die Uebervölkerung im Lande nicht schlimm sein kann, oder aber, dass man nach dem Wohl des untern Volkes nicht fragt. Das letztere scheint nir allerdings für die japanische Politik charakteristisch zu sein.

In Februar I9I I kam ein neuer Handelsvertrag zwischen den Vereinigten. Staaten und Japan zustande, in dem kein Wort von einer Einwanderungsbeschränkung für Japaner enthalten ist. Die Weglassung jeder derartigen Klausel wurde von der japanischen Diplomatic als ein grosser Erfolg hingestellt, während die Bundesregierung in Washington alle Mühe hatte, den Bürgern Californiens diesen Verzicht annehmbar zu machen. Dabei wurde praktisch an dem bestehenden Zustande nichts geändert, da die japanische Regierung sich durch eine besondere Erklärung: verpflichtete, auf administrativem Wege eine Finwanderung von japanischen Arbeitern nach Hawaii und dem Festlande wie bisher zu verhindern. Dies geschah so, dass Japan durch eine besondere Note anerkannte, dass durch den neuen Vertrag das allgemeine (also nicht nur auf Japaner bezügliche) Einwanderungsgesetz vom 14. III. 1907 nicht berührt werde. Tatsächlich ist Sektion I dieses Gesetzes, die bestimmt, dass die Pässe der 
Einwanderer auf ihr Einwanderungsziel lauten müssen, nur gegen Japaner und Koreaner gerichtet. Eine ähnliche Bindung erfolgte in Bezug auf Kanada, dessen Handelsvertrag mit Japan im Juli I9I I ablief. Da man in Kanada der unklaren handelspolitischen Lage der Kronkolonie wegen keine Lust hatte, den Handelsvertrag zu erneuern, beziehungsweise dem neuen englischen beizutreten, so wurde provisorisch vom I7. Juli I9I I ab eine Verlängerung des bestehenden Zustandes für 2 Jahre vereinbart, wobei gleichfalls eine Fortdauer der bisher beobachteten Einschränkung der japanischen Auswanderung festgelegt wurde.

Damit dürfte für die nächste Zukunft die Frage zur Ruhe gekommen sein, und wenn keine neuen Tatbestände entstehen, ist auch keine Aenderung in der japanischen Auswanderungspolitik vorauszusehen.

Das bisher von der japanischen Auswanderung Gesagte konnte meist auf ihre Gesamtheit Bezug nehmen. Im einzelnen sind aber die Schicksale der Auswanderer nach den einzelnen Gebieten sehr verschieden, so dass es notwendig ist, sie gebietsweise einer besonderen Batrachtung $z u$ unterziehen. Es ergibt sich auf diese Weise eine Einteilung der Auswanderung in 3 Gruppen: Die Auswanderung nach dem Osten (Hawaii, Vereinigten Staaten und Kanada), nach dem übrigen Ausland und nach den japanischen Kolonien. Die Unterscheidung dieser drei Gruppen berulit sowohl auf wirtschaftlichen als auch auf politischen Momenten, wie sich aus der folgenden Darstellung ergeben soll.

\section{DIE AUSWANDERUNG NACH DEM OSTEN.}

Dem geschichtlichen Verlauf nach ist naturgemäss der Verkehr zwischen Japan und dem auch heute noch viele Tagereisen zur See entfernten nordamerikanischen Kontinent der jüngste unter den drei genannten Gruppen, doch verdient er eine Voranstellung schon deshalb, weil er die wirtschaftlich und politisch wichtigste der Auswanderungen umschliesst, deren Geschick das der gesamten japanischen Auswanderung bestimmte. Auch war bisher die Zahl der nach Amerika ausgewanderten Japaner an grössten.

Für die ganze Auswanderung nach Nordamerika ist es charakteristisch, dass ihr Schicksal schliesslich von politischen Momenten bestimmt wurde, u. zw. im negativen Sinne, obwohl 
sic seiner\%eit kinnstlich in dic IVege ggeleitet worden war, und ihre Ursache dic Arbeiternot der betreffenden Gebiele war. Diese hatten teils unmittelbar, teils mittelbar, durch ihre holsen Lönue Auswanderer aus Japan an sich gezogen, und ihnen allen wirtschaftliche lirfolge verschiedener Art geboten, bis die ganze, kaum cutwickelte Nassenbewegung mit einemuale zom Stehen kam. Damit ist ein Vorgang zu einem vorläufigen Abschluss gekommen, der zugleich ein Kapitel der Arbeiterfrage auf Hawaii zum Ende bringt.

Dic Inselgruppe, die unter dem Namen Hawaii bekannt ist und in wenigen Jahrzehnten die lintwiclilung von einem prinitiven Staatswesen zur Republik unter dem Schutze der Vercinigten Staaten durchlaufen hat, stelt fast ganz unter dem Zeichen des Zuckerrolyrbaues, dem dic vielen Plantagen des Territoriums gewidmet sind. Da dic cingeborene Bevölkerung durch dic Berührung mit der abendländischen Zivilisation anscheinend zum Aussterben verurteilt ist und immer melu abnimmt, (von I $S_{53}$ bis 1910 von 70036 auf 2604 I oder von $95.76 \%$ auf $13.57 \%$ der Gesamt-Bevölkerung) $)^{1)}$ so entstand bald ein Arbeiternangel, für dessen Beseitigung Regierung und Plantagenbesitzer bis auf den heutigen Tas unermü̈llich tätig sind. Es gibt wenig Volksstämme deren Eignung zur Besiedlung der Insel nicht versucht worden wärc, ja die ganze Geschichte der Arbeiterschaft auf Hawaii erscheint wie cin fortgesetzter Laboratoriunsversuch.

Auf dicsem Hintergrunde ist das Schicksal der japanischen Einwandcrung doppelt interessant, weil es auf kleinen Raum die Vergleichung der japanischen mit den Arbeitskräften beinahe der ganzen Welt gestattet. Als oben von der Geschichte der japanischen Auswanderung die Rede war, wurden bereits die Anfänge der Beziehungen zwischen Japan und Hawaii erwähnt. Die Könige der Inseln, die Pflanzer und die Missionäre, die einen grossen Einfluss auf die Geschichte der Inseln hatten, suchten nach einem Bevölkerungsersatz, der der eingeborenen Rasse ähnlich sei und wandten sich bald nach Japan, wo sie in Jahre I884 eine prinzipielle Einwilligung der Regierung zu einer Auswanderung nach Hawaii erlangten. Bald folgte ein formeller Vertrag hierüber zwischen den zwei Staaten (Jan. I S86) und ein Arbeiterübereinkommen, das die japanische Regierung zur Vermittlung von Arbeitern verpflichtete. Die japanischen

1) Fourth Report of the Commissioner of Iabor on Hawaii. I910. Washingtion I9II. S. II. 
Auswanderer mussten sich für 3 Jahre schriftlich binden und erhielten einen Lohn von $9 \$$, und $6 \$$ ausserdem fiir Lebensmittcl. Der Kontrakt konnte nach seinem Ablauf für weitere 2 Jahre verlängert werden. Für je roo Männer sollten 30 Frauen mitgenommen werden, und die Fragen der Gesundheitsund Rechtspflege, der Rückbeförderung im Krankheitsfalle waren genau geregelt. ${ }^{\text {) }}$ In Hawaii vergab die Regierung des Königs die Arbeiter an die Pflanzer, so dass die Möglichkeit einer Kontrolle gegeben war.

Man hatte früher auf Hawaii chinesische Arbeiter beschäftigt and war nit ihnen recht zufrieden gewesen, besonders da man ihnen im Monat nur I2.50 \$ bezahlte. Als aber Hawaii I876 einen Reziprozitätsvertrag mit den Vereinigten Staaten abschloss, wurde die chinesische Einwanderung eingeschränkt, und das schuf ein Vacuum, das von den Japanern ausgefüllt werden sollte. Die Geschichte der Einwanderung in Hawaii zeigt bis zum völligen Einwanderungsverbot für Chinesen i. J. I 898 ein je nach der geringeren oder grösseren Strenge, mit der dic Einwanderungsbeschränkung für Chinesen behandelt wurde, entsprechendes Nachlassen oder Zunehmen der japanischen Zuwanderung. Bis zum völligen Ausschluss der Chinesen, der eine Folge der Annexion Hawaiis durch die Vereinigten Staaten war, wurde eben das Prinzip verfolgt, dem Arbeitermangel durch "Asiatic labor " abzuhelfen, und Chinesen, Japaner, Koreaner sollten dieselbe Rolle spielen. Da die Koreaner nicht sehr zahlreich waren, die Chinesen bald ausgeschlossen wurden, während die Japaner ungehindert einwanderten und stets willkommen geheissen wurden, da sie ein brauchbares Arbeitermaterial darstellten und als Arbeiter zunächst zu keinen ernstlichen Klagen Anlass gaben, so nahm die Inselgruppe nach und nach den Charakter eines japanischen Siedelungsgebietes an. Die Zusammensetzung der Bevölkerung in den eirzelnen Jahren zeigt folgende Statistik.2)

1) Näheres s. 3. Report of the Commissioner of I.abor on IIawaii 1905. Washington 1906. Im Vertrag zwischen Japan und dem Königreich Hawaii vou I886 ist nur die Bestellung vo: Ilawaiischen Auswandercragenten in Japan und der Schutz der Auswanciercr vorgesehen. Die japanische Regierung crklärte sich prinzipiell der Auswanderung nach Hawaii gewogen. Der Vertrag sollte 5 Jahre in Kraft bleiben und stillschweigend verlängert werden können. (vergl. "Trealies and Conventions between the Empire of Japan and other Powers compiled by the Foreign Office. Tokyo 1S99. S. 365.)

2) Nach 4. Iieport etc. 1010. S. 11. 


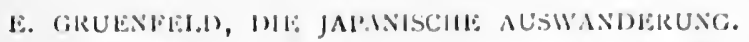

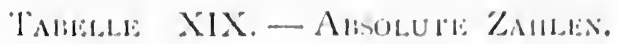

\begin{tabular}{|c|c|c|c|c|c|c|c|c|c|}
\hline R:asse. & $18 ; .3$ & $15 \%$ & 1872 & 1875 & $18 s_{1}$ & isio? & $189 \%$ & $19>0$ & 1910 \\
\hline Ilawaiivah. & 7036 & $571 \div 5$ & $10 \div 1$ & trusis & f(1) 1 & 31136 & 31019 & 29799 & 25,11 \\
\hline $\begin{array}{l}\text { Mar.ıise'ıes } \\
\text { Misolbhut. }\end{array}$ & $9 \mathrm{~S}_{3}$ & 16.4 & 1,57 & it $=0$ & 4218 & fiss & $\$ .45$ & 7857 & 12506 \\
\hline $\left.\begin{array}{l}\text { Im Anslm. } \\
\text { golooren: } \\
\text { Chinestll. }\end{array}\right\}$ & $3^{6}+4$ & 123 & 19.3 & $5916^{\circ}$ & 17937 & $15 ;$ & 19332 & 21745 & $2167+1$ \\
\hline $\left.\begin{array}{l}\text { Im Ausl und } \\
\text { feloorene } \\
\text { Japiner. }\end{array}\right\}$ & - & 一 & - & - & 116 & $12 ; 60$ & 22329 & 56230 & $79^{6} 7 \mathrm{t}$ \\
\hline Alle itlrigen. & 1755 & 2.) $\mathrm{SS}$ & $+12=5$ & $45^{6,1}$ & $1 S 29.3$ & 21707 & $27 \mathrm{SO} 5$ & $3 S_{.50}$ & 52014 \\
\hline Zusa:munen. & 73138 & 62959 & 5897 & 57955 & $\mathrm{~S} 057 \mathrm{~S}$ & 83990 & 109720 & 151001 & 191939 \\
\hline
\end{tabular}

Tabelle XX. - Prozent-Zahlex.

\begin{tabular}{|c|c|c|c|c|c|c|c|c|c|}
\hline Rasse. & 1853 & IS66 & $\mathrm{I} \mathrm{S}_{72}$ & I $S_{\gamma} S$ & I $S S_{t}$ & IS:Jo & 1896 & 1930 & 1910 \\
\hline II wwaiisch. & 95.76 & $9^{0.73}$ & 86.20 & 76.03 & 49.66 & $3 S .27$ & $28 .+5$ & $19 \cdot 35$ & 13.57 \\
\hline $\begin{array}{l}\text { Ilawaiisches } \\
\text { Mischblut. }\end{array}$ & $\mathbf{1}: 3 t$ & 2.60 & $2.6 \mathrm{I}$ & 5.90 & 5.21 & 6.97 & $7.7 \mathrm{~S}$ & 5.10 & 6.53 \\
\hline $\begin{array}{l}\text { Im Ausland } \\
\text { geborene } \\
\text { Chinesen. }\end{array}$ & $5^{\circ}$ & 1.92 & 3.41 & 10.20 & 22.26 & $17 .-$ & $17.7 \mathrm{~S}$ & I 4.12 & 11.29 \\
\hline $\begin{array}{l}\text { Im Ausland } \\
\text { sreborene } \\
\text { Japaner. }\end{array}$ & & 一 & - & - & $0.1+$ & 13.74 & 20.48 & $3^{5.5} \mathrm{I}$ & +1.52 \\
\hline Alle ïbrigen. & 2.40 & 4.75 & $7.7 \mathrm{~S}$ & $7 . S_{7}$ & 22.70 & 21.12 & 25.51 & 24.92 & 27.10 \\
\hline 7usarmmen. & 100.- & 100. & I00.- & $100 .-$ & $100 .-$ & 100.- & 100.- & $100 .-$ & $100 .-$ \\
\hline
\end{tabular}

Diese Zahlen gcben allein noch keine Vorstellung von der Bedeutung der Japaner für Hawaii, insbesondere für sein wirtschaftliches Leben; z. T. auch deshalb, weil die auf amerikanischem Boden geborenen Abkömmlinge der Einwanderer nicht mit diesen zusam:nen aufgeführt sind. Im Jahre I900, in dem der Hundertsatz der Japaner im Verhältnis zur übrigen Bevölkerung am höchsten war, waren von allen Erwerbstätigen über zehn Jahre $75.63 \%$ Chinesen und Japaner; in landwirtschaftlichen Berufen betrug ihr Anteil 9r.32\%, in den häuslichen und persönlichen Dienstleistungen 50.97\%, in Gewerbe 49.17\%, in Handel und 
Verkelı $48.68 \%$ und in den freien Berufen und Beamienstellungen I1.82\%. ${ }^{1)}$ Einzelne Wirtschaftszweige ivaren also fast ganz in Händen der Asiaten, insbesondere Landwirtschaft, Gärtnerei, Wäscherei, psrsönliche Bedienung (Kellner, häusliche Dienstboten, Raseure etc.), Haus erhandel, Bäckerei und Schneiderci. Es sind das natürlich zunächit die Berufe, derentwegen eine Versorgung des Arbeiterbedarfs rom Auslande her in dis IVege geleitet wurde; die übrigen Erworbszweige sind solche, in die die sesshafteren Einwanderer übergetreten sind, da sie in diese dank ihrer Verwandtschaft mit dem häuslichen Leben am leichtesten eindringen und sich durch grössere Arbeitsamkeit und persönliche Anspruchslosigkeit in ihnen anl raschest'n festsetzen konnten. Dieselbe Gattung von Berufen kommt fast überall in Betracht, wo verschiedene Volksstämme auf wirtschaftlichem Gebiet mit einander zusammentreffen.

Auf Hawaii haben es jedenfalls die Japaner verstanden, sich durch ihre persönlichen Eigenschaften erhebliche wirtschaftliche Erfolge zu verschaffen, umsomelrr, je weniger sie durch die Konkurrenz der noch billigeren und fleissigeren chinesischen Arbeitskräfte bedrängt wurden. Das besteuerbare Grundeigentum in japanischen Händen erreichte 1909 den Wert von I748I79 \$, verteilt auf 25I5 Besitzer. Im selben Jahre waren bereits I 34 Japaner mit einer Personaleinkommensteuer von $2002 \$$ in den Steuerlisten eingetragen, die einem Jahreseinkommen von 97930 $\$$ auferlegt war. ${ }^{2)}$

Die Arbeit, derentwegen die Japaner herübergeholt worden waren, ist die auf den Zuckerplantagen, eine anstrengende, oft unangenehme Beschäftigung, die indes wenig Gefahren und gesundheitliche Schädigungen in Gifolge hat und dem tüchtigen und zuverlässigen Arbeiter ziemlich günstige Aussichten zum Aufsteigen auf der sozialen Stufenleiter bietet. Der Monat hat 26 Arbeitstage, der Arbeitstag eine nicht genau geregelte, aber stets sehr grosse Zahl von Arbeitsstunden. Die Löhne sind auch für ungelernte Arbsiter monatsweise bemessen und: sind heute gegen die Zeit, zu der die Japaner zuerst herüberkamen, um etwa 50\% erhöht. Der Mindestlohn ist in Monat etwa I8 \$, von denen 6 bis 7 \$ auf die Ernährungskosten eines erwachsenen Arbeiters in Abzug zu bringen sind. Da die Arbeiter

1) Fourth Report. S. 12/13. Japaner und Chinesen sind hier leider oft zusammen auf gefülırt.

2) Fourth Report. 19ro. S. 15. 
aber nicht jeden Tag arbeiten, dürfte ihr regelmässiges Monatseinkommen etwas geringer sein. IVenn Japaner und Chinesen trotzlem instande sind, herumzuwandern, verhältismässig vicl für Vergnügungen aus\%urgeben und noch Gold nach der Heimat zu schicken, so liommt dats einerseits von den Prämien, dic \%ur Anspornuner des Arbeitscifers bezahlt werden, andererseits von den Einkï̈nften, die die nicht im Tagelohn, sondern im Werklohn stehenden Arbeiter beziehen und die in einzelnen Fällen einc bemerkenswerte Höhe errcichen." Dic Lohnhöh: der ungelernten Arbeiter auf den Pllanzungen ist fast ausschlicsslich auf asiatische Arbeit, unter dieser hauptsächlich auf Japaner zugeschnitten; denn diese machten in den letaten 15 Jahren 6070\% der ungelernten lieldarbeiterschaft aus. Ihre Zahl wuchs fortgeset\%t bis 1904, wo man 3233 I japanische Plantagenarbeiter zählte, nahm dann infolge des Krieges und der Auswanderung nach dem amerikanischen Festlande ab, sijes nochmals plötzlich bis auf $3277 \mathrm{I}$ im Jahre 1908 und fiel dann infolge der inzwischen getroff-nen Einwanderungsbeschränkung merkbar ab. Die Löhne sind etwas niedriger als nach del Annexion Hawaiis, die so viele Veränderuirgen brachte, sind aber seit 1905 rascher gestiegen als die Lebensmittelpreise, so dass die Lolnbewegung im allgemeinsn eine giinstige zu nennen ist.

Die nächste Gelegenheit zu einem wirtschaftlichen Aufstieg für die Piantagenarbeiter bieten die verschiedenen Handwerke, die auf den Pfanzungen betrieben werden. Der Anteil der Japaner an diesen Bzrufsstellungen sties andauernd und erreichte 1910 62.6\%. I)ie Lohnstatistik zeigt aber, dass diesem Eindringen der Japaner in die gelernten Berufe ein Sinken des Lohnes entsprach, und ein Vergleich der Durchschnittstagelöhne von japanischen und andern gelernten Arbeitern beweist, dass dieser Lohndruck ein Ergebnis der Verwendung billigerer Arbeitskräfte ist. Es sank nicht nur der Durchschnittshohn der ganzen in Rede stehenden Arbeiterschicht (von $1.78 \mathrm{~s}$ i. J. 1902 auf I.53 \$ i. J. I910), sondern auch. der Durschnittslohn für jede nichtjapanische nationale Gruppe von gelernten Arbeitern, die

1) Auf die Einヶelheiten der inter:ssanten I.ohnsysteme, die in Lawaii üblich sind, und andere Details ist hier mit Rücksicht auf das Ziel dieser Untersuchung absichtlich nicht näher eingegangen. Sie finten sich näher beschrieb:n in den Reports of the Commisso:aer of Labor on Hawaii, denen die nicht bisonders belegten Angaben ïbor diese Verhältnisie durchwegs entnommen sind. 
die Lohnstatistik verzeichnet." Darunter hatten sogar die Japaner selbst zu leiden, denn auch ihr Durchschnittstagelohn fiel von 1902 bis 1910 von 1.06 auf $1.05 \$$.

Dasselbe Bild ergibt sich für die Lohnbewegung bei den städtischen Arbeitern. Auch hier drang die Konkurrenz asiatischer Arbeitskräfte, insbesondere der Japaner, ein, und der Erfolg war ein erhebliches Sinken der Lohnsätze für gelernte Arbeiter, während für ungelernte der Lohn weiterstieg. Begreiflicherweise ist der Lohndruck besonders im freien Einkommen zu spüren: die Kosten für den notwendigen Lebensunterhalt können unter gegebenen Umständen nur wenig gedrückt werden.

Es scheint tatsächlich, als ob der Unterschied zwischen der wirtschaftlichen Stellung eines japanischen und eines nicht japanischen Arbeiters auf Hawaii ein ziemlich erheblicher wäre. Eine Lohnenquete des Arbeitskommissärs, bei der ${ }_{3} \sigma_{3}$ Arbeiterhaushalte, darunter 30 japanische, untersucht wurden, ergab als Durchschnittseinkommen für einen Arbeiterhaushalt 807.61 $\mathrm{\$}$, für einen japanischen Arbeiterhaushalt 425.06 \$.2) Der Bericht bemerkt hiezu, dass auch dieser Durchschnitt noch günstiger sei als der unter analogen Verhältnissen auf dem amerikanischen Festlande für eine weisse Arbeiterfamilie bestehende. Das Bild, das die Enquete von der Lebenshaltung der japanischen Familie auf Hawaii gibt, ist nicht ungünstig. Der Familienstand ist klein, abər nicht etwa, weil die Familien kinderlos wären. Im Gegenteil, die Zahl der kinderlosen Ehepaare ist kleiner als bei irgend einer andern verglichenen Rasse; dagegen handelt es sich noch meist um jüngere Ehepaare, so dass der Berichterstatter voraussieht, dass in einigen Jahren hier von grösserem Kinderreichtum $z u$ berichten sein wird. Die Wohnungen der Japaner sind die vollsten von allen. Während im Durchschnitt aller Rassen 0.9 Räume auf eine Person des Haushalts kommen, ist die entsprechende Zahl für die Japaner 0.4, die geringste von allen. Dagegen stehen die Japaner an der Spitze, was den Aufwand für Gesundheits- und Körperpflege anbelangt $(4.32 \$$ gegenüber einem Durchschnitt von I.S8 \$). Die Ausgaben der Japaner für Alkohol sind bescheiden. ${ }^{3)}$ Während so ihr privates Leben dem Kenner japanischer Verhältnisse wenig Bemerkenswertes bietet, erregt ihr soziales Leben umsomehr Interesse.

1) Ijie wenigen Chinesen ausgenommen.

2) Fourth Report 19ro. S. 42 .

3) Third Report 1905. S. 56. 
Was \%unïchst auffillt, ist ihr enges \%usammenhalten und der Mangel eines Zusammengehörigkeitsgefulhls mit den übrigen Inselbewohnern. O'bwohl die Japaner nur geringen Einfluss auf die öfentlichen Anerelegenheiten von Hawaii haben, tragen sie cloch viele neue Züge in das Bild seines gesellschaftlichen Lebens hinein. Sie stellen cine Arbeitcrbevölkerung dar, die cinen niedrigen Lebens-Standarel bewahrt, um ale Ersparnisse zurückzulegen und mit ihnen so bald als möglich iir die Heimat zurückzukehren. Ihr Verdienst und ilue Ersparnisse fliessen nicht de:n Gewerbfleiss der Inseln zu, tragen weder zur Errichtung von Heimstätten bsi, noch fördern sic die lintwicklung des Gemeinwesens in irgend einer Hinsicht. ${ }^{1)}$ Der Arbeitskommissär für Hawaii legt besonderes Gewicht auf den Umstand, dass nicht nur äusserlich eine Schranke zwischen amerikanischen Bürgern und den eingewanderten Arbeitern aus Asien besteht, sondern dass sich diese auch fieiwillig noch weiter abschliessen. (D. Chinesen und Koreaner in H wwait wenig zahireich sind, gilt das Gesagte hauptsïchlich für die Japanei.) So kommt es, dass alle gesellschaftlichen und wirtschaftlichen Gegensätze zwischen Unternehmorn und Arbeitern noch durch nationale verschärft werden. Es fehlt an jeglicher Gemeinsamkeit zwischen den billigen, von Asien herangezogenen Arbeitskräften und den übrigen Bswohnern der Insel, die, ob eingeboren oder eingewandert, sie doch als ihre Heimut betrachten. Namentlich entziehen sich die Japaner ganz der Einwirkung jener amerika-. nischen Lebensideale, die, aus der Geschichte der Vereinigten Staaten Amerikas hervorgewachsen, den Szhlüssel zum Verständnis ihres Gcisteslebens bilden: die bibelfeste Schlichtheit der "pilgrim fathers," die Arbeitsamkeit der Kolonisten und der unersshütterliche Glaube an die Unfehlbarkeit der demokratischen und Freiheitsprinzipien, wie sie in der Bundesverfassung niedergelegt sind. Mögen diese Ideale auch im praktischen Leben oft nur getrübt wiederzufinden sein, so sind sie es doch, die der amerikanisshen öfentlichen Meinung den Masstab fur die Beurteilung aller, so auch der wirtsshaftlichen Verhältnisse abgeben. Von diesem Standpunkt ist d.e harte Verurteilung yerständlich, der die billige Arbait der Asiaten unterzogen wird, die sich noch inmer nicht mit der amerikanischen auf eine Stufe

1) Das bruucht übrigens nicht zu bedeuten, dass die Japaner enthaltsa n $\sin 1$, die trinken ihren Sake in klein sn Q.⿲丿nt :n, vertragen aber nicht viel. 
gestellt hat. Auch dis geringe Assimilation der Japan:r an die politischen und sozialen Ideale der Bundesrepublik, ihr zāhes Festhalten an ihrer nationalen Eigenart. verdries it die Machthaber Hawaiis. Und sie müssen mit Bedauern bemerken, dass die geringe Zahl von Amerikanern kaukasischer Rasse auf den Inseln der Assimilation nur wenig Aussicht. bietet. Fin Beispiel hiefür liefert die Gestaltung des Schulwesens auf Hawaii. Die Zahl der japanischen Kinder in sämtlichen Schulen Hawaiis stieg von 1352 unter 15537 andern im Jahre 1900 auf 7078 . unter $25537 \mathrm{im}$ Jahre 1910. Wenn auch im letzten Jahre das Wachstum der japanischen Schülerschar sich etwas verlangisant hat, so ändert das doch nichts an der Tatsache, dass die japanischen Kinder gegenwärtig mehr als ein Viertel der gुesamten Schul-Bevölkerung bilden und ein grösseres Kontingent stellen als irgend eine andere Nation. Es ist klar, dass unter solchen. Umständen die Klagen über ein Nachlassen der Schulerfolge nicht verstummen wollen. Amerikanische Eltern kaukasischer Rasse, die ihren Kindern cine bessere Erziehung bieten wollen, verlassen manchmal den Sshulbezirk, und jede Schwächung der Schule hat wieder eine neue Herabminderung des Schulerfolges und damit der Assimilution zur Folge.

Uebrigens ist es bemerkenswert, mit welchen Opfern die Japaner ein ausgedehntes nationales Schuisysten erhalten. Nach dem Fourth Report etc. rgro (S. 72) gab es im Januar 1909 68 japanische Privatschulen," darunter 27 buddhistische, 8 christliche und 33 ohne konfessionellen Charakter. An diesen Schulen wurden 463r Schüler von So Lehrern unterrichtet. Am besuchtesten sind die konfessionellen Szhulen. Die Zahl der Schüler hat sich besonders seit 1934 sehr stark vermehrt. Natürlich ist die Sorgfdlt, die von den Japanern auf eine nationale Erziehung ihrer Kinder verwendet wird, ein weiteres Hindernis für deren Amerikanisierung, und so sehr man den Patriotismus der Japaner bewundern muss, so ist es andrerseits auch begreiflich, dass den Amerikanern diese Verhinderung der Assimilation nicht passt. Die intellektuellen Führer der Japaner auf Hawaii scheinen sogat in der Förderung des nationalen Gedankens manchmal recht weit zu gehen. Professor Nitole,

1) Vortrïge des Prof. Nitobe in San Francisco, dic in Jitsugyo no Nihon wie lererzählt sind un $l$ äh $r$ die $d \cdot r$, Japan Advertis:r “, Tokyo, vom 9. XI. 1911 berich et. 
der gerale auf ciner Vortragseise in den Vereing gten Stanten Nord-Amerikis wcilt, hatte, wie er in einer Ansprache an seine Lindsleute eryihle, wiederlolt Anlass, den Chauvinismus von Jupanern zu tadeln. Auf Hawaii sei ilum sogar von einem L shrer ein Lehrbuch \%ur Begutachtung vorgelegt worden, das den japanischen Kindern politische Gedunken sehr beckenklicher Art mit Bezug auf dic Zukunft des Territorimms cinzuprären versuclut, und von dem Nitobe bemerkt, es sci nur grut, dass es der schwieriyen Sprache wergen von den Amerikinern nicht scelesen werden kömue."

Abgesehen von ihrer Nichtassimilicrung, dic cloch nur von einem bestimmten Standpunkte aus als fiehler angeschen werden kann, ist gegen die Japaner als Minschen und Arbeiter wenir einzuwenden. Man lobt sogar ilure körparliche Reinlichkeit, ihre stark entwickelte Lernbegierde, ihren festen Vorsatz sich weiter\%ubringen, die Art, wie sie fir ihre Bedürftigen sorgen, ihren Gehorsan gegenüber den Gisetzen; dis Unternehmer schätzen sie als eifrigs und geschickte Arbeiter, und nur im Gewerbe wird öfers behauptet, sie brauchten cine fülurung durch Kaukasier, um ihr Bestes zu leisten. Der genossenschaftliche Gedanke ist unter ihnen sehr entwickelt, und sie cignen sich daher beso:aders gut zur Uebermahme von Kontraktarbeit in Gruppen, fur deren Bildung sie cine gros:e Neigung haben. Es heisst sogar, dass sie sich oft ihrer nationalen O:grmisation bellienen, um irgend einen Gewerbszwei unter ilure , Kontrolle." $\mathrm{zu}$ bringen oder irgend welche wirtschaftlichen Vortcile zu erringen, die ilmen dank ihrer wirtschaftlich-n itionalen Gruppierung sicher zufallen müssen. Natürlich fehlen diesem Bilde der Japaner nicht einige Schatten. So klagren die Unternehmer, dass die japanischen Arbeiter sehr empfinslich seien, insbesondere in allem was ihre Persönlichkeit u.ul Vationalität angeht, dass sie unbeständig seien und ihre Lernbegierde allzuleicht in Neuerungssucht umschlagen lassen. Als Kaufleute und bei Veıträgen zieht man ilusen di. Chinesen vor, die als sehr zuverlïssigr gelten; aber der stirkste Vorwurf. der den Japanern gemacht wirl, ist, dass sic überall dort, wo sie die Uebermacht haben, herrschsüchtig und unverträglich sind."

1) Ein japunischer Bericht (in Bd. 9 dir Sammlg. von I'erichten übar Auswanderung, veröffentlicht vom Gaimusho, März 1912) spricht von 96 japanischen Schulen!

2) Vergl: Aubert und dic Reports passim. 
Vom japanischen Standpunkte aus sind mir nur zwei ausführliche Berichte zur Hand, die das Gesagte z. T. bestätigen, ihm jedenfalls nicht widersprechen'). Auch Ogawahira betont in Anlehnung an japanische Konsularberichte das stramme Zusammenhalten der Japaner und hebt hervor, dıss die Neuankömmlinge den Angesessenen Konkurren\% machen. Die Auswanderer aus den Städten bewähren sich weniger als die aus den Landbezirken. Diś Moral der Frauen scheint dem japanischen Beurteiler zu missfallen, doch äussert er sich darüber ebensowenig, wie über vieles andere. Er belilazt, dass die Japaner so wenig Vergnügungen auf Hawaii hätten, erwähnt aber zugleich die stattliche Menge von gesellschaftlichen und Zweck-Verbänden auf den Inseln, auf denen auch 8 japanische Zeitungen und 3 Zeitschriften erscheincn. Nakamura schildert die Verhältnisse günstiger.

Im allgemeinen hat man sowohl in Japan wie in Amerika die Ueberzeugung, dass die Japaner auf Hawaii ein, wenn auch nicht müheloses und glänzende;, so doch zufriedenstellendes Auskommen finden, das ihnen dic Zurücklegung namhafter Ersparnisse ermöglicht. Dass sie auch Gelegenheit hatten, sich von Plantagenarbsitern $z u$ höher bezahlten Stellungen aufzuschwingen, ist bereits erwähnt worden. Hier mögen noch einige Ausführungen über das wirtschafcliche $\Lambda$ ufsteigen der Japaner Platz finden, weil dieses erst die Schärfı des Gegensatzes erklärt, der sich zwischen ,, weisser “ und ,gelbər " Bevölkerung zu entwickeln begonnen, und die Einschränkung der japanischen Einwanderung vorbereitet hat. Mit der Annexion Hawaiis durch die Vereinigten Staaten wurden die Arbeitskontrakte nach hawaiischem Recht, die dic Arbeiter auf den Plantagen zu einer Art von Hörigen gemacht hatten, abgeschafft. Das kam namentlich den Japanern zugute, die boi ihrem grossen Fleisse, ihrer Lernbegi 2 rde und ihrem khrgeiz buld in die Stellungen der Handwerkir auf den Plantagen einzudringen begannen. $\mathrm{Zu}$ gleich brachten die Auswandererschiffe aus Japan auch schon städtische Elemente mit kleinen Geldvorräten, und in kürzester $Z \doteq i t$ bekamen de kleinen Gewerbetreibenden und Händler die Konkurrenz der Japaner z 1 spüren, die auf den meisten Posten, der Billigkeit des japanischen Haushalts wegen, unwiderstehlich

1) Ogawahira a. a. O. 8. Wapitel und der o.):n genannte 9. Beichtband des Ga aumusho, enthalten.l cinen Bericht ïber dic Insel Maui von Nakamura. 
war. A's den l'lantaeren wa cine Konkurren\% japanischer Arbeit nie vorigelionmen. lis herschte stets ein lebhafter Bedarf an Absitskraften, und da die Einseborenen sich rasch an Zahl verminderten, war jeder Necamkiammling sern greschen. Anders war es in Handel und Gewerbes, wo die Kilhl der Erwerbstätigen eine viel geringere war. llier grab es eine sehr beschräukte Aufnahmefïhigkeit für den \%uwachs, und win erfolgreicher Bewerber beleutete bald den Verlust des Einkommens für die früher tätig gewesenen. Der Berieht des Arbeitskommissärs für I905, (le1 die Iorage der japanischen (und chinesischen) Konkurrenz fü den angessenen Mittelstand sshr crust beurteilt, bringt fü̈ diesen Vorgang cine grosse Zahl vo: Belegen. In 7 Betrieben des Bumewerbes z.13. rring die Zahl cier beschäftigten, nicht asiatischen, gelernten Arbeiter von I903 bis 1905 von I 59 auf 43 herunter. Aehnlich in andern Füllen. Ueberall drangen die Japaner und Chinesen vor und erlangten cine wichtige Stellung, wenn nicht das Monopol innerhalb des Berufes, ausgenommen in einigen Gewerben, wie Druckerei (in englischer Sprache), Verfertigung von Maschinen für Zuckermühlen, elektrotechnischen Arbiten schwicriger Art, Brauerci u. dergl. Abgeschen von geringeren Lebensansprïchen, längerer Arbeitszeit u.s.w. var das Hauptmittel zur Erreichung dieses Zieles Billigkeit der Preise, die nur durch die Billigkcit der Arbeitskräfte erzielt wurde. In einigen Fällen wird auch die Ware als minderwertig bezeichnet, doch ist es klar, dass mit minderwertigen Waren allein auf die Dauer ein Konkurrenzkampf nicht zum Siege geführt werden kann, wo nicht eine Differenzierung des Konsumentenkreises stattfindet. Japanischen Käufern gegenüber schadet z. B. eine Verschlechterung der Qualität von zum Verkauf gebrachten curopäischen Nahrungsmitteln nicht viel, wenn nur der Preis niedriger wird. Natürlich sind zunächst die grossen, kapitalkräftigen Unternehmungen mit anspruchsvollem Käuferkreis weniger bedroht, und der Bericht bemerlit ganz folgerichtig, wie die Erbitterung der befragten Gewerbetreibenden und iłändler über die uncrbittliche Konkurrenz der Japaner und Chinesen an Heftigkeit sich umgekehrt verhalte wie der Geschäftsumfang der Auskunftspersonen.

Noch.cin Gebiet des wirtschaftlichen Lab:ns gibt es, auf dern in Havaii ein Monopol der Asiaten drohte: die Landivirtschaft als kleiner und mittlerer Betrieb. Bisher hatten derartige Betriebe auf Hawaii noch wenicr Raum gefunden. Es scheint, 
dass bei den hohen Lebensansprüchen der amerikanischen und eingewanderten europäischen Bevölkerung der Betrieb sich nicht lohnte, und ein Reinertrag da von nicht erzielt werden konnte. Dagegen haben insbesondere Japaner sich sehr gut zu behaupten verstanden und sind beinahe die Herren im Kaffee-, im Ananasund Bananenbau. Im Jahre 1900 gab es bereits 1203 Asiaten als lileine Iaandwir.e, und ihre Zahl soll beständig im Wachsen begriffen sein. ${ }^{\prime}$ Gerade auf diesem Gebiete trifft das Vordringen der Japaner und Chinesen die staatsmännischen Wünsche der Amerikaner sehr hart, denn man hatte gehofft, durch Schaffung kleineren Grundbesitzes eine bodenständige amarikanische Bevölkerung $z \mathrm{u}$ gewinnen, den Grundstock zum Aufbau eines kraftvollen, demokratischen Gemeinwesens, für das von den Plantaren wenig zu erwarten war. Nun schwand auch diese Hoffnung, und die Aussichten, die sich für dic Bevölkerungsfráge des Territoriums eröffneten, wurden immer trüber. Diesen Eindruck gibt bisonders dər Bericht des Arbeitskommissärs für 1905, wieder, der letzt: Bericht, bevor eine Aenderung der Einwanderungsverhältnisse herbeigeführt wurde.

$\mathrm{Zu}$ einer solchen Massnahme drängten al!erhand Strömungen: der Miltelstand, der sich vergebens gegen dic billige Konkurrenz zu verteidigen suchte und der auch auf dem Wege der O.ganisation erfolglos geblieben war, die Simmen derjenigen, die den amerikanischen Charakter des Territoriums als gefährclet hinstellten, dic auf die Japanisierung der Schulen und auf die grosse Zahl junger, in Hawaii geborener Japaner hinwiesen, denen bald ein entscheidender Einfluss auch auf die politische Geschichte der Inseln zufallen müsste, und schliesslich die weniger laut vernehmlichen, aber ums w wirkungsvolleren Stimmen, die vom strategischen Standpunkt aus darlegten, wie gefahrlich es für die Vereinigten Staaten sci, den wichtigsten Stützpunkt im Stillen Ozean mit Angehörigen einer fremden Nation zu bevölkern, unter denen sich leicht Spione, ja ganze Truppenabteilungen verbergen könnten. Vielleicht wïrn aber selbst diese gewiss nicht zu unterschätzenden Gründe nicht so bald durchgedrungen, wenn nicht noch zwei Tatsachen hinzugekommen wären: Die veränderte Stellungnahme der Palnzer in der Einwanderungsfrage und die Vorgänge in Californien. Der Streik

1) Third Report etc. S. 39. Neuare Angrab ın sind auch im Fourth Report nicht enthalten. 
der Japaner i.J. $1999 \mathrm{kam}$ scho.J \%u spät, um dic Entscheiduner der geset $\%(c)$ suden Fulitoren \%u beeinflussen, er brachte aber gewissermassen die Probe aufs Exempel für das nicht unbedenliliche Monopol, das dic Japaner auf den Pfanzuneren und anderwïts erlangrt hatten, und trug viel zur lintscheidung der Frage in der Praxis bei. Prinzipicll war sic schon früher entschieden, als die Pflu\%er \%ur Einsicht genötigt wurden, dass sic an den Japanen kcine unerschöpliche Reserve an billigen Arbcitskräften hatten, deren sie unbedingt sicher sein konnten. Die Tatsichen, die zu dieser Einsicht führten, waren die Auswanderung der Japaner von Hawaii nach dem amerikanischen Festland und ihre wiederholten Streiks, bei denen sich zweierlei offenbarte: 1.) dass der Charakter der japanischen Arbeiterbevölkerung sich geändert hatte, und 2.) dass sic anfing, sich als eine Gesamtheit zu fühlen, in deren Händen die Entscheidung über das Schicksal der Pflanzungen ruhc.

Dic Auswanderung der Japaner begann etwa Igoo einen grösseren Umfang anzunehmen, als die japanische Regierung dic direkt: Auswanderung nach den Vereinigten Staaten einschränkte, und mit der Annexion Hawaiis die starrea Arbeitskontrakte fielen, die die Plantagenarbeiter serade\% an die Scholle sefesselt hatten. Zugleich lockten hohe Löhne die Arbeiter nach dem Festland, und bald entwickelte sich ein System von Agenten und anderen bei dieser IVeitcrwanderung interwsierten Leuten, die für den Fortbestand dieser Bewegung Sorge trugen. So wanderten vom I. Januar 1902 bis zum jo. September 1906 an die 30000 Japaner von Hawaii nach dem Kontinent, ${ }^{1)}$ und wenn aucl von Japan her nach dem Kriege reichlich Ersatz kam, so spürte man auf dem Arbeitsmarkt doch den Wechsel, umso empfindlicher, als die Plantagenbesitzer sich danals ganz auf die Rekrutierung ihres Arbeiterbedarfs aus Japan cingerichtet hatten. Zunächst versuchte man das Uebel einzuschränken und persönliche Einwirkungen auf die Arbeiterschaft auszuüben. 1903 war die Central Japanese League gegründet worden, an deren Spitze der japanische Generalkonsul in Honolulu stand, und die es sich zu ihrer Aufgabe machte, der Auswanderung nach dem Festland entgegenzuwirken und ein gutes Verhältnis zwischen Japanern und der übrigen Bevöl-

1) Aubert a. a. O. S. Iof; nach dem Fourth Report, S. 6o, waren die 7ah en für 1905: 9649, 1905: 12227, $1907: 513$ S. 
kerung herzustellen. Das geschah mit der ausgesprochcnen Absicht, die offizielle Auswanderungspolitik der japanischen Regierung auch in der Praxis zur Anerkennung zu bringen und das Ansehen der japanischen Arbeiter zu heben. Die Liga versuchte übrigens auch eine Art von Arbeitsinspektoren zu schaffen, wie sie in früheren Jahren die japanische Regierung, solange sie noch selbst die Arbeiter vermittclte, mitgeschickt hatte. Es zeigte sich aber bald, dass die japanischen Arbeiter nach längrerem Aufenthalte in amerikanischer Umgebung sehr an Unabhängigkeitsgefühl zugenommen hatten, und die Inspektoren erwiesen sich noch erfolgsloser als die Versuche zur Hemmung der Weiterwanderung. Die Farmer versuchten also das aussichisreichste Mittel, führten im Mai 1905 eine etwa zehnprozentige Lohnerhöhung durch, verbesserten die Wohnungsverhältnisse und sorgten für bessere Behandlung der Japaner auf den Pflanzungen. Die Regierung von Hawaii erliess im April 1905 ein Gesetz über Auswanderungsagenten, das keinen anderen Zweck hatte, als diesen das Handwerk zu legen. Im nämlichen Monat wurde durch Gesetz ein ,, Board of Immigration " geschaffen, der dazu bestimmt war "desirable immigrants" insbesondere natürlich kaukasischer Rasse zu versorgen. Schliesslich gab zur selben Zeit der japanische Generalkonsul eine Bekanntnachung heraus, in der er seine Landsleute unter Bezugnahme auf das Versprechen der japanischen Regierung und die von den Pflanzern versprochene Lohnerhöhung bittet, nicht fortzuziehen. Nach dem Mai 1905 ging die Auswanderung der Japaner tatsächlich etwas zurück, aber sie hörte deshalb doch nicht auf, wuchs sogar wieder i. J. I905. Auch gingen die Unternehmer auf dem Feitlande jetzt noch energischer vor, um sich Arbeiterzuzug von Hawaii zu sichern, mieteten ein eigenes Dampfschiff, um Japaner darauf zu transportieren u. s. w. Die Plantagenbesitzer sahen sich genötigt Ersatz herbeizuschaffen : sie begannen Koreaner anzuwerben, die von 1902 ab in grösseren Scharen einzutreffen begannen. I904 gab es bereits 2666, I905: 4583 koreanische Arbeiter auf den Plantagen. ${ }^{1}$ Aber alle diese Mittel befriedigten die Pflanzer nicht und sié gingen bereits damit um, wieder dic Zulassung von Chinesen zu verlangen, von deren billigen, stets verfügbaren und leicht $z u$ behandelnden Arbeitermassen sie sich nicht nur eine Abhilfe

1) Third Report. S. II. 
fü die herrschende Kintppheit an Arbeitskräfen, sondern auch eine Durchbrechung des Zustandes versprachen, den man in Hawaii das , japanische Monopol " namnte.

Ich habe bereits angedeutet, dass die japanische Bevolkerung Inwaiis begomen hatte, dic Sympithicn der übrigen, auf Hawaii lebenden Bevölkertungsklassen und Rassen einzubüssen, und nun auch daran war, ihren Rückhalt bei den l'flanzern, dieser in Hawaii so einflusseichen Klasse, zu verlieren. Wie das kam, ist ja \%. T. aus dem erfolgreichen Wettbewerb der Japancr und der bedrängten wirtschaftichen Lage zu crklären, in die weite Kreise anderer Einwohner des Territoriuns daduich gericten. Zum Teil scheint auch „, intra muros et extra“ gesündigt worden $z u$ sein. $A b$ und zu liessen sich Klagen darüber vernchmen, dass die Japaner auf den Pflanzungen hart behandelt würden, und wiederholt mussten nichtjapanische Aufseher entlassen oder gestraft werden. Andrerseits zeigten die Pflanzer meist grosse Bercitwilligkeit, den berechtigten Forderungen ihrer Arbeiter entgegenzukommen. Gerade bei den Forderungen der japanischen Arbeiter war übrigens stets eine genaue Erwāgung erforderlich, denn es wird allgemein berichtet, dass diese oft leichtherzig, ja ziemlich oft auch ganz grundlos erhoben wurden, und dass namentlich eine sehr weitgehende Empfindlichkeit persönlicher und nationaler Art wiederholt den einzigen Anlass zu Beschwerden bot. Im allgemeinen hatte man wenig Ursache über die Japaner zu klagen, nur beobachtete man, dass sie durch längeren Aufenthalt in Hawaii nicht gewönnen, und die kaukasischen, z. T. auch die hawaiischen Arbeiter entschädigten sich für die wirtschaftlichen Schäden, die ihnen ihre Konkurrenz bereitete, durch ein stark betontes Ueberlegenheitsgefühl, das die gekränkten Japaner wiederum mit wenig verhüllter Abneigung erwiderten.

Das alles äusserte sich klar in den Streiks, die die Japaner seit der Aufhebung der Arbeitsliontrakte in imner rascherer Folge wiederholten: I90 I und 1902 gab es je einen, 1903 zwei, 1904 fünf Ausstände und fünf weitere in den ersten 5 Monaten des Jahres 1905. ${ }^{1)}$ Der grösste folgte am Schlusse der ganzen Reihe im Jahre Igog auf der Insel Cahu und kostete die Pflanzer schätzungsiveise 2000000 \$.?

Den Streiks war es fast durchaus eigentümlich, dass sie 
keine typischen Arbeiterausstände waren, die Klassenbewusstsein oder gar Klassenhass zeigen und bloss auf Besserung der wirtschaftlichen Lage oder Anerkennung der Organisation abzielen und den Kampf zwischen Unternehmer- und Arbeiterinteressen auf einem bestimmten Gebiete ausfechten wollen. Meistens handelte es sich um eine Reihe kleinerer Strcitpunkte, die bei irgend einer Gelegenheit plötzlich alle zum Aulass von Forderungen gemncht wurden. Immer wird der Streik auf nationaler Basis durchgeführt, bewegt sich äusserlich ganz in gesctzlichen Formen, bringt meistens keine Gewalttaten gegen Unternehmer, deren Angestellte oder Eigentum mit sich, beweist aber, dass die Japaner der naiven Ansicht sind, sie könnten, wenn auch unter amerikanischem Gesetz, mit ihren Landsleuten nach ihrem Gutdünken umspringen. Sehr häufig war der Anlass zu einem Ausstand die Beleidigung eines einzelnen Japaners durch einen Aufseher oder irgend ein ähnliches Vorkomnınis, durch das sich alsbald die gesamte japanische Arbeiterschaft verietzt fülite. Einigemale kam auch der Anreiz zur Widersetzlichkeit von Nichtarbeitern, zum Beispiel Gastwirten und ähnlichen Leuten, die dabei ihren Vorteil fanden. Die Zahl der Streiks nahm ständig $z u$, obwohl die Ceniral Japanese League, die 1903 gegründet worden war, sich alle Mühe gab, Ausstände zu verhüten, Unfrieden zu bsseitigen und die Bezichungen zivischen Plantagenarbeitern und Planzern zu verbessern. Aber, wie bereits erwähnt, waren die Japaner, die schon zu viel vom Auslande angenommen liatten, meist den Argumenten der Liga wenig zugänglich.

Der Streik von 1909 war zwar hauptsächlich auf Erhöhung des Lohnes gerichtet, aber sein Verlauf ist trotzdem für die ganze Stellung der Japaner auf den Pflanzungen so charakteristisch, dass ich einiges über ihn mitteilen möchte. Seine wichtigsten Merkmale waren nach einer im Bericht des Arbeitsliomnissärs wiedergegebenen Zusammenfassung ${ }^{1)}$ die folgenden:

I.) Die Stimmung für ilhn wurde durch eine Agitation vorbereitet, die nicht von den Arbeitern selbst, sondern von gebildeten japanischen Journalisten und Geschäftsleuten in Honolulu ins Leben gerufen wurde.

2.) Die Bewegung trug von Anfang an einen nationalen Charakter, wurde aber von den gebildeten Japanern nicht durchwegs unterstützt.

1) Fourth Report S. $62 \mathrm{f}$. 
3.) Der Ausstind wurde von cincr Organisation geleitet, die von gebildeten Japanern grelenkt wurde; die führer waren also nicht selbst Arbeiter, wie dies b.i den in Anerika bekannten Gewerkschaftion der liall ist.

4.) Die lionderungen der Streiker lauteten atuf höhere Entlohnung der feldtagclöhner und wurden clamit begründet, dass die Pllanzer den Arbeitern kankasischer liasse unter gkeichen Bedingungen cinen um ein Drittel höheren Lohn zahlten als den Asiaten.

5.) Es gab genügend angesessene Strikbrecher, meist Hawaianer und l'orturgiesen, die sich $\%$ einem Tagelohn von I.50 \$ in der Umgebung von Honolulu anboien, um die Arbeiten auf den Pflnzungen weiterzuführen.

6.) Ausgenommen gegen Strikbrecher und Streiligegner ihrer eigenen Nation, verhiclten sich die Japzner im Streik ganz ordnungsremiss, d.h. sie begingen kcine Gewalttätigkeiten und zerstörten niclits.

7.) Der Ausstand fund cin Ende, weil die Streiker finanziell zu schwach waren, und weil ihre Führer sich gegen ihre japanische Opposition so benahmen, dass sie mit dem Gesetze in Konflikt gerieten.

8.) Nach dem Ausstand wurde die Lage der japanischen Arbeiter verbessert, und sic haben jetzt mehr Einkommen als rüher.

9.) Der Umstand, dass japanische Aufseher und qualifizierte Arbeiter sich bei einem Streik, der hauptsächlich auf Feldarbeiter Bezucr hatte, ihren Lindsleuten anschlossen, hat einige Betriebsleiter dazu veranlasst, nac's und nach Kaukasier und Hawaiianer anstelle von Japanern auf diese Posten mit höherer Verantivoriung zu stellen.

Io.) Die Vertreter der japanischen Regierung unterstützten oder ermutigten die Ausständischen auf keinerlei Weise.

Durcluliest man die Forderungen der japanischen Arbeiter, wie sie von der Japanese Higher Wage Association in einer sauberen Denkschrift vorgebracht wurden, so gewinnt man den Eindruck eines verständigen, wohl begründeten Anliegens. Die Beweisführung war kurz die, dass aus der Steigerung der Lebenskosten, dar zunehmenden Sesshaftigkeit der Japaner, derzufolge Frauen, Kinder und soziale Lasten (Schulen, Kirchen, Tempel) zahlreicher werden, die Notwendigkeit, aus der gleichen Arbeitsleistung japanischer und amerikanischer Arbeiter die 
Bereshtigung höherer Löhne abgeleitet wurde. Der verlangtc Lohn war ein Minimallohn von $22.50 \$$ monatlich, wie ihn die nichtjapanischen Arbeiter tatsächlich erhielten. Das hört sich alles sehr gut an, und es macht den Japanern alle Ehre, dass sie ideale Momente, wie die nationale Gleichstellung aller Arbeiter und die Notwendigkeit der Aufwendungen für kulturelle Bedürfnisse, in den Vordergrund stellten. Als der Streik ausgebrochen war, wurden übrigens au den einzelnen Pflanzungen noch cine Reihe untergeordneter, vorher nicht erwähnter Forderungen aufgestellt.

Der Ausstand, für den mehr als ein halbes Jahr agitiert worden war, brach im Mai 1909 auf mehreren Pflanzungen aus und währte mit verschiedener Stärke bis in den August. Die Pflanzervereinigung weigerte sich mit den Ausständischen zu verhandeln, solange sie nicht zur Arbeit zurückkehrten, und wartete $a b$, bis den Streikern das Geld ausging. Diese standen inzwischen auch unter dem Einfluss der Streikgegner, zu denen die oberen Schichten der japanischen Bevölkerung mit dem Generalkonsul an der Spitze, die Kaufleute und 6 von den bestehenden I I japanischen Zeitungen gehörten. Schliesslich verlief sich der Ausstand im Sande, die Anführer kamen wegen ,, conspiracy " ins Gefängnis und die 6 streikfeindlichen Zeitungen gaben der ganzen Sache einen Abschluss durch Erlass einer längeren Kundgebung gegen den Streik, seine Führer und die findlichen Zeitungen. Diese Kundgebung beantworteten die Pflanzer durch eine weitere, in der sie den Lohnforderungen der Streiker fast ganz nachgaben. Dies geschah in November Igog.

Aus diesem schliesslichen Nachgeben könnte man entnehmen, dass der Streik Erfolg gehabt hat, und die aufgestellten Forderungen berechtigt waren. Jedenfalls würden sie nirgends in den Vereinigten Staaten oder in Europa unbillig genannt worden sein; ebensowenig hätte man dort daran gedacht, den Arbeitern aus ihrer Streikbereitschaft einen Vorwurf zu machen. Für Hawaii und japanische Arbeiter ist es aber gerade charakteristisch, dass das Verhältnis von Unternehmern und Arbeitern auf den Pflanzungen noch keinesivegs ganz vom Geiste des Kapitalismus durchtränkt war. Die Arbeiter waren meist Asiaten, die mit Unterstützung der Pflanzer, beziehungsweise des Einwanderungsamtes, herübergekommen waren, um billige Arbeit zu leisten und dadurch ein Planzungssystem aufrecht $z u$ erhalten, das eigentiich nicht dem Geiste der wirtschaftlichen und poli- 
tischen Ungebundenheit entspricht, wic es anf dem amerikanischen Festlande \%ü Herrschaft gelangt ist. Dieses Betriebssystem hat sich in Königreich und auch noch in der Republik Hawaii schr wohl gefuhlt. In " Curritorium" ist es schon ein Anachronisnus, vorausgesetzt, diss man denl Begrifie "Territorium" den Sinn "Bestandteil der Vereinigrten Staaten " gribt. IVill man den Tatsachen serechter werden, dann muss men interpreticren: "Kolonie der Vereinigten Staten." Das tun auch die heutigen Machthaber und sind so imstinde, einem wirtschaftlichen \%ustande Rechnung zu tragen, den die politischen Ereignisse 1900 überholt haben. Diesem Zustande entspricht das melur patriarchalische Verhältnis zwischen l'flanzern und Arbeitern, wie es bis zur Annexion auch in aller Form rechtens war. So ist den Arbeitern ein Teil ihrer Haushaltungskosten, wie Wohnung, Gesundheitsplege z. T. abgenommen, so kan man auch dazu, in einem reinen Lohnstreit mit moderner Organisation, die tatsächlich vom amerikanischen Festlande herübergebracht worden war, etwas Verurteilenswertes zu sehen, wogegen sich selbst die besseren Japaner wehrten. Uebrigens wurde allgemein von den Streiligegnern ausgeführt, dass auch bei den vor dem Streik bestehenden Lebensverhältnissen viele Japaner ein viel besseres Auskommen haben müssten, als von den Streikern behauptet wurde, wenn sie sich nu! dazu verstehen wollten, an allen Arbeitstagen zu arbeiten, statt sich nur an is Tagen im Monat der Arbeit und die übrige Zeit dem Nichtstun hinzugeben. Der Streik bildete gewissermassen den Abschluss für die ganze "vorkapitalistische " Periode des Plantagenbetriebs, denn es war klar, dass die Gesamtheit der Japaner, die gestreikt hatten, nicht mchr jene gefügigen Leute waren, als welche sie bei ihrer Ankunft bekannt waren. Die länger ansässigen waren beinahe ebenso unbotmässige ,freie" Arbeiter, wie die aus Amerika herübergekommenen. Sie hatten sogar noch eine Waffe im Lohnkampf mehr als diese: ausser der gewerkschaftlichen noch eine nationale Solidarität, die den Arbeitgebern begreificherweise unheimlich sein musste. Bei diesem Streik wurde es vielen klar, wie gefährlich es sei, ganz von Landesfremden abzuhängen, in deren Händen ja tatsächlich der ganze Betrieb ruhte. Dass die japanischen Arbeiter sich ihrer Machtstellung wohl bewusst waren, war bekannt, und diese Zuspitzung des Gegensatzes zwischen Arbeitgebern und Arbeitern zu einem nationalen Gegensatz gab der Angelegenheit einen ernsten Charakter. Zugleich er- 
schütterte er für immer die gesellschaftliche Steliung der Japaner auf den Inseln, denn man wurde gewahr, dass auch die höherstehenden Japaner, die durchaus kein Arbeiterinteresse mehr hatten, sich dem Willen der Mehrheit ihrer Landsleute nur teilweise widersetzen konnten, ja Gefahr liefen, dabei ihr Leben zu gefährden. Die japanische Bevölkerung zeigte sich als eine Gemeinschaft innerhalb der übrigen Gemeinschaft, in die den Aussenstehenden kaum ein Einblick vergönnt war. Infolgedessen entschlossen sich die Farmer, nie mehr ein nationales Monopol unter ihrer Arbeiterschaft gross werden zu lassen, und fingen damit an, den Prozentsatz der Japaner, insbesondere unter clen Aufsehern, herabzudrücken. Das war wohl einer der Gründe, der ihnen das Entgegenkommen in der Lohnfrage erleichterte. Ein weiterer war wolll der, dass sie das patriarchalische Betriebssystem seinem Ende nahe sahen und bei dem voraussichtlichen Verschwinden einer fluktuierenden asiatischen Arbeiterbevölkerung auf eine Differenzierung der Löhne nicht mehr viel Gewicht legten.

Die Aenderung, die inzwischen eingetreten war, ist die Abmachung der japanischen und amerikanischen Regierung über die Beschränkung der japanischen Auswanderung. Ihre Wirkungen und die Ergebnisse der japanischen Bevölkerungsbewegung auf Hawaii überhaupt zeigen die folgenden Zahlen: ${ }^{1}$

TABelle XXI.

Vom 14. Juni I903 bis 30. Juni I910 sind

\begin{tabular}{l|r|r|r|r}
\hline \multicolumn{1}{c|}{ japanische } & Männer & Frauen & Kinder & zusammen \\
\hline eingewandert & 61026 & I 5875 & 520 & $7742 \mathrm{I}$ \\
ausgewandert & 57965 & I 1204 & 6016 & 75186 \\
\hline Ergebnis d. Wanderung & +3060 & $+467 \mathrm{I}$ & -5496 & +2235 \\
\hline Ergebnis d.Volkszählung & - & - & - & $+\mathrm{I} 8563$ \\
\hline
\end{tabular}

1) nach dem Fourth Report S. 59 f. 


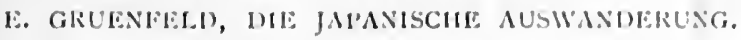

\section{TAMELLE XXII.}

In den Jahren von r905-19ro sind Japance

\begin{tabular}{|c|c|c|c|c|c|c|c|c|c|}
\hline & \multicolumn{3}{|c|}{ angeliommen } & \multicolumn{3}{|c|}{ absefahren } & \multicolumn{3}{|c|}{ 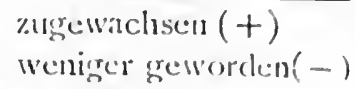 } \\
\hline & M. & $\mathrm{Fr}$. & K. & . & lir & K. & M. & Jir. & K. \\
\hline 1905 & 5447 & 567 & 55 & 10315 & I 339 & I I 54 & -4868 & $-s_{32}$ & -1099 \\
\hline 1906 & 17007 & $\mathrm{III}_{3}$ & 67 & 12723 & 1522 & 1337 & $+42 S_{4}$ & $-40)$ & -1270 \\
\hline 1907 & 11940 & 2877 & $15 S$ & $\epsilon_{959}$ & S9o & 1077 & $+49^{8} \mathrm{I}$ & +1987 & -919 \\
\hline 1908 & 2369 & 1700 & I 33 & I 849 & 695 & 979 & +520 & +1005 & $-s_{46}$ \\
\hline 1909 & 355 & $S_{49}$ & 76 & I 597 & 624 & $9^{1} 7$ & -1212 & +225 & $-84 \mathrm{I}$ \\
\hline 1910') & 199 & $4 S S$ & $3^{I}$ & $79^{6}$ & 356 & 552 & -597 & +132 & $-52 \mathrm{I}$ \\
\hline
\end{tabular}

Das früher so starke Wachstum der japanischen Bevölkerung auf Hawaii hat sich aber sehr verlangsamt und zuletzt sogar einer Verminderung Platz gemacht, da viele Kinder wieder nach Japan geschickt werden. Andererseits haben sich die Frauen stark vermehrt, und bei der grossen Geburtenfrequenz der Japanerinnen ist zu erwarten, dass sie die Hawaiischen Iuseln um eine grosse Anzahl junger amerikanischer Bürger bereichern werden. Von diesen kehren zunächst wohl noch viele mit ihren Eltern nach Japan zurück. Bald aber dürfte eine Zeit kommen, wo das Ab- und Zuströmen der Japaner aufhört, und dann wird die übrigbleibende japanische Kolonie auf Hawaii vor die Frage gestellt sein, ob si : sich amerikanisieren lassen oder weiterhin von der übrigen Bevölkerung national absondern will.")

Wie dem auch sei, die Zeit einer drohenden Japanisierung des Territoriums ist voraussichtlich vorbei. Den Nachschub von Arb itern, den man zunächst von Porto Rico, von Portugal, von Russland und Korea versorgt hatte, liefern jetzt, angeblich zur vollsten Zufiedenheit, die Philippinen, und man muss abwarten, was für eine Völkermischung sich daraus entwickeln wird. Bereits werden übrigens schon einzelne Mischehen zwischen Japanern und andern Nationalitäten gemeldet, und wenn die Pläne des

1) Nur Januar bis Juni. 2) Nakambura a. a. O. glaubt, dass der Geburieniiberschuss $d$ :r Japaner ihre Abwanderung weit macht. 
Einwanderungsamtes in Honolulu gelingen, so ist in einigen Jahrzehnten die Geschichte der japanischen Einwanderung auf Hawaii nur mehr cine Episode in der Entwicklung des jungen amerikanischen Gemeinwesens. Die Prophezeiungen von einem unblutigen Rassenkampf, den m.m mit dem Vordringen der Japaner auf Hawaii für erklärt ansah,") wären damit hinfällig. Jedenfalls scheint mir bei diesen Voraussagen die Widerstandskraft der bald lässigen, bald impulsiven amerikanischen Politik stark unterschätzt worden zu sein.

Eine Fortsetzung der Geschichte der japanischen Einwanderer auf Hawaii bilden die Schicksale der Japaner auf dem amerikanisclecn Fistlandc, im Gebiet der Vercinigten Staaten. Die Verhältnisse sind hier und dort ähnlich, doch sind einige wichtige Unterschiede bemerkenswert: auch im Westen der Vereinigten Staaten herrscht grosse Arbeiternot, aber die Gesetze verbieten die unterstützte Einwanderung, und es gibt auch kein Plantagensystem, demzuliebe man Ausnahnen gelten liesse. Andererseits trägt das Festland, trotz der starken Rassenmischung, die die amerikanische Bevölkerung aufweist, doch einen ausgesprochen amerikanischen Charakter, so dass eine Abschliessung von ihr stark auffallt, und die assimilierende Kraft der Ungebung auf die eingewanderten Japaner vicl grösser ist.

Aber das japanische Einwanderungsgebiet in den Vereinigten Staaten sind in der Hauptsache nur einige Staaten der Union, und zwar Californien, Oregon, Washington, Montana und Nevada, die gegenüber dem Osten des amerikanischen Kontinents, wo die meisten Einwanderer aus Europa landen, grosse Verschiedenheiten aufweisen. Zunächst sind diese Staaten sehr dünn bevölkert. Es hatten im Jahre $1900:^{12}$

TABelle XXIII.

\begin{tabular}{|c|c|c|}
\hline & Einwohner. & auf $\mathrm{I} \mathrm{km}^{2}$ \\
\hline Cilifornien ........................... & 1485053 & 4.- \\
\hline 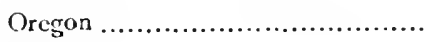 & 413536 & 1.7 \\
\hline 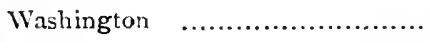 & 518103 & 3.- \\
\hline 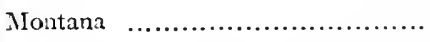 & 243329 & 0.6 \\
\hline Nevada .............................. & 42.335 & $0 . \mathbf{r}$ \\
\hline $\begin{array}{l}\text { Vereinigte Staaten (ohne Alaska) } \\
\text { unl Hawaii) }\end{array}$ & $760 \$ 5794$ & 9.6 \\
\hline
\end{tabular}

1) Vergl. Aubert a. a. O. $\$ .85$ ff. Band, Beilage zu Seite $6 \nmid 6$.

2) Meyers Kl. Konv. Lex. 1909. 6. 
Dieser grobingen Bisiedelung eines so ungehemen Gubietes entspricht eine grosse No: an Arleitskräften, clie zum leil eine Folge der Verlechrsuerbälenisse des anerikanischen IVestens ist, und die in cine Herrschaft der Gewerkschaften ausereartet ist. wie sie katum irgendwo and res mörlich wäle. Die föhne sind becreiflicherweise insserordentlich hoch, und seit die Chinesen ganz vom Gebiet der Verinigten Staten ausugeschlosicn sind. ist fur die Unternchner, Hatushaltvorstände 4. s. W. eine schwere Zeit angebrochen. Man kann sich leicht vorstellen, wie gerne man zugriff, als sich dic Gelegenheit bot, in den Japanem eine, noch dazu billige, Anbeitskraft 7.4 erhalten, mit deren Hilfe man sich von der Dilitatur der trade unions freizumachen hoffe.

Man darf übrigens nicht glauben, dass lie japanische lïnwanderung gleich im grossen angefungen hat, oder dass Arbeitertransporte di erste lïnwanderung gebracht hätten. I)ie japanische Kolonic in den Vereinigten Staten bestand vielmelur zunächst aus jungen Leuten, die mehr oder mincler studienhalber herübergekommen waren, sich allerdings zum grössten Teil die Kosten für ihren L:bensunterhalt clurch ihrer Hände Arbait verdienten, zumeist, da sie nichts anderes gelernt hatten, als Dienstboten, . Kellner, Ladengehilfen und dergl. Die ersten kamen von Hawaii in Jahre $\mathbf{1} 870$, und sie fanden bald Nachfolger: ISS4 gab es 300, ISS6: Soo, Ende 1S87: 200J, 1S9 etwa 3000 . Sie waren meist im Alter zwischen $18-30$ und oft aus guter Familic. Da bei der Einfülirung der allgemeinen VVehrpflicht in Japan dic in Ausland zu Studienzwecken weilenden befreit waren, gab es nach Nitobe ${ }^{1)}$ viele, dic nur aus diesen Grunde ins Ausland gingen. Natürlich war der Aufenthalt aller dieser jungen Leute in einem von der Heimat so verschiedenen Lande nicht ohne bestimmte Gefahren, dencn die christlichen Missionen, warme Freunde der japanischen Einwanderer, zum Teil entgegenwirkten. Es gab auch wenig Frauen, über deren Lebensweise aber nicht immer Klarheit zu herrschen schien. Nitobe vermutet schon I $S_{9}$, dass bei einer Vermehrung der Japaner leicht Reibungen mit der amerikanischen Bevölkerung entstehen könnten. Ueber das weitere Anwachsen der Japaner in Amerika sind die Berichte spärlich und unzuverlässig. I900 gab es jedenfalls 85986 Japaner in den Vereinigten Staaten, darunter 7r386 Mäuner..) Davon waren (siehe oben Seite 69

1) I. (O) Nitobe, The intercourse between the U. S. and Japan. Ballimore xS9r. 2) Meyers Kl. Konv. Lex. 1905. 6. Band, Beilage zu Seite 6,6 . 
Tabelle XIX) 56230 auf Hawaii, so dass auf dem Festlande 29756 anzunehmen sind. Dds waren natürlich längst nicht mehr bloss Studenten oder Studenten-Arbeiter, vielmehr waren jetzt schon die Arbeiter, die teils aus Japan direkt, teils aus Hawaii gekommen waren, in crdrückender Ueberzahl. Es folgte 190ว die bekannte Einschränkung der japanischen Auswanderung nach Amerika durch die japanische Regierung, und seither blieb nur mehr ein Rekrutierungsbøzirk für Arbeiter, nämlich Hawaii, wo nunmehr, glcichzeitig mit der durch die Annexion bewirkten Aufhebung der mehrjähringen Arbeitskontrakte, eine starke Auswanderung nach dem Kontinent einsetzte. Die Zahl der von dort eingewanderten Arbeiter ist bereits auf Seite 79 Anm I. mitgeteilt. In den cinzelnen Jahren kamen in den Vereinigten Staaten an :1)

$\begin{array}{lrrrrr}\text { I } 901 & 5296 & 1932 & 14270 & 1903 & 19968 \\ \text { I904 } & 14382 & 1905 & 11021 & 1906 & 14243 \\ 1907^{\circ)} & 19565 & 1908 & 9544 & 1909 & 2432 \\ 1910 & 2598 . & & & & \end{array}$

Nacin dem amerikanischen Zensus von 1900 befanden sich in Californien 5617, in Oregon und Montana je 2500 Japaner. ${ }^{32}$ Es wird allerdings behauptet, dass der amerikanische Zensus die Zahl der Japaner in Amerika nicht vollständig wiedergegeben hat, und dass sie tatsächlich etiva Iojooo betrug. ${ }^{4)}$ Nach der oben (Seite I6 Tabelie V.) wiedergegebenen Statistik des japanischen Ministeriums des Auswärtigen befanden sich 1909 in den Vereinigten Staaten I 42469 Japaner, von denen 65760 auf Hawaii waren, so dass 76709 für das Festland übrig blieben. Von diesen waren 53351 im Konsulats-Bezirk San Francisco. Aus der Zahl der Zuwandernden kann man keinen Schluss auf die Zahl der Anwesenden ziehen, da sehr viele wieder heimkehren. Nach einer japanischen Statistik aus dem Jahre 1903.5) befanden sich in diesem Jahre 38934 Japaner auf dem amerikanischen Festland, davon I8I23 in Californien, 5123 in San Francisco, 6482 in Washington, 2466 in Oregon, 1365 in Montana, 909 in Idaho, 855 in Wyoming, der Rest auf andere Staaten verteilt.

1) 190I-7 nach Aubert a. a. O. S. $x_{+2 / 3} ; 1908-10$ nach Reports of the De. partment of Commerce and Labor 1910. Washington 19rr. 2) Nur Januar-Juni. Die Zahl für das ganze Jahr war mir nicht zugänglich. 3) P.F. Hall. Immigration and its effects upon the U. S. A. New York 1907. Seite $36 \mathrm{ff}$. 4) "The Japanese American Yearboo'" (japanisch), San Francisco 19ro. S. ${ }_{3} S$ ff. und Hall a. a. O. 5) Mitsgeteilt bei Aubirt a. a. O.S. $\mathbf{x}+3$. 
Wean auch dic Zahlenangaben alle auscinandergelsen, so geben sie doch gewisse Anhaltspunkte und cin Bild der Verteilung der Japanter auf die einzeluen Staaten. Min sicht leicht, dass es sich hier 11 cht $111 \mathrm{~m}$ srosse Zahilen hamdelt, und dass von cince Ucberschwenmung Ancrikis mit Jupanern nicht die Rede sein katnu. Die Unrule, die dis: jayanische binwanderuner hervorgerufen hat, ist also nur so \%u erkläicn, dass sich dicie auf cinzelne Länder und Birirles lon\%entriert, :o insbesondere in Californien, und in diesem wieder in San Francisco, in dessen Völkergemisch eine Gruppe ron einigen tausend Japanern immerhin auff.tlen magr. Für cinige californische Stälte ist das Bild dieser Besiedelung mit Japanem folgendes:"1)

\section{Tabelle XXIV.}

\begin{tabular}{|c|c|c|c|c|}
\hline Es waren Japaner in. & I SSO & I 890 & $190)$ & 1905 \\
\hline Alamada ............... & I6 & $1 S_{4}$ & I I 49 & 4000 \\
\hline Fresno .................. & 1 & 12 & 598 & I 200 \\
\hline Los Angeles............. & $\mathbf{I}$ & $3^{6}$ & 204 & 3500 \\
\hline Monterey .............. & - & I & 710 & 1050 \\
\hline Sacramento ............ & I & $5 \mathrm{I}$ & I 209 & 2030 \\
\hline San Francisco ......... & 45 & 590 & I $73 \mathrm{I}$ & Soco \\
\hline San Mateo ............. & - & 9 & 46 & 5000 \\
\hline Santa Clara ............ & - & 27 & $2 \mathrm{~S}_{4}$ & 2000 \\
\hline Santa Cruz ............ & - & 19 & 235 & $25 \mathrm{co}$ \\
\hline 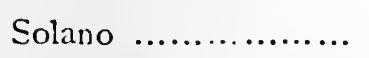 & 2 & 26 & 870 & 2000 \\
\hline
\end{tabular}

Die Zahlen in der 4. Spalte sind so rund, dass sie gewiss nur geschätzt sind. Lcider sind auch die andern Zahlen über die Japaner in Amerika wenig genau, da zu viele an der Verschleierung oder der gefärbten Darstellung der dortigen Verhältnisse interessiert sind. Man muss sich also mit annähernden Ergebuissen zufrieden geben.

61650 erwerbstätige Japaner, die 1900 auf dem Festlande

1) Nach einer amerikanischen Erhebung, mitgeteilt bei Aubert a. a. O. S. 197. 
lebien, verteilten sich angeblich, wie folgt, auf die einzslnen Berufe: ${ }^{1)}$

\section{TABELLE XXV.}

Landwirtschaft

33500

Handel und Verkehr ..................... I 4003

Eisenbahnarbeiter ............................ I 2000

Häusliche Berufi .......................... 800

Bergbau ................................. 600

Fabrikarbeiter.............................. 500

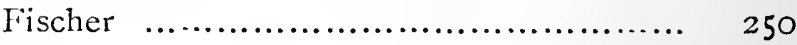

Die Japaner waren also überwiegend als Arbeiter, insbesondere als landwirtschaftliche und nicht qualifizierte Arbeiter beschäftigt. Japanische Geschäftslıute gibt es zwar überall, wo Japaner in grösserer Anzahl leben, aber sie sind zunächst für den Bedarf ihrer eigenen Landsleute cingerichtet; in Californien, besonders in San Francisco, und im Osten der Vereinigten Staaten gibt es grössere Kaufleute. Von den Geschäften der Japaner befanden sich 3114 allein in Califurnien, 465 in Washington.

Die Hauptstellung der Jananer in den Vereinigten Staaten ist unzweifelhaft Californien, über das auch am meisten Burichte voriiegen. ${ }^{2} \quad$ Merkwürdigerweise versuchen die meisten japanischen Berichte, die ich kenne, die Entwicklung des japanischen Wirtschaftslebens in Californien genau in wirtschaftliche Perioden einzuteilen, eiu Beginnen, das so gewaltsam und ins Einzelne gehend durchgeführt wird, dass an seiner Richtigkeit allerhand $Z$ weifel aufsteigen müssen. So teilt z. B. das Jap. Am. Yearbook ${ }^{3}$ die Geschicinte der japanischen Landwirtschaft in Californien in $\mathbf{5}$ Perjoden ein, die das Aufstzigen der japanischen Landwirte von Arbeitem zu Eigentüm $ə$ rn des bəbauten Bodeṇs charakterisieren: I.) Arbeiterperiode vou ${ }^{8} 88_{7}$ an, 2.) Kontralitarbeitsperiode von I 895 an, 3.) Teilbauperiode von $\mathrm{I} 897$ an, 4.) Pachtperiode von 1899 an und 5.) Eigentumspeliode von 1903 an. Das ist natürlich nicht wörtlich zu nehmen, als ob etwa jetzt alle Japaner Eigentümer wären u. s. w. Es zeigt aber, wohin die Eatıick-

1) Jap. Am. Yurbook 1900. S. $3 S$ ff. 9) Leider ist mir die ausführliche Darstellung in den Reports on immigration der $U$. S. Industrial Commission (Washin to: 1901-2) nicht zugänglich gewesen. 3) 19ro. S. 64 ff. 
lung die erfolerreichsten Japauer grebracht hat, und man muss ancrkennen, diss sic sich zicmlich rasch emporgearbeitet hab =n. Es handelt sich meist um Obst- und Gemuiscbau, in denen die Japaner zuerst als lintearbeiter sebraucht wurden wnel sich sehr gut bewährten. Dic Arbeitsweise der Japaner brachte es daun mit sich, dass ilunen dic Arbeiten eruppenweise in Kontrakten vergeben wurden, und alles weitere war dann blos die Frage des Geldbesitzes, demn der Bolen in Californien ist grut und billig, die Beringungen zum Ankauf leicht, und dic landschaftlichen Verhältnisse ähnlich wie in Japan, so dass sich die Japaner dadurch angehcinelt fühlten. Dazu herrschte Not an Mlann wie überall in Californien, besonckers auf dem flaclien Londe, auf dem die amerikanischen Arbsiter oft nicht bleiben wollten; da nun seit den Soer Jahren die Jinwanderung von Chinesen verboten war, war das Feld für die Japaner frei. Deshalb sind sie aber, ausser in einigen kleineren Distrikten, nicht etwa die Herren des Bodens. Fine neue japanische Veröffentlichung ${ }^{1)}$ gibt an, dass gegenwärtigr zusammen I 50000 acres von Japanern bewirtschaftet würden, davon I 5000 von den Eignern. Das übrige sind Paclutbetriebe oder solche, wo die Japaner Angestellte des amerikanischen Besitzers sind. IVenn also auch die wirtschaftliche Stellung der meisten japanischen Landwirte in Californien einc mittelmässige oder bescheidene ist, so haben es einige doch zu schönen Erfolgen gebracht, und cs gibt u. a. einen ,potato king “ und einen ,, baron," Titel, die im ,freien “ Amerika germe Plutoliaten verlichen werden. Den japanischen Stimmen, die mit Bezug auf ciiese Erfolge die Lage ihrer Landsleute in den Vereinigten Staaten zu rosig ansehen, halten die genannten zwei Verfasser entgegen, dass das Jahreserzeugnis der japanischen Landwirte in Californien bestenfalls $\mathrm{J} / 5$ des gesanıten Erzeugnisses des Staates darstellt. Das wäre immerhin schon ein anselunlicher Bruchteil.

Wichtiger noch als die Landwirtschaft ist für die Japaner das Schicksal der Lohnarbeit, das natürlich eng mit den übrigen wirtschaftlichen Zuständen des Landes zusammenhängt und daher nicht selten schwankt. Im einzelnen wäre über die Japaner als Arbeiter auf dem amerikanischen Festlande wenig anderes als über ihre Landsleute in Hawaii zu sagen. Wie diese sind sie

1) S. Fanai \& B. Ito, Hokubei no Nihonjin (Die Japaner in Nordamerika). Tokyo rgro. 
sehr lernbegierig, suchen um jeden Preis in dic einzelnen Berufe einzudrincen und arbeiten zu viel billigeren Löhnen ais ihre eingeborenen Mitarbeiter, so dass diese sich von der Konkurrenz arg bedroht fühlen. Auch auf dem Festlande ist ein starkes Bestreben unter den Japanern vorhanden, in höhere Stellungen aufzusteigen, und eine stattliche Zahl von japanischen Handwerkern, kleinen und selbst grösseren Unternehmern und Geschäftsleuten beweist, dass ihnen der Erfolg nicht versagt blieb. Es gibt wenig Berufe, die von ihnen noch nicht versucht worden wären; in der Hauptsache sind es dieselben, die auch in Hawaii dem Eindringen weniger vorgebildeter Elemente widerstrebten. Eine ganz besondere Veranlagung haben die Japaner für alles, was mit persönlicher Bedienung zusammenhängt: sie sind zu einem grossen Teil Kellner, Haarschneider, häusliche Dienstboten, Angestellte in Gastwirtschaften, Bädern und dergl., und natürlich schreiten sie dann auch zur Erwerbùng von Hotels und Gastwirtschaften vor, von denen ein unverhältnismässig grosser Bruchteil in den Händen von Japanern ist.

Da die meisten Japaner mit den Früchten ihrer Arbeit im Auslande wieder heimkehren und in Vaterlande davon Nutzen ziehen wollen, ist die Spartätigkeit ziemlich stark entwickelt und die Aufbewahrung der Gelder sowie ihre Heimschickung bieten selbst wieder Erwerbsmöglichkeiten. Es entstand daher eine grössere Reihe von kleinen japanischen Banken, die sich zunächst mit den Auswanderungsagenten in die Geschäfte teilten, später aber wohl allein den Plat\% behaupteten. Leider lässt sich von der Entwicklung des japanischen Bankwesens in Amerika wenig Erfreuliches berichten. Abgesehen von den Filialen der grossen Yoliohama Specie Bank, sind die andern klein und haben infolge der häufigen Bankbrüche, clie bei japanischen Unternehmungen dieser Art vorgekommen sind, nicht allzuviel Vertrauen. Der letzte Konkurs dieser Art war der der Kimmon Ginko (Golden Gate Bark) in San Francisco, der die Folge betrügerischen Geschäftsbetriebes war. Natürlich ıiss dieser Konkurs noch eine ganze Reihe von kleineren japanischen Banken um, und der Rückblick des Jap. Am. Yearbook von rgro stellt fest, dass nur mehr 4 japanische Banken ausser der Specie Bank übrig geblieben wären. Auch das müsste genügen.

Die wirtschaftlichen Erfolge der Japaner in den Vereinigten Staaten werden von Japanern und Amerikanern gerne auf Heller und Pfennig in Zahlen ausgedrückt, was natürlich ein etwas un- 
siclneres Beginnen ist. Un aber doch ein Bild davon zu geben, wic sich cinem, übrigens kritisclien japanischen Beurteiler die Verhältnisse darstellen, Eche ich hier seine Aufstellung wiecler." Das Vermögen der Japaner botrïgt nach ihm 16.65 Mill. s, von denen 600,000 \$ in Land angelegt sind; atusserdem sind 3 Mill. \$ in beweglichen und unbewegglichen Werten festegclegt. Das Fapital der Kaufeute betrïgt 10 Mill. \$, also durchschnitlich 5000 auf jeden der etwa 2000 Kaufleute. Die Einnahmen der Arbeiter belaufen sich im Jahre auf rund 6.5 Mill. \$. Die Manken haben 500,000 \$ Kapital und 2 Mill. \$ Depots. Nach Jıpan werden jährlich 7 Mill. \$ geschickt.

Die Lage der Japaner in den andern Staaten der Union zeigt ein verkleinertes Bild der Zustände in Californien. In Oregon z. B. gab es 1902: I 500, I90S: 3872 Japaner, darunter 3573 Männer, ${ }^{2}$ meist in kleinen Verhältnissen als Arbeiter, kleine Handwerker, Händler und Landwirte. In Washington ${ }^{3)}$ leben jetzt etwa 2600 Japaner, meist in der Nähe der Küste um Seattle und Tacoma herum. Früher soll es noch um ctwa ı 000 mehr, gegeben haben, bevor die Einwanderungsbeschränkungen sich bewerlibar machten. Die Japaner verdienen ihren I.ebensunterhalt entweder in der Landwirtschaft oder als Arbeiter, zumeist als Eisenbahnarbeiter. Zur Selbständigkeit haben es bisher nur wenige gebracht, die ein kleines Anwesen crworben haben, und in der Nähe der Städte Genüsebau und Milchwirtschaft treiben. In Seattle gibt es über 20 japanische Hotels jeder Grössengattung.) Von den Arbeitern heisst es, dass sie im Jahre etwa 200 $\$$ zurücklegen können, dass aber die Lebenskosten gegen früher sehr gestiegen sind. Auch haben anscheinend noch viele an die Auswanderungsgesellschaften daheim zu zahlen. Der japanische Berichterstatter des Tolkioer Auswärtigen Amtes bemerkt übrigens, dass scine Landsleute sich als Arbeiter nicht sehr gut bewähren, da sie zu schwach und wenig ausdauernd sind. Sie essen vorwiegend fleischlose Kost, brauchen aber dasselbe für ihren Unterhalt wie die übrigen Arbeiter. Die Japaner sollen in Washington nicht sehr beliebt sein, da sie sich abseits halten und nur untereinander verkehren. Eine bessere Stellung haben sie im benachbarten Staate Idaho,") wo es I9Io etwa I 200 gab. Unter ihnen waren etwa 500 Eisenbahnarbeiter, die ähnlich wie in

1) Kinnai \& I:o 2. Kapital a. a. O. 2) Jap. Am. Yearbook 191o. 3) Bericht d. Sekretärs Sato, Bu. IX. der Berichtsamlg. des Gaimushō. Igrz. 4) Hotel Gazette, New York, 27. IV. 1912. 5) Bericht von Oyama. a. a. O. I912. 
Washington imstande sind, jährlich (250-280) \$ zurückzulegen. Noch bessar geht es den etwa 200 japanischen Gärtnern, von denen die besten $7 \mathrm{~S}$ Lohn haben. Die Landwirte sollen nicht viel Erfolge aufzuweisen haben, da sie nicht zu wirtschaften verstehen; aber nach und nach bessert sich auch ihre Lage. Es gibt auch etwa 50 Haushalte, die vom Handel leben, meist nur kleine Geschäftsleute. In Montana ${ }^{1)}$ gibt es 1258 Japaner, die meist als Eisenbahnarbeiter ins Land kamen. I $\$ 97$ gab es allein I 500 Bahnarbeiter, I903:6000. Obwohl sie alle als mittellose Leute ins Land kamen, haben sich viele von ihnen ein kleines Guthaben erworben und sind Landwirte, Händler usw. geworden. Der erfolgreichste Unternehmer hat es zu einem Kapital von I 5000 S gebracht. In Wyoming' lebten im Sept. I910 I250 Japaner, von denen 90 v. H. Arbeiter waren, überwiegend Eisenbahn- und Minenarbeiter. Ihr Verhältnis zu den übrigen Bzwohnern des Staates soll ein befriedigendes sein, namentlich wird hervorgehoben, dass sie Mitglieder der Gewerkschaften sind. Auch in Nevada, Utah und Colorado leben Japaner in geringen Mengen als Arbeiter, kleine Landwirte und Kaufleute, Gastwirte usw. Mit der Entferung von der Küste nimmt natürlich auch die Zahl der sesshaften Japaner $a b$, so dass sie in der übrigren Bevölkerung ganz verschwinden müssten, wenn diese Staaten nicht so dünn besiedelt wären. Die wirtschaftlichen und gesellschaftlichen Verhältnisse der Japaner in den V. St. sind denen ihrer Landsleute auf den Hawaiischen lnseln fast gleich, nur mit dem Unterschiede, dass es sich hier nirgends um Kontraktarbeiter handelt, sondern diss japanische und andere Arbeiter sich rechtlich und wirtschafilich ganz gleich sind, oder vielmehr gleich wären, wenn die Japaner sich den Gewohnheiten und Anschauungen der Ainerikaner anłassen würden. Die Japaner haben nicht etwa eine besondere Beschäftigung, derentwegen sie herübergeholt wurden, wie auf Hawaii, sondern sie arbeiten in denselben Berufen wie alle übrigen Einwohner des Landes, und wenn sich hierin eine Unterscheichng bemerkbar macht, so geschieht es nur deshalb, weil die Japaner sich aus allerhand Gründen auf gewisse Gewerbe geworfen haben und diese hie uncl da fast monopolisieren. Daher gilt es für die Japaner überall mit den übrigen Arbeitern, Geschäftsleuten und dergl. in eine scharfe Konkurrenz einzutreten, während in Hawaii auf ihrem eigent-

1) Bericht von Sèretär Cuiakus a. a. O. 2) Pericht von Oyama a. a. O. 
lichen Arbeitserebict, der Plantigenarbsit, des Arbeitermangels halber kaum von einer Konkurren\% die kecle scin könnte: dor: war jeder Mann bei ker Arbeit willkommen. Hier auf dem Festlande war zo:ar atuch Not an Mann, abur da sich die Gewerkschafiler auf hohen Lohn versteiften, uncl dic Japaner sic betrïchtlich unterboten, kim es übrall \%u einem heftigen Kampfe zwischen dem billigen und dem amerikanischen oder aus Europa eingewanderten teuren Arbeiter.

Dabei ist von eine Verwischung der Gerensätze die längste Zeit nicht die Rele gewesen. Die Japaner schliessen sich gegen dic übrige IVelt ab, bilken, wo sic halbwegs zahlreich genug sind, kleine Gemein chaften und führen dasselbe Leben, wie ihre Landsleute auf Hawaii. Sic haben eigene Schulen, cigene Zeitungen," Vereine, besonders Wohltätigkeitsvereine. Diese Abgeschlossenheit ist nicht unbedenklich, denn sic widerspricht auf das heftigste dem, was die Amcrikaner von Einwanderem erwarten, und es ist auch nur begreiflich, dass ein solches Verhältnis mit der Zeit zu Missverständnissen führen muss, insbesondere, da dic Japaner dadurch erst recht verhindert werden, sich mit Sprache und Anschauungen der Amerikaner vertraut zu machen. Fin mit der Auswanderung sehr gut beliannter japanischer Herr, der so freundlich war, mir scine Erfahrungen zur Verfügung zu stellen, erzählte, er habe im Jahre I899. Amerika zum ersten Male besucht und dort eine solche Abgeschlossenheit der japanischen Kolonie gegen die Amerikaner gefunden, dass man Konflikte fast mit Bestimmtheit voraussagen kounte. Inzwischen hätten sich die Zustände allerdings geändert, namentlich seit die Japaner durch die Beschränkung der Zuwanderung sesshafter geworden wären, gäben sic sich viel mehr Mühe, sich den Amerikanern zu nähern. Auch jetzt noch hören aber die Klagen darüber nicht auf, dass die Japaner sich der Assimilation widersetzen, ja sogar ihre Kinder vor der Amerikanisierung bewahren wollen und oft von den durchreisenden Japanern in dieser Haltung bestärkt werden. ${ }^{2)}$

Und cloch müsste die Assimilation bei einigem guten Willen gar niclit so schwer fallen, dem die Wanderungsbewegung nach

1) Nach dem Jap. Am. Yearbook gibt es gegenwärtigg japanis:he Zeilungen in: Los Angeles, Sacramento, Seattle, Purtland, Vancuver, New York, Salt Lake City, Denver und San Francisco.

2) a. a. O. $215 \mathrm{ff}$. 
dem amerikanischen Festlande schafft von selbst eine gewisse Auslese unter den einwandernden Japanern, die sie ähnlich auswählt, wie alle amerikanischen Einwanderer in früheren Zeiten. Es sind natürlich die unternehmendsten Elemente, die von Hawaii und dem Vaterlande nach dem amerikanischen Festlande übersiedeln. Aber dieses Unabhängigkeitsgefühl allein schliesst sie noch nicht genügend an die Amerikaner, es sind zuviel andere Gegensätze vorhanden. Man lese nur bei dem geistvollen Aubert, dessen an hübschen psychologischen Beobachtungen reiches Buch ich wiederholt zu zitieren Gelegenheit hatte, nach, wie amerikanisches und japanisches Wesen einander gegenüberstehen $:^{3)}$ „Un Americain, un typical aestern man, le type d'homme précisément qui est en rapport avec les Japonais-c'est un homne très sociable, familier avec les étrangers, quoiqu'ils ne soient pas ses éfaux, et qui met tout le monde à l'aise en prenant ses aises. Il ne veut pas qu'on l'oublie, il tient à ce qu'on l'appelle par son nom avec toutes les initiales de ses prénoms, et non pas John tout court, comme lui-meme appelle indistinctement tous les Chinois. Il parle haut, rit fort, bombe, se hausse, exige qu'on le traite à son rang, plutôt un peu au-dessus, joue franc jeu, pense à haute voix, défend sans modestie sa chance, avoue la bonne opinion qu'il a de ses capacités, respecte infiniment la valeur de son travail et exige sans plus le plus haut salaire. C'est un homme libre.

Le Japonais entre en saluant trop bas, sollicite trop humblement qu'on le prenne au pair, qu'on lui fasse le grand honneur de le laisser regarder, imiter. Il n'est pas d'humble métier qui le rebute, celui qu'on lui offre lui ira très bien; le plus petit est encore à sa taille. Tout le monde connait aux États-Unis l'anecdote si souvent contée d'un officier de marine américain, retrouvant aux Philippines, comme commandant d'un navire de guerre japonais, un boy qu'il avait jadis gardé longtemps au mess de son bord. Le fils d'un Samurai n'hésite pas à s'engager comme domestique à Yokohama ou aux États-Unis; on l'appellera John. En Amérique, les Blancs refusent à servir comme domestiques; à plus forte raison, ils s'y refusent à l'étranger, chez des étrangers.

3) Vergleiche einen Artikel im Yorodzu (Tōkyō), übersetzt und abgedruckt im Japan Weekly Chronicle (Kobe) vom r9. X. I I und die oben zitierten Reden Prof. Nitobes, die sich auch auf das amerikanische Festland beziehen, die Reden des Grafen Okumh, des Ab scordneten Shimada, der 19u/12 die Japaner in Amerika besuchte, u. a. 
Le Juponais reste silencieus, mysterieus, souriant. Sunf les officiels, il n'est jamais tout it fait it son rang on it sit taille i l'étranerer. Ce ne sont pas lit les manieres américaines: dans la lutte internationale, ce n'est pas fair play.....

Et puis ce Japonais parait si peu sûr de lui! L'Américin, lui, est certain que dans son pays il n'est rien qui ne soit the be't in the world. Le Chinois, mandarin égaré chez les Barbares, est tellement convaincu de l'execllence de sa race qu'il ne s'inquiete guère des , diables" étrangers et reste impassible sous les quolibets. Certes les Japonias, eux aussi, sont persuadés de leur supériorité, mis leur conviction n'est guère impassible. Toujours inquiets que cette supériorite ne soit pas assez reconnue, ils vont devant un étranger jusqu'à s'lumilier par orgueil. Un amour-propre maladif, la crainte qu'on ne les traite pas avec tous les égards qu'ils souhaitent, joints à la peur que la couleur de leur peau et leur faible stature n'excitent le rire,- tout conspire à les isoler, a les raidir: arrogants et brutaux ou trop aimables, au total rarement assez maitres de soi ni assez détendus pour attirer la sympathic.

Ne parlez pas à un Japonais de la beauté de son pays et de son art, du charma de ses vieilles moeurs et de sa vie simple d'autrefois: ne lui vantez pas la nudité artistique de sa demeure ni la séduction de ses geishas, toutes choses qu'il aime tenacement, profondément et qu'il regrette à l'étranger. I.e voilà gêné et qui ricane en s'excusant: il croit que vous vous moquez, que vous le louez de son passé pour n'avoir pas à lui parler de son présent ou de son avenir. Ses jardins japonais, ses maisons de bois, c'est trop petit, trop simple de style, trop pauvre de materiaux, trop modeste et trop périssable pour plaire vraiment à un Occidental qui construit d'énorme palais de blocs de pierre. L'anour du sol japonais et du Mikado, c'est un sentiment sacré qu'il garde au profond de soi. C'est une passion intense, très prompte à douter ses éloges, âpre à les souhaiter et qui se dissinule, s'effarouche, honteuse à s'avouer. Froissez-la au vif, comme à San Francisco, et sous les habits et manières d'emprunt, elle éclate: la douceur souriante s'est nuée en arrogance brutale.

Au vrai, si le désir dı Japonais de s'américaniser ne parait aux Californiens que faux semblant, c'est qu'ils croient sentir que le Japonais ne se livre pas entièrement à l'emprise de la terre et de la civilisation américaines, qu'il se réserve et que de 
l'Amerique il ne veut pas tout prendre, en bloc. Il enquête, juge, distingue, ne s'abandonne jamais et jamais ne perd ni sa tête ni son coeur de Japonais."

Was Aubcrt hier beschreibt, ist vielleicht ein wenig grell aufgetragen, aber jeder, der Japan kennt, weiss, dass er den Nagel auf den Kopf trifft, und der Verlauf der Ereignisse bestätigt seine Schilderung. Er ist meines Wissens der einzige, der sich eingehend um das psychologisehe Verständnis der Japaner in Anerika bemüht. Amerikaner und Japaner, die natürlich eine ziemlich umfangreiche, wenn auch nicht wertvolle Literatur über die Einwanderung in den Vereinigten Staten aufweisen, suchen fortwährend naçh sittlichen Werturteilen, als ob das genügen würde, um die Frage zu lösen. Der Streit geht gewöhnlich darum, wie die Japaner in Amerika nach ihrem moralischen Standard einzuschätzen sind.

Die Amerikaner selbst haben hierfür zwei Massstäbe: die öffentliche Meinung sucht nach Argumenten, um ihre Ablehnung der japanischen Einwanderung $z u$ rechtfertigen, während die verantwortlichen Männer sich Mühe geben, der Sachlage in melı objektiver Weise gerecht zu werden. Merkwürdigerweise ist dieser Zwiespalt auch auf der japanischen Seite vorhanden; aber während die Männer von Verantwortung hier wie dort nach Sachlichlieit streben, ist in der allgem inen Diskusssion sowohl überschwängliches l.ob als überschwänglicher Tadel zu finden. Ich möchte auf die extremen Ansichten beider Parteien hier umsoweniger eingehen, a!s sie meist der tieferen Begründung entbehren und nur dazu dienen, den Streit ins Endlose zu ziehen, verweise nur darauf, dass sich sowohl auf japanischer Seite heftige Verurteilungen der Japaner in Amerika wie auf amerikanischer Seite grosse Lobeserhebungen über sie finden. ${ }^{1)}$ Aus den übrigen Urteilen geht hervor, dass im grossen ganzen über die Japaner nicht mehr zu klagen ist als über alle andern Einwanderer, die sich aus armen und ungebildeten Volksschichten rekrutieren, und das; manche von den behaupteten sittlichen Schäden der Japaner auf Mangel an gegenseitigem Verständnis oder auf unangebrachten Forderungen beruhen, die die Amerikaner so gerne andern Nationen gegenüber erheben. Anderer-

1) Als Beispiel erwähne ich: H. Wakabayastii \& $K$. Takata, Nihonjinmondai shinsō (" die jap. Frage richtig dargestellt "), San Francisco Mai I9Ir (gedruckt Tōkyō), und $I I . B$. Johnson D. D. Discrimination against the Japanese in California. Perkeley (Cal) rgo 7 . 
seits ist nicht \%11 lenruen, dass die Jupaner in Anerikat nicht durchwegs dic besten Vertreter ihres Volless sinct und dass sic nicht szlten atuch den Verstuchungen erliegen, dies cin ungebundenes Leben in der livente und cine ctwats rable Umegebung ihnen stcllen.

Im Verglcich mit den äbrigen Einwanderem, dic segenwärtigr in dic Vercinisten Staaten strömen, schneiden dic Japaner keineswegs schlecht ah, und auch dicjenigen, die aus Grundsaty der Einwanterung im allgemeinen feindlich gegenïberstehen oder gerarte die asiutiche Einwanderung vermieden z.u schen wünschen, haben gegen sic keine sachlichen Klagren vorzubringen, die cine Ausnahmergesetzgebung rechtfertigen könnten. Dic Untersuchunğ der lïnwanderer ergibt, dass der Pro\%entsatz der Analphabeten 2r.6\% ist, ${ }^{1)}$ dass sie durchschnittlich $45 \$$ bei der Einwanderuns besitzen, dic meisten allerdings gerade nur die rorgeveluiebenen 30 s vorzuzeigen haben, (woraus der Berichterstatter") schliesst, dass ihnen das Geld vom $\Lambda$ genten in die Hand gedrüclit worden sei), dass sie reinlich und ordentlich sind, wenig Verbrecher und Kranke mit sich bringen und den Gesetzen des Landes gehorsam sind, besonders die besseren Japaner, die in der Mitte und im Osten der Vereinigten Staaten leben. IVas die persönlichen Verhältnisse der japanischen Einwanderer anbelangt, so unterscheiden sie sich ein wenig vom Durchschnitt der übrigen Einwanderer und bestätigen das oben von ihrer wirtschaftlichen Stellung auf dem Kontinent Gesagte und auch, dass die Voraussetzungen für eine rasche Assimilation bei Ilnnen schnächer sind als bei den übrigen, da sie etwas älter sind als der Durchschnitt, mehr den untern Schichten angehören und weniger Frauen mitbringen, was immer ein Beweis für geringere Sesshaftigkeit ist. ${ }^{3)}$ Es waren von den Einwandernden im Jahre $1906:^{+1}$

1) P. F. Hall. Immigration etc. $\Vdash$ o. Hall ist Sekretár der Immigration Restriction League.

2) $\mathrm{Ob}$ diese Festellung richtig ist, wäre zu untersuchen. Schreiben-Können bedeutet im Japanischen viel mehr als in einem Lande westlicher Kultur. Aber auch abgagesehen davon scheint mir die Ziffer etwas zu niedrig.

3) John R. Conmoons. Races \& Immigrants in America. New York 1907 Seite 108. Zum Handel (in der viertletzten Spalıe) gehören auch die Hotels und dergl. Die Beschäftigungslosen sind nicht mitgezählt.

4) Das Verhältnis der Geschlechter hat sich in allerletzter Zeit bedeutend verschoben; 1909 wurden zur Auswanderung zugelassen: I462 M. I8I3 Fr., I9Io: 915 M. 1883 Fr., 191 I : I409 M. 3166 Fr. (Auszug aus der amerikan. Statistik, veröffentlicht im Japan Advertiser, Tokyo, 23. V. 1912) 


\section{Tabelle XXVI.}

\begin{tabular}{|c|c|c|c|c|c|c|c|c|c|c|c|}
\hline & \multirow{2}{*}{$\begin{array}{l}\text { Kopf } \\
\text { zahl }\end{array}$} & \multicolumn{2}{|c|}{ in $\%$} & \multicolumn{3}{|c|}{$\%$ im Alter von } & \multirow{2}{*}{$\begin{array}{l}\text { Erwetbs- } \\
\text { tätige }\end{array}$} & \multicolumn{4}{|c|}{ davon in $\%$} \\
\hline & & M. & Fr. & $\begin{array}{c}\text { weni- } \\
\text { ger als } \\
14 \\
\end{array}$ & $\mid \begin{array}{r}14- \\
45 \\
\end{array}$ & $\begin{array}{c}\text { iiber } \\
45\end{array}$ & & $\begin{array}{l}\text { Han- } \\
\text { del }\end{array}$ & we- $\begin{array}{c}\text { Ge- } \\
\text { werbe }\end{array}$ & $\begin{array}{l}\text { unge- } \\
\text { lernt }\end{array}$ & $\begin{array}{c}\text { ge- } \\
\text { lernt }\end{array}$ \\
\hline Japaner & 14243 & 89.6 & 10.4 & I.- & 97.1 & 1.9 & I I 797 & 10.3 & 2.2 & 2.8 & 84.7 \\
\hline $\left.\begin{array}{l}\text { Einwan- } \\
\text { derer } \\
\text { iiberhaupt }\end{array}\right\}$ & 1100735 & 69.5 & 30.5 & 12.4 & 83.0 & 4.6 & 815275 & 3.1 & г.8 & 21.7 & $73 \cdot 4$ \\
\hline
\end{tabular}

Das Schicksal jeder Einwanderung wird schliesslich von den Herren des Landes bestimmt, in das die Einwanderung stattfindet. Die Amerikaner waren sich darüber ganz im klaren und fest entschlossen, ihre Rechte zu wahren; ich habe ja oben bereits von dem Ausgang berichtet, den die Geschichte der japanischen Auswanderung nach den Vereinigten Staaten nahm. Hier bleibt nur noch etwas über den Meinungsstreit nachzutragen, der sich über die Zweckmässigkeit oder Unzweckmässigkeit der Einwanderungsbeschränkungen erhob, sowie über den Anlass, der die Frage zur Entscheidung brachte.

Seit dem Verbot der chinesischen Einwanderung nach den Vereinigten Staaten im Jahre 1892, das auch nicht ohne vorausgehende Agitation erlassen worden war, bestand in Amerika eine gewisse Animosität gegen jede Einwanderung aus Asien, und da die Amerikaner zunächst die Japaner von den Chinesen nicht $z u$ unterscheiden vermochten, so mag den Japanern manche Unannehmlichkeit durch diese Verwechslung beraitet worden sein. Als die Japaner dann zahlreich ins Land zu kommen begannen, entstand bald ein Widerstand dagegen, der zunächst von den Gewerkschaften ausging, weil diese natürlich den Wettbewerb der billigen fremden Arbeiter nicht wollten. Es wäre übrigens verfehlt, zu glauben, dass die amerikanischen Arbeiter sich gerade nur gegen japanische oder chinesische Einwanderung stemmen: sie sind gegen jede Einwanderung von Arbeitskräften, die ihren Lohnsatz oder ihre Herrschaft auf dem Arbeitsmarkte gefährdet, und die Einwanderer aus Europa, die wegen Mittellosigkeit oder aus Unkenntnis sich $\mathrm{zu}$ jeden Diensten hergeben, wissen ein Lied davon $\mathrm{zu}$ singen. Nur assimiliert sich ,der europäische Einwanderer meist nach wenigen Jahren, wenigstens in Bezug auf 
Lebcusansprüche und Sprache, oft auch in Be\%g auf Politik und nationale Anschantmen, denn die neisten Einnanderer europïischer Abstammuner wollen richtige Amerikaner werden, und erst die neuste Entwicklung hat dic Art von Ëinwanderern gebracht, die je nach der Crunst des Arbeitsmatktes kommen und gehen oder sar nur für einige Jahre herüberkommen. Es ist begreiflich, dass die Gesetzgebuner der amerikinischen Regierung Mittel an die Hand sab, die es ihr ermörslichen, cine strenge Auswahl unter den IBinlasssuchenden zu treffen. Dic Italiener \%. B., die seit einiren Jahren in hellea Ifaufen in die Vereinigten Staaten kommen und sich verhältnismässig schwer oder gar nicht assimilicren, zum Teil auch gar nicht sesshaft werden, sind keineswegs gern gesehen. Aber man weiss, dass diejenigen, die sich assimilicren wollen, es gar nicht so schwer haben, und die assimilierende Kraft der amerikanischen Lebensideale ist tatsächlich erstaunlich. Immerhin haben mehr oder minder alle armen und unwissenden Einwanderer Ursache, sich über schlimme Ausbeutung, Betrügerei und ungerechte Behandlung zu beklagen, die den freiheitlichen Grundsätzen der neuen Welt geradezu Hohn sprechen. ${ }^{1)}$

Es ist begreiflich, dass die japanischen Einwanderer eine noch viel schwierigere Stellung haben als die aus Europa kommenden. Sie sprechen fast durchwegs nicht die Sprache, ja sic sprechen überhaupt keine europäische Sprache, und der Unterschied zwischen dieser und der der Japaner ist so gross, dass es ausserordentlich schwer für sic ist, Englisch zu lernen, besonders für ungebildete Leute, die auch daheim mit dem Schreiben und Lesen nicht weit kommen. Denn auch hier ist wieder eine neue Schwierigkeit: die in Japan benützte Schrift ist die chinesische mit ihren Idiogrammen, in denen n'ur der Gebildete gut Bescheid weiss. Es braucht mehrere Jahre, bis der Japaner so viel von ihr erlernt hat, dass er halbwegs schreiben und lesen kann, denn die 2 japanischen Alphabete, die auch noch schwer genug sind, werden verhältnismässig weniç gebraucht und genügen nicht zum Verständnis der Literatur. Für dic Europäer aber ist es ohne vieljähriges, schweres Studium ganz ausgeschlossen, sich mit dem Inhalt japanischer Druck- oder Handschriften bekannt zu machen. So ist also die Verständigung

1) Vergleiche: Prof. Edw. A. Stciner. The immigrant tide, its cbl and flow. New York. Chicago. Toronto 909. 
zwischen den japanischen Einwanderern und den Amerikanern überaus schwer. Dazu kommt, dass auch Sittén, Anschauungen, Lebensweise, ja selbst die Denkweise der Japaner verschieden ist, dass sie eine andere Geschichte, Religion, kurz eine völlig verschiedene Kultur besitzen, die einen engeren Verkehr mit Ausländern ausserordentlich schwierig machen. Ist doch die landläufige Bezeichuung, die die Japaner selbst den Europäern, Amerikanein und Australiern geben, ,andere Menschen“ (Ijin). Nun kommit noch hinzu, dass die Japaner sich, wie oben berichtet, zunächst wenig Mühe gaben, sich dem fremden Boden anzupassen, da sie nicht daran dachten, ihre Zugehörigkeit zur alten Heimat aufzugeben. Umso leichter war es also für alle Gegner der japanischen Einwanderung, das Rassenproblem in den Vordergrund zu stellen.

Schliesslich kann es niemand den Amerikanern verargen, dass sie eine Ansiedelung einer fremden Rasse, die keine Neigung zeigt, in der übrigen Bevölkerung aufzugehen, die sich aber von Tag zu Tag vermehrt, mit scheelen Augen ansehen. Bei den Chinesen war die Sache noch leichter; diese gaben gute und bescheidene Arbeiter ab und versuchten nicht, in höhere Stellungen aufzusteigen. Auch waren sie wenig empfindlich und zeigten keine politischen Interessen, liessen sich ruhig als Bürger 2. Klasse behandeln und kamen nicht als Angehörige eines fremden Staates in Betracht, da dieser Staat nicht in Stande war, sie zu schützen. Ganz anders die Japaner: Sie waren nicht imner so fleissig wie die Chinesen, stellten höhere Ansprüche an das Leben und gaben sich mit einer Stellung als Bürger 2. Klasse nicht zufrieden. Im Gegenteil: sie verrieten sogar eine allzugrosse Empfindlichkeit, ja Reizbarkeit, wenn ihre Nationalehre ins Spiel kam, gingen selbst manchmal zur Offensive über und zeigten sich namentlich da, wo sie die Oberhand erlangt hatten, als wenig bequeme Herren. Das wurde noch heikler, nachdem Japan sich als Weltmacht erwiesen hatte, als nicht nur jeder einzelne Japaner sich als Angehöriger einergrossen Nation fühlte, wie er das ja auch früher tat, sondern es auch öfentlich zeigte, und als die Amerikaner erkannten, dass sie aus politischen Gründen die Japaner keinen solchen Beschränkungen würden unterwerfen können wie die Chinesen. Nun begann man auch die Bildung japanischer Kolonien im eigenen Lande mit Misstrauen anzusehen, und es wurde und wird auf amerikanischer Seite oft behauptet, dass dieses Misstrauen sich 


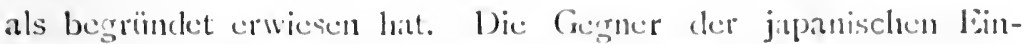
wanderung crhiclten dielurch cinc newe Unterstït\%ung.

lis fohlte und fehlt nicht an Stimmen at den amerilianischen Lager, dic warm für lic Jipbuer cintraten und hatascharf bewiesen, dass gan\% und gar kein frund vorhanden sei, sic ans sachlichen oder formellen liswïgungen vom anmerikanischen Boden auszuschliessen. Aber für die Ë̈nwanterung der Japaner liessen sich nut schwer Grinde ausfundies machen, und nur einige Obstpflanzer, deren Meinungen in der Diskuision - Wenn auch nicht ungehört - veiliallten, setzten sich aus sachlichen Gründen dafïir cin.

Endlich erkannte man auch in Japan, dass es besser wöre, sich nicht wegen einiger tausend Auswanderer in Amerika unbelicbt zu machen, und suchte von regierungswegen mit leichten Mitteln die Auswanderung nach den Vereinisten Staten cinzuschränken; abe! ich hatte bercits auszuführen, wie wenig diese Massnahme von 1900 gefruchtet hat. Ja, es begann sich sogar ein lebhatter Schmuggel von japanischen Einwanderern über die festländischen Grenzen zu entwickeln, über den die Berichte der japanischen Einwanderungskommissäre laute Klagen erhoben. Das wurde den Amerikanern erst recht verdächtig, und sie fingen an, durch diese stumme Widersetzlichlieit goegen ihre Einrichtungen und ihren Willen als die Herien des Landes gereizt zu werden. Die Zahl der Japaner nahn schnell zu und damit vergrösserten sich die Reibungsflächen. ${ }^{1)}$

So fehlte nichts mehr als der Funke ins Pulverfass, und er kam in Gestalt des Schullionfliktes in San Francisco. Dort war natürlich die antijapanische Stimmung am stärksten gèworden, und in der aufgeregten Zeit nach dem grossen Erdbeben am I I. X1I. 1906 ging in der Schulkommission der Stadtverordneten-Versammlung der Beschluss durch, die sämtlichen Kinder asiatischer Abstammung in einer einzigen Anstalt einzuschulen. Der Beschluss wurde damit begründet, dass das Zusammenleben der japanischen und übrigen Kinder zu Unzuträglichkeiten geführt hätte, und dass insbesondere die japani-

1) Die Grïnde für und wider die japanische Ausschliessung sind sehr hübsch zusammengestellt in: The annals of political and social science Vol. XX.XI/2 Philadelphia Sept. 1909: Chinese and Japanese in America. Das Einzige, was bei dem Für und Wider von Wert ist, ist die Hinfälligkeit aller andern als der einen Erwägung, dass man keine neue Rassenfrage will, und dass die Amerikaner das Recht haben, über das Schiclisal ihres Landes allein zu entscheiden. 
schen Schüler, die längst über das Knabenalter hinaus seien, eine sittliche Gefahr für die amerikanischen Mädchen bildeten, die mit ihnen die Schule teilten.

Ueber diese Massnahme entstand eine ungeheure Aufregung unter den Japanern, die sich dadurch für schwer gekränkt erklärten. Die Erregung griff auch bald in Japan selbst um sich, es kam zu Unruhen in San Francisco, die öffentliche Meinung hüben und drüben gährte, und es war so weit, dass man bereits von Krieg und kriegerischen Vorbereitungen sprach.

Es ist nicht meine Sache, die Phasen dieses aufgeregten Streites in einzelnen darzustellen. Der Sachverhalt kam zur Klarlegung durch das Eingreifen des Präsidenten Roosevelt, der den Sekretär .Metcalf mit besondern Vollmachten nach San Francisco sandte, um die Berechtigung der Klagen der Japaner untersuchen zu lassen. Sie erstreckten sich jetzt bereits auf 3 Punkte: I.) die Schulfrage. 2.) auf die Boykottierung japanischer Gastwirte durch die Gewerkschaften. 3.) auf Ueberfalle und Roheiten, denen die Japaner, auch der bessern Schichten, auf den Strassen der Stadt ausgesetzt seien. Die Untersuchung des Sekretärs Metcalf, die Präsident Roosevelt als Belag zu seiner 2. Botschaft an den Kongress (vom IS. XII. 1907) veröffentlichte, stellite fest: ad r.) Die Klage, dass erwachsene Japaner mit den übrigen Kindern zur Schule gingen, erwies sich als berechtigt. Fast alle erwachsenen Schüler verschwanden allerdings bein Ausbrechen des Konfliktes aus den Schulen, aber es blieben doch noch einige übrix. Dagegen waren keine Beweise dafür aufzutreiben, dass Unzukömmlichkeiten vorgekommen. waren. Der Plan der Schulbehörde, alle Kinder asiatischer Abstammung in eine Schule zu schicken, wäre eine grosse Härte für die Kinder, da sic über die ganze Stadt verstreut wohnen, und caher nicht durchführbar. ad 2.) Japanische Wirte wurden tatsächlich boykottiert, doch nicht alle und nicht nur japanische Virte, sondern auch andere. Der Streik wurde dadurch beigelegt, dass die Vereinigung der Wirte den Streikführern eine Summe Geldes aushändigte. ad 3.) Eine Reihe von Rohheitsakten und Ueberfällen gegen Japaner auf den Strassen San Francisco's ist erwiesen. Meist waren aber junge Burschen die Täter, und Polizei und Behörden taten, was sie konnten, un ihrer habhaft $z u$ werden und die Japaner zu schützen. Es war die Zeit nach dem grossen Erdbeben und Brand, und es gab zu 
dieser \%eit viele Streiks und Unruhen, und auch Nicht-Japaner wurclen auf den Straseen belistigt. Ja, es wurden sogar Ueberfalle solcher Art, dic in der Hauptsache harmlos waren, als von Japanern ausgeführt nacligewiesen. Die Klagen, die der japanische Konsul bei der Bohörde vorgebracht hatte, wurden rasch und zuvorkommend erledist. Stadtverwaltung und Polizei waren übrigens damals äberlastet, und I/5 der Polizeimannschaft fehlte im Dienst. Dic Schuld für die feindselige Stimmung wird hauptsächlich auf Agritation, insbesondere der Japanese and Corean Exclusion Lague zurückgcführt.

Es zeigte sich also diesclbe Erscheinung wie stets in erregten Zeitläufen, dass nämlich tatsächliche Vorkomnmisse durch die Aufregung der Beteiligten übertrieben werden und dann erst recht Unfrieden stiften. Diesmal wurde durch das energische Zugreifen des Präsidenten, der die Jundesgewalt der Staatsgewalt von Californien gegenüber nachdrücklich zur Geltung brachte, eine weitere Gefährdung des öfentlichen Friedens verhütet. Die Schulkommission nahm ihren Beschluss zu Gunsten cines andern zurück. Für das Nachgeben in dieser und einigen ähnlichen Angelegenheiten, die auf derselben Linie lagen, hatte der Präsident versprochen, für die Unterbindung der japanischen Einwanderung Sorge zu tragen. Der Erfolg seiner Unterhandlungen waren die bereits gemeldeten Bestimmungen, die die japanische und amerikanische Regierung gleichzeitig trafen und die, ohne das Nationalgefühl der Japaner zu verletzen, ein gänzliches Aufhören der Einwanderung japanischer Arbeiter bewirkten.

Der Erfolg dieser Einschränkung zeigt sich bereits in den auf Seite $90^{\circ}$ mitgeteilten Zahlen. Die Berichte der japanischen Einwanderungskommissäre lassen keinen Zweifel darüber, dass die geschaffenen Handhaben ausreichen und einen befriedigenden Erfolg gebracht haben :

\section{Tabelle XXVII.}

\begin{tabular}{|c|c|c|c|c|c|c|}
\hline \multirow{2}{*}{ Japaner } & \multicolumn{2}{|c|}{ I908 } & \multicolumn{2}{|c|}{1909} & \multicolumn{2}{|c|}{ I910 } \\
\hline & $\begin{array}{l}\text { U.S.A. } \\
\text { Feitl. }\end{array}$ & Hawaii & $\begin{array}{l}\text { U.S.A.A. } \\
\text { Festl. }\end{array}$ & Hawaii & $\begin{array}{l}\text { U.S.A. } \\
\text { Festl. }\end{array}$ & Hawaii \\
\hline $\begin{array}{c}\text { Zur Einwanderung } \\
\text { angemeldet }\end{array}$ & - & 一 & 2644 & I 539 & 2687 & I 56 I \\
\hline
\end{tabular}




\begin{tabular}{l|r|r|r|r|r|r} 
Zugelassen & 9544 & 8694 & 2432 & 1493 & 2598 & I 527 \\
$\begin{array}{l}\text { Abgewiesen } \\
\begin{array}{l}\text { Nach Zulassung } \\
\quad \text { ausgewiesen }\end{array}\end{array}$ & 643 & 60 & 2 I 2 & 46 & 89 & 34 \\
Fortgereist & - & - & 288 & 3 & 178 & $\mathbf{i}$ \\
\hline
\end{tabular}

Es ergibt sich für die Berichtsjahre $1908 / 09$ und I909/10 folgende Verminderung der Zahl der Japaner durch Wanderung: ${ }^{1)}$

\begin{tabular}{c|c|c}
\hline & auf dem Kontinent & auf Hawaii \\
\hline $1908 / 9$ & 2572 & 885 \\
$1909 / 10$ & 2426 & 828 \\
\hline
\end{tabular}

Nach einer andern Statistik beträgt der Ueberschuss der Rückwanderer über die Einwanderer in den Vereinigten Staaten (anscheinend einschliesslich Hawaii): 1908 : 1657, 1907 : 2625 ; 1910 : 2079, zusammen $637 \mathrm{I}$; für Arbeiter allein beträgt der Ueberschuss in den 3 Jahren zusammen I $1,152 .{ }^{2)}$ Natürlich ist hicr der Zuwachs der Japaner durch Geburten nicht berücksichtigt. Seit neuestem ist auch. die Einwanderung von alleinreisenden Mädchen unter I7 Jahren in die Vereinigten Staaten verboten, und die japanische Regierung hat entsprechende Weisung gegeben, an solche Mädchen keinen Pass mehr auszuteilen.

Jamit ist die Einwanderung von japanischen Volksmassen in die Vereinigten Staaten zu einem Ende gekommen, und da dieser Zustand durch den neuen Handelvertrag festgelegt wurde, ist anzunehmen, dass in nächster Zeit kaum eine Aenderung eintreten dürfte. Deshalb werden aber die Japaner in Amerika nicht rasch aussterben, denn es gibt genug Frauen, auch folgen noch jährlich viele ihren erfolgreichen männlichen Landsleuten über das Meer, so dass für Nachwuchs gesorgt ist. Aber es kehren auch viele Japaner zurück und der Rest wird durch längere Sesshaftigkeit doch mehr und mehr assiniliert werden,

1) Nach keports of the Dept. of Commerce \& Labor I9Io Washington IqII. Enthaltend Reports of the Commissioner general of immigration. Daselbst 278/80. Die Zahlen stimmen nicht ganz mit den auf Seite 87 mitgeteilten.

2) Bericht des Generalkonsuls $N_{a} ; a i$, San Francis $\approx$. Auszugsweise mitgeteilt im Japan Advertiser (Tokyo) vom 6. April IgrI. 
so dass die Gegensït\% nicht mehr so schroff cimander gegenüberstehen werden. Auf japanischer Seite mehren sich dic Stimmen, dic ancrkennen, dass dic Amerikance ein Recht dazu haben, ohn: Rïcksicht auf Empfindlichkeiten irgend welcher Art, darüber zu bestinumen, wer ihr Lund besiedeln soll, und wer nicht. Ls felılt allerdings auch nicht an Männern, denen die, wenn aich nicht prinzipiclle, so doch praktische Ausschliessung der japanischen lënwanderer vom ankrikanischen Gubiet nach wie vor cin Dorn im Auge ist und die, wenn schon nicht fur die nächste, so doch für spätere \%eit cine Oeffinung der Grenzen verlangen. Dass die Japaner auf beiden Seiten des Ozcans versuchen, wenigstens den jetzigen Zustand zu erhalten, wird man ihnen nirgends vesargen können, aber die Versuche für Neubildung einer politischen Freundschaft zwischen den zwei Grossmächten am Stillen Ozean und die bevorstehende Ausstellung aus Anlass der Eröffnung des Panamakanales (die man übrigens San Francisco zugestanden hat, um es für die Unterwerfung unter den Willen der Bundesregierung in Sachen der japanischen Einwanderung zu entschädigen) müssten eigentlich genügen, um beiderseits Ruhe zu schaffen. Trotzden fehlt es nicht an Reibungen. I9I I brachte die vorgeschlagene Neuordnung der amerikanischen Einwanderungsgesetze die japanische Oeffentlichkeit in Erregung, da vorgesehen war, allen dic Einwanderung in die V.St. zu verbieten, die clem Gesetz nach von der Erwerbung des Bürgcrrechts ausgeschlossen sind. Das konnte sich nur auf Japaner beziehen, denn alle nicht Einwandfreien, Bestrafte, Leute mit schlechtem Vorleben usw. sind ohnehin schon ausgeschlossen, so dass grundsätzlich nur noch Angehörige der gelben Rassen keine Bürger der V. St. Werden können, da die amerikanische Verfassung nur Weisse, Schwarze und Rote vorgesehen hat." Von den "Gelben " sind aber die Chinesen bereits durch Geset\% von der Einwanderung ausgeschlossen, so dass fast nur noch Japaner von der vorgeschlagenen Gesetzesänderung betroffen werden können. In Japan und unter den Japanern Amerikas verstand man dies sofort, und trotzdem die japanische Regierung sich anscheinend sehr zurückhielt, bekamen die Amerikaner bald deutlich zu hören, dass man den Gesetzesvorschlag als Beleidigung empfinde und bei Gelegenheit, z.B.

1) Vergl. Review of the recent decision in re Saito 62 Fed. I 25 holding, that a native of Japan, of the Mongolian race is not entitied to naturaiisation. New York Iaw Journal, Vol. XI. pp. I336... r\$95. 
auch bei der bevorstehenden Ausstellung vergelten werde. Vielleicht hat es auch die japanische Regierung versucht, sich Gehör zu verschaffen, jedenfalls wurde den ganzen Vorgehen gegen Japan die Spitze dadurch abgebrochen, dass die SenatsKommission auf Ersuchen der Bundesregierung nach den Worten " ineligible to become citizens by naturalization" den Nachsatz einschob "unless otherwise provided by treaty". Damit war in Fühjahr I9I I dieser Vorfall geschlossel). Dagegen hat die Magdalena Bay Angelegenheit noch immer nicht aufgehört, die Gemüter zu beunruhigen, ja im Fühjahr I9I 2 hat Senator Lodge durch scine Anfrage an den Präsidenten wieder die allgeneine Aufmerksamkeit auf die Tatsache gelenkt, dass Japan angeblich durch Strohmänner den Besitz der genannten mexikanischen Bucht anstrebt; da diese für wirtschaftliche Unternehmungen ganz ungeignet sein soll, so wird behauptet, dass Japan eine Flottenstation anlegen will. Bisher haben alle Dementis die Angelegenheit nicht aus der Welt zu schaff:n vermocht. Da es noch eine Reihe von politischen und wirtschaftlichen Reibungen zwischen Japan und den V. St. am asiatischen Kontinent gibt, so gitt es trotz aller Benühungen der beiden Regierungen stets eine gewisse Spannung, die um die Einwanderungsfrage zentriert: Dass es also bei den japanischen Einwanderern liegt, den Grundton für die politischen Beziehungen der beiden Länder zu geben ist klar. Die japanische Regierung hat durch ibre energische Abstellung der Auswanderung nach den V. St. und deren Nachbarländern bewiesen, dass sie von ihren Aussendlingen nicht viel Erspriessliches erwartet, und tatsächlich haben die früheren Botschafter bezw. Gesandten Japans in Amerika sich über ihre Landsleute wenig freundlich geäussert. Seit neuestem lat man aber von Japan aus angefangen, auf die ausgewanderten Japaner einzuwirken, um sie nach jeder Richtung hin dem amerikanischen Bürgerideal näher zu bringen, ja man scheint sich sogar darüber klar geworden zu sein, dass man Japaner opfern müsse, um Freunde in Amerika zu gewinnen, die dann als Pioniere der Interessen ihres oder ihrer Eltern Vaterlandes wirken können. Uebrigens gleichen sich die noch in Amerika befindlichen Japaner jetzt anscheinend mehr und mehr ihrer Umgebung an, und mancher Umstand kommt noch hinzu, die Stimmung den Japanern freundlicher zu gestalten. Der Abgeordnete Shimada, der als Friedensredner I9I I nach Amerika ging und die Lage seiner dortigen Landsleute sehr vernünftig beurteilt, berichtete in einer 
in Toligo in Jan. 1912 gehaltenen Rede, r.) dass in San Francisco ein grosser Unuschwung der öffentlichen Meinungr zugunsten der Japaner eingetreten sei, der 3 Ursachen habe :13 1.) Der Umschwung in der Haltung des Sim Francisco Chronicle, der früluer japanfeindlich war, aber 19 I r seine llaltunge änderte, nachdem er cinen Vertreter nach Jipan gesandt hatte, tum dort Material(!) für cine 200 Seiten starke Sondernummer seines Blattes ïber Japan zu sammeln; 2.) Die lischütterung der Stellung der Gewerkschaften durch den Mac Namara Prozess; 3.) Dic bevorstelsencle Ausstellung in San Francisco, bei der man auf die japanische Beteiligung rechnet. Dic Zeitungsyeschichte ist allerdings charakteristisch, kann aber niemanden überraschen, der weiss, wie viel Geld Japan auf Bearbeitung (ler ausländischen Offentlichkeit verwendet, insbesondere in den V. St. A. und England, wo die Sonderausgabe des amerikanischen Blattes einen ebenso erfolgreichen Vorläufer in der oftgenannten "Japan Number “ der Londoner „,Tines" hat. Ob die Freundschaft zwischen den beiden Ländern am stillen Ozean so fest ist, wie von den Friedensaposteln auf beiden Seiten behauptet wird, vermas wohl niemand vorauszusagen. Keinenfalls aber glaube ich, dass die Auswandcrungsfrage in nächster Zukunft den Anlass zu ernsthaften Konflikten zu bieten vermag.

Die Verhältnisse in Kanada sind denen in den Vereinigten Staaten ganz analog. Hier aber handelt es sich nur un eine kleine Zahl von japanischen Answanderern, und die ganze Frage hat daher wenig Bedeutung, obwohl sie fast denselben Verlauf nahm wie im Nachbarlande.

Vor den Jahre I 896 gab es überhaupt keine grössere japanische Einivanderung in Kanada. Dann aber entwickelte sie sich gleichzeitig mit der Aufnahme der regelmässigen Schiffahrtsverbindung nach Seattle durch die Nippon Yusen Kaisha ziemlich rasch, und vom I. Juli $1896-30$. Juni I90 I landeten I 3913 Japaner in Victoria, die freilich zum Teil weiterwanderten. Die Berichte der Einwanderungskommissäre melden den uns bereits von Hawaii und dem Festlande der Vereinigten Staaten bekannten Sachverhalt über die Tüchtigkeit der japanischen Arbeiter, über ihre den Chinesen überlegene Unabhängigkeit, Energie und Anpassungsfähigkeit, auch über ihre Abneigung, sich wirklich zu assimilieren, und über ihr Streben nach höheren Stellungen.

1) Nach dem Auszug im Japan Advertiser, v. 30. I. 1912. 
Meist waren die Japaner Holzarbeiter und Fischer, auch Arbeiter in den Bergwerken und bei Eisenbahnbauten, sowie häusliche Dienstboten, Angestellte von Gastwirtschaften und kleine Händler. Bei der dünnen Besiedelung, namentlich des westlichen $\mathrm{Ka}$ nadas, ${ }^{\text {, }}$ begann man bald auch die wenigen tausend Männer auf dem Arbeitsmarkte und in der Zusammensetzung der Bevölkerung zu spüren, und in dem zunächst betroffenen Staate Brit. Columbia richtete sich bereits eine Bewegung auf den Ausschluss der Japaner, die aber von der Bundesregierung der Kolonie unterdrückt wurde. Die japanische Regierung schränkte dann selbst die Auswanderung ein, lonnte aber ihr nochmaliges Anschwellen nicht verhindern, besonders da von Hawaii viele Japaner herüberkamen. ${ }^{2}$ Im Jahre 1907 schätzte man die Zahl der Japaner in Columbia auf 6-12000.

$\mathrm{Zu}$ dieser Zeit hatten die Japaner schon in der Fischerei des Strates Brit. Columbia eine ansehnliche Stellung erreicht, wie die folgenden Zahlen beweisen $:^{3)}$

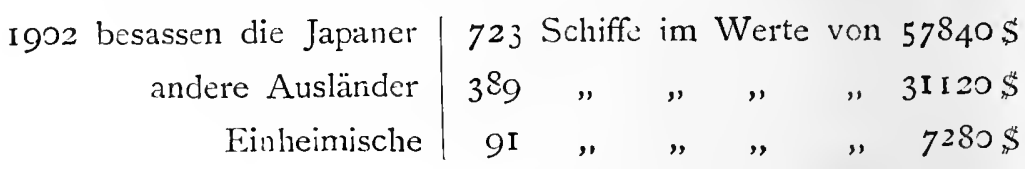

Damit sind die Japaner nach den Angaben unseres Gewährsmannes schon in die "Unternehmer-Periode " aufgerückt, denn sie sind nicht nur mehr Fischer, sondern auch Konserven-Fabrikanten oder andere Unternehmer.

Tatsächlich waren die wirtschaftlichen und politischen Verhältnisse in Kanada den japanischen Einwanderern ausserordentlich günstig : die Arbeitsnot war womöglich noch grösser als in den Vereinigten Staaten, die Lölnne daher hoch, die einheimische Bevölkerung aber weniger gemischt als dort, und die politischen Beziehungen infolge der englisch-japanischen Freundschaft die besten. Vom Januar I904 an waren die Chinesen durch die Bestimmung, dass sie beim Eintritt in das Land eine Kopfsteuer von $500 \$ \mathrm{zu}$ zahlen haben, so gut wie ausgeschlossen, und so war erst recht wieder freier Raum für das Eindringen von

1) Ver jeiche Tabelle auf Seite 45. Das oben Gesagte teilweise nach einem Bericht der (weekly) Times London vom 27. 9. 07.

2) Nach Ogazualiira a. a. O. 8. Kapitel.

3) Brit. Columbion hat te 1901 : 178657 Einwolner d. i. o.18 auf I Km=. Vergl. Metin La Colombie Mrit. Paris 1908. 
Japanern geschaften. Ja, sie haten in Kinnula sogar das Recht, sich naturalisieren zu lassen, was sie in den Vereiniegten Staaten ganz und gar nicht hatten, so dass ihre Stellungr eine fast uningreifbare wurde. Anscheinend waren also die Bezichungen die besten, ihre wirtschaftliche und gesellschaftliche Stellung eine ausgezeicinnete." Trotzden kam es plötzlich zu Uuruhen wegen ihrer Anwesenheit.

Es hatte immer schon cine starisc Strömurg gegen die Einwanderung nichteuropiischer Arbeitsliäfte gegeben, auch cine Liga nach dem Master der amerikanischen arbeitete bereits für die Ausschliessung aller Asiaten. Nach dem siegreichen Kriege Japans gegen Russland scheint die Abneigung gegen die Zulassunger von Arbeitern aus Japan besonders stark geworden zu sein, und während einer Verfolgungsepidemie, dic an der westamerikanischen Küste ausgebrochen war und ihre Opfer zunächst unter den wenis zahlreichen Indiern gefunden hatte, kam es zu einem Exzess gegen die anwesenden Japaner, der im Anschluss an eine Protestversammlung der Exlusion League in Vancouver ausbrach. Es war dies im September 1907, und dic Unruhen wiederholten sich in der nächsten Zeit. Der Erfolg war in Kanada der gleiche wie in den Vereinigten Staaten, nur ging die Entwicklung rasche: vor sich. Die politische Freundschaft, die die beiden Regierungen verband, und das noch frische Ansehen Japans als Grossmacht liess es anscheinend nicht zu einer so grossen bedrohlichen Spannung kommen wie bei den Amerikanern." serdem waren ja nur viel weniger Japaner betroffen, und die kanadische Regierung, die durch ihre vertragliche Bindung gegen die Einwanderung der Japaner nichts ausrichten konnte, musste sich Mühe geben, eine schiedliche Lösung herbeizuführen. Sie schickte daher im November 1907 den Minister M. Lemieux nach Tokyo, und es gelang ihm der Abschluss eines FormalAbkommens, das durch einen Notenaustausch bewerkstelligt wurde. In diesen zwei Briefen, die vom 13. XII. 1907 datiert sind, wird zwar prinzipiell daran festgehalten, dass eine Einschränkung der japanischen Einwanderung nach Kanada nicht möglich ist, gleichzeitig erklärt sich aber die japanische Regierung bereit, zur Vermeidung von Unfrieden aus freien Stücken nicht

1) Der Bericht der Royal Commission on Chinese \& Japanese immigration, Ottawa 1902 - Canada Parliament Sessional paper 54, 1902, ist mir leider hier in Tokyo nicht erreichbar gewessen. Er hat aber für das von mir benützte Buch von Aubert als Matorial gedient. 2) Vergl. Metin La Colombie Britannique ; Paris IgoS. 
auf der vö!ligen Einhaltung ihrer Vertragsrechte zu beharren und die Auswanderung nach Kanada einzudämmen.

Damit war derselbe Zustand erreicht, der kurz darauf durch das Einvernehmen mit den Vereinigten Staaten herbeigeführt wurde. Gegenwärtig haben die japanischen Einwanderer in Kanada einen Pass und den Besitz von 25 \$ vorzuweisen, unterliegen aber sonst keinen Beschränkungen. Trotzdem ist die ohnehin nicht grosse Zahl von japanischen Einwanderern stark zurückgegangen. Das Ergebnis für die letzten 2 Jahre war :1)

\section{TABElle XXVIII.}

\begin{tabular}{c|r|r|r|c}
\hline $\begin{array}{c}\text { Einwanderung } \\
\text { nach Kanada }\end{array}$ & $\begin{array}{r}\text { Rechnungs- } \\
\text { jahr } \\
\text { I908-9 }\end{array}$ & I909-10 & Zunahme & $\begin{array}{c}\text { Abnahne } \\
\text { durch } \\
\text { Wanderung }\end{array}$ \\
\hline $\begin{array}{l}\text { aus Japan } \\
\text { insgesamt }\end{array}$ & $\begin{array}{r}495 \\
\text { I46908 }\end{array}$ & $\begin{array}{r}291 \\
208794\end{array}$ & 6 I886 & 224 \\
\hline
\end{tabular}

Man ist in Kanada in Regierungskreisen mit dem Erfolg dieses Zustandes recht zufrieden, wenn auch einzelne Abgeordnete aus dem Westen immer noch strenge Ausschliessungs-Massregeln verlangen zu müssen glauben. Es ist kaum anzunehmen, dass in nächster Zeit hier grössere Veränderungen auftreten, so dass die Auswanderungsfrage mit Bezug auf Kanada ebenso auf einem Ruhepunkt angekommen ist, wie für die übrigen, bereits besprochenen Gebiete.

Ich gehe nun zu einer andern Gruppe von Auswanderungszielen für Japan über, die bisher überhaupt wenig Bedeutung hatten; es sind dies Lateinisch Amerika, Australien und alle übrigen Küstengebiete des Stillen Ozeans, ausgenommen China und die japanischen Kolonien.

Der Zahl der Auswanderer nach, die diese Länder gegenwärtig bewohnen, verdient dieser Teil der Auswanderung kaum, dass man ihn näher erwähnte; denn es handelt sich auf diesen grossen Gebieten nur um wenige Tausende, so dass kein volkswirtschaftliches oder politisches Interesse stärker in Frage kommt. Aber das Bild der japanischen Answanderung soll hier so vollständig

1) Report on Immigration part II. annual rsp. I9ro Dept. of the Interior. Dominion of Canzda. Ottawa I9ro. S. 6. 
wie möglich festgehalten werden, und es gribt einige Gebiete unter den eben zu einer Gruppe zusammengefassten, die in Japan als Zukunftslïnder für japanische Ansiedler bezeichnet werden. Das sind Südamerikia und dic Inseln der Südsec sowie die Malayen-Staaten. Es gibt zwar wenig Länder, die in der japanischen Oeffentlichkeit nicht schon eine ähnliche Bewertungr erfahren hätten, aber im vorliegrenden Falle hat die Behauptung etwas für sich.

Tatsächlich herrscht auch iı viclen Lïndern Südamerikas Mangel an Arbeitskräften, und es gibt noch viel Land zu besicdeln. Aber die Löhne sind selten so hoch, dass sie wie die nordamerikanischen eine grosse Verlockung darstellen, und wemu sic dies doch tun, dann ist zu befürchten, dass sie durch ungünstige Verhältnisse aufgewogen werden. Auch waren die Verbindungen mit Japan die längste Zeit nicht die besten, und erst als die Tōyö Kisen Kaisha 1906 ihre Linien Hongkonş Japan - Hawaii - Callao - Iquique - Valparaiso einrichtete, war dieser Uebelstand behoben. Ende der goær Jahre waren kleinere Auswanderertrupps vercinzelt in Südamerika selandet. Die Aufmerksamkeit richtete sich aber erst auf jenen Kontinent, als fast gleichzeitig mit der Errichtung der neuen Schiffuhrtslinie die Auswanderung nach Nordamerika und Hawaii eingeschränkt, ja fast abgeschnitten wurde und die betreffenden Ausivanderungsgesellschaften sich nach Abhilfe umsahen. Seit diescr Zeit konnte man fortgesetzt in der japanischen Presse begeisterte Schilderungen über die Länder Südamerikas lesen, und man predigte Auswanderung und Ausdehnung des Handels nach dem verheissungsvollen Ziel. Seither folgten auch verschiedene Versuche mit der Aussendung von Auswanderern, aber die Erfolge waren sehr bescheiden. Dagegen hörte main wiederholt von Misserfolgen und Uebelständen. Es konnte natürlich nicht fehlen, dass die $\mathrm{zu}$ hoch gespannten Erwartungen der Auswanderer enttäuscht wurden, dazu kamen noch allerhand Missbräuche von Seiten der Auswanderungsgesellschaften, die der Regierung einen wahrscheinlich willkommenen Anlass zum Einschreiten boten.

Es kam nocl eins hinzu: Man hatte sich in Japan viel von den freundschaftlichen Gefühlen der südamerikanischen Republiken gegenüber Japan versprochen, aber bald musste man merken, dass diese bei Inanspruchnahme bedeutend kühler waren, als man vermutet hatte. Einige von Ihnen erliessen sogar Einwanderungsverbote oder entsprechende Massregeln, andere wieder waren 
bereits durch die Aufnahme von Chinesen, mit denen si: nachher die Japaner verwechselten, gegen die Aufnahme nichteuropäischer Kolonisten eingenommen, und andere wieder schienen das siegreiche Japan nach dem Frieden von Portsmouth für $z u$ gefährlich zu halten, um ihm in ihren Grenzen die Errichtung von Gemeinschaften zu gestatten. Dazu kamen noch Rassenvorurteile, schlechte Erfahrungen mit einem der eingewanderten Japaner, das Beispiel und vielleicht auch der Einfluss Nordamerikas, kurz es scheint, als ob die Aussichten am Schluss des ersten lustrums nach der Eröffnung der japanischen Schiffahrtslinien nur mehr bescheiden wären. ${ }^{1}$

Die wichtigsten Einwanderungssländer sind Peru und Brasilien.

Peru soll sich für Ansiedlung ganz gut eignen: das Klima ist günstig, die Arbeit für Landwitte nicht zu schwer, jedenfalls leichter und angenehmer als in Hawaii. Dagegen gibt es allerhand Krankheiten, deren 3ekämpfung freilich nicht unmöglich ist. Die Ursachen des Misserfulges für japanische Ansielder, von denen im Jahre 19104625 übrig waren, sind zum Teil schon oben zusammengefasst. Es komnst noch hinzu, dass die Meiji Shokumin Kaisha (Meiji Ansiedlungsgesellschaft) den Boden für Japaner durch unredliches Gebahren verdarb"), dass das Leben in Peru wenig Freuden bietet, dass daher die Moral der ziemlich gut mit Geld versehenen, vereinsamten Japaner leidet, da natürlich Spielen, Trinken und geschlechtlicher Genuss zu grosse Anziehung ausüben. Noch da zu wurden die armen Leute von den Agenten betrogen und um einen Teil ihrer Ersparnisse gebracht, die auf dem Wege nach der Heimat einfach verschwanden. In Durchschnitt soll ein Arbeiter 25.33 Yen im Jahre nach Japan schicken, was mit Rücksicht auf die gebrachten Opfer sohr wenig ist. Es ist naheliegend, dass die Japaner, die auch auf Hawaii und in den Vereinigten Staaten ihr Heimweh nicht unterdrücken können, erst recht nicht in Peru aushalten wollen, und zurückkehren, sobald sie können. Auch fehlt ihnen ausser dem Willen auch die Möglichkeit zur Assimilation an die nicht sehr rassen-starke Bevölkerung, und diese vergilt das

1) Die aufgeführten Gründe finden sich in einem Bericht des Sekretärs des Gaimishō Akatsuka an das Ministerium des Aeussern. Absedruckt im Band 6 der erwähnten Berichtsammlung, Tokio I9II. - Vergleiche auch Aubert a.a.O. passim.

2) Vergl. Bd. IX. der „ Bericht: usw “. 1912. 
durch Klagen äber die Beschaffenheit des jayanischen Einwanderermaterials, die schwer nachzuprüfen sind.

Der librichterstatter der japanischen Regicrung' empfichlt etwas \%ur Hebung der Lige seiner Litndslente in l'eru zu tum, da er \%ur Erkemntnis geckommen ist, dass das Schicksal der zukïnftigen Einwanderung von dem der gegenwïrtigen Einwanderer abhängt und es viel darauf ankonmt, atuf dem keineswegs aussichtslosen Boden Perus sich die notwendigen Sympathicn der Einheimischen zu bewahren. Man scheint sich auch in Japan diesen Ansichten angeschlossen zu haben, wenigstens hält es jetzt für die Auswanderungsagenten schwer, Erlaubnisse zur Auswanderung zı erhalten. Für eine kleine Zahl Auswanderer, die ausgesucht und nicht etwa durch Lügen und Ueberredungen zur Reise gewomen wurden, ist sicherlich Plat\% in Peru. Aber cinen Eirsatz für Hawaii dïrfte man dort kaum finden.")

Von der Auswanderung nach Brasilicnis wurden gleichfalls clic grössten Erfolge erwartet, da man auf das Beispiel der deutschen u.a. Kolonien im State Sao Paolo hinweisen konnte. Aber dic Ansiedlung der fremden Ankömnlinge in geschlossenen Kolonien ist vielen Bewohnern Brasiliens ein Dorn im Auge und sic dulden sie nur, wo sic angesichts anderer grosser Vorteile nicht anders können. Zur Anlegung von Siedlungen fehlt es den Japanern meist noch an Geld. Sie kanen als Plantagenarbeiter für die grossen Pflanzungen, haben sich aber nur teilweise bewährt, blieben meistens nicht auf den angewiesenen Plätzen wohnen, so dass die Staatsregierung die in Aussicht gestellten Unterstützungsgelder zu einem Teil wegen Nichterfüllung der Voraussetzungen verweigerte. Die wirtschaftlichen Aussichten für dic Einwanderer sind ziemlich günstig, aber es bedarf richtiger Siedler, die mehrere Jahre zunächst auf die Schaffung einer Heimstätte verwenden wollen, sowie etwas Kapital mitbringen. Auch die Arbeiter müssen sich natürlich erst cine zeitlang einleben, bis sie Erfolge aufweisen können. Bisher hat es die japınische Kolonie in Brasilien noch nicht auf 2000 Köpfe gebracht (die Zahlen werden so verschieden angegeben,

1) Sekretär $1 t \bar{o}$ in seinen 2 Berichten rom Jahre 19 ro in der genannten Berichtsammlung. ferligt.

2) Neuerdings wurde ein Transport von 200 Auswanderern nach Peru abge-

3) 4 Berichte in der Samulung des Gaimushō aus den Jahren rgoS-11. 
dass ich sie nicht an(ühre) ${ }^{1)}$ und ihre Zunahme vollzieht sich in mässigem Zeitmass, da die japanische Regierung sehr zurückhaltend mit der Erteilung von Pässen geworden ist. Natürlich ist für Brasilien wie Peru eine Auswanderung nur unter Beihilfe einer Auswanderungsagentur möglich, von deren Geschick und Bemühungen auih die Zukunft der japanischen Auswanderung zu einem grossen Teil abhängen dürfte. In Brasilien soll jetzt ein grösseres Unternehmen zum Zwecke der Reiskultur von japanischen Kapitalisten in Vorbereitung sein. Im Mä̀z I9I2 wurden 2600 Japaner nach Brasilien gebracht für deren Transport die Regierung von Sao Paolo den Auswanderungsgesellschaften als Beitrag zu den Transportkosten io $\$$ für jeden Mann, $8 \$$ für jede Frau und $6 \$$ für jedes Kind über 4 Jahre zahlt. Die japanische Regierung hat die Erlaubnis zu diesem Unternehmen nach langem Drängen der Gesellschaften versuchsweise erteilt, nachdem Baron Ucihda die Leitung des Auswärtigen Antes übernommen hatte.

In den übrigen Staaten Südamerikas ist die Zahl der anwesenden Japaner kaum nennenswert. Zum Teil sind sie von Peru oder Brasilien herübergekommen. Die Berichte der Regierung schildern diese Länder meist als nicht ohne Aussicht, aber immer wieder wird verlangt, dass nicht Leute ohne Vermögen oder solche, die das Ansehen Japans gefährden könnten, hinausgeschickt werden. Bei Chile und Argentinien wird sogar aufmerksam gemacht, dass die Haltung des Volkes gegenüber asiatischer Einwanderung vielleicht zu Bedenken Anlass gebe.")

Im Zusammenhang mit den südamerikanischen Auswanderungszahlen wäre noch kurz Mcxiko zu erwähnen." Die Schicksale der Auswanderer in diesem Staate sind ähnlich wie in den übrigen Staaten Lateinisch Amerikas: Die Auswanderung ist jung, wenig zahlreich, doch hat sich ein Bruchteil von ihr

1) Nach einer Aeusserung des Vize-Konsuls Noda aus Rio de Janeiro, in der Osaka Mainichi (abselruckt im Japan Weekly Chronicle vom 24. VIII. I9II) gibt es derzeit etwa I 400 Japaner in Brasilien, die meist Plantagenarbeiter, Bergarbeiter und Zimmerleute sind. Ein Bericht von Fujita im Bd. IX. der „Berichte usw.“ 1912 spricht von 788 Japanern im März I9II.

2) Berichte (in der Sammlung des Gaimushō) ïber Kolumbien, 19ro, Argenlinien r9ro und r911, Chile r908 und 1909 und Bolivien r909.

3) Ueber Mexiko vergleiche den Bericht aus dem Jahre 1908 in der Sammlung das Gaimusho, einen Bericht in der Jap. Times vom I. IV. Igrr und Ogazuahira a.a.O. 8. Kapitel. 
hübsche lirfolge gresichert. Fin oft besprochener Versuch ist die von Vicomte Emomsto angelegte japanische Siedlung in Isidoro, die zuerst Erfoly \%u haben schien, sich aber später auflöste. Ihre Mitglieder \%oren \%um Teil in die nahe Kleinstadt Chapas, wo sie sich mit der eingeborenen Bevölkerung vernischt zu haben scheinen. Eine nete Meldung besagt allerdings, dass es dort auch eine japaniscise Schule gebe, so dass das $\Lambda$ ufgehen in der Bevölkerung in Zweifel gezogen werden könnte. IVenn es stimmt, dass die Zahl der Japaner I91 I : 2479, I9oS aber etwas über 3000 war, so kann hicr von einem Fortschreiten der japanischen Einwanderung nicht gesprochen werden. Es wäre möglich, dass das eine Folge der japanischen $A$ uswanderungspolitik ist, die sich genötigrt sah, auch die Abfahrten nach Mexilo 1907 einzudämmen, um zu verhindern, dass ihre Auswanderer heimlich über die ungeschützte Grenze der Vereinigten Staaten dringen, wie das 1900 in grossem Umfang geschehen sein soll.

Im Stillen Ozean wäre natürlich seiner wirtschaftlichen und Bevölkerungsverhältnisse, auch seiner Ausdehnung wegen, Australien und Neusceland das vorzüglichste Ziel für japanische Auswanderung. Aber diese britischen Kolonien sind so zäh in der Verfolgung ihrer Besiedelungsideale, des IVhite Alustralia, dass sie die allerschärfste Ueberwachung der Einwanderung durchfülaren, und seit Jahren nur mehr wenig japanische Einwanderer Einlass finden. Die jetzt noch vorhandenen sind zum grössten Teil Perlenfischer, an deren Verdrängung man aber bereits arbeitet. ${ }^{1)}$

So ist eigentlich im Süden das aussichtsreichste Gebiet versperrt. Auch das übrigbleibende Inselgebiet und die angrenzenden Teile Ostasiens besitzen noch genug Anziehungskraft für eine bestimmte Gruppe japanischer Politiker, die durch den Namen des Abgeordneten Y. Takekosli: gekennzeichnet wird. Dieser ist ein unermüdlicher Anwalt der Auswanderung nach dem Süden, dessen menschenarme Gebiete mit Lebensbedingungen die denen der japanischen Inseln ähnlich sind, von ihm als ein

1) Ph. S. Edershaw B.A. S P.P. Olden, Univ. law school. Sylney. "The exclusion of Asiatic Immigrants in Australia in "The Annals of Academy of pol. \& soc. science." Vol. XXXIV/2 1909. p. I90 ff. Zur Einwanderung zugelassen wurden 1903: 558; 1904: 46I; 1905: 25x; 1906: 356; 1907:521; 1908 : 555; 1909 : 509 ; 1910 : 565 Jap ın:r. Die Zahl der Ausgewewanderten ist mir nicht bekannt. Vergleiche Official Yearbook of the Commonivealth of Australia, Containing statistics for the period I901-ro. Nelbourne I911. S. I155. 
begehrenswertes Besiedlungsobjeltt für seine Nation hingestellt werden. Selbstverständlich ist aus politischen Gründen gar nicht daran zu denken, dass die Mächte, die das Kolonialreich unter sich a'ıfgeteilt haben, eine planınässige Kolonisation ihres Besitzes dulden könnten, aber man muss Takekos/li beistimmen, wenn er behauptet, dass da unten das natürliche Feld für japanische Ausdehnung wäre. Bis zu einem gewissen Grade gibt auch die Stellung der japanischen Schiffahrt und des japanischen Handels auf den Inseln dieser Behauptung Nachdruck. Wenn diese Tätigkeit nicht ausreicht, un Japan dort unten irgend einen Einfluss zu sichern, so kömmt das daher, dass das wirtschaftliche Leben meist nicht sehr rege ist, und die politischen Gründe die einzig ausschlaggebenden sind. $\mathrm{Zu}$ einer nachhaltigen Kolonisation fehlen übrigens Japan sowohl die Kapitalien als auch die Menschen, die bereit sind ihrem Vaterlande auf lange Zeiträume, wenn nicht für immer zu entsagen.

Es ist eine verhältnismässig grosse Anzahl über alle Inseln hin verstreut, aber absolut sind cs nur wenige tausend auf einem ungeheuren Flächenraum. Die meisten von ihnen sind auf den französischen Inselgruppen, besonders in den Nickelgruben von Taliti, wo seit 1892 japanische Arbeitertrupps gelandet wurden, die sich sehr gut bewähren sollen. Aehnlich steht es mit französisch Neukaledonien wo jetzt über I 700 Japaner, fast nur Arbeiter, leben. Diese werden nach einigen Jahren abgelöst, verdienen inzwischen ziemlich gut, so dass sie etwa ein Viertel ihres Lohnes ersparen können, haben aber ein wenig genussreiches Leben. Frauen befinden sich fast gar nicht unter ihnen. Früher gab es viele Fälle von Beriberi unter den Auswanderern nach den Inseln, doch soll das jetzt behoben sein. In Australien hat man wegen der dichten Besiedlung der kleinen, verhältnismässig nahe gelegenen Inseln mit Japanern wiederholt schon Nervosität gezeigt. Auch bis nach Reunion sind japanische Auswanderer gelangt.

Auf niedcrländ. Borneo, Sumatra, britisch Nordborneo, den Fidsclsi Inseln und einigen andern englischen Inseln gibt es einige hundert Japaner, übrigens meist weiblichen Geschlechtes, die von der Prostitution leben, sonst nur wenige versprengte Matrosen und Kaufleute, die Reste einer früher etwas zahlreicheren Schar. Ihre wirtschaftlichen Verhältnisse sind beschei-

2) Bd. VIII der , Berichte “ Tokio IgII. 
den, manchmal gut." Auch auf alen deutscluen Inseln leben Japanes.

Auf den Plsilifpincn gibt es beinahe zojo Japancr. Dort ist zwar eigentlich jede asiatische linwanclerung von der amerikanischen Regierung verboten, aber das Vejbot scheint nicht strenge gehandhabt zu werden, dem auch jetyt noch findet eine likine Einwandering statt. Charakteristisch ist für dic frülace binwanderung nach den Philippinen, dass sie meist olne Inanspruchnahme von Agenturen vor sich ging. Sic begrann etwa r 898 und stieg langsam bis 1902. In diesen 5 Jahren kamen insgresamt 595 Männer und I 35 Frauen hinülser, von denen I 27 Männcr und 45 lìnen zurückwanderten, SS starben, während 10 plus 6 durch Geburt hinzukamen. Es waren meist Fischer und Seeleute, die sich oft nur vorübergehend aufnielten. Von 1903-rgos nahm die Einwanderung zu und brachte vicle Kontraktarbeiter zur Aufführung der vielen öfentlichen Bauten, dic dic Vereinigten Staaten in ihrer neuen Kolonie aufführen liessen. Im ganzen kamen damals 3277 Japaner, zunächst nur für öffentliche Arbeiten, dann auch für Bargwerk und Landwirtschaft. Seit Igog hat die Einwanderung aus Japan wieder abgenommen, da die offentlichen Bauten meist wieder eingestelit sind. Im letzten Berichtsjahr gab es 1919 Japaner, davon 35\% Zimmerleute, $16,4 \%$ landivirtschaftliche Arbeiter, I I, $4 \%$ Prostituierte und dergl., S, I \% Dienstboten, 4.4\% Handiungsgehilfen und 24.4\% andere. Auch jetzt noch dauert die Einwanderung fort, doch vermisst man wiederum Leute die etwas Geld mitbringen. Die Aussichten für die Ansiedlung von kleinen Landwirten sollen günstig sein.2) Die Japaner sind bei der eingeborenen Bevölkerung recht gut aufgenommen und scheinen sich ziemlich wohl zu fühlen. Nur gab es manchmal Missstimmung durch die vermutete Anwesenheit von Spionen, nach denen die amerikanischen Behörden mit Eifer fahndeten.

In Franä̈siscl, Indien,"3) Siam ${ }^{4)}$ und in den Malaycnstaatin finden sich wenige hundert Japaner in allerhand Lebensstellungen

1) Nehrere Berichte des Auswärtigen Amtes in Tokyo IgoS-r2. auf Sumatra lebən etwa 60د Japaner; 2/3 davon sind Prostituierte.

2) Bericht des Gaimusho wie oben Dez. rgoS; Russcll M:Culloch Stury A.MI. Oriental Immigration into the Philipines; The Anuals of the Am. Academy of pol. \& Soc. science XXXIV/2 ri,09 p. I68 ff.

3) Ministerialbericht (wie o'sen) Band 4. 19 ro.

4) Ebda.

5) Ebrla. 
verstreut, davon ein ansehnlicher Bruchteil als Kaufleute. Sie haben hart gegen den Wettbewerb der Chinesen, Javaner und anderer Völkerschaften anzukämpfen, auch sind die Löhne nicht hoch, wohl aber die Kosten des Lebensunterhaltes gering für Eingeborene und Chinesen. Die Berichterstatter der japanischen Regierung empfehlen diese Länder nicht gerade zur Einwanderung, aber sie heben hervor, dass Leute mit einigem Kapital vielleicht ganz hübsche Erfolge erzielen könnten. In den Malayenstaaten sind die Aussichten etwas günstiger. Man hofft, in den Kautschukpflanzungen japanische Ansiedler in grosser Zahl unterbringen zu können, und wie ich von einem Beamten einer Auswanderungsgessellschaft erfuhr, sind diese Ernittlungen, auf die man allerhand Hoffnungen setzt, noch nicht abgeschlossen. Es ist nicht unmöglich, dass künftig die Zahl der Auswanderer nach diesen Gebieten zunimmt, aber es scheint mir zweifelhaft, ob dort tatsächlich grössere Massen dauernd untergebracht werden können, da die Bevölkerung sehr zahlreich ist, und es sich nicht um einen Mangel an Menschen, sondern nur um einen solchen an Arbeitskräften handelt. Auch genügen die Löhne nicht den Ansprüchen der Japaner. ${ }^{1)}$ Für Niederländisch Indien verzeichnet die oben wiedergegebene Statistik des Auswärtigen Amtes (Seite I6 Tabelle V.) 78 I Japaner im Jahre 1909, doch ist mir nichts Näheres über ihre Beschäftigung bekannt. Ein Mangel an Menschen besteht jedenfalls in ganz Indien nicht.

Dasselbe ist der Fall in China, wo eine stattliche Anzahl von Japanern sesshaft ist. Der grösste Teil von ihnen wohnt allerdings in den unter japanischer Verwaltung stehenden Ländern, doch leben auch in dem übrigen China noch recht viele Japaner, die natürlich unter einem Volk, dessen Angehörige auf Hunderte von Millionen geschätzt werden, der Zahl nach nicht ins Gewicht fallen. Angaben über Zahl und Beschäftigung sind mir nicht bekannt, da die Auswanderung nach China nicht so sorgfältig überwacht wird und aus dem Innern des Landes auch nicht viel zu erfahren ist. Es kann sich natürlich nur um Kaufleute und Gewerbetreibende handeln, da in dem dichtbesiedelten, ungeheuren Land für Kolonisten kein Platz ist.

In Russisch Ostasien ${ }^{2 j}$ gibt es einige tausend Japaner, die

1) Seit wenigen Jaluren haben auch japanische Kapitalisten Gummipflanzungen in den Malayenstaaten erworbın; rgr r hatten sie 83789 acres, auf denen wohl viele Japaner ein Unterkommen finden können (B」 VIII der „Berichte." Tokio 19rI).

2) C. v. Zeppelin. Der ferne Osten 3. T'eil (Russland in Asien B.1. XI) Berlin 1911 Seite 50-51, 55-58;-Ministerialbericht Tokyo (wie oben) liand 1. rgós. 
teils als Fischer hinkamen, teils von den grossen Bauten angelockt wurden, die dic russische Regierung auffuhren liess. Die erste Gelergenheit dieser Art war die Verlegung des Kriegrhafens von Nikolajewsk nach Wladiwostock (1872). Seither gibt es dort noch immer Zimmerlente, Tischler und kleine Händler japanischer Nationalität. Später kam dann cine regelmässige Dampferverbindung mit Japan zustande, es wurde: eine konsularische Vertretung Japans eingerichtet, und die japanische Kolonie nahm cinen dauernden Charaliter an. Der Bau der Ussuribahn übte wieder starke Anzichungskraft aus und gab vielen Mensche: Beschäftisung. Nach dem Krieg wurclen die Japaner durch den Handelsvertrag von 1907 sehr günstig gestellt und erhielten dieselben Rechte wie der russische Untertan. Sic hatten aber inzwischen an Zahl abgenommen, da sie bei Beginn des Kricges das Feld hatten räumen müssen. Es wird besonders hervorgehoben, dass die Japaner ausserordentlich fest durch Vereine und berufsgenossenschaftliche Organisationen zusammengeschlossen sind und sich dadurch gegenseitig forthelfen, so dass alle Ankömmlinge, die durchwegs ohne Geld sind, bald in dic Lage kommen, Ersparnisse in die Heinat \%u schicken. Der nach russischen Quellen zusammengestellte Bericht $\%$. Zcppelin's weiss noch von eine!n sorgfältigen Ausbau des japanischen Nachrichtendienstes zu erzählen, dem sogar die kleinen Fischerboote dienstbar gemacht werden und von einem regen Schlcichhandel, der von den Japanern insbesondere von ihrer Kurilen-Insel Schumschu aus betrieben wird. Diese Angaben erhalten beständig Bekräftigung durch Berichte ostasiatischer, namentlich russischer Zeitungen, nach denen die Küste Nordostasiens bis tief ins Land hinein von einem wohlorganisierten Heer japanischer Spione durchforscht wird. Als Stationen dienen dabei neben den japanischen Konsulaten eine grosse Anzahl über dis ganze Land verstreuter japanischer Händler, Restaurants und Bordelle, die regelmässig von Berichterstattern besucht werden. Japanische Prustituierte sind auf dem asiatischen Kontinent sehr stark vertreten; in Charbin allein gab es I9I 2 nach einer mir gremachten Mitteilung eines schr zuverlässigen Gewährsmannes 30o. Auch die Klagen über Schleichhandel und ungeniertes Spionieren in den russischen Gewässern durch japanische Fischerboote wollen nicht verstummen; sie sind ein Beweis für die feste Stellung Japans auf dem Kontinent. Aus Zeitungsmeldungen scheint hervorzugehen, dass die japa- 
nische Einwanderung in letzter Zeit zurückgegangen ist, und dass die beiden beteiligten Regieruugen einverständlich ihre Hand im Spiel gehabt haben. Das würde sich ganz gut in das Bi!d einpassen, das die Einwanderungspolitik der russischen Regierung sonst darbietet. Es scheint, dass man dort versucht, sich ganz von fremden Arbeitskräften unabhängig zu machen, denn man ist auch gegen chinesische und koreanische Arbeiter sehr schroff mit Ausweisungen vorgegangen. Wie weit in jenen menschenarmen Gebieten solche Massnahmen durchführbar sind. und wie sich diese Verhältnisse in nächster Zeit gestalten werden, ist bei den wechselvollen Schicksalen jener Provinzen schwer vorauszusagen. Es liegt nahe anzunehmen, dass die russische Regierung, die keinen Grund hat, sich mit Japan von neuem zu verfeinden, zwar den japanischen Auswanderern keine Hindernisse in den Weg legt, keinesfalls aber gestatten wird, dass sich irgendwo grössere geschlossene Ansiedlungen von Angehörigen einer Macht bilden, mit der sie noch vor wenigen Jahren einen so blutigen Krieg geführt hat.

Ein Rückblick über die Auswanderung nach den in der 2. Gruppe (Seite II4 - I24) zusammengefassten Lïnder zeigt, dass sie sich mit der nach Nordamerika nicht vergleichen lässt. Hier handelte es sich um ein grosses Gabiet mit hohen Löhnen und lebhaftem Arbeiterbedarf, der es ermöglicht, dass geschlossene Massen mittelloser und garnicht vorgebildeter japanischer Arbeiter hingebracht werden, nicht nur ein reichliches Auskommen, sondern auch Gelegenheit $z u$ raschem wirtschaftlichen Aufsteigen finden, ein Gubiet, das zugleich eine Schule westländischer Kultur darstellt und die Heinkehrenden mit erweiterten Kenntnissen und Erfahrungen entlässt. Die übrigen Länder des Stillen Ozeans dagegen bieten, soweit sie überhaupt der japanischen Einwanderung offen sind, zwar zum Teil nicht ungünstige Aussichten, aber meist keinen hohen Lohn und keine Gelegenheit zu raschem Aufiteigen. Es bedarf schwerer Arbeit und langjähriger Bemühungen, um zum Erfolg zu gelangen, und dieser ist nur dem in Aussicht gestellt, der wirklich ein Bürger des neuen Landes zu werden und für seine Segnungen auch die Lasten mitzutragen bereit ist, die ein junges Staatswesen dem Kolonisten aullegt. Grössere geschlossene Ansiedlungen sind in Südamerika und auf einigen andern Gebieten nicht unmöglich. Aber sie verlangen namhafte Aufwendung von Mühe und etwas Kapital, dann aber auch Vorbildung, und es "ist 
wenigr Grelegenheit geboten, sich alles dies in neuen Lande selbst, am allerweniesten aber in ku\%er \%eit \%u erwerben. Dic Erfolge, die in Aussicht stehen, sind bescheiden bis grut. Auch für den Kinfmann ist cin weites field gesteckt, aber er muss gleichfills Creld und Kenntnisse mithringen und nicht darauf ausgehen, in wenigea Jahren sem Glück \%u machen. Dics alles hat bisher nur eine kleine Schar von Japancen ansezogen und unter ihnen sind die Angehörigen der nichtewalifizicrten Berufe, die Kontraktarbeiter noch eine ansehnliche Mehrheit. Die vorhandenen Erfolge scheinen in Jeimatland wenig Eindruck gemacht zu haben, und man sucht weiter nach einem Ersatz für Hawaii, statt die gebotene Galegenheit zu ergreifen. Es scheint, dass der Wettbewerb unter gleichen Bedingungen, wie er in den Gebieten der 2. Gruppe den Japancrn angeboten ist, ihnen keine grenügende. Bürgschaft des Gelingens für ihre Auswanderer bietet, und so lieģt es nahe, sich nach den Schicksalen ihrer Ansiedler in den eigenen Kolonien umzusehen, wo sie ja zugleich die Herren des Landes sind.

Die Auswanderung nach den japanischen Kolonien. Die älteste japanische Kolonic ist der Hokkaido, der heutzutage zwar als cin Teil des Hauptlandes gilt, der aber noch durch seine schwache Besiediung und durch scine Verwaltungseinrichtungen einen besonderen Charakter erhält, der mich nötigt, ihn hier im Zusammenhang mit den übrigen Kolonien zu erwähnen. Fr ist gegenwärtig das Hauptgebiet der japanischen Kolonisation, das einzige, auf dem grössere Erfolge aufzuweisen sind.

Einc genauere Schilderung seiner Verhältnisse darf ich mir hier ersparen, da bereits ein kleines Buch von K. Takarka über ihn in deutscher Sprache vorliegt, das sich mit der Frage seiner Besiedlung beschäftigt. ${ }^{1)}$ Dieses Gabiet, das etwa 1/4 des ganzen japanischen Hauptlandes ausmacht und etwa ziveimal so gross wie Holland ist, ist noch ausserordentlich schwach besiedelt : es kommen beiläufig 12 Einwohner auf das $\mathrm{km}^{2}$ gegenüber einem

1) Dr. K: Takaoka. Die innere Folonisation Japans. I.eipzig I9o $;$; Band XXIII, Ileft 3 der von Schmoller und Serins herausgegebenen ,Staats- und sozialwissenschaftlichen Forschungen“. Der Titel verspricht zu viel, denn das Buch bezieht sich nur auf clen Hokkaidō und berïhrt gar nicht die Frage, was sonst an kolonisatorischen Leistungen in Japan ausgefiihrt wurde oder auszuführen wäre. Auch ist das Buch ersichtlich für das Ausland geschrieben.

Vergleiche auch eine von der Provinzialregierung in Hakodate I9 ro herausgegebene Geschichte der Ansiedlung im Hokkaidō, (japanisch) die aller.lings etwas rosig gefärbt zu sein scheint. 
Durchschnitt von I 30 für das ganze japanische Hauptland und dabei reicht die planmässige Besiedlung der Insel schon weit vor die Meiji Aera zurück. Sie wurde aber erst von einem verhältnismässig späten Zeitpunkt an crfolgreich, da früher die Interessen der Landesverteidigung mehr betont worden waren als die der Besiedlung und auch der mangelhafte Verkehr zu grosse Schwierigkeiten geboten hatte. Charakteristisch für die ganze Kolonisationstätigkeit der Regierung, die durch die verschiedensten Organe, am erfolgreichsten aber durch eine Art Kolonialregierung betrieben wurde, die heute noch besteht, ist, dass es sich fast durchwegs um Ansiedler handelte, die von der Regierung geworben und festgehalten werden müssen. Der freiwillige Zuzug scheint ganz ungenügend $z u$ sein und vielleicht auch nicht immer das gewünschte Menschenmaterial zu bringen. Auch sind die Zuzügler wenig sesshaft, so dass nicht selten, wem eine Aenderung in der Kolonisationspolitik eintrat, die Einwanderer wieder fortzogen.

Auch gegenwärtig wird die Einwanderung sehr ernutigt, die Einwanderer erhalten grosse Fahrterleichterungen, Preisermässigungen, es gibt verschiedene Auskunftsstellen für Auswanderer nach Hokkaidō in den wichtigsten Hafenplätzen Japans, Vorsorge für die neuankommenden Ansiedler usw. Das verfügbare Land wird nach den im Gesetz vom 15. IV. Ig08 (bis dahin galt das von I \&97) festgelegten Grundsätıen an die Ansiedler aufgeteilt. Das noch nicht urbar gemachte Land wird zunächst pacht- oder leihweise ausgegeben und ist Io Jahre von der Beendigung der Kulturarbeit angefangen steuerfrei. Es ist vorgesehen, dass das vergebene Land auch wirklich landwirtschaftlich nutzbar gemacht und nicht etwa zu Spekulationen benutzt wird. Für die Vertcilung der Ländereien sind Grössen-Maxima festgelegt, die von 500-80) cho schwanken. Früher, als es kein Maximum gab, wurden manchmal ganz grosse Ländereien an einzelne ausgegeb:n, und die Folge hiervon war, dass von den I880-I 895 vergebenen Landstellen $32 \%$ über 100000 tsubo (d. i. 33.05 ha) waren, was Takaoka angesichts der landwirtschaftlichen Verhältnisse Japans

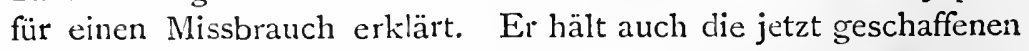
Grössen-Maxima für zu reichiich, da nach seiner Ansicht ein Gut von 50 ha in Hokkaidō schon als Grossbetrieb zu bezeichnen sei. Die grösseren Lose geben ihren Eignern nur die Möglichkeit, sie weiterzuverpachten, und das sei entschieden weniger zuträglich, als wenn es zahlreiche Eigenwirte auf den Inseln gébe. 
Dic lirfolge der Kolonisationstittigkeit sind immerhin als recht befriedigend $\%$ be\%cichen. Seit 1886 , der Zeit, wo das gregenwairtige Regierungssystem eingeführt wurde, sind rund I Million ha Lind an 201703 Ansiedler vergeben worden. Davon wurden allerdings $23.3 \%$ zurückegegreben, was anscheinend zum Teil Schuld der Verwaltungr ist. Nach den Berechnungen Takaokias strönten von $\mathbf{1} 869-1901696204$ Ansicdler ins Land. Dic Zahl der Rückwanderer ist nicht für den ganzen Zitraum bekannt, doch ist sie nicht unerheblich und dürfte rund $\mathrm{r} / 6$ der Eingewanderten betragen. Dic Statistik gibt über diese Erscheinungen wenig Auskunft, cbenso wic bei der Auswandurung nach dem Ausland. Den grössten Teil der Einwanderer bilden Landwirte und Fischer, und natürlich wandern mehr Männer als Frauen ein. Dass unter den Rückwanderern der Anteil der Landwirte ein geringer ist, ist selbstverständlich und auch, dass die Frauen, die ja meistens mit ihren Familien auswandern, sesshafter sind als die Männer. Dic Ansicdler rekrutieren sich in erster Linie aus den dem Hokkaidō zunächst gelegenen Landesteilen, die selbst wieder nicht allzustark besicdelt sind und dadurch für Nachrückende wieder Raum gewinnen. Für die letzten Jahre weist die Statistik folgende Zahlen aus:1)

\section{Tabel.le XXIX.}

\begin{tabular}{l|c|c|c}
\hline & $\begin{array}{c}\text { Einwanderung nach } \\
\text { dem Hokkaido }\end{array}$ & $\begin{array}{c}\text { Auswanderung aus } \\
\text { mehr }\end{array}$ \\
\hline I903 & 44942 & 8738 & 36204 \\
I904 & 501 II & 9027 & 41084 \\
I905 & 58224 & 10395 & 47829 \\
I906 & 66793 & 10092 & 56701 \\
I907 & 79737 & 13457 & 66280 \\
I903 & 80578 & I 5578 & 65000 \\
I909 & 63948 & I 3799 & 50049 \\
I910 & 59905 & I 3725 & 44980 \\
\hline
\end{tabular}

1) Rẻs. stat. du Japon I9II. S. 30; die Zahlen für Igro aus amll. Quellen. (mündl. Mitteilung). 
Der Zuwachs ist also Veränderungen unterworfen, und der Prozentsatz der Rückwanderung noch beträchtlich hoch; es bleibt abzuwarten, ob es nicht gelingen wird, ihre anscheinend unbekannten Ursachen zu bekämpfen.

Takaoka berechnet inj Jahre 1904, dass die Regierung noch 2.24 Millionen Hektar zu vergeben hatte, und dass der Hokkaidō überhaupt 4 Millionen Menschen zu fassen imstande sei, so dass bei dem Fortdauern der gegenwärtigen Zustände in 33 Jahren, also 1937, die höchste Grenze der Besiedlungsfähigkeit erreicht sein müsse. Dann würde allerdings der Hokkaidō noch längst nicht dieselbe Bevölkerungsdichte aufweisen wie das übrige Japan, denn wollte man diese erreichen, so müsste man ihn mit mehr als 9 Millionen Menschen anfüllen. Regierungskreise rechnen angeblich mit einer Aufnahrnsfähigkeit des Landes von 6 Millionen Einwohnern, so dass Takaoka vielleicht etwas zu tief gegriffen hat. Da der Hokkaidō im Jahre I908 I.45 Mill. Einwohner aufwies, so wären selbst nach Takaok:x noch immer 2.55 Millionen dort unterzubringen, und es bleibt fraglich, ob tatsächlich jedes Jahr 50000 neue Ansiedler ins Laná kommen werden, und die ansässige Bevölkerung sich durch Geburtenüberschuss jährlich um 1.79\% vermehrt, Angaben, die Takaoka zur Grundlage seiner Berechnung gemacht hat. ${ }^{\mathrm{l}}$ ) Jedenfalls besitzt Japan in seinem Niederlassungsbereich noch ein weites ind aufnahmefähiges Feld für seine überschüssige Bevölkerung in den nächsten Jahrzehnten.

Anstossend an diese älteste Kolonie Japans, den Hokkaidō, liegt seine zweitjüngste, Sachalin, das seit dem Kriege mit Russland bis zum $50^{\circ} \mathrm{zu}$ Japan gehört. Es hat eine Ausdehnung von 2,20S.92 $\mathrm{ri}^{2}{ }^{2}$ ) und ist beinahe so gross wie Formosa. Die Insel hat reichen Wald- und Kohlenbestand und liefert Fischern eine gute Ausbeute. Des Klimas wegen ist die Landwirtschaft nicht so aussichtsreich wie auf dem Hauptland, doch bietet die Forstivirtschaft im Winter genügend Beschäftigung.

Das Land war bei der Uebernahme in japaniscise Verwaltung so gut wie unbekannt und fast gar nicht besiedelt, so dass

1) Nach einer Ermittlung der Polizei in Hokkikidō soll der Geburtenüberschuss zwischen I902 und rooS sogar I.9\% im Jahr gewesen sein. In Kolonialamt zu 'Tokyo rechnet man iibriggens auch nur mit einer Aufnahmefähigkeit von 4 Mill Menschen im ganzen.

2) Finanzielles und wirtschaftliches Jahrbuch von Japan I9II. I ri $^{2}=15$. $423+7 \mathrm{~km} 2$. 
die Kolonialbehörde zunichst an die Aufnahme des Lundes schreiten musste. Die Untersuchumeren sind noclı nicht abgeschlossen.

Man ging sofort daran, das I, and zu besiedelu, und beabsichtigt, jührlich 103-500 Familien ansässig \%u machen. Dic Familien bekommen unentegeltich I and anerewiesen, und zwar 1000 tsubo $(=33.057$ a) per liamilic in der Stadt und das füntfache auf dem Lande, wem es zum Aclicrbau, das 50 fache, wenn es nur zur Vielyzucht gecignet ist. Das Land wird nicht in Pacht, sondern als Eigentum ausgegeben. Den Ansiedlern wird eine Reile von Vurgünstigungen ertcilt: 30-50\% Nachlass aut den Bahnen und Schiffen zur Zuwanderung, Freifalirt auf den Balinen in Sachalin unentgeltliche Austeilung von Satgetreide, leihweise Ueberlassung von Vieh (für jede Familic I Pferd, I Schwein, I Ochse), das mach 5 (2) Jahren zurücligestellt bezw. durch anderes ersetzt werden muss, Bargeld fur die Aufführungr cines Hauses, Unterstïtzung der Vichzucht, Unterstützung beim Ankauf landwirtschaftlicher Maschinen.

Das Ergebnis der Ansiedlung ist bisher folgendes:

\section{TABelle XXX.}

\begin{tabular}{c|c|c|c}
\hline & $\begin{array}{c}\text { Neu zugewan- } \\
\text { derte Familien. }\end{array}$ & $\begin{array}{c}\text { Bis zum Ende des } \\
\text { Jahres waren } \\
\text { zugewandert. }\end{array}$ & $\begin{array}{c}\text { Am Ende des } \\
\text { Jahres waren } \\
\text { noch anwesend : }\end{array}$ \\
\hline 1906 & 365 & - & \\
1907 & 433 & 798 & 794 \\
1908 & I 16 & 914 & 830 \\
I909 & IOI & IOI 5 & 866 \\
I910 & I38 & I I53 & 1065 \\
\hline
\end{tabular}

Diese Zahlen stimmen nicht mit den im (jap.) statistischen Jahrbuch von I9Io (Seite I040) veröffentlichten, wo für das Jahr I909: 2382 zugewanderte und I 549 fortgewanderte Familien ausgewiesen sind. Die Unterschiede sind allerdings bedenklich.

Nach den Angaben des Kolonialamtes waren in Jahre I909

1) Die Angaben über Sachalin sind meist dem entsprechenden Kapitel aus einer Denkschrift entnommen, die das Kolonialamt in Tokyo (I9Io?) über die „japanische Auswanderung nach den japanischen Kolonien " herausgab. 
I I 7,8 cho, das sind fast ebensoviel Hektar, von Einwanderern bestellt. Diese haben zunächst ein anstrengendes Leben zu führen, doch verspricht man sich eine baldige Besserung ihrer Lage, wenn erst das Anfangsstadium überwunden ist. Das jährliche Einkommen einer landwirtschaftlich tätigen Familie wird auf 200-250 Yen beziffert. Die Löhne der Arbeiter sollen recht günstig sein, auch die gesundheitlichen Zustände werden gelobt. Die Forstwirtschaft soll sehr aussichtsreich sein, und man sieht einen grossen Bedarf an Arbeitskräften für diese und die damit in Verbindung stehende Industrie voraus, deren Entwicklung aber noch nicht in Angriff genommen ist. Auch die Fischerei soll erfolgversprechend sein. An der Westküste sind bereits 2 Abschnitte verpachtet, die das Beste hoffen lassen. Bis jetzt zälılt der Bericht 3540 Fischer auf Sachalin.

Soweit sich aus den bisher zur Verfügung stehenden dürftigen Angaben ein Schluss ziehen lässt, ist es der, dass hier ein stattliches Gebiet mit vielversprechenden Hilfsquellen zu erschliessen ist, das voraussichtlich eine grosse Anzahl von Japanern beherbergen kann. Bis 1910 zählte die Kolonie rund 31000 Einwohner. ${ }^{1)}$ Beinahe die Hälfte der Einwanderer scheint aus dem Hokkaidō zu konmen, der sicherlich einen guten Uebergang bildet. Die geringe Sesshaftigkeit der Einwanderer ist hier noch viel auffallender als bei den andern Kolonien, und es wäre interessant zu wissen, worauf diese Erscheinung zurückzuführen ist. Laider fehlt es auch zur Beantwortung dieser Frage an Material.

Bis I9I hat die Landesvermessung 150000 cho bebaubare Fläche ergeben, von denen jeder Ansiedlerfamilie 7.5 cho zugeteilt werden, so dass man 20000 Familien, also etwa 80000 Menschen darauf ansässig machen kann. Rechnet man dazu ebensoviel Gewerbtreibende, Händler u. Angehörige freier Berufe, so gibt das eine Besiedlungsfähigkeit des Landes von 160000 Menschen auf dem vorläufig untersuchten Gebiet.") Nach der zitierten Denkschrift von I9Io war übrigens die bebaubare Fläche grösser. Dazu kamen noch 90 cho Kohlenfelder. I 50000 cho bebaubare Fläche stellen nur etwa $1 / 20$ der Oberfläche der Kolonie dar. Es ist anzunehmen, dass weitere Landvernessungen noch eine grössere Bebauungsfähigkeit und damit Besiedlungsfähigkeit ergeben werden.

1) Mündl. Mitteilung im Kolonialamt.

2)

, 
Gan\% andere Verhältuisse \%eigt die Kolonic Jiormose (japanisch: Taivan), dic heute den südlichsten Teil des japanischen Inselieiches bildet. lis gehört seit 1895 , dem fricelen von Shimonoseki, \%u Jurm, und dieses hat also nur wenig Zeit gehabt, um dort scinc kolonisatorischen Fälnigkeiten zu erweisen. liekanntlich ist es ihm trotzdem bereits geglüclit und ein weiteres Kennzeichen seiner fihigen Verwaltung ist, dass es bereits cine Volkszählung durchgeführt hat und über Material verfügt, wie es leider noch nicht cimmal auf dem Hauptlande zu haben ist. ${ }^{\text {") }}$

Dic Insel hatte zur Zeit der Volkszählung im Jahre 1905 eine Bevölkerung von 303975 I Einwohnern, wobei die wilden Fingeborenen-Stämme nicht mitgezählt sind. Diese bewohnen die Gebirgsgegend, die das Innere der Insel bildet. Die übrige Einwohnerschaft zerfällt in Formosaner, meist Chinesen und friedlich gemachte Eingeborenenstämme, in Japaner und Fremde, die meist wieder Chinesen sind. Die japanische Statistik weist für das Jahr 1907 die folgende Zusammensetzung der Bevölkerung auf: ${ }^{2}$

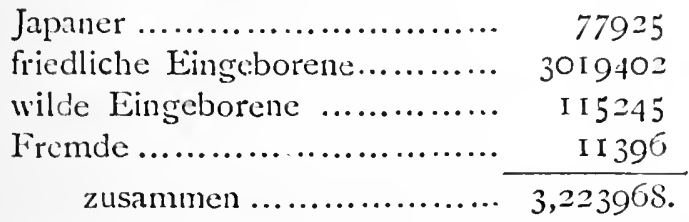

Das entspricht einer Bevölkerungsdichte von etwa 90 Menschen auf das $\mathrm{km}^{2} \mathrm{~d}$. i. etwas weniger als im nördlichen Honshü. Nach europäischem Massstab wäre das eine ziemlich dichte Besiedlung, aber Takekoshii weist darauf hin, dass Kiushu, das beinahe dieselbe Flächenausdehnung hat, eine Bevölkerung von 6.5 Millionen Menschen ernährt, und dass man auch für Formosa, das noch wenig gewerbliches und städtisches Leben zeigt, eine ähnliche Bevölkerungsdichte erhoffen kann. Jedenfalls besteht vorderhand ein starker Bedarf für Arbeitskräfte und landwirtschaftliche Siedler, und die natürliche Vermehrung der einheimi-

1) The special population census of Formosa 1905. Report of the Committee of the Formosa special census investigation. Tokyo 1907. Ueber Formosa geben auch Auskunft die bereits zitierte Denkschrift des Kolonialamtes in Tokyo und das ins Englische iibersetzte Buch des Abgeordneten Y. Takekoshi, Japanese rule in Formosa. London 1907.

2) Rés. stat. du Japon 1910. I. tableau 19. 
schen Bevölkerung geschieht so langsam, dass ein Zuzug von aussen doppelt wünschenswert ist.

Es kommen auch jährlich viele Japaner nach der Kolonie herüber, aber da viele wieder abgehen, ist dic Zunahme der japanischen Bevölkerung eine bescheidene. Die Zahlen über diese Bevölkerungsbewegung sind die folgenden: ${ }^{1)}$

\section{TABELLE XXXI.}

\begin{tabular}{|c|c|c|c|}
\hline . & $\begin{array}{c}\text { Einwanderung von } \\
\text { Japanern nach } \\
\text { Formosa }\end{array}$ & Rückwanderung & $\begin{array}{c}\text { Mehr eingewan- } \\
\text { dert als ausge- } \\
\text { wandert. }\end{array}$ \\
\hline i $S_{9} \mathrm{~S}$ & I 32 I 4 & 3078 & IOI 36 \\
\hline I 899 & 20743 & 7903 & I 2840 \\
\hline 1900 & 20995 & I I 29 I & 9704 \\
\hline I90I & I $78_{4} \mathrm{I}$ & 14054 & 3787 \\
\hline 1902 & I $3 S \geq 1$ & I 1478 & 2343 \\
\hline 1903 & I 5892 & I 3 I 49 & 2743 \\
\hline 1904 & I I 564 & I 2 I 55 & -591 \\
\hline 1905 & I 3427 & I 2190 & 1227 \\
\hline I 906 & IS278 & I 2391 & 5887 \\
\hline 1907 & I 7966 & 14223 & 3743 \\
\hline I 90 S & 20360 & 14393 & 5967 \\
\hline
\end{tabular}

Die geringe Sesshaftigkeit der japanischen Einwanderer erklärt sich zum Teil aus den Berufen, denen sie angehören; der Bericht der Volkszählungskommission verzeichnet sie zu $39.7 \%$ als Angehörige der freien Berufe (einschli sslich öfentliche Dienste), 3 I.10\% von Handel und Verkehr, 22.5\% von Gewerbe. Auf Landwirtschaft, Forstwirtschaft und Fischerei entfielen nur 1.4\%. Auch der verhältnismässig geringe Anteil der Frauen an der Einwanderung (39\%) beweist, dass es sich meist um Ansiedler von grosser Beweglichkeit handelt. Diese Verhältnisse, die allerdings von keiner Kolonialregierung als

1) Die Zahlen von $\mathbf{1} \$ 98-1904$ nach dem Bericht über die Volkszählung Seite 153, die übrigen nach dem japanischen statistischen Jahrbuch 1910. Seite 987. 
erfeculich bezcichnet "erelen kömnen, haben anscheinend das Gouvernement von formosia dazn bestimnt, die linwanderung \%u beeinflussen und die Sesshaftnachung erwänschter Elenente in die Hand \%u nelumen.

Nach den Angaben des Kolonialantes kannen die ersten Finwanderer, dic vom Gonvernensent ecfüht wurden, Igo6 an und wurden in Taichu und Dailo als Landwirte angesicdelt. Nach rgos nahm dic binwanderung zu. Dic Einwanderung wurde zuniichst durch Privatagenten bewerkstelligt, damu aber übernahm dic Regierung das Guschïf selbst und verwendet jetzt jährlich 30000 Yen dafür. Im übrigen liess es sich die Regicrung aber angelegen sein, jede Finwanderung zu fördern. Sie unternahm I909 eine Untersuchung der Insel, um passende Stellen für Ansiedler ausfindig zu machen, erliess ein eigenes Einwanderungsgesetz und schuf neben andern Vorbereitungen im Jahre r9ro cine cigene behörde, der für das genannte Jahr 79755 Yen für ihren Zweck zur Verfügung stehen.

Es sind zwei Ansiedlungsgebicte bereitgestellt, eines im Osten und ein lileineres in Westen der Insel, die zusammen 536.84 $\mathrm{km}^{2}$ gross sind." Man rechnet, dass auf dem ersten rund I 3000 , auf dem zweiten rund 7000 Familien untergebracht werden können. Das wären zusanmmen etwa 100000 Menschen..2) Es scheint, dass man bisher mit den von der Regierung besorgten Einwanderern sehr zufrieden war, jedenfalls viel mehr als mit den von privaten Agenten herübergebrachten: sie kommen alle mit Familien, sind erfahrene Landwirte, gesund und fleissig und geben zu Klagen keinerlei Anlass. Sie sind auch recht sesshaft und erfüllen so die auf sie gesetzten Hoffnungen. Ueber die von den privaten Agenten gebrachten Einwanderer ist das Urteil nicht so gut, insbesondere wird über ihre Auswahl und ihren Mangel an Sesshaftigkeit geklagt. Die Einwanderungsgesellschaften scheinen sich auch das Wohl ihrer Kunden wenig angelegen sein $z u$ lassen. Nur 2 von ihnen gewähren ihnen Unterstützungen für Reise und Ansiedlung, aber sie können es mit den Massnahmen der Regierung für die von ihr besorgten Einwanderer nicht aufnehmen. Diesen geht es viel besser: sie haben eine grosse Zahl von Erleichterungen und Begünstigungen bei der Reise und der Ansiedlung, geniessen Steuernachlass

1) Private Mitteilung aus dem Kolonialant Tokio.

2) Denkschrift des Kolonialamtes. 
oder Befrciungen, erhalten Land, Häuser, Vieh, Maschinen billig oder umsonst und verfügen auch über fast unentgeltliche Krankenpflege.

Die gesundheitlichen Verhältnisse werden abgesehen von der Malaria als ziemlich gut geschildert, und es ist bekannt, dass die Regierung der Insel sich grosse Verdienste um ihre Befreiung von Krankheiten aller Art gemacht hat. Inzwischen hat auch das gewerbliche Leben der Kolonie einen grossen Aufschwung genommen, und es lässt sich erwarten, dass ausser den I00000 Landwirten, die vorderhand angesiedelt werden sollen, auch zahlreiche gewerbliche Arbeiter Beschäftigung finden werden. Die eingeborenen Formosaner dürften allerdings zunächst den Arbeiterbedarf noch decken können, aber da schon jetzt bei noch wenig entwickelten wirtschaftlichen Zuständen eine verhältnismässig so grosse Anzahl von Menschen ihren Unterhalt auf der Insel findet, so wird vermutlich die Aufnahmefähigkeit in kommenden Jahren noch bedeutend zunehmen.

Korea und die Mandschurci sind die Gebiete, die als Auswanderungsziel am meisten genannt sind und die auch eine zeitlang offiziell als die Länder bezeichnet wurden, die den ganzen Ueberschuss der japanischen Bevölkerung an sich ziehen sollten. Von diesen Plänen ist es zwar inzwischen still geworden, und es scheint auch, als ob man sich mit Bezug auf die Mandschurei übertriebenen Hoffnungen hingegeben hätte, aber es ist nicht einzusehen, warum Korea als Gegenstand von Besiedlungsplänen nicht mehr in Frage kommen sollte.

Es handelt sich hier um eine Fläche, die beinahe so gross ist wie die von Honsh $\bar{u}$, die aber nicht wie diese 165 , sondern nur etwa 62 Einwohner auf $\mathrm{I} \mathrm{km}^{2}$ aufweist. Die Angaben über Korea sind noch ziemlich dürftig oder ungenau. Der Flächeninhalt ist noch nicht genau bekannt und erst seit kurzem weiss man, dass die einheimische Bevölkerung etwa I 3 Millionen Menschen beträgt. Eine Jahrhunderte lange, traurige Geschichte hat es mit sich gebracht, dass das Land heute arm, und seine wirtschaftlichen Verhältnisse sehr betrüblich sind. Einer der Hauptübclstände ist die völlige Entwaldung der zahlreichen Gebirge, die eine stete Ueberschwemmungsgefahr für die Felder der Halbinsel bedeutet. Es liegt viel Land brach, das landwirtschaftlich nutzbar gemacht werden könnte, und obwohl die Koreaner viel natürliche Anlagen zur Landwirtschaft zu háben 
scheinen, so sind doch auch die Ergebnisse ilures oft selur primitiv betricbenen lecldbaus wenig befriedigend.

Obwohl dic Landesaufuahme erst in 5 Jahren beendigt sein wird, weiss man doch schon, dass i. J. Ig I die bebaute joläche $2398 S_{4}$ o cho, die unbebaute i i 55 I 2 cho betrug. Da die letztere nicht olune grössere Auslagen der Landwirtschaft nutabar gemacht werden kams, und der Generalgouveneur Graf Terauchi dazu auch keine Lust zu habon scheint, so kommen nur die 2.3 Mill. bebauter Fläche in lietracht, von der man anninmt, dass sie bei besserer Bewirtschaftung zu ro v. H. noch mit Japanern besieclelt werden kann, wenn eine entsprechende Zusammenlegung vorausgeht. Da für eine Familic 2 cho benötigt werden, so könnte mon auf diese Weise I 5000 Familien $=460000$ Menschen ansässigg machen. Später kamn man dann auf der bisher unbebauten liäche 2.2 Mill. Menschen ansiedeln, so dass bloss an ländlicher Bevölkerung 2660000 Menschen in Korea untergebracht werden können."

Bis zum Kricg soll es nicht mehr als 40-50000 Japaner in Korea gegeben haben, die meist in den offenen IHäfen lebten und inmitten einer ihnen feindlich gesinnten Bevölkerung Handel trieben. Der Krieg brachte natürlich viel Einwanderer, dic im Gefolge der Armee kamen, und als das Land endgültig an Japan fiel, d. h. ais Protektorat crilärt worden war, kamen noch mehr Japaner vom Hauptland herüber, die aber durchaus niclit immer sesshaft waren. Es handelte sich zu einem grossen Teil um unruhige Elemente, die hir- und herfluteten. Zahlen über diese Bewegung sind mir leider nicht zugänglich gewesen. Nach dem Japan Yearbook sollen sich in Korea aufgchalten haben

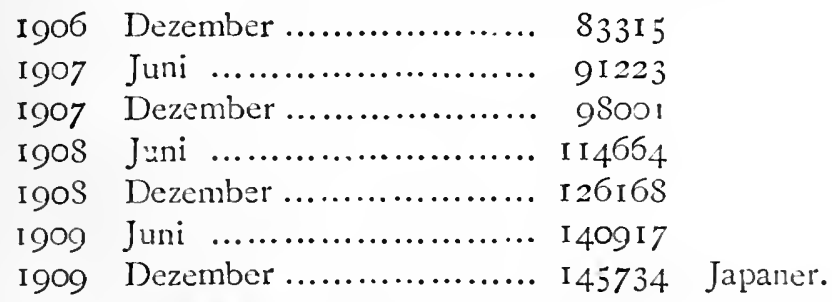

Die Zahlen scheinen beiläufig zu stimmen, denn auch der 3. Annual report on reforms and progress in Korea (IgoS-10).2) weist für Ende Dezember 1909: I46r47 Japaner aus. Obwohl

1) Mündliche Mitteilungen im Tolioer Kolonialamt.

2) Soeul, I910; Seite 16. 
also so viel unstete Elemente mitgeionmen sind, ist doch die Zunahme eine ziemlich starke, und zwar haben die Frauen stärker zugenommen als die Männer, was auf grössere Sesshaftigkeit schliessen lässt. Die Einwanderer in Korea stammen zumeist aus Tsushima und aus den nahe gelegenen westlichen und südlichen Provinzen Japans. Aber es fehlte auch an Einwanderern aus den Stadtkreisen nicht; wahrscheinlich befanden sich unter ihnen gerade die unerwünschtesten. Die Klagen über die wenig zufriedenstellende moralische und wirtschaftliche Beschaffenheit der Zugewanderten in Korea wurden so oft und von so verschiedenen Seiten erhoben, dass sie wohl begründet zu sein scheinen. Meist wird versichert, es handle sich um Abenteurer, städtisches Gesindel, das erwartete, in der neuen, leicht erreichbaren Kolonie ein aussichtsreiches Feld für lichtscheue Operationen aller Art zu finden, das glaubt, der Krieg sei nur geführt worden, um ihnen das Recht auf Ausbeutung und Betrügerei unter den Eingeborenen zu verschaffen, und das daher den Ruf der neuen Herren in Korea auf das ärgste blosstellte. Diese Klagen sind so allgemein, dass ich sie durch einzelne Beispiele eher zu entkräften als zu belegen fürchte. Ich lasse daher nur einen Zeugen zu Worte kommen, der gewiss unverdächtig ist und der dem eben Gesagten noch etwas neues hinzufügt, $H . N$. Allen, der als Arzt und amerikanischer Gesandter 21 Jahre in Korea gelebt hat; er sagt: ${ }^{1)}$,...... Japanese immigrants seem to think, that as they represent the allconquering people who drove the enemy from Korea, the natives owe them profound gratitude, which should be shown in the surrender of property as well as in the observance of a most obsequious and servile manner...... Now I am fully persuaded, that the Government of Japan would wish this to be otherwise. They want the Koreans to have as good a chance as is possible, consistent with the due development of the Japanese interests in that land....."; $;$ ) und sicher hat die Regierung auch alles Mögliche getan, um Missbräuchen von Seiten ihrer Landsleute einen Riegel vorzuschieben, ja seit neuestem kann man sogar in Japan Klagen darüber hören, dass die energische Hand des General-Gouverneurs, des Grafen Terauchi, zu fest zugreife, wenn es gelte, Uebelstände dieser Art ab-

1) Blakeslee, George :II. a. o. China and the Far East. Clark university lectures. New York 1910. Darin: Allen. The awakening of Korea; Seite 386/88.

2) Aehnlich $I V$. E: Griffis, Korea, The Hermit Nation. New York. 8. ed. I907 S. 499 . 
\%ustellen. Diesem \%ugreifen und dem natülichen binteten der Realition gegen das , Korea-Pieber," das so manchen unruhigen Kopf nach dem Kriegr erfisst hat, ist es wohl auch \%uzuschrciben, dass in Letoter Zeit die Klagren nachgelassen haben. Sellostverstïndlich sind auch die Möglichliciten fur Uebergriffe und Betrïgereien gegenüber den lingeborenen seriner, sobald die Zalıl der anständigen Ansiedler zunimmt, und vor allem, sobald der Apparat der Verwaltung und Rechtspflege sich vervollkommnet. Und man muss der japanischen Verwaltung in Korea die Anerkennung zollen, dass sic tatsïchlich bestrebt ist, clas l3este zu leisten, unch schöne Erfolge aufauweisen hat.

Die Beschäftigung ler Japaner in Korea ist niclit leicht zahlenmässig festzustellen, da es wiederum an Angaben hierüber fehlt. Zu cinem grossen Teil leben sie noch in den geschlossenen Niederlassungen in den Häfen: Fusan, Tschimulpo, Molpo, Wonsan u. s. w. und auch in Scoul wohnen sie noch meist zusammen in einem besondern Viertel mit eigener Munizipalverwaltung. Wer aus den schmutzigen, verwahrlosten und ärmlich aussehenden Gassen nit ausschliesslich koreanischen Bewohnern in die japanischen Stadtviertel tritt und dort die saubern nettgehaltenen Häuser wicderfindet, wie sie in den besseren Strassen der japanischen Städte zu sehen sind, wer das rege Leben in diesen Strassen, die zahlrcichen Geschäfte, reicheren Vorräte sieht, der kann nicht im Zweifel darüber bleiben, dass es, wenn auch nicht allen Japanern, so doch vielen von ihnen in Korea recht gut gehen muss. Diese Vermutung wird auch bestärlkt, wenn man den verhälnismässig grossen Aufwand sieht, der in Unterhaltung und Luxus aufgeht und wieder einer grossen Reihe von japanischen Wirten und dergl. Unterhalt gibt. Natürlich sicht man daneben auch viele Japaner, denen es anscheinend nicht leicht wird, ihren Lebensunterhalt zu verdienen, aber bis zu einem gewissen Grade hält doch die politische Vorzugsstellung, die der Japaner heute in Korea geniesst, diese Leute über Wasser.

Die Löhne für japanische Arbeitskräfte sind in Korea durchwegs höher als die für einheimische, und der Unterschied beträgt manchmal mehr als I00\%. Da fortwährend Bauten aufgeführt, Bahnen gebaut, öffentliche Arbeiten aller Art betrieben werden, da mehr und mehr Kapital im Lande investiert wird und allerhand gewerbliche Unternehmungen ins Leben ruft, so gibt das einer Reihe von höher qualifizierten Arbeitskräften Beschäftigung, ganz.abgesehen davon, dass auch der Bedarf für 
Verwaltungsbeamte, Soldaten und Bahnbeamte, der meist intportiert werden muss, einer stattlichen Schar von Händlern und Gewerbetreibenden Unterhalt gibt. Der auswärtige Handel, der sich von 1903 bis 1909 von 27.7 Millionen auf 52.9 Millionen gehoben hat, liegt fast ganz in den Händen der Japaner, wenn auch der Anteil des japanischen Handels am Gesamt-Aussenhandel um einige Prozente heruntergegangen ist.

Neben diese Berufe, die sich meist auf die Verkehrszentren beschränken, sind in neuer Zeit auch landwirtschaftliche Ansiedler getreten, deren Zahl und wirtschaftliche Erfolge natürlich von der grössten IVichtigkeit für die Zukunft der japanischen Kolonisationsarbeit sind. Der langsame und bedächtige Gang, den die Entwicklung der japanischen Landwirtschaft in Korea genommen hat, lässt hoffen, dass es sich um ein gesundes Fortschreiten handelt, dem grosse Rückschläge erspart bleiben dürften. I909 gab es 80538 cho im Werte von 8,3 Mill. Yen in japanischem Besitz, die sich auf $72 \mathrm{~S}$ Eigentümer verteilten (I910 : \$6952 cho). Die Erfolge der Bebauung sollen sehr gut sein und rechnungsmässig eine Verzinsung des angelegten Kapitals von etwa 10-12\% ergeben. ${ }^{1)}$ Im Jahre 1908 gründete die japanische Regierung zusammen mit der damals noch bestehenden koreanischen ein grosses Kolonisationsunternehmen, die Toa Takushoku Kaisha (Oriental Development Co.) mit einem Kapital von Io Millionen Yen, das z. T. durch eingebrachte Grundwerte der koreanischen Regierung eingezahlt wurde. Es ist vorgesehen, dass die Gesellschaft Pfandbriefe begeben und die ersten 8 Jahre ilıres Bestehens auf die Geldbeihilfe der Regierung rechnen kann. Die Gesellschaft soll durch Erwerbung und Besiedlung von Land, durch dessen Urbarmachung und Darlehen an Landwirte die Landwirtschaft in Korea fördern, und hat sich bereits daran gemacht, ihre Aufgabe zu erfüllen. Allerdings hört man in der japanischen Presse, die alles noch besser weiss als ihre Kolleginnen im Auslande, bereits Klagen über schleppenden Geschäftsgang und $\% u$ grosse Bedächtigkeit. Auch in der Parlamentssession I9II-12 wurden heftige Anklagen in gleichen Sinne erhoben, sowie Unredlichkeiten in der Geschäftsgebahrung behauptet. Die Regierungsvertreter aus dem Kolonialamst wiesen den letzteren Vorwurf zurück und erklärten auch, dass man mit der Besicdelung nicht so rasch vorgehen könne, weil man das Land in kleinen Parzellen kaufen nüsse und erst

1) Miindl. Mitteilung. 
für Verbesserung des Landbaus unter den Koreancrn Sorge tragen müsse, danit sic auf der ihnen verbleibenden lilïbe soviel erriclen kömen, wie bisher. 1911 wollte dic Takushoku Kaisha 1000 Pamilien nach Korea schaffen, fand aber nur 560 , dic grecignet waren. 1912 hoff sil; 1000 kamilien ansiedein $z u$ können. ${ }^{3}$ Die Gesellschaft hat bisher recht hübsche finanzielle Erfolge: erziclt und könnte sogar noch höhere Dividenden zahlen als $6 \%$

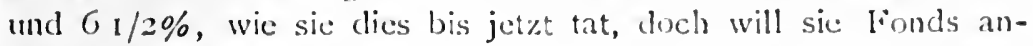
sammeln und noch nicht der Regierungszuschüsse verlustig werden, die ihr \%ufliessen, solange sie nicht $8 \%$ Dividende verteilt.

Ein Erwerbszweig, der gieichalls vielen Japanern Nahrung \%u geben verspricht, ist die Fischerei, die schon lange vor der Herrschaft Japans über Korea viele Japaner dosthin grefihurt hat. Sie soll sehr ergiebig sein, und es heisst sogar, dass die durchschnittliche Ausbeute für den einzelnen Fischer in koreanischen Gewässern 200 Yen betrag̣en soll, wälrend sie in japanischen Gewässern nur 43 erreicht. Die Japaner scheinen sich, wie' aus den folgenden Zahlen hervorgeht, eine nambafte Stellung unter den Fischern Koreas gemacht zu baben. Nach dem letzten Jahrgang des Japan Yearbook gab es:

\section{Tabelle XXXII.}

\begin{tabular}{l|c|c|c|c}
\hline & Fischerboote & Fischer & $\begin{array}{c}\text { Mit einer Aus- } \\
\text { beute im ganzen } \\
\text { von Yen }\end{array}$ & $\begin{array}{c}\text { Auf den } \\
\text { Kopf Yen }\end{array}$ \\
\hline Koreaner & $1241 \mathrm{I}$ & 68520 & 3139100 & 45.8 \\
Japaner & 3898 & 16644 & 3418850 & 205.6 \\
\hline Zusammen & 16309 & 85164 & 6557950 & 77.0 \\
\hline
\end{tabular}

Auch hier also eröffnen sich japanischen Einwanderern gute Aussichten.

Zusammenfassend lässt sich sagen, dass Korea für Japan tatsächlich eine wertvolle Erwerbung bedeutet, und dass es eine grosse Menge von Zuwanderem aufzunehmen vermag, umsomehr, je besser sich die Wirtschaftslage gestaltet, und je mehr die japanische Kolonialverwaltung im Stancle ist, die Bevölkerung, an der früher so viel gesündigt wurde, zu heben. Zahlenmässig

1) Mündliche Mitteilungen aus d. Kolonialamt. 
lassen sich angesichts der dürftigen, bisher zur Verfügung stehenden Angaben die Aussichten der Japaner nicht ausdrücken, doch ist es wohl nicht zu viel gesagt, wenn ich annehme, dass Korea in Zukunft 3 und mehr Millionen Japaner aufzunehmen vermag.

Die Mandschurei, diese grosse chinesische Provinz, die etwa zweimal so gross ist als Oesterreich-Ungarn, gehört seit dem Frieden von Portsmouth in ihrem südlichen Teil zu Japan. Der südlichste Teil der Provinz bildet das sog. Kwantung-Gouvernement und steht unter der Regierung eines japanischen General-Gouverneurs, dem ein Zivil-Gouverneur beigegeben ist. Anschliessend an dieses Gebiet stelit ein schmaler Streifen rechts und links von der südmandschurischen Bahn bis Changchung (Kwangtschentze) für die Dauer der Bahnkonzession unter japanischer Verwaltung, die von der Direktion der Bahn ausgeübt wird. Hinter den Grenzen des Kwantung Gabietes und der sogenannten Babnzone liegt das weite, fruchtbare und noch menschenarme mandschurische Land, das von den gegenwärtigen Herrschern Chinas, der Dynastie der Mandschus, lange Zeit für die chinesische Einwanderung gesperrt war. Nach dem Taiping Aufstand und noch mehr nach der Aufhebung der Militäiverwaltung im Jahre 1880 strömten aber doch Chinesen in das Land. Dem gleichzeitigen Vordrängen der Russen von Norden her wurde durch den russisch-japanischen Krieg ein Eide gemacht, und nach dem Friedenschluss verschwanden die Russen ziemlich rasch aus dem Grenzgebiet, in dem sie noch keinen festen Fuss gefasst hatten. An ihrer Stelle drangen die Japaner vor, und man musste eine zeitlang glauben, dass sie das ganze grosse Gebiet rrit ihren angeblich unerschöplichen Menschenmassen bevölkern würden.

Wie wcit die Besiedlung der Mandschurei ausserhalb des Pachtgebietes an Japaner möglich sein würde, war damals noch eine offene Frage. Man hat den Eindruck, ais ob es Japan zunächst versucht hätte, cie ungeklärte Sachlage via facti zu klären und sich durch Vorschieben seiner Ansiedler ein Heimatsrecht auf dem in zwei blutigen Kriegen so heiss erkämpften Boden zu erwerben. Vielleicht lassen sich die wiederholten Zwischenfälle, in denen es sich stets um das Recht der Ansiedlung handelte, wie die von Chientao, Taolu und Hsinmintung in diesen Zusammenhang einreihen. Jedenfalls sieht es so aus, als ob die Hartnäckigkeit, mit der die Chinesen das Recht 
auf ihren Boden verteidigten, zum Ziele geführt und atuch bei den Japanern Anerkenumer grefunden hïtte. Das ChientaoUebereinkommen zwischen China und Japan vom 4. IX. 1909, das dic strittigen Gren\%fragen in der Hamptsache beilegt, ist vielleicht der Schlussstein dieser lintwicklung. Es mag aber noch etwas anderes \%u diesem Zurückweichen veranlasst haben, nämlich dic Ueberzeugung, dass dic japanischen Ansiedler den Wettbewerb mit den chinesischen nicht anfnchmen können. 1908 bereiste der damalige Minister des Acussern Graf (spïter Marquis) Komura die Mandschurei, lenkte dann 1909 und I9Io die allgemeine Aufmerksamkeit auf dic Einwanderungsgebiete Korea und Mandschurei uncl crweclite den Anschein, als ob die Regierung sich zu einer Konzentrierung der gesamten japanischen Auswanderung nach diesen Ländern entschlossen hätte. Tatsächlich fulgten $\mathrm{kem}$ Minister in den folgenden Jahren eine grosse Reihe von Sachverständigen und mit besonderen Aufträgen betrauten Beamten nach cler Mandschurei, untersuchten sie auf ihre Eignung als Einwanderungsland, kamen aber alle zu dem Schluss, dass die japanischen Einwanderer dort keine Aussichten hätten, da es sich un ein Ackerbau-Land handle, in dem dic Chinesen als genügsame und fleissigge Arbeiter nicht aus dem Felde zu schlagen seien. Man hörte auch bald nichts mehr von dem sog. Konzentrationsplan des Grafen Komura, der allerdings nie wiederrufen wurde, dessen Beweggründe vielleicht auch nur in der äussern Politik Japans zu suchen sind (siehe oben Seite $\sigma_{3}$ ff.) Inzwischen waren die Chinesen nicht müssig geblieben und begannen bald ihre Einwanderung planmässig zu betreiben. Es scheint ihmen zwar an Kapital dabei zu fehlen, aber ihre ungeheuren Menschenmassen, ihre kolonisatorischen Fäligkeiten dürften ihnen trotzdem einen Erfolg sichern. Namentlich der neue Vize-König Chao-Erh-Shün scheint die Kolonisation des Landes mit grosser Energie betrieben zu haben. Durch die Pest und die bürgerlichen Unruhen des Jahres I9I I ist allerdings alles ins Stocken geraten, aber es scheint doch, als ob die Zunahme, die die chinesische Bevölkerung bisher erfahren hat, eine sehr beträchtliche wäre. Der japanische Seezoll-Direktor Tachibana nimmt in seinem Bericht über den Handel Dairens von Iglo an, dass der grösste Teil der 200000 Personen, die jährlich den Ueberschuss zwischen eingehenden und ausgehenden chinesischen Passagieren bilden, als Zuwachs für die Mandschurei zu rechnen sei, und er be- 
gründet diese Behauptung mit der Statistik der eingeführten Waren, namentlich für den täglichen Gsbrauch.

Angesichts einer derartigen Zuwanderung chinesischer $\mathrm{Na}$ tionalität ist natürlich für die japanische Besiedlung der gesamten Mandschurei nicht viel $\mathrm{zu}$ hoffen. In den durch politische Vorrechte geschützten Pachtgebieten ist aber die japanische Einwanderung deshalb noch nicht aussichtslos. ${ }^{\text {) }}$

Die japanische Auswanderung nach der Mandschurei bietet allerdings zunächst das bekannte Bild: eine starke Einwanderung, die zum grössten Teil bald wieder das Land verlässt und einen grossen Beisat\% von unerfreulichen Elementen mit sich führt. In der Mandschurei war natürlich die Einwanderung durch den Krieg in Fluss gekommen, der im Gefolge der Armee eine Schar von Händlern und Abenteurern aller Art nit sich geführt hatte. Auch nach dem Friedenschluss strömte solches Volk ins Land, von dem oft wenig Gutes zu berichten war, und das selbst japanische Beamte, wie den japanischen Generallionsul in Mukden oder den Zivilgouverneur des KwantungGouvernements, zu ernsten Klagen und Warnungen veranlasste. Da das Geld auch in der Mandschurei nicht auf der Strasse liegt, und die Behörden wahrscheinlich nicht zu allem durch die Finger sahen, kehrten die meisten Einwanderer dem Lande wieder den Rücken, und der jährliche Zawachs beträgt nur einige tausend Menschen.

Das Kwantung Gouvernement wies in den letzten Jahren folgende Bevölkerung auf:

\section{TABELlE XXXIII.}

\begin{tabular}{|c|c|c|c|c|c|c|c|c|}
\hline & $\begin{array}{l}\text { Jap. } \\
\text { Männer }\end{array}$ & Frauen & $\begin{array}{c}\text { Zusami- } \\
\text { men }\end{array}$ & $\begin{array}{c}\text { Chines. } \\
\text { II. }\end{array}$ & Fraten & $\begin{array}{l}\text { Zusam- } \\
\text { men }\end{array}$ & $\begin{array}{c}\text { Auslän- } \\
\text { der }\end{array}$ & $\begin{array}{c}\text { Zusam- } \\
\text { men }\end{array}$ \\
\hline โ906 & $82+5$ & $+5+7$ & 12792 & 202777 & 157651 & 360129 & II 4 & 373259 \\
\hline 1907 & 15272 & 9300 & 24572 & 216194 & I $6888_{12}$ & .385006 & 85 & $40965=$ \\
\hline 1908 & $I_{7} S_{31}$ & I 1939 & 29773 & $21+356$ & $1653+1$ & 380697 & 74 & 410555 \\
\hline 1909 & $18 ; 22$ & 1.3580 & 32102 & 231782 & 181391 & 413173 & 39 & 445389 \\
\hline
\end{tabular}

Dem Berufe nach waren die Chinesen meist landwirtschaftlich tätig, die Ausländer Beamte des auswärtigen Dienstes

1) Die folgende Iarstellung der Lage der Japaner in der Mandscliurei stützt sich auf die bereits zitierte Denkschrift des Kolonialam!es in Tokyo. 
Hnrer Länder und Katullente. Dic Japaner aber verteilten sich (im Jahre 19ro) anf die enzelnen Berufe wie folgt:

\begin{tabular}{|c|c|c|c|c|c|c|c|c|c|c|}
\hline licambe & $\begin{array}{l}\text { Iand- } \\
\text { wirle }\end{array}$ & $\begin{array}{l}\text { Kand- } \\
\text { leute: }\end{array}$ & $\mid \begin{array}{l}\text { Inclu. } \\
\text { stric:lle }\end{array}$ & liselier & \begin{tabular}{|} 
Bilhu. \\
Beante
\end{tabular} & $\begin{array}{l}\text { Versch. } \\
\text { lierufe }\end{array}$ & $\begin{array}{l}\text { Geishias } \\
\text { S rlergh. }\end{array}$ & $\begin{array}{c}\text { Ar- } \\
\text { beiter }\end{array}$ & $\begin{array}{l}\text { Ohine } \\
\text { licruf }\end{array}$ & $\begin{array}{l}\text { Zusann- } \\
\text { men }\end{array}$ \\
\hline 4901 & 67 & 6209 & 4301 & 2.48 & .1173 & Sggi & 1276 & $539 \mathrm{~S}$ & 428 & 35995 \\
\hline
\end{tabular}

Dic Japaner stellen also eine durchwegs städtische Bevölkerung dar. Von ihnen lebten 26660 in I Dairen,"3) 8306 in Port Arthur, 1029 in Kinchau. 70-80\% lebten nit ihren Familien, was für ein so junges Einwanderungsland ein recht hoher Prozentsatz ist und beweist, dass die japanische Verwaltung es verstanden hat, die Lobensverhälnisse auch für Frauen und Kinder erträgrich zu machen.

Ueber die Fin- und Rückwanderung aus Japan seben die folgenden Zahlen Auskunft. Es betrug:

\section{Tabelle XXXIV.}

\begin{tabular}{|c|c|c|c|c|}
\hline & die Einwanderung & die & Rückivanderung & der Ueberschuss \\
\hline 1907 & 36247 & & 20179 & I6069 \\
\hline 1908 & 27279 & & 21606 & 5673 \\
\hline 1909 & $2054 \mathrm{I}$ & & 15347 & 5294 \\
\hline
\end{tabular}

Es zeigt sich also, dass bei verhältnismässig grosser $\mathrm{Ab}-$ und Zuwanderung der Zuwachs ein bescheidener ist, dass allerdings die Einwanderung rascher abnimnt als die Abwanderung, während der Ueberschuss seit neuestem ständig zu bleiben scheint, was für die Gesundung der Verhältnisse ein gutes Zeugnis ablegt. Die Herkunft der Auswanderer ist fast dieselbe

1) Aerzte, Rechtsanwälte, Gastwirte, Bankbeamte, Redakteure, Badehausbesitzer und dergl.

2) Die Arbeiter sind meist Zimmerleute, ILafen- \& Eisenbalmarbeiter und Metallarbeiter.

3) Eine neue, verlässlich aussehende Nlittuilung der Japan Times (Tokyo 3 o. IX. I911.) berichtet, dass die japanische Bevölkerung in Dairen ausserordentlich rasch wächst und dass man 1911 31037 Pers. in 9069 Haushalten gezählt hat, gegenuiber $68_{3} 6$ Japanern in $\mathbf{1 . 1 2 3}$ Haushalten im August $x_{906 .}$ 
wie die aller übrigen japanischen Auswanderer: meist der Süden und Südwesten des Hauptlandes mit einer etwas starken Beimischung von grossstädtischen Elementen, die wahrscheinlich auf Rechnung der vielen Beamten und Kaufleute zu setzen ist.

Dass für die niederen Berufe, namentlich für Arbeiter, wenig in der Mandschurei zu holen ist, geht aus einem Vergleich der Löhne von chinesischen und japanischen Arbeitern hervor. Durchwegs sind die der Japaner ein Dreifaches von denen der Chinesen, zum Teil auch schon deshalb, weil die Chinesen ansässig, die Japaner aber Ankömmlinge sind. Ucbrigens weisen nicht nur die Löhne der japanischen Arbeiter untereinander eine verschiedene Höhe auf, sondern sie sind auch nach den einzelnen Plätzen sehr verschieden. Die Löhne in Dairen sind viel höher als die in Port Arthur. Im Vergleich mit den Löhnen des Hauptlandes ist kein grosser Unterschied zu verzeichnen. Die Löhne sind etwas höher, aber anscheinend doch durch die niedrigen Löhne der Chinesen bceinflusst.

Noch viel mehr als bei der Arbeiterklasse merkt man die wirtschaftliche Vormachtstellung der Chinesen in der Landwirtschaft. Hier können die Japaner überhaupt nicht mit. Es gab :

\section{Tabelle XXXV.}

\begin{tabular}{|c|c|c|c|c|c|}
\hline & & \multicolumn{2}{|c|}{ Selbständige Lindwirte } & \multicolumn{2}{|c|}{ Pächter } \\
\hline & & im $\begin{array}{c}\text { Haupt- } \\
\text { beruf }\end{array}$ & $\begin{array}{c}\text { im Neben- } \\
\text { beruf }\end{array}$ & $\begin{array}{c}\text { im Haupt- } \\
\text { beruf }\end{array}$ & $\begin{array}{c}\text { im Neben- } \\
\text { beruf }\end{array}$ \\
\hline \multirow[t]{2}{*}{1907} & Japaner & - & $2 \mathrm{I}$ & 4 & - \\
\hline & Chinesen & 201324 & 2 I 747 & 52522 & I 5456 \\
\hline \multirow[t]{2}{*}{ I90S } & Japaner & 26 & - & 一 & 5 \\
\hline & Chinesen & I69 I 23 & 30366 & 63202 & $1 弓 200$ \\
\hline
\end{tabular}

Das Land ist also ganz in den Händen der Eingeborenen, und wahrscheinlich dürfte sich daran wenig ändern, denn das in den Händen der Regierung befindliche Land reicht nach den angestellten Berechnungen höchstens zur Sesshaftmachung von rund $300 \mathrm{Köpfen.} \mathrm{Der} \mathrm{vorhandene} \mathrm{Wald} \mathrm{kann} \mathrm{vorderhand} \mathrm{als}$ Nahrungsquelle noch nicht in Betracht gezogen werden. 
Bessere Aussichten dagergen eroffuct die liischerei, Man berechnet, dass in Jipan auf cine Uferstreclic von I ri $(-3.927$ $\mathrm{km}) 253$ Fiseher kommen, wïhrend es 1909 in kiwantung mur ro3 lisclue für clieselbe Uferstrecke gab (zusimmen gab es 22972 chinesische und 1303 japanische lischer). Unter der Voraussetzung, dass die lischerei in Kwantung ebensovicle Menschen emähren könne wie auf clen jalpanischen Inseln, könnte man im Gouvernement noch 44000 Fischer unterbringen, die wahrscheinlich ein gutes Auskommen finden, denn selbst bei den noch wenig ausgebildeten Fangmethoden, dic dort im Schwunge sind, ist die Ausbeute cine recht gute: durchschnittlich verdient cin lBoot im Jahre 2 IS Yen, während ein gleiches Boot in Japan nur I90 Yen im Jahr cinbringt.

Der Aufenthalt in der Mandschurei ist wegen der kalten Winter nicht für jeden anzichend, aber or ist leineswegs bedenklich. Die politischen und gesellschaftlichen Zustände sind befriedigend, und die Gesundheitsverhältnisse recht gut, da man in den Städten über Kanäle und IVasserleitung verfügt. Allerdings ist man nicht im Stande, sich ganz gegen die ansteckenden Krankheiten, die aus China herüberkommen, abzuschliessen, und die Dysentrie ist nicht auszutilgen. Immerhin sind das alles noch nicht genügend Gründe, um irgend jemand von der Auswanderung aus Japan nach der Kolonie abzuhalten.

Ganz ähnlich wie im Kwantung- Gouvernement sind die Verhältnisse in der Balnnone, was Gesundheit, Verhältnis der eingewanderten Japaner $\mathrm{zu}$ den billiger lebenden Chinesen und wirtschaftliche Verhältnisse anbelangt. I909 gab es in der Bahnzone 49007 Einwohner, darunter 27203 Chinesen (2434I Männer und 2862 Frauen) und 21 $8 C_{4}$ Japaner (1 3396 Männer und 8408 Frauen). Die Japaner waren dem Berufe nach hauptsächlich Beamte, insbesondere der Südmandschurischen Bahn, Angestellte des öfentlichen und privaten Dienstes, Regierungsbeamte, Zimmerleute, Krämer u. s. w. Landwirte gab es nur I 26. Die unqualifizierten Arbeiter, Taglöhner, Diener aller Art, wurden durchwegs von den Chinesen gestellt, unter denen es übrigens auch 216r Landwirte und eine stattliche Zahl ron Händlern und Unternehmern gab.

Der Grund und Boden, der nicht von der Südmandschurischen Bahn oder der Militärverwaltung gebraucht wird, wird verpachtet. Gegenwärtig sind 14618032 tsubo verpachtet und 2858616 sind noch zu vergeben. Da es sich bei dieser noch 
zu vergebenden Flāche meist um Baugrund handelt, der natürlich mehr Menschen aufnimmt als das flache Land, rechnet man, dass noch rund 36000 Menschen dort angesiedelt werden können. Das zur Verfügung stehende Reisland ist wenig umfangreich, und man glaubt auch an keine Besetzung des ganzen Landes mit wirtschaftlichen Siedlern. Kraft ihrer unerschöpfichen Menschenmassen haben die Chinesen einen so grossen Vorsprung, dass er selbst in dem unter japanischer Verwaltung stehenden Teil Chinas, als cler die Bahnzone anzusehen ist, nicht eingeholt werden kann.

Ich sagte ja auch schon, dass man von den Plänen, die Mandschurei zu besiedeln, in der Hauptsache abgekommen zu sein scheint. Das heisst natürlich noch nicht, dass man es aufgibt, das Land den Interessen Japans dienstbar zu machen. Dieses hat zuviel 1 Tenschenleben und Arbeit, auch zuviel Kapital für das Land verbraucht, um auf ein Entgelt in irgend einer Form zu verzichten. Es scheint, als ob man sich gegenwärtig mit dem Gedanken trägt, die Mandschurei als Handelskolonie zu behandeln und zugleich durch Aufwendung von Kapital die natürlichen Hilfsquellen des Pachtgebietes zu erschliessen. Von der Hebung des WohIstandes durch Handel und Gewerbe hängt das Schicksal dieser Kolonie ab, und es sind allerhand Versuche im Gange, die besten Vege zur Erreichung dieses Zieles ausfindig zu machen. Hier handelt es sich nur darum, wie weit diese Pläne auf die Auswanderung der Japaner nach dem Festlande von Einfluss sein können, und es ist klar, dass ein Land, das nicht mit dem Pluge erobert wird, für grössere Menschenmassen nicht aufnahmefahig ist, wenn man nicht etwa Kuli-Arbeiter importiert. $\mathrm{Da}$ diese im vorliegenden Falle durchaus von China gestelit werden, so ist zwar voraussichtlich für tausende von japanischen Händlern, Privatbeamten und Werkmeistern ein Feld der Tätigkeit geboten, nicht aber für eine irgendwie in Betracht kommende grössere Menge von Auswanderern.

Ich habe besondern IVert darauf gelegt, zu zeigen, dass die mir bei meiner Berechnung der voraussichtlichen Aufnahmefähigkeit der japanischen Kolonien zur Verfügung stehenden Daten sehr dürftig sind, und es lässt sich auf dieser Basis schwer eine genaue Rechnung anstellen. WVenn ich trotzdem unter allem Vorbehalt die gefundenen Zahlen zusammenziehe, so gibt das bei sehr vorsichtiger Einschätzung eine Aufnahmefähigkeit von ètiva 
90000 Menschen in der Mandschurei

$\begin{array}{rll}3000000 & , & \text { in Korca (und mehr) } \\ 200050 & , & \text { in liormosa } \\ 160000 & , & \text { in Sachalin (vorderhand) }\end{array}$

\section{zusammen 3450000 Menschen.}

Nimnt man noch den Hokkaido hinzu, der ganz vorsichtis geschätzt 2400000 Menschen aufnehnen kann, so wäre Raum für wenigstens 6 Millionen Menschen, wahrscheinlich aber für erheblich mehr. Das ist ja für einc Bevölkerung von 67 Millionen Menschen, wie sic das gesamte japanische Reich vermutlich aufiveist (ich betone hier nochmals das Fehlen verlässlichè Angaben), nichts Ausserordentliches, aber doch immerhin eine gewisse Beruhigung dafür, diss dem Bevölkerungszuwachs noch immer ein vorderhand ausreichender Spielraum geboten ist, namentlich wenn man sich daran crinnert, dass auch in Innern Japans noch verhältnismässig weite Gebiete der Landwirtschaft dienstbar gemacht werden können. Ueber diese Fragen werden die hoffentlich bald erfolgenden ersten Volkszählungen noch vicle Aufklärungen zu bringen haben.

Zum Schluss meiner gedrängten Darstellung der japanischen Auswanderung möchte ich noch ihre Rückivirkung auf das japanische Land lintersuchen und die Frage aufwerfen, wie sich die japanische Auswanderung zur Auswanderung überhaupt stellt, und was für Gesichtspunkte sich aus dieser Vergleichung für die Bewertung der japanischen Probleme gewinnen lassen.

Von den verschiedenen Wirkungen auf das Vaterland, die bei jeder Auswanderung in Betracht konmen, ist die nächstliegende die Abnahme der einheimischen Bevölkerung, bezw. die Veränderung ihres Aufbaus nach Alter und Geschlecht. Diese Frage erübrigt sich für Japan, da fast alle Auswanderer wieder zurückkehren; die wenigen Tausende, die sich datuend im Auslande festsetzen und ihre Familien nachkommen lassen, fallen angesichts der grossen Menschenmenge Japans nicht ins Gewicht.. Die Auswanderung betrifft zu einen grossen Teil Männer, die für mehrere Jahre ihrem Vaterland entzogen werden. Aber eine Störung der Familienverhältnisse dürfte dadurch nicht hervorgerufen werden. Man heiratet frühzeitig in Japan, und die Ausziehenden lassen oft eine Frau und Kinder zurück, die inzwischen in der Obhut der Familie bleiben und den Heimkehrenden bei ihrer Zurückkunft wieder eine Heimstätte bieten. 
Dort, wo eine stärkere Auswanderung nach den Kolonien Platz greift, dürfte wohl eine Veränderung in den Bevölkerungs- und Besitzverhältnissen eintreten, doch wahrscheinlich nur lokaler Natur und von keinem zu grossen Einfluss auf die gesamte Volkswirtschaft. Darïber müsste eine Untersuchung an Ort und Stelle in den wichtigsten Auswanderungszentren Aufschluss geben, doch war es mir nicht möglich, eine solche auszuführen, und von Japanern wurde sie meines Wissens nicht unternommen, selbst nicht von Ogawahira, dem Verfasser des einigemale angeführten Buches über japanische Aus'vanderung. Es lässt sich daher auch nicht genau sagen, wie weit die Produlitivität Japans durch die Auswanderung gelitten hat. Bei der meist noch geringen Intensität des hiesigen wirtschaftlichen Lebens und angesichts der unqualifizierten Arbeitskräfte, um die es sich handelt, glaube ich eine Schädigung der japanischen Produktivität getrost verneinen zu dürfen. Der von den Industriellen Japans oft beklagte Mangel an Arbeitskräften für die Fabriken, insbesondere für die Textilfabriken, trifft hauptsächlich weibliche Arbeitskräftè und ist bei der im Verlältnis zur Bevölkerung kleinen Zahl von Arbeitskräften, die gebraucht wird, keinesfalls aus einem Mangel an Menschen, sondern aus den Verhältnissen der Industrie, Behandlung der Arbeiterschaft in den gewerblichen Betrieben und der Psychologie der Japaner zu erklären.

Was die Geldsendungen der japanischen Auswanderer nach ihrer Heimat anbelangt, so ist es schwer, Klarheit darüber zu gewinnen. Die in Betracht kommenden Stellen haben anscheinend nicht die Absicht, die Zahlen, die ihnen bekannt sind, zu veröffentlichen, und auch ich bin genötigt, mich mit Andeutungen aus dem mir zugänglich gewordenen Material zu begnügen. Nach den Erfahrungen des letzten Jahres dürften jährlich etwa 30 Millionen Yen aus dem Auslande einfliessen, meist aus Nordamerika, einschliesslich Hawaii. Für 1905 soll sich der von Japanern in Hawaii nach Hause geschickte Geldbetrag auf 6,5 Millionen Yen beziffern, ${ }^{1)}$ und das dürfte mit einer Angabe für das Jahr 1909 stimmen, für das die Geldsendungen aus Hawaii mit etwa 7 Millionen angeführt werden. ${ }^{2)}$ Das von Rückwanderern und Reisenden mitgebrachte Geld ist nicht mitgezählt. Die Summe von 30 Mill. ist ja nicht allzugross, aber wenn man bedenkt,

1 Aubert a. a. O. S. 6 o.

2) Kanai \%. Ito Hokubeino Nihonjin. 1910. 2. Kap. 
dass sic beinahe dic Iälfte von dem ist, was der Stat jührlich an Zinsen für seine in Ausland begebenen Anleilıen an dieses z.u zahlen hat, und dass Japair auch für importicrte Waren stark verschuldet ist, so verstelit man, class sie den Japanern eine willkommene Verbesserung ihrer Zahlungsbilanz darstellen. Den durch die Banlien und die Post heingeschickten Geldern wïren natürliclı die Summen entgegenzustellen, die von den Auswanderern in bar mitgenommen werden, aber hier dürfte es sich nur um geringe l3etrïge handeln, ausgenommen bei den verhältnismässig wenig zahlreichen Reisenden, die zu Vergnügungsoder Studienzwecken nach dem Ausland gehen. Dic Geldsendungen gehen zu einem grossen Teil durch japanische Banken, insbesondere dic Yoliohama Specic Bank, durch die AuswanderungsAgenten oder durch die lost. Auch die Reisekosten kommen zu einem grossen Teil japanischen Schiffahrtsgesellschaften zugute, um deren Wachstum dic Auswanderung ein grosses Verdienst hat. Wie weit die japanische Auswanderung zu der raschen Entwicklung der japanischen Schiffahrt beigetragen hat, lässt sich natürlich schwer sagen. Die Nippon Yusen Kaisha, deren Senttle Linie schon $1_{4}$ Jahre alt ist, hat noch die Zeit der starken Auswanderúng ausnützen können. Die andern Gesellschaften sind erst in deri letzten Jahren auf den Plan getreten und haben gerade wïhrend ihres Entstehens das Zurückgehen der Auswanderung erlebt, auf deren Fortbestand sic wahrscheinlich gerechnet hatten. Sie sind ja durch reichliche Regierungssubventionen schadlos gehalten, aber sicherlich würden sie eine stärkere Auswanderung, als sic jetzt möglich ist, gerne sehen. Insofern als der japanische. Aussenhandel durch die Auswanderung gefördert wurde, haben sie natürlich mittelbar von dieser Vorteil, es ist aber nicht leicht zu sagen, wie weit der Aussenhandel auf die Auswanderung zurückzuführen, und wie weit er von ihr unab. hängig ist.

Hawaii und die Vereinigten Staaten, bisher die wichtigsten Auswanderungsländer, sind allerdings für die japanische Ausfuhr von grosser Bedeutung. Hawaii bezog in den letzten Jahren für fast 4 Mill. Waren von Japan, und darunter ist eine grosse Menge von solchen, die hauptsächlich für den Bedarf der Auswanderer bestimmt sind, so insbesondere für mehr als I,5 Millionen Yen Reis, dann Fische, Soya Sauce, Sake, Tee, Matten und dergl. Die Einwanderer in den Vereinigten Staaten sind anscheinend weniger auf den Bezug von Nahrungsmitteln aus 
der Heimat angewiesen, auch spielt bei dem grossen Export von etwa 144 Millionen Yen die Lebensmittelausfuhr cine geringe Rolle; meist handelt es sich um Seide, die dem Werte nach I/3 des Aussenhandels Japans mit den Vereinigten Staaten darstellt, dann Tee, Kampfer, Porzellan, Matten und Strohborten. Dass sich unter den Japanern in den Vereinigten Staaten eine stattliche Reihe von Kaufleuten befindet, ist selbstverständlich. Auch sonst sind natürlich die von japanischen Ansiedlern bewolinten Länder von japanischen Händlern besucht und stellen Abnehmer für den japanischen Markt dar. Bis zu einem gewissen Grade sind die Auswanderer überall Pioniere des Handels, wie das Beispiel von Peru und Chile zeigt, wo seit den letzten Jahren der Handel bedeutend gestiegen ist, ohne aber auch nur in der Ausfuhr 1/2 Million Yen zu erreichen. ${ }^{\prime}$ Nur ein verhältnismässig geringer Teil des Aussenhandels dürfte der Anwesenheit von japanischen Ansiedlern im Auslande zuzuschreiben sein; der meiste ist lediglich ein Ergebnis von Handelsoperationen und dient dazu, den Bedarf des Auslands zu decken. Zu einem ganz grossen Teil ist ja auch der auswärtige Handel noch in der Hand von in Japan ansässigen Ausländern.

Die Wirkungen der Auswanderung auf das wirtschaftliche Ieben Japans sind also bescheiden, und dasselbe ist von den Einflüssen kultureller Natur zu sagen. Die Japaner, die als unqualifizierte Arbeiter einige Jahre im Ausland gelebt haben, kommen gewiss nicht ohne Bereicherung ihrer Kenntnisse zurück, aber in die Kultur des andern Landes sind nur wenige eingedrungen, und die Luft der japanischen Inseln scheint die rückgekehrten Japaner jeder Stellung sehr rasch alles Nichtjapanische vergessen $\mathrm{zu}$ lassen. Die Japaner passen sich sehr schwer fremden Verhältnissen an. Wir haben gesehen, was für Konflikte daraus in fremden Ländern entstehen, und es ist daher weiter nicht auffälig, dass die kulturelle Ausbeute der Rückgekehrten gering ist. Es fehlt natürlich nicht an Leuten, die mit leidlicher Kenntnis der englischen Sprache nach Japan zurückkommen, an Friseuren, Wäschern, Köchen, Restaurateuren, Schustern usw, die mit ihren Erfahrungen aus Amerika und Kanada und mit dem von dort mitgebrachten kleinen Kapital

1) Finanzielles und wirischaftliches Jahrbuch fïr Japan. Tokyo 1911 und Annual return of the foreign trade of the Empire of Japan. The Dept. of Finance Tokyo 1910. 
das im Auslande crlernte Gewerbe daheim weiterbetreiben. Im allgemeinen aber nuss man sich wundern, wie rasch der vom Ausland I Heingekehrte wieder gan\% den Einflüssen seiner Heimat unterliegt, und wic wenigr Sprachkenntnis Leute, dic viele Jahre in Nordamerika oder Hawaii gelebt haben, aufweisen. Auffallend ist atuch, wic gering dic Beihilfe ist, die die christlichen Missionen durch den Aufenthalt so vieler Japaner in christlichen Lïndern haben. Es fohlt zwa in Westamerika und Hawaii keineswegs an japmischen Christen, die oft sogar eigene Missionen haben. Ob aber die christlichen Missionen, dic in Japan bekannterweise nur bescheidene Erfolge haben, sich überhaupt von den heimgekchrten Japanern gefördert sehen, scheint mir nach cingeholten Auskünften fragrlich. Von den zu Studienzwecken fortgereisten abgesclien, ist also auclı der kulturelle Einfluss der Auswanderungr auf dic Japancr dahcim nur ein geringer.

Versucht man zu cinem Schlussurtcil über die gesamte japanische Auswanderung zu kommen, so ist natürlich die nach den Kolonien von der nach dem Auslande zu trennen. Dic letztcre ist von den Vorteilen, dic vorübersehend dem Mutterlande zugefülırt wurden, abgesehen, ohne Erfolg geblicben: dic meisten Auswanderer sind heingekelurt oder werden dies in den nächsten Jahren sein, und was übrig bleibt, ist eine geringe Zahl von Erfolgreichen oder ganz Erfolglosen, die nach einigen Jahrzehnten von der sie umgebenden Menschenmenge aufgesogen scin werden, besonders, wenn dic Eröffnung des Panamakanals den curopäischen Menschenstrom, der bisher nur an die Osiküste Amsrikas kam, auch nach dessen Westen gerichtet haben wird. Als Erfolg hätte in Betracht kommen können : entweder Durchsetzung eines Landteiles mit starken, national mehr oder minder geschlossenen Massen, wie es z.B. die Chinesen in Hinterindien und auf Niederländisch Indien erreicht haben, oder die Anlegung grosser landwirtschaftlicher Siedlungen und Beherrschung des Lundes, wic dies den Engländern in Australien gelungen ist, oder bloss militärische Beherrschung eines nur schwachbesıedelten Gebiets (z. B. Russisch Ostasien) oder, vom allgemein menschlichen Standpunkt aus, Beschenkung eines fremden Landes mit wertvollen Ansiedlern und Kulturelementen, wie es die Deutschen für Amerika, besonders aber für die Vereinigten Staaten und Brasilien getan habe.. In allen diesen Fällen bleiben natürlich auch wirtschaftliche Vorteile für das Land, das solche 
Erfolge zu crzielen hat, nicht aus. Voraussetzungen dafür sind, wirtschaftliche Tüchtigkcit, nationale Energic, Verfügung über einen Bevölkerungsübcrschuss, Kapital und über einen Reichtum. an kulturellen Werten.

An wirtschaftlicher Tüchtigkeit haben es die Japaner anscheinend nicht fehlen lassen, denn obwohl ihr AuswandererMaterial nicht immer gut ausgesucht war, haben sich doch viele von ihnen in kurzer Zeit einen für ihre Verhältnisse ansehnlichen Wohlstand erarbeitet, allerdings nur dort, wo dies in wenigen Jahren möglich war. An Orten, wo es Kapital und die Arbeit von Jahrzehnten gebraucht hätte, wie in der Südsee, ist vorderhand noch kein Erfolg zu vermelden. Auffallend ist, dass dic, Japaner es nirgend wo mit den Chinesen an wirtschaftlicher Energie aufnehmen konnten: In Hawaii, den V. St., Kanada, konnten sie sich erst nach Unterbindung der chinesischen Einwanderung durchsetzen, und in Siam, Formosa, der Mandschurei haben sie es nicht vermocht, die chinesische Vormachtstellung zu beseitigen.

Das Vorhandensein von nationaler Energie und politischem Geschick haben die Japaner durch ihre Geschichte bewiesen. Die Erfolge ihrer Ansiedlungspolitik in den Kolonien $z u$ beurteilen, ist angesichts der kurzen Zeitspanne, die bisher überschaut werden kann, noch nicht möglich, abgesehen vom Hokkaidō, dessen Besiedlung im Verhältnis zu der langen zur Verfügung stehenden Zeit zu langsam vor sich geht.

Merkwürdig ist es, dass eine so geschlossene, und hochstehende Kultur, wie die japanische, nicht imstande war, sich in den nicht von Japan beherrschten Gebieten irgendwie durchzusetzen. Selbst in den Südseeinseln, auf Hawaii und in dem nicht gerade kulturreichen amerikanischen Westen, haben die Japaner ihre Kultur nicht einzubürgern, bezıv. ausserhalb ihrer Häuslichkeit zu behaupten vermocht; dies ist ein Bewcis dafür, dass die japanische Kultur zu sehr an ihre Heimat gebunden ist, als dass sie beim Zusammentreffen mit andern Kulturclementen eine gleichberechtigte Stellung $z u$ erwerben vernöchte. Kleidung und Sprachc, Schrift und Kunst, Sitten, Gedanken und Religion der Japaner haben nirgends ausserhalb der japanischen Grenzen sich dauernd festzusetzen oder gar neue Anliänger heranzuziehen vermocht. Es mag befremdlich erscheinen, dass dieselben Japaner, deren Unvermögen, sich der westländischen Kultur anzugleichen und die heimische aufzugeben, sie zu Kolonisatoren wenig gecignet 
macht, nicht wenigstens \%u Ausbreitung ihrer cigenen Kultur beizutragen vermocht labben. 1)ic Lösung dieses scheinbaren Widerspruchs liegt aber in der l'sychologic der Japaner. Sic sind durch Geschichte und, wie ich glaube, durch Veranlagung so schr mit ihren Kulturformen verwachsen, und dabei so sehr in unserem Sinne unwissenschaftlich und so wenig schöpfurisch veranlagt, dass sic es \% B. noch nicht cinmal dazu gebratcht haben, ein Haus \%u urfunden, das dem Klima ihrer Inschn cntspricht. Das japanische l laus ist für Strohbedachung und warme Gergenden bestimme." In dem wechsclvollen Klima des mittleren und nördlichen Japan und mit dem neucren schweren koreanischen Zicgeldach ist das Haus im Winter kalt (unlıcizbar!), im Sommcr warm und bci den häufigen Erdbeben in ständiger Einsturzgefahr, dabei allerdings künstlerisch vollendet. Dieses Beispicl erscheint mir typisch für dic obcrflächliche Art, wic der Japaner fremden Kulturcrzeugnissen entgegentritt, und die viclleicht auch für andere orientalische Völker kennzeichnend ist. Die Geschichte der Zivilisation Japans ist dic Gcschichte der fremden Kultureinflüsse auf sein lcrnbegicriges und stolzes Kriegerund Künstlervolk. Aber es hat stets lange gebraucht, bis dic fremden Einflüsse wirlilich im japanischen Wesen aufgingen. So ist auch heute noch die westliche Kultur in Japan reclit wenig in die Tiefe gedrungen, und die ins Ausland geschicliten Japaner stehen ihr innerlich meist so teilnahmslos gegenüber, als wärc dic Meiji Acra (seit I 868 ) noch nicht hereingebrochen. Ja, dic Japaner dic wirklich im Ausland europäjsiert werden, sind unter ihren Landsleuten halbe, wenn nicht ganze Fremde: Und doch ist Japan dem Aeussercn nach so europäisch! Das erklärt sich aus derselben orientalischen Obcrflächlichkeit, dic das wahre Verständuis fremder Verhältnisse so erschwert. Der Japaner längt am Aeussern: Er ist als Nation von krankhaftem Ehrgeiz, es den lBesten gleichzutun, und glaubt oft sein Ziel errcicht, wenn er Aeusserlichkeiten bewältigt, die er für das Wesen hält, und die ihm stets das Nächstliegende sind. Die Europäer und Amerikaner sind die erfolgreichsten Völker der Gegenwart. Ihnen will der Japaner gleichen und opfert diesem Streben nach aussen hin seine eigene formvollendete Kultur, insbesondere alles, was seine Leistungsfähigkeit im Wettbewerb beeinträchtigt; seine Gemütsverfassung, seine Anschauungen und Gedanken und

'1) Vergl. E. S. M/orse Japanesc Houses. Boston. ISS6. S. 323 ff. 
was ein Franzose treffend "le Japon intime" nannte, bleiben vorderhand unberührt von fremden Finfluss und werden es noch lange bleiben. Japan will nicht das fremde Wesen, sondern die fremden Erfolge. Was es sich auf dem Wege dazu an Selbstentfremdung sparen kann, das spart es, und niemand wird ihm das verargen. Aber dieser Zwiespalt und allzugrosse „, Sparsamkeit" erklären die auffallenden Erscheinungen bei Berührungen mit dem Ausland. Auch wo es den Japanern gelungen ist, dic Grenzen ilurer Herrschaft zu erweitern, war es stets der Krieger, der das neue Land eroberte und dem der friedliche Bürger folgte, und die Vorbilder für die erfolgreiche Kolonisation sind durchwegs aus der Fremde herbeigeloolt. Diese Erschcinung ist zu allgemein, als dass sie sich bloss durch die Qualität der japanischen Auswanderer und den politischen Widerstand der Nationen erklären liesse, mit denen sic in Berührung kamen. Aber diese beiden Hemmnisse sind für die Art der japanischen Auswanderung so charakteristisch, dass sie zu weiteren Schlüssen führen.

Die Geschichte der Wanderungen zeigt zwei typische Formen: die alte, wie sie die Geschichte etwa bis zum I5. Jahrliundert sah, die meist Volks- und Staatssache war, und die neuc, die ganz auf der Tätigkeit und Initiative der Individuen beruht." Diese wieder ist entweder eine vorübergehende Auswanderung von unqualifizierten Arbeitern oder eine dauernde, bei der Bcvölkerungselemente der verschiedensten Art in die Fremde ziehen, um dort eine neue Heimat zu suchen. Nur diese letztere Art kann nachlialtige kolonisatorische Erfolge erzielen; sie stellt allerdings auch einen grossen Verlust an kostbarem Menschenmaterial und Kapital dar, und es ist fraglich, ob die oft beneideten Erfolge der Auswanderungsländer diese Verluste aufzuwiegen instande sind. Mit Zahlen ist das überhaupt nicht festzustellen, denn hier handelt es sich um kulturgeschichtliche Vorgänge, bei denen die unberechenbaren Werte den Ausschlag geben. Das Interessante an der japanischen Auswanderungs-Politik ist, dass sie, obwohl ein Kind der neuesten Zeit, den Versuch macht, die Auswanderung ganz und gar dem staatlichen Interesse dienstbar zu machen. Sie wurde in Japan von der Regierung ins Leben gerufen, von ihr sogar eine zeitlang geführt, dann an Private abgegeben, von denen man sich jedoch vergewissert hatte, dass sie ganz den Wünschen der Regierung gemäss handeln würden.

1) Schmoller, Grundriss der allgemeinen Volkswirlscliaftslehre Band I. I901 Seite 171 ff. 
Man glaulste, es besonklers gut cinzurichten, wenn man fïr dic Rïckkeltr aller Auswankerer Sorge trug und so die gan\%e Auswanderung zu ciner periodischen machte, un \%u vermeiden, dass Menschen oder Kapital dem Vitterland verloren gingen. I) Irrolg war, dass dic Auswanderer sich kein anderes Ziel set\%ten, als in möglichst kur\%er \%eit eine mörlichst hohe Summe nach Hause zu bringen, wïhrend ihnen das Gasclick des vorübergelenden Aufenthaltsortes, - von neuer Heimat war ja bei den meisten nicht die Rede, - glcichgrïltig bleiben musste. Auch dort also, wo die japanischen Menschenmassen wirklich in einer /ahl auftraten, die ihnen einen kolonisatorischen Erfolg hätten sichern müssen, wic in Hawaii, wo es ihnen an wirtschaftlichen Erfolgen und den Sympathien der lBevölkerung zunächst nicht fehlte, ist heute der japanische Finfluss im Schwinden begrriffen, zum Teil infolge des energischen Zugreifens der Vereinigten Staaten, dic kaltblütig die Inseln ihrem Kolonialbesit\% einverleibten, allerdings erst, nachdem sic ihnen in jahrzehntelanger Kulturarbeit ihr Kapital, ihre Religion, ihre politischen Einrichtungen und vieles andere gebracht hatten. Andererseits aber ist es gewiss auch ein Misserfolg japanischer fricdlicher Expansion, der übrigens einen politischen Beigeschmack hat: die japanische Einwanderung brachte nach Hawaii und von dort nach dem amerikanischen Festlande eine Klasse von Arbeitern, für die sich heute in europäischem Sprachgebrauch die Bezeichnung Kuliarbeiter eingebürgert hat. Das soll heissen, Angehörige einer asiatischen Rasse, die nur unqualifizierte Arbeit zu leisten bestimmt sind und sie infolge ihrer niedrigen Lebenshaltung unter besonderen Umständen und billigen Löhnen zu leisteir imstande sind. Selbstverständlich führt diese Art von Arbeit und Lebenshaltung, verbundei mit den Umstand, dass es sich durchwegs um vorübergehende Einwanderung handelt, dazu dass diese Arbeiter ein Leben für sich führen und nicht so hoch im Ansehen stehen wie der europäische Arbeiter, den sie als Surrogat zu ersetzen bestimmt sind. Das alles passt ausgezeichnet auf die Chinesen; bei den Japanern zeigt sich aber, dass der hier in Rede stehende Begriff eine Abänderung erfahren muss. Die Japaner waren nämlich weder geneigt, in der untergeordneten Stellung von uuqualifizierten Arbeitern zu verharren, noch hatten sie Lust, sich als Bürger 2. Klasse behandeln oder auch nur ansehen zu lassen. Beides macht ihrer Tüchtigkeit und ihrem Nationalgefühl alle Ehre; schlimm aber ist es, dass sie, namentlich seit ihren erfolgreichen Kriegen, begannen, eine übertriebene 
nationale Empfindlichkeit herauszukehren und sich sogar beruflich national zu organisieren, so dic Solidarität verleugnend, deren Verweigerung von Seiten der amerikanischen Aibeiter sie als Beleidigung empfanden. Man hat den Japanern mit Recht vorgehalten, dass diese Empfindlichkeit unso unangebrachter sei, als sie selbst in ihrem eigenen Lande die Fremden durchaus nicht als gleichberechtigt und ohne Misstrauen behandeln und sie bis zum heutigen Tage nicht vergessen lassen, dass man in Japan die Restorationskämpfe der 6oer Jahre mit dem Rufe „, es lebe der Kaiser, fort mit den Barbaren! “') einleitete. Doch das sind Fragen, die nicht nach Recht und Billigkeit abgewogen werden können. Wohin die Entwicklung in Hawaii und Amerika geführt hat, habe ich ausführlich geschildert. Sie war der Anlass zu einer grossen Wandlung in der japanischen Auswanderungspolitik, deren Wirkungen heute noch nicht übersehen werden können. Die Regierung und die Einsichtigen unter den führenden Männern Japans haben anscheinend eingesehen, dass man im internationalen Verkehr nicht nur auf den eigenen Vorteil bedacht sein darf, und dass es hier mehr als irgendwo anders heisst: "wen: du nehmen willst, so gib."

Dic unmittelbare Wirkung dieser geänderten Politik war jedenfalls eine starke Einschränkung der Auswanderung, die wieder ängstliche Warnungsrufe vor einer Uebervöllkerung Japans heraufbeschworen hat. Ich glaube $\mathrm{zu}$ der Annahme berechtigt zu sein, dass soweit das gegenwärtig zur Verfügung stehende Material reicht, kein Grund vorhanden ist, in diese Rufe einzustimmen. Japan ist selir stark besiedelt, aber es vermehrt sich wahrscheinlich nicht so rasch, als manchmal geglaubt wird, hat in seinen Kolonien und bei einigem Willen zur inneren Kolonisation auch im eigenen Lande noch Platz für den Menschenzuwachs der nächsten Zukunft, und darüber hinaus sich Sorge zu machen, wärc heute wenig am Platze. Nicht als ob ich dem nationalen Leichtsinn das Wort recien wollte, aber das Bevölkerungsproblem ist ein so altes, und seine Behandlung ein so weites Feld, dass es, wic die Geschichte gezeigt hat, schwer hält, Voraussicht zu bekunden. Je nach den Verhältnissen, dem Stand der wissenschaftlichen Erkenntnis und Geistesrichtung, vor allem aber je nach den in den Völkern

1) „Sonõ jöi"; das Wort "Barbar" wird hier in selben Sinne gebraucht, wie bei den alten Griechen und bedeutet alle Ausländer mit Ausnahme der Chinesen und Koreaner. 
lebendiggen geistigen und sittlichen Köriften, waten die Antwonten,

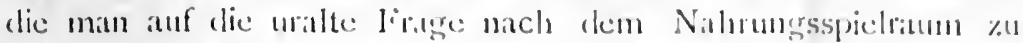
geben wusste, entweder pessimistisch oder optinistisch. W'ie stets, so liegt die Waluheit atuch hier in cler Mitte. Dic linlturillen leortschritte haben ungeahnte Möglichleciten fïr die Verdichtung der Bevölkerung auf demselben Flichenraum agebracht, und wenn diese Entwiclines auch nicht ins Unendliche fortgesctzt werden kann, so diufte sie doch nit der (iergenwart noch nicht zum Abschluss grelangt scin. Girade in der Kunst, sich auf engem Raum \%u bescheiden, hat es das japanische Volk so weit sebracht, wie kaum ingend cin anderes. Scine saln\% geistige und materielle Kultur hängt auf das innigste \%usimmmen mit den räumlichen bieschränkungen, denen die Entivicklung des Volkes, dem Verkehrsmittel nicht zur Verfüguns standen, ausgesetzt war. Dic Japaner haben es zuwege gelbracht, nicht nur den Gefahren, die diese beschränliungen andern Völkern grebracht haben, zu entgelsen, sondern sogar eine diesen $V$ crhältnissen angepasste Kultur zu entwickeh, die die licwunderung und \%um 'Teil den Neid der übrigen Kulturwelt crweckt, demn sic ist, auf kleincm und armen Boden erstanden, cin Mluster defür, was mit den einfachsten Mitteh und durch vollstïndige Beherrschung des zur Verfügung stehenden Menschen- und Satehen-Vorrats geleistet werden liann.

IVemn dichte Bevölkerung ein Massstab für hohe Kultur ist, und das ist sic olne Zweifel, so kann Japan auch diese Probe bestehen, und es scheint mir wenig angebracht, in einer Zcit allgemeinen Aufschwungs, in der eine fremde Kultur mit der cinheimischen zu vereinigen gesucht wird, die Fähigkeit zu weiteren Fortschritten in Frage zu ziehen. ,, Das Bevöllicrungs. problem greift in alle Lebensgebiete hinein, fördert überall Zucht und Selbstbeherrschung, weitsichtiges und kräftiges Handeln. Auch das tüchtigste Volls wird die zwei selbständigen Bewegungen der zunchmenden Menschenzahl und des wirtschaftlichen Fortschritts nie ganz in Uebcreinstimnung bringen liönnen; aber es kann die Dissonanzen mildern in dem Masse, wic es moralisch, geistig und technisch sich vervolliommnet."1)

1) Sclimoller, a. a. O. S. IS7. 


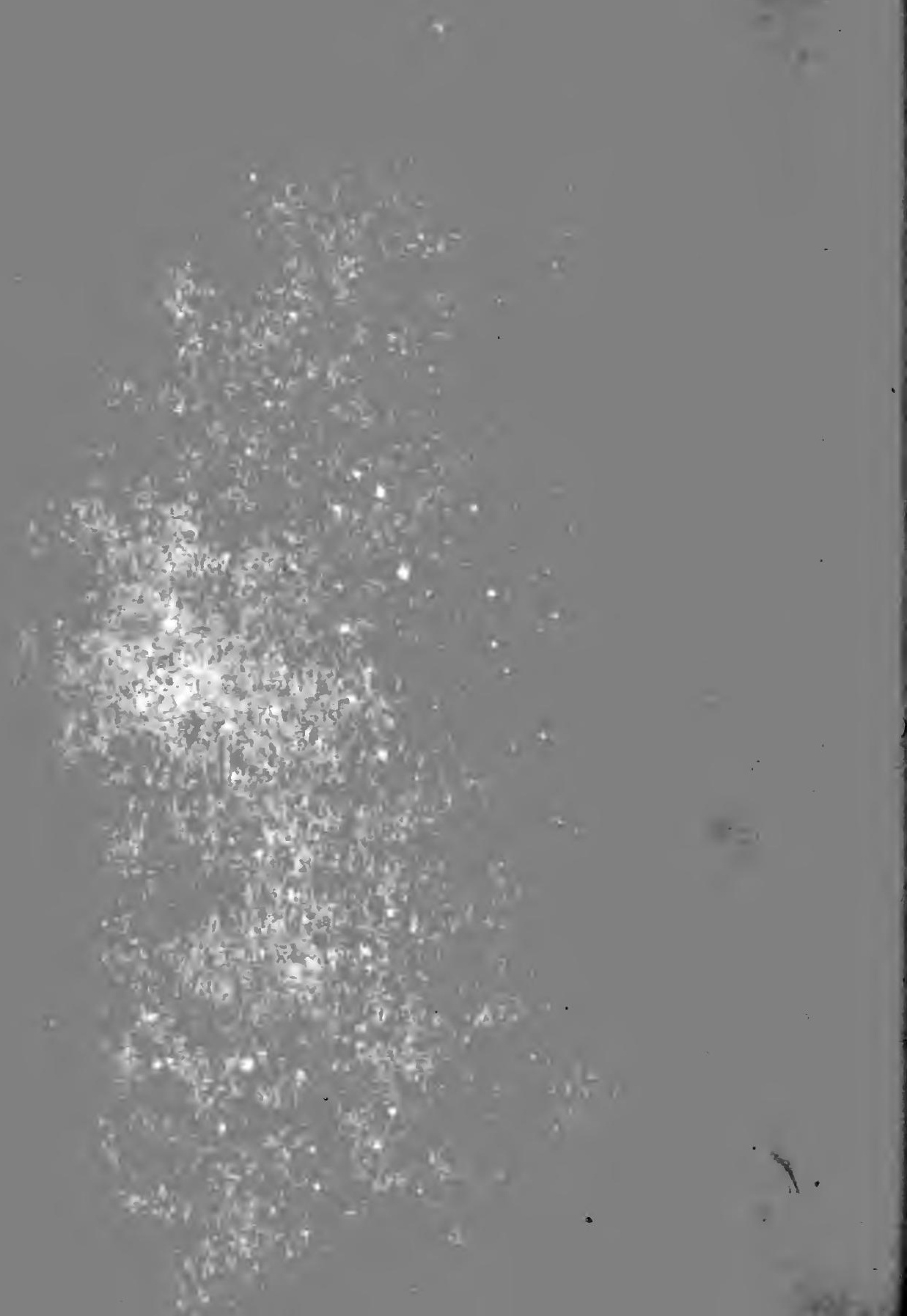





\section{PLEASE DO NOT REMOVE CARDS OR SLIPS FROM THIS POCKET \\ UNIVERSITY OF TORONTO LIBRARY}

JV

8721

$\mathrm{Z6}$

(35)

1913

Grünfeld, Ernst

Die japanische-Auswanderung 
